\title{
American Thoracic Society
}

EUROPEAN RESPIRATORY S OCIETY

Q

ATS

Standards for the Diagnosis and Management of Patients with COPD

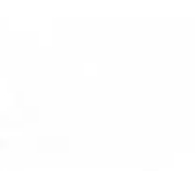

Clinical Presentation

Ât Risk Symptomatic

Exacerbations

Respiratory

Failure

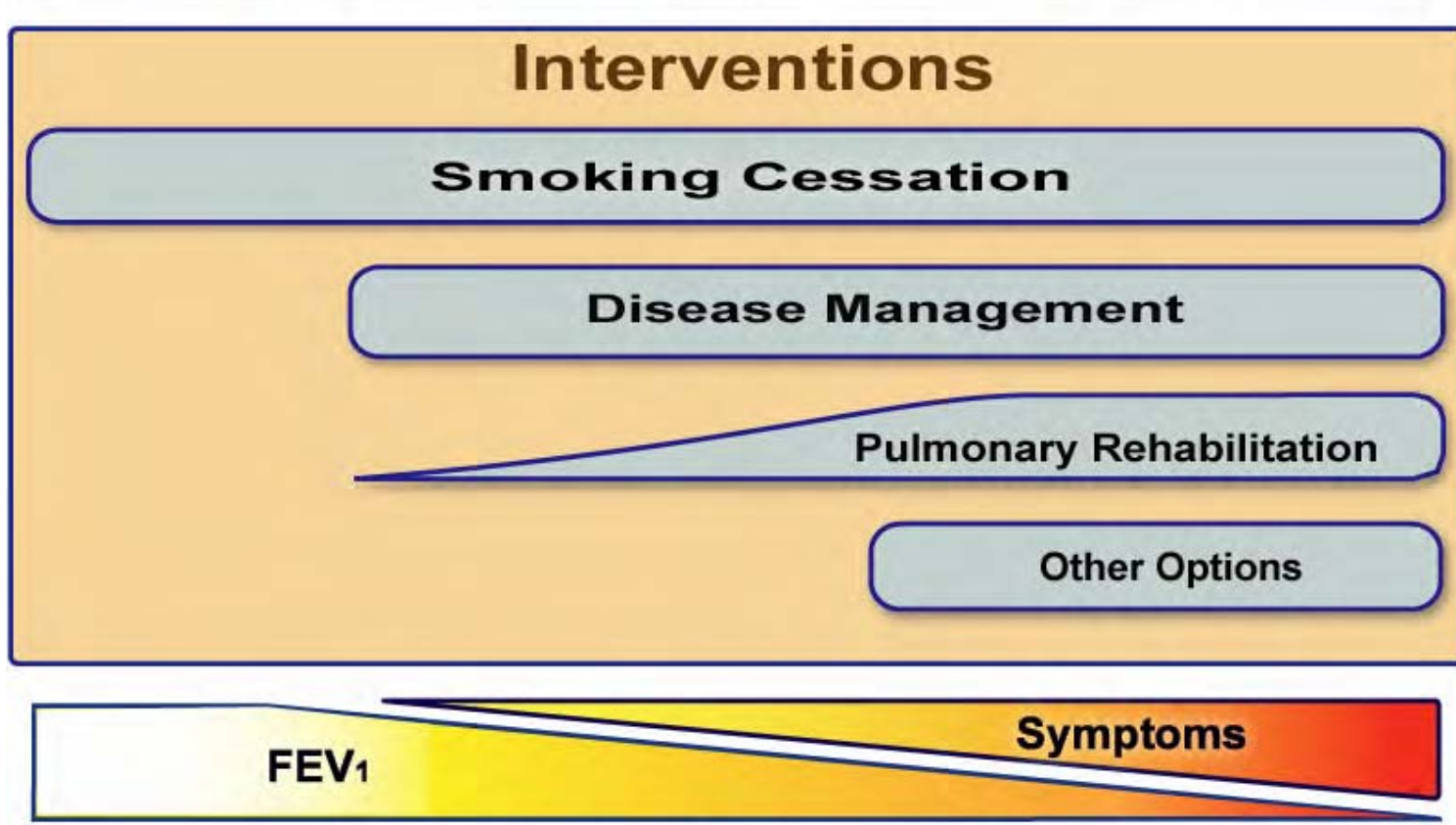

Disease Progression

American Thoracic Society

61 Broadway

New York, NY 10006-2755

Voice: $212-315-8600$

Fax: 212-315-649

\section{European Respiratory Society}

4, Ave Sainte-Luce

$\mathrm{CH}-1003$ Lausanne Switzerland

Voice: +41212130101

Fax: +41212130100 


\section{Introduction}

\subsection{Background}

This project, to update the position papers on chronic obstructive pulmonary disease (COPD) published by the American Thoracic Society (ATS) and the European Respiratory Society (ERS) in 1995 [1, 2], is sponsored by both societies, who have agreed to develop a document entitled "Standards for the diagnosis and treatment of patients with chronic obstructive pulmonary disease". It was felt that the document needed updating due to the following.

- The prevalence and overall importance of COPD as a health problem is increasing.

- There have been enough advances in the field to require an update, especially in the area of therapeutics.

- It allows for the creation of a "live" modular document based on the web and it should provide healthcare professionals and patients with a user friendly and reliable authoritative source of information.

- The care of COPD should be comprehensive, is often multidisciplinary and rapidly changing.

This document aims to fulfil all these needs.

Both societies acknowledge the recent dissemination of the Global Initiative of Obstructive Lung Disease (GOLD) [3] as a major worldwide contribution to the battle against COPD. However, the specific requirements of the members of both societies require adaptation of the broad GOLD initiative. Those requirements include specific recommendations on oxygen therapy, pulmonary rehabilitation, non-invasive ventilation, surgery in and for COPD, sleep, air travel, and end-of-life. In addition, a special emphasis has been placed on issues related to the habit of smoking and its control. 


\subsection{Goals and objectives}

This is an international consensus statement sponsored by the ATS and ERS. The main goals are to improve the quality of care provided to patients with COPD and to develop the project using a disease-oriented approach. To achieve these goals, both organisations have agreed to develop a modular electronic web-based document with two components.

1. A component for health professionals, that intends to:

- raise awareness of COPD

- inform on the latest advances in the overall pathogenesis, diagnosis, monitoring and management of COPD

- promote the concept that COPD is a treatable disease.

2. A component for the patient that intends to:

- provide practical information on all aspects of COPD

- $\quad$ promote a healthy lifestyle to all patients afflicted with the disease.

\subsection{Participants}

The committee members are clinicians, nurses, respiratory therapists and educators interested in the field of COPD. The document is unique in that it also had input from patients suffering from COPD. The committee members were proposed and approved by the ATS and ERS. The members were selected because of their expertise and willingness to participate in the generation of the document. A unique feature of this project was the development of a patient document that could serve as a formal source of information for the patients, thereby making them partners in the effort to decrease the burden of the disease.

A list of the chapters in this document and the contributors to these chapters are listed below. 


\section{Introduction}

B.R. Celli, W. MacNee

Definition, diagnosis and staging

B.R. Celli, R. Pauwels, G.L. Snider

Epidemiology, risk factors and natural history

J. Vestbo, A.S. Buist

Pathology, pathogenesis and pathophysiology

W. MacNee, A. Agusti, J.C. Hogg, R. Rodriguez-Roisin

Clinical assessment, testing and differential diagnosis

N. Siafakas, B.R. Celli

Management of stable COPD: smoking cessation

S. Rennard, W. Bailey, M.E. Wewers, M. Fiore, M. Myramoto

Management of stable COPD: pharmacological therapy

P. Calverley, N. Gross, J. van Noord

Management of stable COPD: long-term oxygen therapy

B.L. Tiep, R. Carter, L. Hoffman, J. Zielinski

Management of stable COPD: pulmonary rehabilitation

E.F.M. Wouters, R. ZuWallack, S.C. Lareau

Management of stable COPD: nutrition

E.F.M. Wouters, A.M.W.J. Schols

Management of stable COPD: surgery in and for COPD

F.J. Martinez, C. Bolliger, M. Estenne, R.M. Kotloff, J.B. Orens, J.J. Reilly, W. Weder, I.M.

Weisman, R.D. Yusen

Management of stable COPD: sleep

W. McNicholas, W MacNee, B.R Celli

Management of stable COPD: air travel

B. Berg, T. Dillard, B.R. Celli

Exacerbation: definition, evaluation and treatment

A. Fein, A. Anzueto, R. Grossman

Exacerbation: inpatient oxygen therapy

B.L. Tiep, R. Carter, L. Hoffman, J. Zielinski 


\section{Exacerbation: assisted ventilation}

A. Rossi, B.R Celli,W.MacNee

\section{Ethical and palliative care issues}

J. Heffner, N.H. Chavannes, E.W. Ely, N.M. Lazar, J. Lynn, L. Sicilian

\section{Integrated disease management}

N.H. Chavannes, S.C. Lareau, B.L. Tiep, J.W.M. Muris

\section{Patient section}

P. Meek, S.C. Lareau, B. Fahy, E. Austegard, A.A. Silverthorn, N.L. Specht, D. Upson, K. Busby, C. Werpy, S. Nicolaisen, R. Andenæs, T. Weller, C. Hernandez. In addition, patients from Loma Linda VA Hospital (Loma Linda, California, USA); St Joseph's Hospital (Tucson, Arizona, USA); St. Joseph's Hospital and Medical Center (Phoenix, Arizona, USA); patients from Tucson, Arizona, USA; patients of B Celli, Boston, Massachusetts, USA; patients of W. MacNee, Edinburgh, Scotland; as well as J. Walsh, President and CEO Alpha One Foundation, USA, reviewed this section.

\section{Web Design}

ERS: A. Agusti

ATS: B. Tiep

\subsection{Evidence and methodology}

Several well-accepted guidelines served as the blueprint for this document. Namely, the ATS and the ERS Standards of 1995 and the GOLD initiative published in 2001. At the initial meeting, each member of the subcommittees was assigned a specific section of the document, and was asked to select a subcommittee to gather literature and review the existing evidence. Several of the basic source documents reviewed have used an evidence-based approach, and the committee utilised those references as a source of evidence wherever appropriate. The final document was discussed in four group meetings, and the content and validity of each section was thoroughly reviewed. The final statement is the product of those discussions and has been approved by all the members of the committee. 


\subsection{Validation}

The draft document was reviewed by a diverse group of experts whose input was also considered. Peer review was identified by the ATS and ERS, and the final document was submitted for review and approval by the board of directors of the ATS and the Executive Committee of the ERS.

\subsection{Organisation of the document}

1. Introduction

2. Definition, diagnosis and staging

3. Epidemiology, risk factors and natural history

4. Pathology, pathogenesis and pathophysiology

5. Clinical assessment, testing and differential diagnosis

Management of stable COPD

6. Smoking cessation

7. Pharmacological therapy

8. Long-term oxygen therapy

9. Pulmonary rehabilitation

10. Nutrition

11. Surgery in and for COPD

12. Sleep

13. Air travel

Exacerbation

14. Definition, evaluation and treatment

15. Inpatient oxygen therapy

16. Assisted ventilation

17. Ethical and palliative care issues

18. Integrated disease management

Patient section

19. General

20. Medication

21. Other treatments 


\subsection{References}

1. American Thoracic Society. Standards for the diagnosis and care of patients with chronic obstructive pulmonary disease. Am J Respir Crit Care Med 1995; 152: S77-S121.

2. Siafakas NM, Vermeire P, Pride NB, et al. Optimal assessment and management of chronic obstructive pulmonary disease (COPD). The European Respiratory Society Task Force. Eur Respir J 1995; 8: 1398-1420.

3. Pauwels RA, Buist AS, Calverley PM, Jenkins CR, Hurd SS, the GOLD Scientific Committee. Global strategy for the diagnosis, management, and prevention of chronic obstructive pulmonary disease. NHLBI/WHO Global Initiative for Chronic Obstructive Lung Disease (GOLD) Workshop summary. Am J Respir Crit Care Med 2001 163: 1256-1276. 


\section{Definition, diagnosis and staging}

\subsection{Key points}

- Chronic obstructive pulmonary disease (COPD) is characterised by airflow limitation.

- The diagnosis is confirmed with spirometry.

- Assessment of COPD severity is performed using spirometry, dyspnoea and body mass index (BMI).

\subsection{Definitions}

Chronic obstructive pulmonary disease (COPD) is a preventable and treatable disease state characterised by airflow limitation that is not fully reversible.

The airflow limitation is usually progressive and is associated with an abnormal inflammatory response of the lungs to noxious particles or gases, primarily caused by cigarette smoking.

Although COPD affects the lungs, it also produces significant systemic consequences.

Chronic bronchitis is defined clinically as chronic productive cough for 3 months in each of 2 successive years in a patient in whom other causes of productive chronic cough have been excluded [1].

Emphysema is defined pathologically as the presence of permanent enlargement of the airspaces distal to the terminal bronchioles, accompanied by destruction of their walls and without obvious fibrosis [2].

In patients with COPD either of those conditions may be present. However, the relative contribution of each to the disease process is often difficult to discern.

Asthma differs from COPD in its pathogenic and therapeutic response, and should therefore be considered a different clinical entity [3]. However, some patients with asthma develop poorly 
reversible airflow limitation. These patients are indistinguishable from patients with COPD but for practical purposes are treated as asthma.

The high prevalence of asthma and COPD in the general population results in the co-existence of both disease entities in many individuals. This is characterised by significant airflow limitation and a large response to bronchodilators. In these patients, the forced expiratory volume in one second (FEV1) does not return to normal and frequently worsens over time. There is a great need to design studies aimed at determining the prevalence, natural history, clinical course and therapeutic response in these patients.

Other conditions: poorly reversible airflow limitation associated with bronchiectasis, cystic fibrosis and fibrosis due to tuberculosis are not included in the definition of COPD and should be considered in its differential diagnosis.

All patients with a family history of respiratory illnesses, patients presenting with airflow limitation at a relatively early age (4th or 5th decade) should be tested for $\alpha_{1}$-antyripsin deficiency.

\subsection{Diagnosis}

Diagnosis of COPD should be considered in any patient who has the following:

- symptoms of cough

- $\quad$ sputum production or

- dyspnoea or

- history of exposure to risk factors for the disease.

The diagnosis requires spirometry; post-bronchodilator FEV1/forced vital capacity $<0.7$ confirms the presence of airflow limitation that is not fully reversible. 
Spirometry should be obtained in all persons with the following history:

- exposure to cigarettes and/or environmental or occupational pollutants

- family history of chronic respiratory illness

- presence of cough, sputum production or dyspnoea.

\subsection{Spirometric classification}

Table 1. - Spirometric general classification

\begin{tabular}{lll}
\hline Severity & $\begin{array}{l}\text { Postbronchodilator } \\
\text { FEV1/FVC }\end{array}$ & FEV1\% predicted \\
\hline At risk & $>0.7$ & $\geq 80$ \\
$\quad$ Patients who: & & \\
$\quad$ smoke or have exposure to pollutants & & \\
$\quad$ have cough, sputum or dyspnea & & \\
$\quad$ have family history of respiratory disease & $\leq 0.7$ & 580 \\
Mild COPD & $\leq 0.7$ & $50-80$ \\
Moderate COPD & $\leq 0.7$ & $30-50$ \\
Severe COPD & $\leq 0.7$ & $<30$ \\
Very severe COPD & & \\
\hline
\end{tabular}

FEV1: forced expiratory volume in one second; FVC: forced vital capacity.

Spirometric classification has proved useful in predicting health status [4], utilisation of healthcare resources [5], development of exacerbation [6, 7] and mortality [8] in COPD. It is intended to be applicable to populations [9] and not to substitute clinical judgment in the evaluation of the severity of disease in individual patients. 


\subsection{Assessment of severity: staging}

It is accepted that a single measurement of FEV1 incompletely represents the complex clinical consequences of COPD because: 1) many patients are practically asymptomatic; 2) persistant cough and sputum production often precede the development of airflow limitation [3] and, in others, the first symptom may be the development of dyspnoea with previously tolerated activities; and 3) in the clinical course of the disease, systemic consequences, such as weight loss [10, 11], and peripheral muscle wasting and dysfunction [12, 13], may develop.

Due to these and other factors, a staging system that could offer a composite picture of disease severity is highly desirable, although it is currently unavailable. However, spirometric classification is useful in predicting outcomes such as health status and mortality, and should be evaluated. In addition to the FEV1, the BMI [10, 11] and dyspnoea [14] have proved useful in predicting outcomes such as survival and this document recommends that they be evaluated in all patients.

BMI is easily obtained by dividing the weight (in $\mathrm{kg}$ ) over the height (in $\mathrm{m}^{2}$ ).

Values $<21 \mathrm{~kg} \cdot \mathrm{m}^{-2}$ are associated with increased mortality.

Functional dyspnoea can be assessed by the Medical Research Council dyspnoea scale.

0 not troubled with breathlessness except with strenuous exercise.

1 troubled by shortness of breath when hurrying or walking up a slight hill.

2 walks slower than people of the same age due to breathlessness or has to stop for breath when walking at own pace on the level.

3 stops for breath after walking $\sim 100 \mathrm{~m}$ or after a few minutes on the level.

4 too breathless to leave the house or breathless when dressing or undressing. 


\subsection{References}

1. American Thoracic Society. Chronic bronchitis, asthma and pulmonary emphysema: a statement by the Committee on Diagnostic Standards for Nontuberculous Respiratory Diseases. Am Rev Respir Dis 1962; 85: 762-768.

2. Snider GL, Kleinerman J, Thurlbeck WM, Bengali ZK. The definition of emphysema: report of a National Heart, Lung and Blood Institute, Division of Lung Diseases, Workshop. Am Rev Respir Dis 1985; 132: 182-185.

3. Pawels R, Sonia Buist A, Calverley P, Jenkins C, Hurd S. Global strategy for the diagnosis, management and prevention of chronic obstructive pulmonary disease. NHLBI/WHO Global Initiative for Chronic Obstructive Lung Disease (GOLD). Workshop summary. Am J Respir Crit Care Med 2001; 163: 1256-1276.

4. Ferrer M, Alonso J, Morera J, et al. Chronic obstructive pulmonary disease and health related quality of life. Ann Int Med 1997; 127: 1072-1079.

5. Friedman M, Serby C, Menjoge S, Wilson J, Hilleman D, Witek T. Pharmacoeconomic evaluation of a combination of ipratropium plus albuterol compared with ipratropium alone and albuterol alone in COPD. Chest 1999; 115: 635-641.

6. Burge PS, Calverley PM, Jones PW, Spencer S, Anderson JA, Maslen TK. Randomised, double blind, placebo controlled study of fluticasone propionate in patients with moderate to severe chronic obstructive pulmonary disease: the ISOLDE trial. BMJ 2000; 320: 1297-1303.

7. Dewan N, Rafique S, Kanwar B, et al. Acute exacerbation of COPD. Factors associated with poor treatment outcome. Chest 2000; 117: 662-671.

8. Anthonisen NR, Wright EC, Hodgkin JE, the IPPB Trial Group. Prognosis in chronic obstructive pulmonary disease. Am Rev Respir Dis 1986; 133: 14-20.

9. Celli B, Halbert R, Isonaka S, Schau B. Population impact of different definitions of airway obstruction. Eur Respir J 2003; 22: 268-273.

10. Schols AM, Slangen J, Volovics L, Wouters EF. Weight loss is a reversible factor in the prognosis of chronic obstructive pulmonary disease. Am J Respir Crit Care Med 1998; 157: 1791-1797.

11. Landbo C, Prescott E, Lange P, Vestbo J, Almdal TP. Prognostic value of nutritional status in chronic obstructive pulmonary disease. Am J Respir Crit Care Med 1999; 160: 1856-1861. 
12. Maltais F, Leblanc P, Simard C, et al. Skeletal muscle adaptation to endurance training in patients with chronic obstructive pulmonary disease. Am J Respir Crit Care Med 1996; 154: $442-447$.

13. Decramer M, Gosselink R, Troosters T, Verschueren M, Evers G. Muscle weakness is related to utilization of health care resources in COPD patients. Eur Respir J 1997; 10: 417423.

14. Nishimura K, Izumi T, Tsukino M, Oga T. Dyspnea is a better predictor of 5-year survival than airway obstruction in patients with COPD. Chest 2002; 121:1434-1440. 


\section{Epidemiology, risk factors and natural history}

\subsection{Key points}

- Chronic obstructive pulmonary disease (COPD) is a leading cause of morbidity and mortality worldwide, and results in an economic and social burden that is both substantial and increasing.

- Prevalence and morbidity data greatly underestimate the total burden of COPD because the disease is usually not diagnosed until it is clinically apparent and moderately advanced.

- In people aged 25-75 yrs in the USA, the estimated prevalence of mild COPD (defined as forced expiratory volume in one second (FEV1)/forced vital capacity (FVC) $<70 \%$ and FEV $1 \geq 80 \%$ predicted) was $6.9 \%$ and of moderate COPD (defined as FEV1/FVC $<79 \%$ and FEV1 $\leq 80 \%$ predicted) was $6.6 \%$, according to the National Health and Nutrition Examination Survey (NHANES).

- COPD is the fourth leading cause of death in the USA and Europe, and COPD mortality in females has more than doubled over the last $20 \mathrm{yrs}$.

- COPD is a more costly disease than asthma and, depending on country, 50-75\% of the costs are for services associated with exacerbations.

- Tobacco smoke is by far the most important risk factor for COPD worldwide.

- Other important risk factors are occupational exposures, socioeconomic status and genetic predisposition.

\subsection{Epidemiology}

\subsubsection{Prevalence}

Estimates of the prevalence of COPD depend on the definition and criteria used. Estimates based on the presence of airflow limitation are the most accurate, since symptoms and selfreport or clinician diagnosis lack sensitivity and specificity. 
A postbronchodilator $\mathrm{FEV} 1 / \mathrm{FVC}<70 \%$, in combination with an $\mathrm{FEV} 1<80 \%$ pred, in an individual with cough, sputum production or dyspnoea and exposure to risk factors confirms the diagnosis [1].

The best prevalence data available at present come from the third NHANES (NHANES III), a large national survey conducted in the USA between 1988 and 1994. In the USA, for those aged 25-75 yrs, the estimated prevalence of mild COPD (defined as FEV1/FVC <70\% and FEV1 $\geq 80 \%$ predicted) was $6.9 \%$ and of moderate COPD (defined as FEV1/FVC $<70 \%$ and FEV1 $\leq 80 \%$ predicted) was $6.6 \%$. The prevalence of both mild and moderate COPD was higher in males than females, in Whites than in Blacks, and increased steeply with age [2].

In the NHANES III study, COPD (defined as the presence of airflow limitation) was estimated to be present in $14.2 \%$ of current White male smokers, $6.9 \%$ of exsmokers and $3.3 \%$ of neversmokers. Among White females, the prevalence of airflow limitation was $13.6 \%$ in smokers, $6.8 \%$ in exsmokers and $3.1 \%$ in never-smokers [2].

Less than $50 \%$ of individuals with COPD based on airflow limitation have a doctor's diagnosis of COPD and, somewhat surprisingly, this is not only true for mild COPD [3].

\subsubsection{Morbidity}

Morbidity data include physician visits, emergency department visits and hospitalisations. COPD databases for these outcome parameters are less readily available and usually less reliable than mortality databases.

The limited data available indicate that morbidity due to COPD increases with age and is still greater in males than females.

The risk of hospital admission increases with decreasing lung function and when chronic respiratory symptoms are present [4]. Admission rates are also increased in patients with lower socioeconomic status [5]. 
Morbidity is likely to increase in the future, not only due to changes in smoking habits but also because of ageing of populations [6].

\subsubsection{Mortality}

Mortality data for COPD are inaccurate because of inconsistent use of terminology.

COPD death rates are very low under the age of 45 yrs and increase steeply with age.

COPD is the fourth leading cause of death worldwide and is estimated to be the third leading cause of death by 2020 [7].

Recently, the most important change has been the huge increase in the COPD death rate in females that has occurred in the USA over the last 20 yrs: from 20.1 out of 100,000 in 1980 to 56.7 out of 100,000 in 2000 ; as compared to the values in males, 73.0 out of 100,000 in 1980 to 82.6 out of 100,000 in 2000 [2].

\subsubsection{Economic burden}

COPD is a more costly disease than asthma. The direct costs of COPD are the value of healthcare resources devoted to diagnosis and medical management of the disease. Indirect costs reflect the monetary consequences of disability, missed work, premature mortality and caregiver or family costs resulting from the illness [8].

When medical costs for COPD are compared across countries for which data are available, there is surprising similarity. When adjusted to 1993 US dollars, the costs per capita (in the entire population) are: $\$ 65$ for the UK, $\$ 60$ for Sweden and $\$ 87$ for the USA. Distribution of the costs in different countries, however, is different. In the USA, for example, $\sim 75 \%$ of the costs for COPD are for services associated with exacerbations, such as hospitalisation [8]. 


\subsection{Risk factors}

The risk factors for COPD are shown in table 1, and they are separated into host factors and exposures.

Table 1. - Risk factors for COPD

\begin{tabular}{ll}
\hline Host factors & Exposures \\
\hline Genetic factors & Smoking \\
Sex & Socioeconomic status \\
Airway hyperreactivity, immunoglobulin E and asthma & Occupation \\
& Environmental pollution \\
& Perinatal events and childhood illness \\
& Recurrent bronchopulmonary infections \\
& Diet \\
\hline
\end{tabular}

\subsubsection{Host factors}

Little is known at present about the many genetic factors that probably increase (or decrease) a person's risk of developing COPD.

The genetic risk factor that is best documented is a severe hereditary deficiency of $\alpha_{1^{-}}$ antitrypsin, a major circulating inhibitor of serum proteases. Although $\alpha_{1}$-antitrypsin deficiency is relevant to only a small part of the world's population, it illustrates the importance of gene-environment interactions in the pathogenesis of COPD [9, 10]. All patients with airflow limitation and family history of respiratory illnesses, and patients presenting with airflow limitation at relatively early age (4th or 5th decade) should be evaluated for $\alpha_{1^{-}}$ antitrypsin deficiency.

Exploratory studies have revealed a number of candidate genes that influence a person's risk of COPD. However, when several studies of a given trait are available, the results are often inconsistent. Several of these genes are thought to be involved in inflammation and, therefore, are related to potential pathogenic mechanisms of COPD [9]. 
Airway hyperresponsiveness has also been demonstrated to be a risk factor for COPD [11]. The mechanism for this, however, is not clear. Some asthma patients also develop fixed airflow limitation and thus fulfil the requirements for COPD diagnosis [12].

Worldwide, COPD is more prevalent in males than in females. However, this is a consequence of the marked difference in smoking (and other) exposures between males and females. Recent data from several large studies suggest that females may in fact be more susceptible to the effects of tobacco than males. More data are needed to verify this. The importance of these new data, however, is that male sex is now clearly not a risk factor for COPD [13].

\subsubsection{Exposures}

Tobacco smoke is by far the most important risk factor for COPD worldwide [1, 10, 14].

It is helpful, conceptually, to think of a person's exposures in terms of the total burden of inhaled particles. Each type of particle, depending on its size and composition, may contribute a different weight to the risk and the total risk will depend on the integral of the inhaled exposures. For example, tobacco smoke (active and passive tobacco smoke), outdoor and indoor air pollution, and occupational exposures probably act additively to increase a person's risk of developing COPD.

Recent data from the US NHANES III survey indicate that occupation can be an important risk factor for COPD. The fraction of COPD attributable to work was estimated as $19.2 \%$ overall and $31.1 \%$ in never-smokers [2].

A subject's socioeconomic background plays an important role that is not only the result of exposure to tobacco and occupational hazards [5]. Whether the effect is due to impaired growth of lungs and airways or an increased rate of infection is not clear. 
In developing countries, indoor air pollution, due to the use of biomass fuels for heating and cooking, may pose a significant particulate burden and contribute to COPD, especially in females [1].

\subsection{Natural history}

COPD has a variable natural history and not all individuals follow the same course [15]. The often-quoted statistic that only $15-20 \%$ of smokers develop clinically significant COPD is misleading and greatly underestimates the toll of COPD.

It is increasingly apparent that COPD often has its roots decades before the onset of symptoms [14]. Impaired growth of lung function during childhood and adolescence, caused by recurrent infections or tobacco smoking, may lead to lower maximally attained lung function in early adulthood [16]. This abnormal growth will, often combined with a shortened plateau phase in teenage smokers, increase the risk of COPD. This is visualised in figure 1 [17].

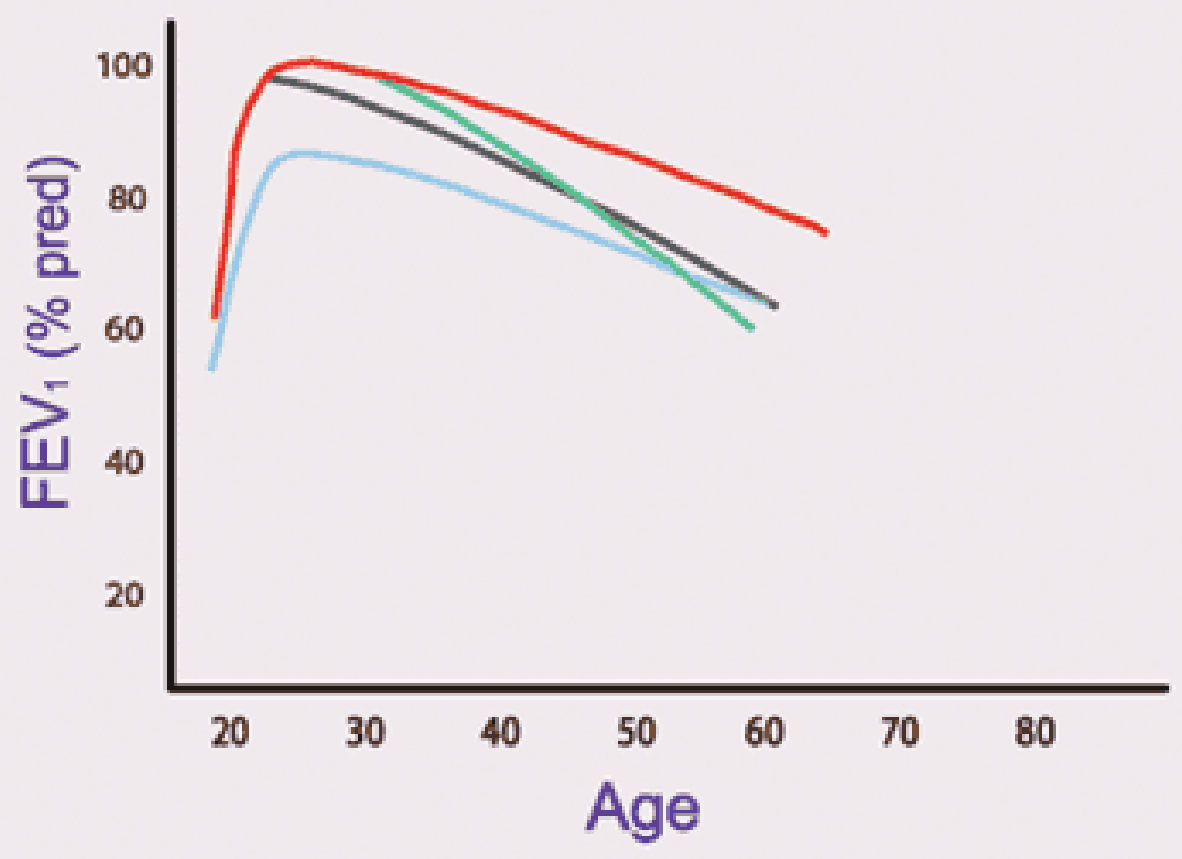

Fig. 1. - The normal course of forced expiratory volume in one second (FEV1) over time (-) is compared with the result of impaired growth of lung function $(-)$, an accelerated decline $(-)$ and a shortened plateau phase (-). All three abnormalities can be combined. Figure reproduced with permission from [17]. 
An accelerated decline in lung function is nevertheless still the single most important feature of COPD. COPD is generally a progressive disease, especially if the patient's exposure to noxious substances, most often tobacco smoking, continues. If exposure is stopped, the disease may still progress, mainly due to the decline in lung function that normally occurs with ageing. Nevertheless, stopping exposure to noxious agents, even after significant airflow limitation is present, can result in some improvement in function and will slow or even hold the progression of the disease. This is best illustrated by recent longitudinal data from the US Lung Health Study, spanning $11 \mathrm{yrs}$, shown in figure 2.

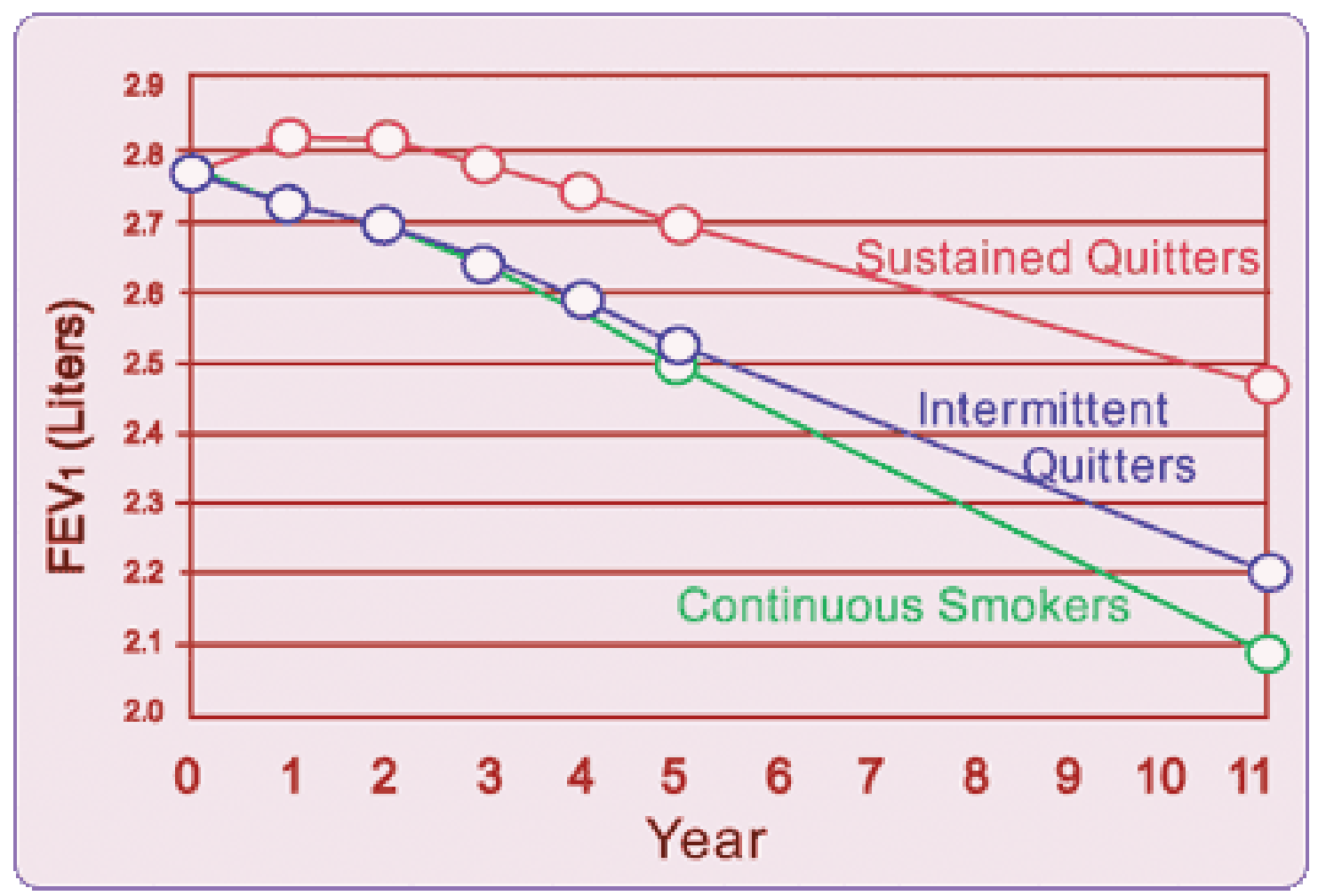

Fig. 2. - Loss of lung function over 11 yrs in the Lung Health Study for continuous smokers $(-)$, intermittent quitters (-) and sustained quitters (-). FEV1: forced expiratory volume in one second. Figure reproduced with permission from [18]. 
Males who quit at the beginning of the Lung Health Study had an FEV1 decline of 30.2 $\mathrm{mL} \cdot \mathrm{yr}^{1}$, whereas females who quit declined at $21.5 \mathrm{~mL} \cdot \mathrm{yr}^{-1}$. Males who continued to smoke throughout the $11 \mathrm{yrs}$ declined by $66.1 \mathrm{~mL} \cdot \mathrm{yr}^{-1}$ and women who continued to smoke declined by $54.2 \mathrm{~mL} \cdot \mathrm{yr}^{-1}$. If these declines are expressed as a percentage of the predicted value, there is no difference between the declines in males and females who continued to smoke [18].

\subsection{Future expectations}

COPD is expected to increase globally in the coming decades. The main reasons are the changing age distribution in all countries, with increased life expectancy and an everincreasing proportion of the population living to $>60 \mathrm{yrs}$, and the increased uptake of smoking, especially in developing countries $[1,6,7]$.

In the western world, age-specific rates of mortality, as well as morbidity, have started to decrease for males and will presumably stabilise for females in the near future. The time trends in developing countries will depend on tobacco control and control of other particulate exposures. 


\subsection{References}

1. Pauwels R, Buist A, Calverley P, Jenkins C, Hurd S. Global strategy for the diagnosis, management and prevention of chronic obstructive pulmonary disease. NHLBI/WHO global initiative for chronic obstructive lung disease (GOLD) workshop summary. Am J Respir Crit Care Med 2001; 163: 1256-1276.

2. Mannino DM, Homa DM, Akinbami LJ, Ford ES, Redd SC. Chronic obstructive pulmonary disease surveillance - United States, 1971-2000. MMWR 2002; 51: 1-16.

3. Mannino DM, Gagnon RC, Petty TL, Lydick E. Obstructive lung disease and low lung function in adults in the United States: data from the National Health and Nutrition Examination Survey, 1988-1994. Arch Intern Med 2000; 160: 1683-1689.

4. Vestbo J, Prescott E, Lange P, and the Copenhagen City Heart Study Group. Association of chronic mucus hypersecretion with FEV1 decline and COPD morbidity. Am J Respir Crit Care Med 1996; 153: 1530-1535.

5. Prescott E, Vestbo J. Socioeconomic status and chronic obstructive pulmonary disease. Thorax 1999; 54: 737-741.

6. Feenstra TL, van Genugten MLL, Hoogenveen RT, Wouters EF, Rutten-van Mölken MPMH. The impact of aging and smoking on the future burden of chronic obstructive pulmonary disease. Am J Respir Crit Care Med 2001; 164: 590-596.

7. Murray CJL, Lopez AD. Alternative projections of mortality and disability by cause 19902020: Global Burden of Disease Study. Lancet 1997; 349: 1498-1504.

8. Sullivan SD, Ramsey SD, Lee TA. The economic burden of COPD. Chest 2000; 117: 5S9S.

9. Sandford AJ, Weir TD, Pare P. Genetic risk factors for chronic obstructive pulmonary disease. Eur Respir J 1997; 10: 1380-1391.

10. Silverman EK, Speizer FE. Risk factors for the development of chronic obstructive pulmonary disease. Med Clin North Am 1996; 80: 501-522.

11. Rijcken B, Scouten JP, Xu X, Rosner B, Weiss ST. Bronchial hyper-responsiveness to histamine is associated with accelerated decline of FEV1. Am J Respir Crit Care Med 1995; 151: 1377-1382.

12. Lange P, Parner J, Vestbo J, Jensen G, Schnohr P. A 15-year follow-up of ventilatory function in adults with asthma. N Engl J Med 1998; 339: 1194-1200. 
13. Prescott E. Tobacco-related diseases: the role of gender. Dan Med Bull 2000; 47: 115-131. 14. Anto JM, Vermeire P, Vestbo J, Sunyer J. Epidemiology of chronic obstructive pulmonary disease. Eur Respir J 2001; 17: 982-994.

15. Fletcher CM, Tinker CM, Peto R, Speizer FE. The natural history of chronic bronchitis and emphysema. Oxford, Oxford University Press, 1976.

16. Gold DR, Wang X, Wipyj D, Speizer FE, Ware JH, Dockery DW. Effects of cigarette smoking on lung function in adolescent boys and girls. N Engl J Med 1996; 335: 931-937.

17. Kerstjens HAM, Rijcken B, Schouten JP, Postma DS. Decline of FEV1 by age and smoking status: facts, figures, and fallacies. Thorax 1997; 52: 820-827.

18. Anthonisen NR, Connett JE, Murray RP, for the Lung Health Study Research Group. Smoking and lung function of Lung Health Study participants after 11 years. Am J Respir Crit Care Med 2002; 166: 675-679. 


\section{Pathology, pathogenesis and pathophysiology}

\subsection{Key points}

\section{Pathology}

- Chronic obstructive pulmonary disease (COPD) comprises pathological changes in four different compartments of the lungs (central airways, peripheral airways, lung parenchyma, pulmonary vasculature), which are variably present in individuals with the disease.

\section{Pathogenesis}

- Tobacco smoking is the main risk factor for COPD, although other inhaled noxious particles and gases may contribute. This causes an inflammatory response in the lungs, which is exaggerated in some smokers, and leads to the characteristic pathological lesions of COPD. In addition to inflammation, an imbalance of proteinases and antiproteinases in the lungs, and oxidative stress are also important in the pathogenesis of COPD.

\section{Pathophysiology}

- The different pathogenic mechanisms produce the pathological changes which, in turn, give rise to the physiological abnormalities in COPD: mucous hypersecretion and cilliary dysfunction, airflow limitation and hyperinflation, gas exchange abnormalities, pulmonary hypertension, and systemic effects.

\subsection{Pathology}

COPD comprises major pathological changes in the following four different compartments of the lung, which are variably present in individuals with the disease: central airways, peripheral airways, lung parenchyma and pulmonary vasculature.

\subsubsection{Central airways (cartilaginous airways $>2 \mathrm{~mm}$ of internal diameter)} See figure 1 .

Bronchial glands hypertrophy and goblet cell metaplasia occurs [1,2]. This results in excessive mucous production or chronic bronchitis. Cell infiltrates also occur in bronchial glands. 
Airway wall changes include squamous metaplasia of the airway epithelium, loss of cilia and ciliary dysfunction, and increased smooth muscle and connective tissue [2, 3].

Different inflammatory cells predominate in different compartments of the central airways. In the airways wall these are lymphocytes, predominantly of the CD8+ type, but as the disease progresses neutrophils also become prominent $[4,5]$. In the airspaces, in addition to lymphocytes, neutrophils and macrophages can also be identified [6,7].

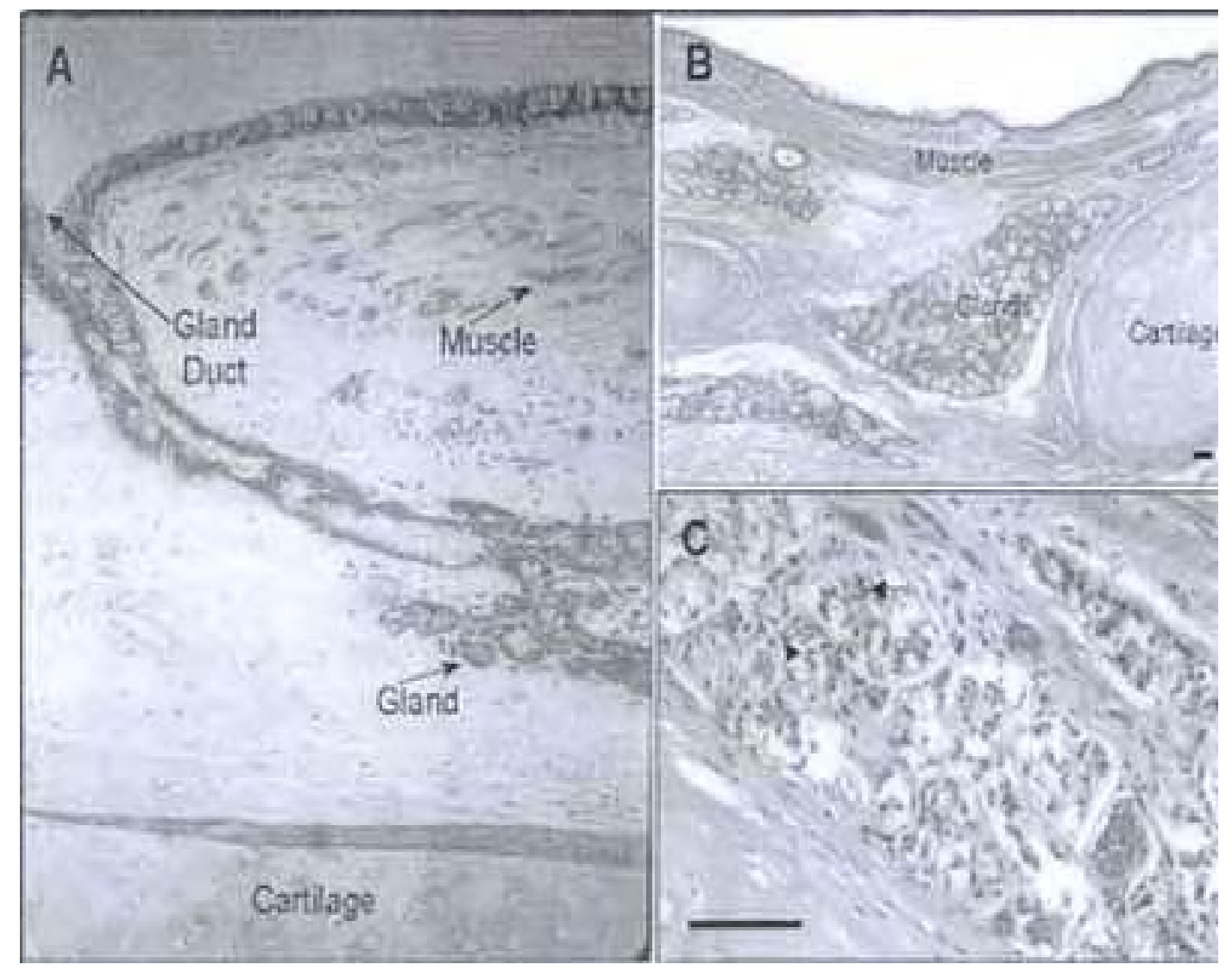

Fig. 1. - a) A central bronchus from the lungs of a cigarette smoker with normal lung function; very small amounts of muscle are present; there are small epithelial glands. b) Bronchus from a patient with chronic bronchitis; shows a thick bundle of muscle and enlargement of glands. c) A higher magnification of the enlarged glands with evidence of chronic inflammation involving polymorphonuclear (arrow head) and mononuclear cells, including plasma cells (arrow). Printed with kind permission from J.C. Hogg and S. Green. 


\subsubsection{Peripheral airways (noncartilaginous airways $<2 \mathrm{~mm}$ internal diameter)}

See figure 2 .

Bronchiolitis is present in the peripheral airways at an early stage of the disease [8].

There is pathological extension of goblet cells and squamous metaplasia in the peripheral airways [9].

The inflammatory cells in the airway wall and airspaces are similar to those in the larger airways [10].

As the disease progresses, there is fibrosis and increased deposition of collagen in the airway walls [11].

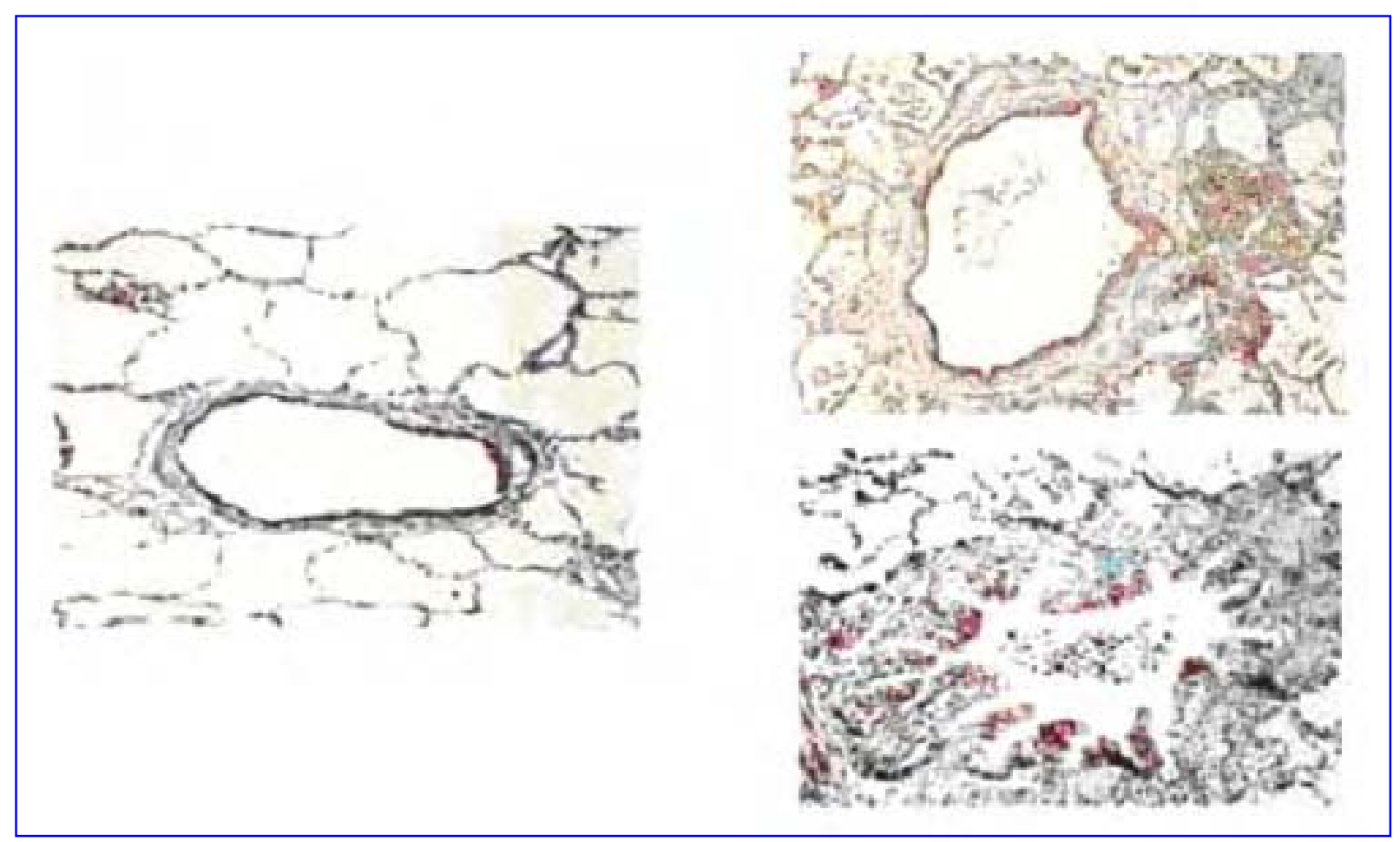

Fig. 2. - Histological sections of peripheral airways from a cigarette smoker with a) a nearly normal airway showing some airway inflammation, b) the presence of an inflammatory exudate in the wall and lumen of the airway, and c) an airway with reduced lumen and structural reorganisation of the airway wall, increased smooth muscle and deposition of peribronchial connective tissue. Printed with kind permission from J.C. Hogg and S. Green. 


\section{Lung parenchyma (respiratory bronchioles, alveoli and capillaries)}

See figure 3 .

Emphysema, defined as an abnormal enlargement of air spaces distal to the terminal bronchioles, occurs in the lung parenchyma in COPD.

As a result of emphysema there is a significant loss of alveolar attachments, which contributes to peripheral airway collapse [12].

There are two major types of emphysema, according to the distribution within the acinus: 1) centrolobular (which involves dilatation and destruction of the respiratory bronchioles); and 2) panlobular emphysema (which involves destruction of the whole of the acinus). The former is the most common type of emphysema in COPD and is more prominent in the upper zones, while the latter predominates in patients with $\alpha_{1}$-antitrypsin deficiency and is more prominent in the lower zones.

In the early stages of the disease, these are microscopic lesions. During the course of the disease, they may progress to macroscopic lesions or bullae (defined as an emphysematous space $>1 \mathrm{~cm}$ in diameter). Bullous disease can also occur in the absence of COPD.

The inflammatory cell profile in the alveolar walls and the airspaces is similar to that described in the airways and persists throughout the course of the disease [13]. There is some evidence suggesting the persistence of inflammation in the proximal and distal airspaces after smoking cessation $[14,15]$. 

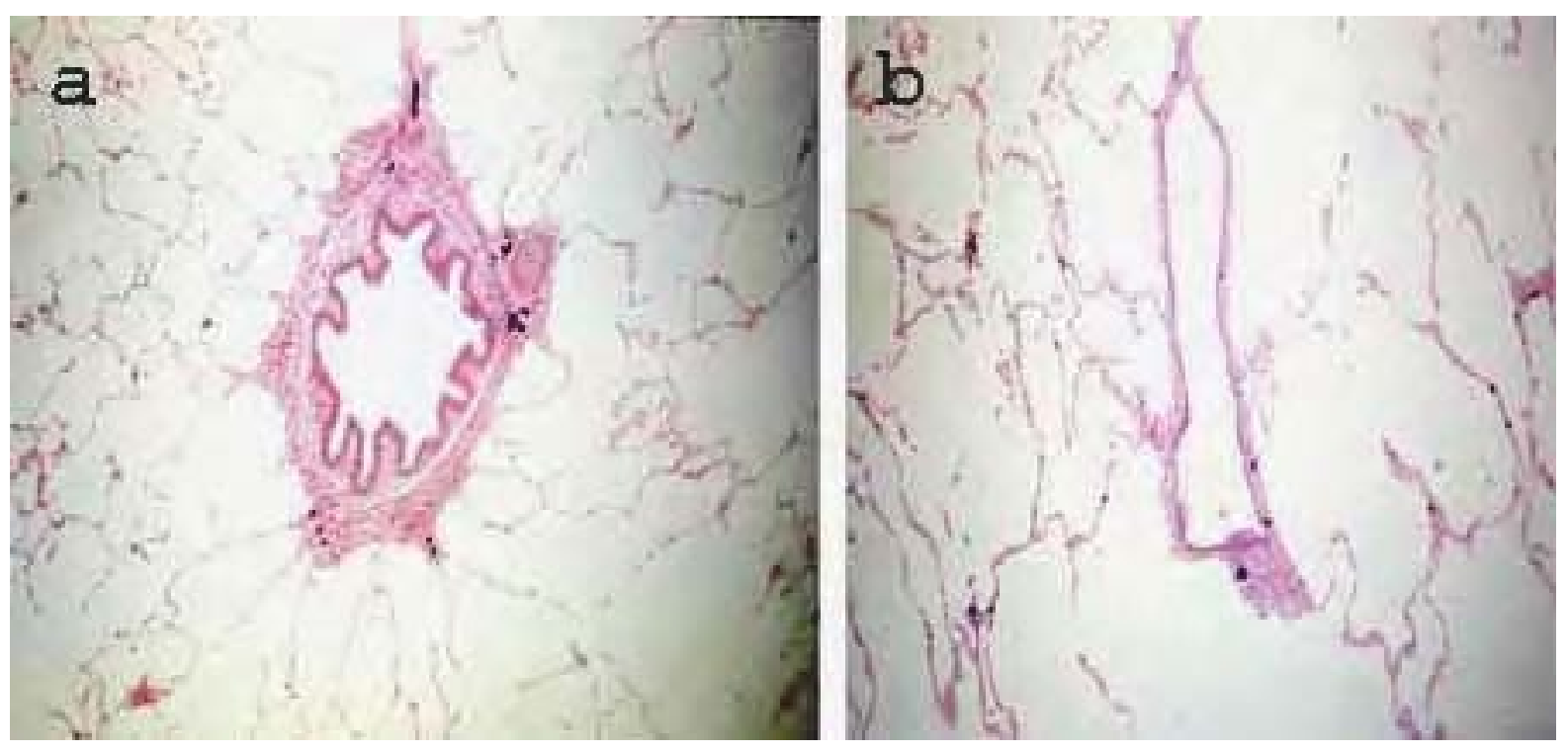

Fig. 3. - a) Common airway with alveolar attachments. b) Loss of alveolar walls, enlargement of alveolar spaces and decreased alveolar wall attachment in emphysema. Printed with kind permission from W. MacNee and D. Lamb.

\subsubsection{Pulmonary vasculature}

See figure 4.

Pulmonary vascular changes begin early during the course of the disease [16].

Initially, these changes are characterised by thickening of the vessel wall and endothelial dysfunction [17].

These are followed by increased vascular smooth muscle and infiltration of the vessel wall by inflammatory cells, including macrophages and CD8+ T lymphocytes [16].

In advanced stages of the disease, there is collagen deposition and emphysematous destruction of the capillary bed [18]. Eventually, these structural changes lead to pulmonary hypertension and right ventricular dysfunction (cor pulmonale) [19]. 


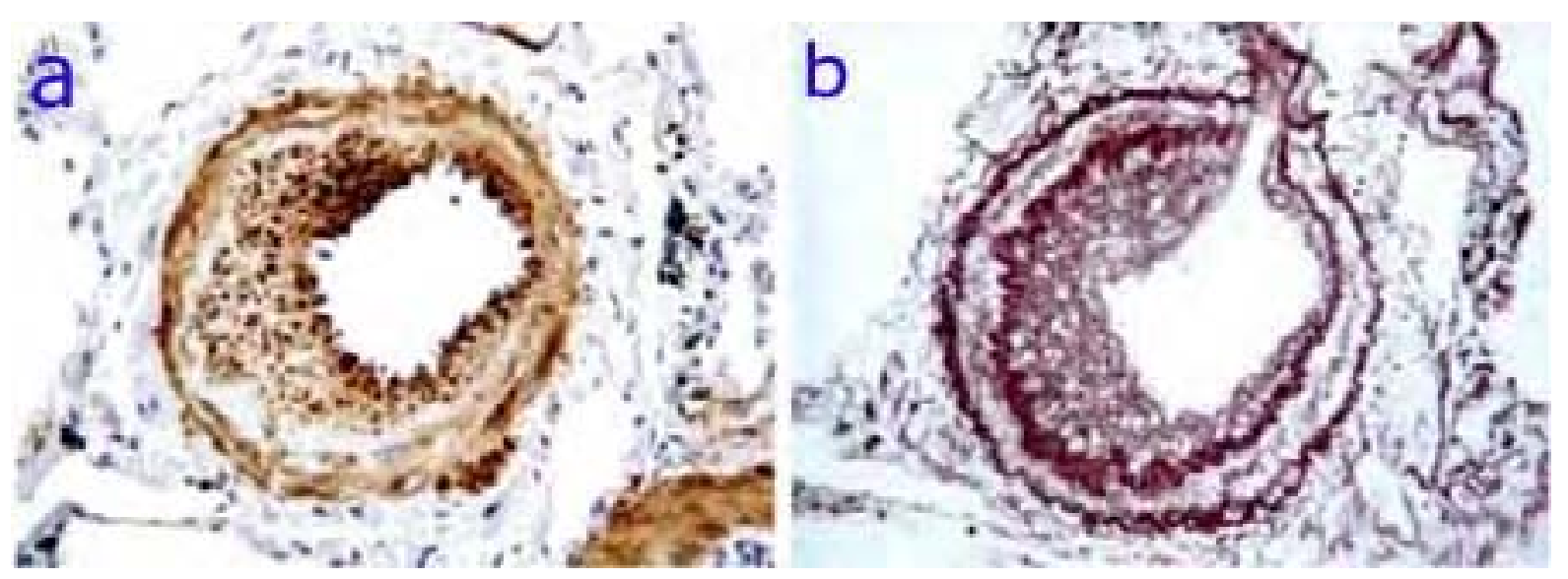

Fig. 4. - Pulmonary muscular artery from a patient with chronic obstructive pulmonary disease, showing prominent intimal thickening and luminal narrowing. a) Immunostaining with monoclonal antibody against a-smooth muscle actin, showing abundant proliferation of smooth muscle cells in the intima. b) Orcein stain showing abundant deposition of elastic fibres in the intimallayer. Internal scale bar $=42.2 \mathrm{~mm}$.

\subsection{Pathogenesis}

Tobacco smoking is the main risk factor for COPD, although other inhaled noxious particles and gases may also contribute. This causes an inflammatory response in the lungs of all smokers [8].

Due to, as yet, unknown reasons, some smokers display an exaggeration of this normal, protective inflammatory response to these inhalation exposures, which eventually causes tissue destruction, impairs the defence mechanisms that limit such destruction and disrupts the repair mechanisms, leading to the characteristic pathological lesions of COPD (see above).

In addition to inflammation, two other processes that are also important in the pathogenesis of COPD are an imbalance of proteinases and antiproteinases in the lungs, and oxidative stress.

\subsubsection{Inflammation}

COPD is characterised by an increase in neutrophils, macrophages and T-lymphocytes (specifically CD8+) in various parts of the lungs, which relate to the degree of airflow 
limitation [10]. There may be an increase in eosinophils in some patients, particularly during exacerbations $[20,21]$.

These inflammatory cells are capable of releasing a variety of cytokines and inflammatory mediators, most notably leukotriene 4 , interleukin- 8 and tumour necrosis factor- $\alpha$.

This inflammatory pattern is markedly different from that seen in patients with bronchial asthma.

Inflammatory changes may persist after quitting smoking. The mechanisms explaining the perpetuation of this inflammatory response in the absence of the inciting events are unknown.

\subsubsection{Proteinase and antiprotease imbalance}

This may occur in COPD due to increased production (or activity) of proteinases or inactivation (or reduced production) of antiproteinases.

Cigarette smoke (and possibly other COPD risk factors), as well as inflammation itself, can produce oxidative stress that, on the one hand, primes several inflammatory cells (macrophages, neutrophils) to release a combination of proteinases and, on the other hand, decreases (or inactivates) several antiproteinases by oxidation.

The major proteinases involved in the pathogenesis of COPD include those produced by neutrophils (elastase, cathepsin $\mathrm{G}$ and proteinase-3) and macrophages (cathepsins B, L and S), and various matrix metalloproteinases (MMP).

The major antiproteinases involved in the pathogenesis of COPD include, $\alpha_{1}$-antitrypsin, secretory leukoproteinase inhibitor and tissue inhibitors of MMPs.

Neutrophil elastase not only contributes to parenchymal destruction but it is also a very potent inducer of mucous secretion and mucous gland hyperplasia [22, 23]. 


\subsubsection{Oxidative stress}

Different markers of oxidative stress are found in increased amounts in the lungs, exhaled air breath condensate and urine of smokers and patients with COPD, including hydrogen peroxide, nitric oxide and lipid peroxidation products (isoprostane F2 $\alpha$-III) [24].

Oxidative stress can contribute to COPD by oxidising a variety of biological molecules (that can lead to cell dysfunction or death), damaging the extracellular matrix, inactivating key antioxidant defences (or activating proteinases) or enhancing gene expression (either by activating transcription factors (e.g. nuclear factor- $\mathrm{\kappa B}$ ) or promoting histone acetylation) [25].

\subsection{Pathophysiology}

The different pathogenic mechanisms discussed above produce the pathological changes, which, in turn, give rise to the following physiological abnormalities in COPD: mucous hypersecretion and cilliary dysfunction, airflow limitation and hyperinflation, gas exchange abnormalities, pulmonary hypertension, and systemic effects.

\subsubsection{Mucous hypersecretion and cilliary dysfunction}

These are typically the first physiological abnormalities in COPD.

The former is due to stimulated secretion from enlarged mucous glands. The latter due to squamous metaplasia of epithelial cells.

\subsubsection{Airflow limitation and hyperinflation}

Expiratory (largely irreversible) airflow limitation is the physiological hallmark of COPD.

The major site of the airflow limitation is in the smaller conducting airways $<2 \mathrm{~mm}$ in diameter and is mainly due to airway remodelling (fibrosis and narrowing) $[9,26]$.

Other factors that also contribute include loss of elastic recoil (due to destruction of alveolar walls), destruction of alveolar support (alveolar attachments) [12], accumulation of 
inflammatory cells, mucous and plasma exudate in the bronchi, and smooth muscle contraction and dynamic hyperinflation during exercise. The latter is one of the major contributors to exercise limitation in these patients [27].

Airflow limitation in COPD is best measured by spirometry, which is key to the diagnosis of the disease.

\subsubsection{Gas exchange abnormalities}

These occur in advanced disease and are characterised by arterial hypoxaemia with or without hypercapnia.

An abnormal distribution of ventilation-perfusion ratios (due in turn to the anatomical alterations described above) is the main mechanism of abnormal gas exchange in COPD [28].

An abnormal diffusing capacity of carbon monoxide per litre of alveolar volume correlates well with the severity of the emphysema [29].

\subsubsection{Pulmonary hypertension}

This occurs late in the course of COPD, normally after the development of severe gas exchange abnormalities.

Factors contributing to pulmonary hypertension in COPD include vasoconstriction (mostly of hypoxic origin), endothelial dysfunction, remodelling of pulmonary arteries and destruction of the pulmonary capillary bed. This combination of events may eventually lead to right ventricular hypertrophy and dysfunction (cor pulmonale) $[19,30]$.

\subsubsection{Systemic effects}

COPD is associated with extrapulmonary effects, including systemic inflammation and skeletal muscle wasting. These systemic effects contribute to limit the exercise capacity of these patients and to worsen prognosis, independent of their pulmonary function [31]. 


\subsection{Pathology; pathogenesis; pathophysiology of exacerbations}

Patients with COPD often present with acute episodes (exacerbations) of increased symptoms that frequently require a change in their usual medications. These episodes vary in severity from mild exacerbations (normally managed at home by the patient) to moderate exacerbations (requiring consultation with primary care physicians) and severe exacerbations (needing hospitalisation).

\subsubsection{Pathology}

Available evidence of pathological changes during exacerbations is scanty and mostly indirect (sputum and bronchial biopsies).

In general, exacerbations are associated with increased neutrophilic inflammation and, in mild exacerbations, with the presence of eosinophils [20, 21]. There is no information on the pathology of severe exacerbations.

\subsubsection{Pathogenesis}

Many exacerbations are infectious in origin (either bacterial or viral). However, many patients with COPD are colonised by bacteria when clinically stable. Thus, there is a substantial percentage of exacerbation episodes of unclear cause. Potential mechanisms include air pollution, changes in ambient temperature and pulmonary emboli, among others (smoking and cessation of medication) [32].

\subsubsection{Pathophysiology}

Airflow obstruction is almost unchanged during mild exacerbations [20] and only slightly reduced during severe exacerbations [33].

Severe exacerbations are accompanied by a significant worsening of pulmonary gas exchange (due mostly to increased ventilation-perfusion inequality) [34] and, potentially, by respiratory muscle fatigue. 
Worsening ventilation-perfusion relationships in exacerbations of COPD are multifactorial and relate to airway inflammation and oedema, mucus hypersecretion and bronchoconstriction, which affects ventilation and causes hypoxic vasoconstriction of pulmonary arterioles, which reduces perfusion.

Alveolar hypoventilation and respiratory muscle fatigue also contribute to hypoxaemia, hypercapnia and respiratory acidosis leading to severe respiratory failure and death.

Hypoxia and respiratory acidosis produce pulmonary vasoconstriction imposing an additional load on the right ventricle and, together with renal and hormonal changes, can result in peripheral oedema. 


\subsection{References}

1. Reid L. Measurement of the bronchial mucous gland layer: a diagnostic yardstick in chronic bronchitis. Thorax 1960; 15; 132-141.

2. Mullen JB, Wright JL, Wiggs BR, Pare PD, Hogg JC. Reassessment of inflammation of airways in chronic bronchitis. Br Med J (Clin Res Ed) 1985; 291: 1235-1239.

3. Jamal K, Cooney TP, Fleetham JA, Thurlbeck WM. Chronic bronchitis. Correlation of morphologic findings to sputum production and flow rates. Am Rev Respir Dis 1984; 129: 719 722.

4. O'Shaughnessy TC, Ansari TW, Barnes NC, Jeffery PK. Inflammation in bronchial biopsies of subjects with chronic bronchitis: inverse relationship of CD8+ T lymphocytes with FEV1. Am J Respir Crit Care Med 1997; 155: 852-857.

5. Saetta M, Di Stefano A, Maestrelli P, et al. Activated T-lymphocytes and macrophages in bronchial mucosa of subjects with chronic bronchitis. Am Rev Respir Dis 1993; 147: 301-306.

6. Pesci A, Balbi B, Majori M, et al. Inflammatory cells and mediators in bronchial lavage of patients with chronic obstructive pulmonary disease. Eur Respir J 1998; 12: 380-386.

7. Pesci A, Majori M, Cuomo A, et al. Neutrophils infiltrating bronchial epithelium in chronic obstructive pulmonary disease. Respir Med 1998; 92: 863-870.

8. Niewoehner DE, Kleinerman J, Rice DB. Pathologic changes in the peripheral airways of young cigarette smokers. $N$ Engl J Med 1974; 291: 755-758.

9. Cosio M, Ghezzo H, Hogg JC, et al. The relations between structural changes in small airways and pulmonary-function tests. N Engl J Med 1978; 298:1277-1281.

10. Saetta M, Di Stefano A, Turato G, et al. CD8+ T-lymphocytes in peripheral airways of smokers with chronic obstructive pulmonary disease. Am J Respir Crit Care Med 1998; 157: $822-826$.

11. Rennard SI. Inflammation and repair processes in chronic obstructive pulmonary disease. Am J Respir Crit Care Med 1999; 160: S12-S16.

12. Lamb D, McLean A, Gillooly M, Warren PM, Gould GA, MacNee W. Relation between distal airspace size, bronchiolar attachments, and lung function. Thorax 1993; 48: 1012-1017. 13. Finkelstein R, Fraser RS, Ghezzo H, Cosio MG. Alveolar inflammation and its relation to emphysema in smokers. Am J Respir Crit Care Med 1995; 152: 1666-1672. 
14. Turato G, Di Stefano A, Maestrelli P, et al. Effect of smoking cessation on airway inflammation in chronic bronchitis. Am J Respir Crit Care Med 1995; 152: 1262-1267.

15. Rutgers SR, Postma DS, ten Hacken NH, et al. Ongoing airway inflammation in patients with COPD who do not currently smoke. Thorax 2000; 55: 12-18.

16. Peinado VI, Barbera JA, Abate $\mathrm{P}$, et al. Inflammatory reaction in pulmonary muscular arteries of patients with mild chronic obstructive pulmonary disease. Am J Respir Crit Care Med 1999; 159: 1605-1611.

17. Wright JL, Lawson L, Pare PD, et al. The structure and function of the pulmonary vasculature in mild chronic obstructive pulmonary disease. The effect of oxygen and exercise. Am Rev Respir Dis 1983; 128: 702-707.

18. Riley DJ, Thakker-Varia S, Poiani GJ, Tozzi CA. Vascular Remodeling. The Lung: Scientific foundations. 1589-1597. Philadelphia, Lippincott-Raven, 1977.

19. MacNee W. Pathophysiology of cor pulmonale in chronic obstructive pulmonary disease. Part two. Am J Respir Crit Care Med 1994; 150: 1158-1168.

20. Saetta M, Di Stefano A, Maestrelli P, et al. Airway eosinophilia in chronic bronchitis during exacerbations. Am J Respir Crit Care Med 1994; 150: 1646-1652.

21. Saetta M, Di Stefano A, Maestrelli P, et al. Airway eosinophilia and expression of interleukin-5 protein in asthma and in exacerbations of chronic bronchitis. Clin Exp Allergy 1996; 26: 766-774.

22. Sommerhoff CP, Nadel JA, Basbaum CB, Caughey GH. Neutrophil elastase and cathepsin G stimulate secretion from cultured bovine airway gland serous cells. J Clin Invest 1990; 85: 682-689.

23. Dekhuijzen PN, Aben KK, Dekker I, et al. Increased exhalation of hydrogen peroxide in patients with stable and unstable chronic obstructive pulmonary disease. Am J Respir Crit Care Med 1996; 154: 813-816.

24. Repine JE, Bast A, Lankhorst I. Oxidative stress in chronic obstructive pulmonary disease. Oxidative Stress Study Group. Am J Respir Crit Care Med 1997; 156: 341-357.

25. MacNee W, Rahman I. Is oxidative stress central to the pathogenesis of chronic obstructive pulmonary disease? Trends Mol Med 2000; 7: 43-62. 
26. Matsuba K, Wright JL, Wiggs BR, Pare PD, Hogg JC. The changes in airways structure associated with reduced forced expiratory volume in one second. Eur Respir J 1989; 2: 834839.

27. O'Donnell DE, Revill SM, Webb KA. Dynamic hyperinflation and exercise intolerance in chronic obstructive pulmonary disease. Am J Respir Crit Care Med 2001; 164: 770-777.

28. Rodriguez-Roisin R, MacNee W. Pathophysiology of chronic obstructive pulmonary disease. Eur Respir Mono 1998; 3: 107-126.

29. McLean A, Warren PM, Gillooly M, MacNee W, Lamb D. Microscopic and macroscopic measurements of emphysema: relation to carbon monoxide gas transfer. Thorax 1992; 47: 144149.

30. Biernacki W, Flenley DC, Muir AL, MacNee W. Pulmonary hypertension and right ventricular function in patients with COPD. Chest 1988; 94: 1169-1175.

31. Schols AM, Slangen J, Volovics L, Wouters EF. Weight loss is a reversible factor in the prognosis of chronic obstructive pulmonary disease. Am J Respir Crit Care Med 1998; 157: 1791-1797.

32. Wedzicha JA. Mechanisms of exacerbations. Novartis Found Symp 2001; 234: 84-93.

33. Seemungal TA, Donaldson GC, Bhowmik A, Jeffries DJ, Wedzicha JA. Time course and recovery of exacerbations in patients with chronic obstructive pulmonary disease. Am J Respir Crit Care Med 2000; 161: 1608-1613.

34. Barbera JA, Roca J, Ferrer A, et al. Mechanisms of worsening gas exchange during acute exacerbations of chronic obstructive pulmonary disease. Eur Respir J 1997; 10: 1285-1291. 


\section{Clinical assessment, testing; differential diagnosis}

\subsection{Key points}

- Chronic obstructive pulmonary disease (COPD) runs an insidious course, measured over years, with an often undiagnosed initial phase.

- Its presence can be suspected after a directed clinical evaluation and then confirmed physiologically with a simple spirometry.

- Chest radiography helps in differential diagnosis.

- Other tests may be useful to better determine the phenotype and physiological characteristics of individual patients.

\subsection{Clinical assessment}

Clinical assessment is based on medical history and physical examination [1-3]. Although a complete examination is indicated for all patients, these two components are specifically important for patients with suspected COPD.

\subsubsection{Medical history}

A directed medical history should assess the following issues.

\subsubsection{Symptoms}

Cough may be intermittent (early morning) at the beginning, progressively becoming present throughout the day, but is seldom entirely nocturnal [4]. Chronic cough is usually productive and is very often discounted as it is considered an expected consequence of smoking. Cough syncope or cough rib fractures may occur.

Sputum initially occurs in the morning but later will be present all day long. It is usually tenacious and mucoid and in small quantities [2]. Production of sputum for $\geq 3$ months in 2 consecutive years is the epidemiological definition of chronic bronchitis. A change in sputum colour (purulent) or volume suggests an infectious exacerbation. 
Dyspnoea is usually progressive and over time it becomes persistent. At the onset it occurs during exercise (climbing up stairs, walking up hills) and may by avoided entirely by appropriate behavioural changes (e.g. using an elevator). However, as the disease progresses, dyspnoea is elicited even during minimal exertion or at rest. A quantification of dyspnoea using the Modified Medical Research Council scale (see Definition, diagnosis and staging) is indicated since it predicts quality of life and survival.

\subsubsection{Past medical history and review of systems}

Any of the following should be noted.

- Any history of asthma, allergy, respiratory infections in childhood or any other respiratory diseases such as tuberculosis.

- Any family history of COPD or other respiratory disease.

- Any history of exacerbations of COPD or hospitalisations.

- Any comorbidities, e.g. those associated with the heart or peripheral vasculature, or neurological comorbidities that share the same risk factor (i.e. cigarette smoke exposure). In addition, symptoms of depression and anxiety may indicate the need for appropriate treatment of these conditions.

- Any history of unexplained weight loss is important because, if caused by COPD, it heralds a poor prognosis.

- Other, nonspecific symptoms, such as wheezing and chest tightness or pain, and morning headache.

\subsubsection{Exposure history}

The history of exposure to risk factors, such as smoking, or occupational or environmental noxious agents, should be noted. A detailed smoking history is essential (pack-years). Pack-years are calculated by multiplying the number of pack equivalent smoked every day by the total number of years. 


\subsubsection{Physical examination}

A normal physical examination is frequent in early COPD [6]. As the disease progresses some signs become apparent and in the advanced stages many are almost pathonogmonic.

As part of the vital signs, all patients should have their respiratory rate measured, weight and height determined, and their body mass index calculated (see Definition, diagnosis and staging).

The examination should be aimed at eliciting the presence of the respiratory and systemic effects of COPD.

\subsubsection{Respiratory signs}

Inspection: check for barrel chest deformity, pursed-lips breathing, chest/abdominal wall paradoxical movements and use of accessory respiratory muscles. All these are signs of severe airflow limitation, hyperinflation and impairment of the mechanics of breathing.

Percussion: check for decreased motion of the diaphragm and tympanic sounds due to hyperinflation or bullae; in addition the liver becomes easily palpable.

Auscultation: adventitious rhonchi and wheezing may help differentiate COPD from congestive heart failure or pulmonary fibrosis, which are often associated with crackles.

Auscultation of the heart: may show signs of cor pulmonale, such as split of second sound (pulmonic), murmurs of pulmonary or tricuspid insufficiency.

\subsubsection{Systemic signs}

Neck vein distension, liver enlargement and peripheral oedema could be due to cor pulmonale or due to severe hyperinflation.

Loss of muscle mass and peripheral muscle weakness are consistent with malnutrition and /or skeletal muscle dysfunction. 
Cyanosis or bluish colour of the mucosal membranes may indicate hypoxaemia.

\subsection{Testing}

A number of different tests should be performed when investigating COPD. These include tests that should be performed on all patients and those that should be performed only on selected patients.

\subsubsection{All patients}

Spirometry should be performed in all patients suspected of COPD. This is necessary for diagnosis, assessment of severity of the disease and for following the progress of the disease (see Definition, diagnosis and staging).

Bronchodilator reversibility [8] should be performed at least once to exclude asthma and to establish the best lung function for the individual patient, and, to a lesser degree, to estimate the prognosis. The increase in forced expiratory volume in one second (FEV1) should be expressed as a percentage of the predicted value that is less dependent on the baseline FEV1. Although some bronchodilation may be present in some patients with COPD, a large increase in postbronchodilator FEV1 supports the diagnosis of asthma.

Chest radiography $[1-3,8]$ should be obtained in all patients. It is not sensitive for the diagnosis, but it is helpful in excluding other diseases (pneumonia, cancer, congestive heart failure, pleural effusions and pneumothorax). It is also of value to detect bullous disease. Common but not specific signs of emphysema are flattening of the diaphragm, irregular lung radiolucency, reduction or absence of vasculature (rapid tapering).

\subsection{2. $\quad$ Selected patients}

$\alpha_{1}$-antitrypsin levels $[1,2,3]$ should be measured in young patients (4th or 5 th decade) who develop COPD and have a strong family history. This may be followed by family screening. A serum value of $\alpha_{1}$-antitrypsin $<15-20 \%$ of the normal limits is highly suggestive of homozygous $\alpha_{1}$-antitrypsin deficiency. 
Static lung volumes [9], including total lung capacity (TLC), residual volume (RV), functional residual capacity and the ratio RV/TLC are all characteristically increased in advanced COPD. A good index of hyperinflation is the measure of the inspiratory capacity. Lung volumes are useful in patients with more advanced disease and those being considered for surgery (see Management of stable COPD: surgery in and for COPD).

Transfer factor of the lung for carbon monoxide (TL,CO) is usually reduced in COPD, particularly in emphysema [8]. If TL,CO is reduced, asthma can be excluded. A low diffusion capacity is helpful in stratifying patients for lung resection (see Management of stable COPD: surgery in and for COPD).

In stable patients, the measurement of arterial blood gases $[2,8]$ is recommended in moderate and severe stages of the disease. The determination of oxygen saturation is very helpful and patients with values $<94 \%$ at sea level breathing room air suggests the need for blood gases (see Exacerbation: inpatient oxygen therapy).

Blood gases monitoring is mandatory during a severe exacerbation, leading to respiratory failure (see Exacerbation: definition, evaluation and treatment).

Exercise testing [8] is of practical value in patients with a disproportional degree of dyspnoea to FEV1. It can be performed on a cycle or treadmill ergometer or by a simple timed walking test (e.g. $6 \mathrm{~min})$. Exercise testing is of use in selecting patients for rehabilitation or surgery.

Respiratory muscle function [1] could be tested in poor nutrition and suspect steroid myopathy, as well as if dyspnoea or hypercapnia are disproportionally increased with respect to FEV1.

Maximum inspiratory pressure is impaired usually due to hyperinflation and/or abnormal mechanics of breathing. In contrast, a reduction in maximum expiratory pressure could be attributed to muscle weakness. 
Pulmonary vascular pressure and right ventricular function [9] can be assessed using noninvasive methods, such as Doppler echocardiography, to assess pulmonary hypertension. The gold standard method of measuring pulmonary hypertension remains right heart catheterisation.

Computed tomography should be recommended if the diagnosis is in doubt and preoperative for bullectomy or lung volume-reduction surgery.

Indications for a polysomnographic sleep study [10] in COPD are suspicions of co-existing sleep apnoea (see Management of stable COPD: sleep).

\subsection{Differential diagnosis}

The differential diagnosis of COPD is shown in table 1. 
Table 1. - Differential diagnosis of COPD

\begin{tabular}{|c|c|}
\hline Diagnosis & Suggestive features \\
\hline \multirow[t]{2}{*}{ COPD } & Mid-life onset; Slowly progressing symptoms \\
\hline & Long history of smoking \\
\hline \multirow[t]{5}{*}{ Asthma } & Early onset; Varying symptoms \\
\hline & Symptoms during the night/early morning \\
\hline & Presence of allergy, rhinitis and/or eczema \\
\hline & A family history \\
\hline & Airflow limitation that is largely reversible \\
\hline \multirow[t]{4}{*}{ Congestive heart failure } & Fine basilar crackles on auscultation \\
\hline & Dilated heart on chest radiography \\
\hline & Pulmonary oedema \\
\hline & Volume restriction not airflow limitation on pulmonary function tests \\
\hline \multirow[t]{4}{*}{ Bronchiectasis } & Large volume of purulent sputum \\
\hline & Commonly associated with bacterial infection \\
\hline & Coarse crackles/clubbing on auscultation \\
\hline & Bronchial dilation and bronchial wall thickening on chest radiography/CT \\
\hline \multirow[t]{4}{*}{ Tuberculosis } & Onset at all ages \\
\hline & Lung infiltrate on chest radiography \\
\hline & Microbiological confirmation \\
\hline & High local prevalence of tuberculosis \\
\hline Obliterative & Younger onset and in non-smokers \\
\hline \multirow[t]{2}{*}{ bronchiolitis } & History of rheumatoid arthritis/fume exposure? \\
\hline & Hypodense areas on expiration on CT \\
\hline \multirow[t]{3}{*}{ Diffuse panbronchiolitis } & Effects mostly male nonsmokers \\
\hline & Almost all have chronic sinusitis \\
\hline & $\begin{array}{l}\text { Diffuse small centrilobular nodular opacities \& hyperinflation on chest radiography } \\
\text { and HRCT }\end{array}$ \\
\hline
\end{tabular}

CT: computed tomography; HRCT: high-resolution computed tomography. Modified from [5].

Some patients with chronic asthma cannot be distinguished from COPD with the current imaging or lung function testing. In these cases it is assumed that the two diseases (asthma/COPD) co-exist and their management should be similar to that of asthma. 


\subsection{References}

1. Siafakas NM, Vermeire P, Pride NB, et al. Optimal assessment and management of chronic obstructive pulmonary disease (COPD). The European Respiratory Society Task Force. Eur Respir J 1995; 8: 1398-1420.

2. Celli B, Snider GL, Heffener J, et al. Standards for the diagnosis and care of patients with chronic obstructive pulmonary disease. Am J Respir Crit Care Med 1995; 152: S77-S120.

3. Pauwels RA, Buist S, Calverley PMA, Jenkins CR, Hurd SS, on behalf of the GOLD Scientific Committee. Global strategy for the diagnosis, management and prevention of chronic obstructive pulmonary disease. Am J Respir Crit Care Med 2001; 163: 1256-1276.

4. Georgopoulos D, Anthonisen NR. Symptoms and signs of COPD. In: Cherniack NS, ed. Chronic obstructive pulmonary disease. Toronto, WB Saunders Co, 1991; pp. 357-363.

5. Management of COPD: assess and monitor disease. In: Global strategy for the diagnosis, management, and prevention of chronic obstructive pulmonary disease. NHLBI/WHO Workshop. NIH/NHLBI, 2001.

6. Calverley PMA, Georgopoulos D. Chronic obstructive pulmonary disease: symptoms and signs. In: Postma DS, Siafakas NM, eds. Management of chronic obstructive pulmonary disease. Eur Respir Mon 1998; 8: 6-24.

7. American Thoracic Society. Lung function testing: selection of reference values and interpretative strategies. Am Rev Respir Dis 1991; 144: 1202-1218.

8. Gibson GJ, MacNee W. Chronic obstructive pulmonary disease: investigations and assessment of severity. In: Postma DS, Siafakas NM, eds. Management of chronic obstructive pulmonary disease. Eur Respir Mon 1998; 7: 25-40.

9. MacNee W. Pathophysiology of cor pulmonale in chronic obstructive pulmonary disease. Am J Respir Crit Care Med 1994; 150: 833-852 (part one); 1158-1168 (part two).

10. Connaughton JJ, Catterall JR, Elton RA, Stradling JR, Douglas NJ. Do sleep studies contribute to the management of patient with severe chronic obstructive pulmonary disease? Am Rev Respir Dis 1988; 138: 341-345. 


\section{Management of stable COPD: smoking cessation 6.1. Key points}

- Smoking is an addiction and a chronic relapsing disorder.

- Smoking should be routinely evaluated whenever a patient presents to a healthcare facility

- All smokers should be offered the best chance to treat this disorder.

- Permanent remissions can be achieved in a substantial percentage of smokers with currently available treatments.

- Successful treatment of this disorder can have a substantial benefit in reducing many secondary complications of which chronic obstructive pulmonary disease (COPD) is one.

- Smoking cessation activities and support for its implementation should be integrated into the healthcare system.

\subsection{Background}

\subsubsection{Smoking as a primary disorder}

Cigarette smoking is an addiction and a chronic relapsing disorder regarded as a primary disorder by the Department of Health and Human Services Guidelines in the USA [1, 2] and by the World Health Organization. Therefore, treating tobacco use and dependence should be regarded as a primary and specific intervention.

Preventing the development and progression of COPD can be regarded as one of the secondary effects prevented by treating the primary disorder, because although cigarette smoking is the single most important cause of COPD, it is also a major risk factor for many other diseases including atherosclerotic vascular disease, cancer, peptic ulcer and osteoporosis. 


\subsubsection{Smoking prevention}

Effective primary prevention of smoking would eliminate the need for smoking cessation.

Unfortunately, measures to decrease smoking initiation have had limited success. Yet, the following measures have been shown to prevent smoking addiction:

- increasing the price of cigarettes [3]

- enforced programmes which limit access to cigarettes [4]

- society can have a major effect on smoking behaviour and it is hoped that comprehensive programmes designed to control smoking initiation can have similar benefits [5].

\subsubsection{Smoking in COPD}

Smokers experience an accelerated rate of decline in lung function [6]. Individual susceptibility, however, varies greatly and depends on a complex interaction of many genetic and environmental factors.

It is often stated that $15 \%$ of smokers will develop COPD. This dramatically underestimates the impact of smoking because the majority of smokers will develop loss of lung function [6, 7], and reduced lung function, at any level, is predictive of increased mortality [8].

Many smokers with undiagnosed COPD have symptoms [9]. It is necessary to identify and properly diagnose individuals earlier in the course of the disease when physiological limitation and symptoms are milder [10].

Quitting smoking can slow the progressive loss of lung function [11] and can reduce symptoms [12] at any point in time. Yet, the beneficial impact of smoking cessation on the natural history of COPD is greatest the earlier cessation is achieved. Adolescents who quit smoking will have increased lung growth. 


\subsubsection{Passive smoking and COPD}

Smoking during pregnancy is associated with low birth weight, and infants with low birth weight appear to have a greater risk of developing COPD [13].

Smoking and probably passive smoke exposure in childhood compromises lung growth leading to diminished maximal lung function in young adulthood [14].

Passive smoke exposure is a risk factor for symptoms of cough and sputum production, and may account for some of the COPD that develops in nonsmokers [15].

\subsection{Smoking cessation}

\subsubsection{Guidelines}

The most comprehensive of the guidelines prepared on smoking cessation is "Treating Tobacco Use and Dependence", an evidence-based guideline sponsored by the US Department of Health and Human Services and released in 2000 [2], which updates the previous evidencebased guideline "Smoking Cessation" released in 1996 [16].

The guideline and the meta-analyses on which it is based are available at www.surgeongeneral.gov/tobacco/default.htm. The key findings of this report are summarised in table 1. 
Table 1. - Key points of the Treating Tobacco Use and Dependence guidelines

- Tobacco dependence is a chronic condition that warrants repeated treatment until long-term or permanent abstinence is achieved

- Effective treatments for tobacco dependence exist and all tobacco users should be offered these treatments

- Clinicians and healthcare delivery systems must institutionalise the consistent identification, documentation and treatment of every tobacco user at every visit.

- Brief tobacco dependence intervention is effective and every tobacco user should be offered at least brief intervention

- There is a strong dose-response relationship between the intensity of tobacco dependence counselling and its effectiveness

- Three types of counselling were found to be especially effective: practical counselling, social support as part of treatment and social support arranged outside treatment

- Five first-line pharmacotherapies for tobacco dependence are effective: bupropion SR, nicotine gum, nicotine inhaler, nicotine nasal spray and nicotine patch, and at least one of these medications should be prescribed in the absence of contraindications

- Tobacco-dependence treatments are cost effective relative to other medical and disease prevention interventions

\subsubsection{General principles}

Smoking behaviour should be considered in the routine assessment of all patients who present to a healthcare facility.

Smokers vary in their readiness to quit. The concept that smokers progress through recognisable stages has been helpful in guiding both research and clinical practice [17].

- Before being ready to plan a quit attempt, smokers are regarded as "precontemplators". It is in this stage that tailored advice and encouraging support is likely to be of the most benefit.

- Smokers then enter the "contemplation" phase, where advice, particularly about the need for an action plan that optimises success, can be most helpful.

- Only then are smokers believed to enter the "action" phase. 
- Interestingly, smokers may progress through these stages when acutely ill, presenting the attentive clinician with windows of opportunity where intervention is more likely to be successful [18].

Each patient should be provided with an individualised approach based on their current smoking behaviour and readiness to quit (fig. 1).

- Brief interventions should be implemented in all practices.

- Intensive interventions are appropriate for many COPD patients and, ideally, each practitioner caring for COPD patients should have the option to refer patients for intensive interventions.

- The most effective treatment of tobacco use and dependence requires a systems approach providing adequately supported and integrated resources throughout the healthcare system.

- Smokers should be addressed in different ways depending on whether they are not ready to make a quit attempt, ready to make a quit attempt or have recently quit.

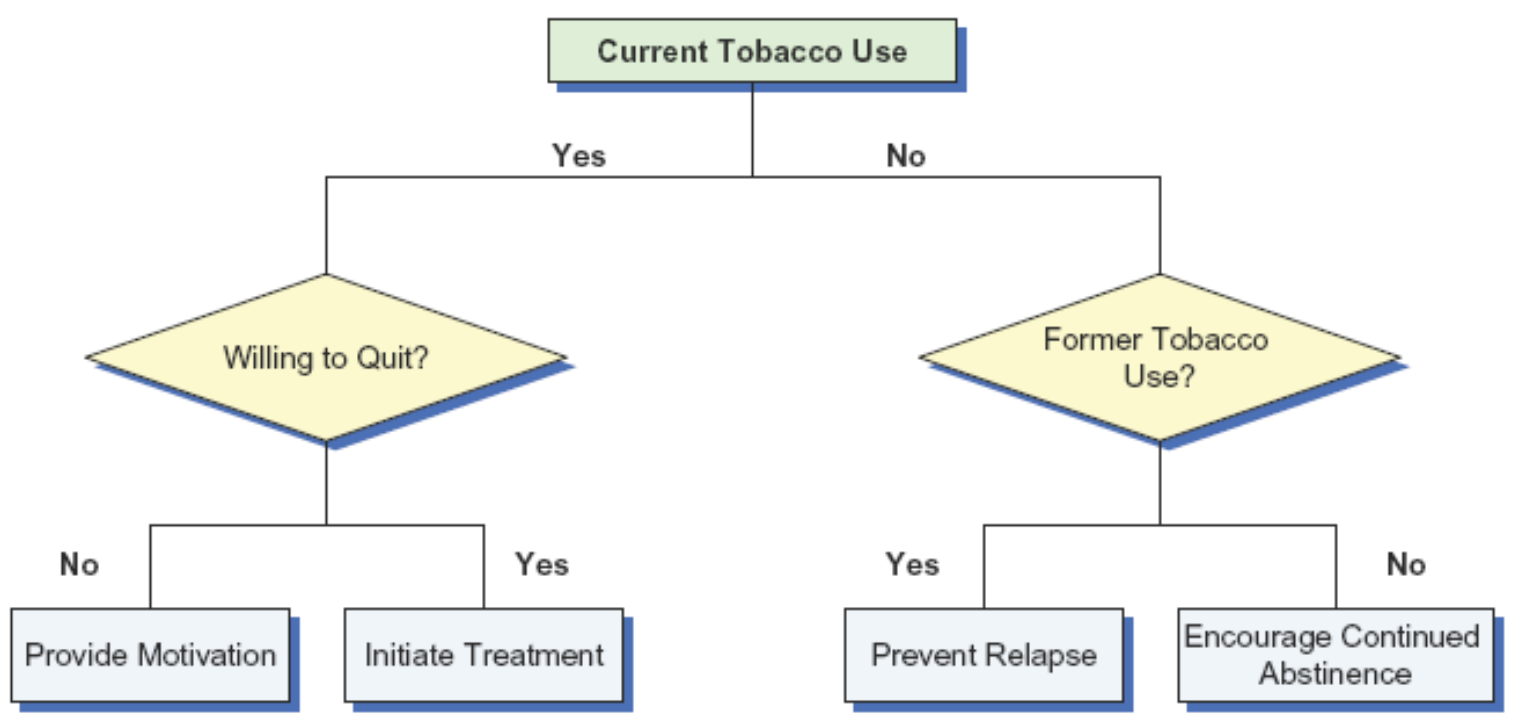

Fig. 1. - Algorithm for smoking. Modified from [2]. 


\section{Brief intervention}

A brief intervention can be effective for many smokers and should be practiced in all clinical settings. Often this can take the form of several minutes during a routine visit [19].

The key steps in the algorithm for brief intervention are the " 5 As".

- Ask: systematically identify all tobacco users at every visit; implement an office-wide system that ensures that tobacco-use status is queried and documented for every patient at every clinic visit.

- Advise: strongly urge all tobacco users to quit, in a clear, strong and personalised manner.

- Assess: determine willingness to make a quit attempt.

- Assist: help the patient with a quit plan, provide practical counselling, provide intratreatment social support, help the patient obtain extra-treatment social support, recommend use of approved pharmacotherapy (except in special circumstances) and provide supplementary materials.

- Arrange: schedule follow-up contact, either in person or via the telephone.

\subsubsection{Intensive intervention}

Intensive intervention refers to behavioural programmes more extensive than the brief intervention described above.

Review of multiple studies demonstrates a dose-response effect, indicating that quit rates increase with the intensity, duration and frequency of behavioural support sessions $[2,16]$.

All smokers willing to participate in intensive intervention should be offered the opportunity as quit rates will increase. Many smokers, however, will not wish to participate in such programmes and, for these individuals, properly executed brief intervention is the best alternative. 
Intensive intervention can be provided by any suitably trained clinician with adequate resources. Availability of such a programme should be an essential part of every healthcare system, particularly those caring for COPD patients.

\subsubsection{Systems approach}

A major impediment in the delivery of established treatments to treat tobacco use and dependence has been lack of appropriate institutional support [2].

Adequately trained staff with access to the necessary materials and with sufficient time to diagnose, stage and treat the smoking patient must be provided by all reputable healthcare systems.

Systems approaches are particularly important as coordinated interventions, involving healthcare providers at a variety of levels, are both more effective and more cost efficient.

The healthcare provider has the obligation to provide state-of-the art behavioural and pharmacological treatments.

The healthcare administrator has a clear responsibility to insure that smoking cessation services are adequately provided.

The healthcare purchaser should expect that tobacco intervention, at the most effective level, will be a contractually covered obligation of insurers and providers.

Patients have a reasonable expectation that the most preventable threat to their health will be addressed.

\subsubsection{Intervention in the smoker not ready to make a quit attempt}

Empathetic, nonconfrontational interactions that maximise patient participation are believed to be most effective when dealing with smokers not ready to make a quit attempt. 
The "5 Rs" can serve as a guide permitting the clinician to focus on the important issues, recognising that multiple interactions are likely to be required in order to achieve a quit attempt.

- Relevance: personalise the reasons to quit. This may include issues in addition to COPD.

- Risks: both acute (i.e. dyspnoea, cough, exacerbations, increased carbon monoxide), chronic (i.e. COPD progression, cancer, cardiovascular disease, osteoporosis, peptic ulcer) and other environmental risks (i.e. disease risk to spouse, household members, increased risk of smoking in children).

- Rewards: such as improved health, improved self image, regaining sense of taste and smell, and saving money.

- Roadblocks: such as withdrawal symptoms, fear of failure, weight gain, lack of support, depression and the enjoyment of tobacco.

- Repetition: most smokers make several quit attempts before achieving long-term abstinence; smoking can be regarded as a chronic relapsing condition, but prolonged remissions are possible

A variety of interventions including acupuncture, hypnosis and aversive training methods, among others, have been suggested to aid cessation. None have been shown to be more effective than behavioural interventions alone [2].

\subsubsection{Intervention in the smoker ready to make a quit attempt}

Every effort should be made to maximise the chances of success [2] in the smoker ready to make a quit attempt, and the following should be offered: behavioural support, pharmacological treatment and follow-up.

\subsubsection{Behavioural support}

Table 2 shows the elements of support thought to improve cessation rates. 
Table 2. - Elements of support thought to improve cessation rates

\begin{tabular}{ll}
\hline Help establish a quit plan & Set a quit date (ideally within 2 weeks) \\
& Tell family and friends \\
& Anticipate challenges \\
& Remove tobacco products \\
Abstinence is essential & Utilise experience from previous attempts \\
Counselling & Anticipate challenges \\
& Avoid alcohol \\
& Discourage others from smoking at home \\
Encourage other support & $\begin{array}{l}\text { Enlist the help of family, friends and co-workers } \\
\text { Provide materials }\end{array}$ \\
& Many are available through a variety of health- \\
& related agencies \\
\hline
\end{tabular}

Modified from [2].

\subsubsection{Pharmacological treatment}

See detailed information below.

\subsubsection{Follow-up}

Every smoker making a serious quit attempt should be offered the opportunity for follow-up with the treating clinician [2]. It is recommended that the patient be contacted within 1 week of the quit day and 1 month after. Additional follow-up improves cessation. Follow-up can be performed by telephone and can involve nonphysicians.

Success should be encouraged in follow-up interventions.

Medication use should also be reviewed and an effort made to identify potential problems, particularly alcohol use.

A plan should be established to deal with high-risk situations. 
Relapses should be evaluated and lessons that have been learned should be incorporated into subsequent quit attempts.

Relapse prevention should include congratulating continued nonsmoking, informing the exsmoker about the risks of concurrent alcohol use and establishing an action plan for individual patients.

\subsubsection{Intervention in the smoker who has recently quit}

Relapse is most common in the first few days after quitting, but may occur months or years later. Therefore, whenever the clinician interacts with former smokers, smoking status should be reassessed.

\subsubsection{Pharmacological treatment}

All smokers willing to make a serious quit attempt should be offered pharmacological support [2].

The approach to males and females and to racial and ethnic groups should not vary.

Pregnant women should quit, although use of medications in pregnancy has undefined risks.

Smoking cessation treatments can be initiated in hospitalised patients.

Patients with concurrent psychiatric morbidities may require specific treatment of these conditions.

Smoking cessation treatment in adolescence is difficult. The same approaches used in adults can be tried.

Quit rates approximately double with first-line pharmacological treatments. First-line treatments include various forms of nicotine replacement treatment and bupropion. Second-line treatments can be considered for smokers unsuccessful with or unable to utilise first-line medications. 


\subsubsection{First-line treatments}

Nicotine replacement is available in five approved formulations and several others are in development. Their different routes of administration permit individual preference. All that have been assessed are similar in efficacy.

- Nicotine polacrilex (gum) contains nicotine bound to a polacrilex resin together with a buffering agent. Chewing releases the nicotine from the polacrilex. Varying the rate of chewing varies the rate of nicotine release. Once released, nicotine is present in the saliva and is absorbed across the buccal mucosa. Low oral $\mathrm{pH}$ causes the nicotine base to ionise and the charged form is absorbed much more slowly. Both 2- and 4-mg formulations are available. Eight to 10 gums per day should be recommended, but are often difficult to chew. Treatment for 3-6 months is recommended, but some smokers will substitute gum for smoking and sustain their addiction with gum.

- Transdermal nicotine system or "patch" is applied to the skin in a nonhairy area of the torso or proximal area of the extremities. Each device contains an adhesive, a reservoir that contains nicotine and an impermeable backing. Nicotine diffuses from the reservoir through the skin and is absorbed into the capillary blood of the skin. Absorption is continuous and relatively slow. Several formulations are available [20]. Transdermal nicotine reduces the intensity, but does not eliminate, withdrawal symptoms [21]. Treatment with nicotine patches is generally recommended at "full dose" for 4-6 weeks. This is often followed by a tapering regimen for several additional weeks.

- Nicotine inhaler consists of a mouthpiece and a nicotine-containing cartridge [22]. Nicotine is released when air is inhaled through the device. Most of the nicotine is deposited in the mouth and absorbed through the buccal mucosa. The device should not, therefore, be inhaled like a cigarette as very little nicotine will reach the lower respiratory tract. Because the nicotine is absorbed through the buccal mucosa, absorption is into the venous circulation. The device contains $\sim 10 \mathrm{mg}$ of nicotine, of which $\sim 1 \mathrm{mg}$ is released with $\sim 100$ inhalations.

- Nicotine nasal spray consists of an aqueous solution of nicotine. It is delivered by direct spray to the nasal mucosa [23]. One spray in each nostril delivers $1 \mathrm{mg}$ of nicotine. The nicotine is absorbed into the venous blood in the nasal mucosa. 
Absorption, however, is relatively rapid with peak levels being achieved in $\sim 10 \mathrm{~min}$. This comes closest to that observed with smoking. As a result, the nicotine nasal spray has increased potential for prolonging nicotine dependence as compared to other nicotine replacement therapies. Local irritation is exceedingly common and can be severe, although most individuals are able to adjust to the local effects with continued use.

- Nicotine lozenges are the most recently approved formulation of nicotine as an aid for smoking cessation [24]. It is approved for over-the-counter use in the USA and is available in 2- and 4-mg nicotine doses. The smoker is allowed to select the dose based on the time from awakening to the first cigarette, a measure of intensity of addiction. Those who use a cigarette within 30 min of awakening are advised to use the 4-mg nicotine dose. Dosing is recommended at nine lozenges per day, one every $1-2 \mathrm{~h}$ for up to 6 weeks, followed by tapering of daily use with discontinuation after 6 months.

- Combined modality treatment with several formulations, while not approved by regulatory agencies, has been reported to improve efficacy. Retreatment after a failed attempt can be successful.

Treatment is generally started on the quit day. Variable durations of treatment have been suggested. Nicotine replacement can be discontinued abruptly, but gradual tapering is generally preferred. Concurrent cardiac disease should always engender caution, but evidence does not demonstrate an increase in acute cardiac events with the use of nicotine replacement.

Bupropion is a non-nicotine drug previously approved for use as an anti-depressant [12].

- It approximately doubles quit rates compared to placebo.

- Treatment is usually initiated at $150 \mathrm{mg}$ daily and increased to $150 \mathrm{mg}$ twice daily after 3 days, if tolerated.

- The quit day should be after 1 week of treatment.

- Treatment is generally continued for 7-12 weeks.

- Bupropion may be more effective than nicotine replacement therapy for individuals with a past history of depression. 
- It may also be useful for those concerned about weight gain since it has been shown to delay but not prevent weight gain during cessation.

- Bupropion may cause insomnia and dry mouth. It has been reported to cause seizure in patients with known history of seizure disorder.

- Bupropion can be combined with nicotine replacement treatment, although this may lead to worsening of hypertension.

- Contraindications include increased seizure risk, bulimia, concurrent use of monoamine oxidase inhibitors or a bupropion preparation for depression.

\subsubsection{Second-line treatments}

Clonidine has been evaluated in several trials, and while results are equivocal, efficacy is supported by a meta-analysis.

Nortriptyline is also supported by two studies.

Neither second-line treatment currently has an indication for smoking cessation approved by regulatory agencies, but both are approved for other indications and may be used by the experienced clinician "off label" for smoking cessation.

Use of other medications for smoking cessation is not supported by currently available data.

\subsection{Harm Reduction}

For the smoker who is unable or unwilling to quit, there are few options.

The concept that the toxic effects of smoking can be partially mitigated while smoking continues is termed harm reduction [25].

Several strategies are possible, including partial nicotine replacement, substituting cigarettes for less harmful tobacco products and engineering the cigarette to produce less toxins.

None of these approaches have been demonstrated to have clinical benefit. 


\subsection{References}

1. Fiore M, Bailey W, Cohen S, et al. Treating tobacco use and dependence. Rockville, MD, U.S. Department Of Health and Human Services, June 2000.

2. Fiore MC. US public health service clinical practice guideline: treating tobacco use and dependence. Respir Care 2000; 45: 1200-1262.

3. Sweanor DT. Tobacco taxes: the Canadian experience. Alaska Med 1996; 38: 40-41.

4. Jason LA. Active enforcement of cigarette control laws in the prevention of cigarette sales to minors. JAMA 1991; 266: 3159-3161.

5. Gilpin EA, Lee L, Evans N, Pierce JP. Smoking initiation rates in adults and minors: United States, 1944-1988. The natural history of chronic bronchitis and emphysema. New York, Oxford University Press, 1976.

7. Burrows B, Knudson RJ, Cline MG, Lebowitz MD. Quantitative relationships between cigarette smoking and ventilatory function. Am Rev Respir Dis 1977; 115: 195-205.

8. Sorlie PD, Kannel WB, O'Connor G. Mortality associated with respiratory function and symptoms in advanced age. The Framingham Study. Am Rev Respir Dis 1989; 140: 379-384.

9. Mannino DM, Gagnon RC, Petty TL, Lydick E. Obstructive lung disease and low lung function in adults in the United States: data from the National Health and Nutrition Examination Survey, 1988-1994. Arch Intern Med 2000; 160: 1683-1689.

10. Pauwels RA, Buist AS, Calverley PM, Jenkins CR, Hurd SS, the GOLD Scientific Committee. Global strategy for the diagnosis, management, and prevention of chronic obstructive pulmonary disease. NHLBI/WHO Global Initiative for Chronic Obstructive Lung Disease (GOLD) Workshop summary. Am J Respir Crit Care Med 2001 163: 1256-1276.

11. Anthonisen NR, Connett JE, Kiley JP, et al. Effects of smoking intervention and the use of an inhaled anticholinergic bronchodilator on the rate of decline of FEV1. JAMA 1994; 272: $1497-1505$.

12. Buist AS, Sexton GJ, Nagy JM, Ross BB. The effect of smoking cessation and modification on lung function. Am Rev Respir Dis 1976; 114: 115-122.

13. Barker DJP, Godfrey KM, Fall CHD, Osmond C, Winter PD, Shaheen SO. Relation of birthweight and childhood respiratory infection to adult lung function and death from chronic obstructive airways disease. BMJ 1991; 303: 671-675. 
14. Gold DR, Wang Z, Wypij D, Speizer FE, Ware JW, Dockery DW. Effects of cigarette smoking on lung function in adolescent boys and girls. N Engl J Med 1996; 335: 931-937.

15. Leuenberger P, Schwartz J, Ackermann-Liebrich U, et al. Passive smoking exposure in adults and chronic respiratory symptoms (SAPALDIA Study). Am J Respir Crit Care Med 1994; 150: 1222-1228.

16. Fiore MC, Bailey WC, Cohen SJ. Smoking cessation. Guideline technical report no. 18. Publication No. AHCPR 97-Noo4. Rockville, MD, US Department of Health and Human Services, Public Health Service, Agency for Health Care Policy and Research, October 1997.

17. Prochaska JO, DiClemente CC. Stages of change in the modification of problem behaviors. Prog Behav Modification 1992; 28: 183-218.

18. Daughton DM, Susman J, Sitorius M, et al. Transdermal nicotine therapy and primary care: importance of counseling, demographic and patient selection factors on one-year quit rates. Arch Fam Med 1998; 7: 425-430.

19. Jaen CR, Crabtree BF, Zyzanski SJ, Goodwin MA, Stange KC. Making time for tobacco cessation counseling. J Fam Pract 1998; 46: 425-428.

20. Fiore MC, Jorenby DE, Baker TB, Kenford SL. Tobacco dependence and the nicotine patch. JAMA 1992; 268: 2687-2689.

21. Fiore MC, Jorenby DE, Baker TB. Tobacco dependence and the nicotine patch. Clinical guidelines for effective use. JAMA 1992; 268: 2687-2694.

22. Schneider NG, Olmstead RE, Franzon MA, Lunell E. The nicotine inhaler: clinical pharmacokinetics and comparison with other nicotine treatments. Clin Pharmacokinet 2001; 40: 661-684.

23. Hurt RD, Dale LC, Croghan GA, Croghan IT, Gomez-Dahl LC, Offord KP. Nicotine nasal spray for smoking cessation: pattern of use, side effects, relief of withdrawal symptoms, and cotinine levels. Mayo Clin Proc 1998; 73: 118-125.

24. Shiffman S, Dresler CM, Hajek P, Gilburt SJ, Targett DA, Strahs KR. Efficacy of a nicotine lozenge for smoking cessation. Arch Intern Med 2002; 162: 1267-1276.

25. Clearing the Smoke. Washington, D.C, National Academy Press, 2001. 


\section{Management of stable COPD: pharmacological therapy}

\subsection{Key points}

- The medications for chronic obstructive pulmonary disease (COPD) currently available can reduce or abolish symptoms, increase exercise capacity, reduce the number and severity of exacerbations, and improve health status.

- At present no treatment is shown to modify the rate of decline in lung function.

- The change in lung function after brief treatment with any drug does not help in predicting other clinically related outcomes.

- The inhaled route is preferred.

- Changes in forced expiratory volume in one second (FEV1) following bronchodilator therapy can be small but are often accompanied by larger changes in lung volume, which contribute to a reduction in perceived breathlessness.

- Combining different agents produces a greater change in spirometry and symptoms than single agents alone.

\subsection{General principles}

Effective medications for COPD are available and all patients who are symptomatic merit a trial of drug treatment.

Therapy with currently available medications can reduce or abolish symptoms, increase exercise capacity, reduce the number and severity of exacerbations, and improve health status. At present no drug treatment has been shown to modify the rate of decline of lung function.

The inhaled route is preferred when both inhaled and oral formulations are available. Smaller doses of active treatment can be delivered directly with equal or greater efficacy and with fewer side-effects when administered by inhalation.

Patients must be educated in the correct use of whatever inhalation device is employed. Significant numbers of patients cannot effectively coordinate their breathing with a metered 
dose inhaler (MDI) but can use a breath-activated inhaler, a dry powder inhaler (DPI) device or a spacer chamber. The latter may be useful when inhaled corticosteroids are administered, as it reduces the oropharyngeal deposition and subsequent local side-effects associated with these drugs.

Compliance with treatment is variable, but when assessed in large clinical trials at least $85 \%$ of patients take $70 \%$ of the prescribed doses [1]. This probably reflects the fact that COPD patients are constantly symptomatic. Adherence to treatment is helped by a clear explanation of the purposes and probable outcome of therapy, together with reinforcement and review of both of these aspects of management.

Although spirometry is needed to make an accurate diagnosis, the change in lung function occurring after brief treatment with any drug is not helpful in predicting other clinically related outcomes. Categorising treatment responses by whether the patient is "reversible" or "irreversible" using spirometric criteria is not useful. Several studies have demonstrated worthwhile clinical benefits in groups classified initially as having irreversible disease [2-4].

\subsection{Bronchodilators}

Three types of bronchodilator are in common clinical use: $\beta$-agonists, anticholinergic drugs and methylxanthines.

Despite substantial differences in their site of action within the cell and some evidence for nonbronchodilator activity with some classes of drug, the most important consequence of bronchodilator therapy appears to be airway smooth muscle relaxation and improved lung emptying during tidal breathing.

The resultant increase in FEV1 may be small but is often accompanied by larger changes in lung volumes, with a reduction in residual volume and/or a delaying of the onset of dynamic hyperinflation during exercise. Both of these changes contribute to a reduction in perceived breathlessness $[4,5]$. In general, the more advanced the COPD, the more important the changes in lung volume become relative to those in FEV1. 
To date, monitoring more complex variables, such as inspiratory capacity as a predictor of improved exercise performance, has not been validated beyond the research laboratory. Changes in forced vital capacity and relaxed vital capacity may be associated with significant improvements in exercise capacity. This can occur even when these spirometric volume improvements are more modest.

Other factors, such as nutritional status, cardiopulmonary fitness and peripheral muscle strength influence exercise capacity and may limit the effect of bronchodilator treatment on exercise capacity.

\subsubsection{Clinical outcomes for bronchodilators}

Short-acting bronchodilators can increase exercise tolerance acutely in COPD $[2,5]$.

Anticholinergics given q.i.d. can improve health status over a 3-month period compared with placebo [6].

Long-acting inhaled $\beta$-agonists improve health status, possibly to a greater degree than using regular ipratropium [7, 8]. Additionally, these drugs reduce symptoms, rescue medication use and increase the time between exacerbations compared with placebo.

Combining short-acting agents (salbutamol/ipratropium) produces a greater change in spirometry over 3 months than either agent alone [9].

Combining long-acting inhaled $\beta$-agonists and ipratropium leads to fewer exacerbations than either drug alone [10]. No good comparative data between different long-acting inhaled $\beta$ agonists are presently available although it is likely that their effects will be similar.

Combining long-acting $\beta$-agonists and theophylline appears to produce a greater spirometric change than either drug alone [11]. 
Tiotropium improves health status and reduces exacerbations and hospitalisations compared with both placebo and regular ipratropium $[12,13]$. It is at least equivalent to long-acting $\beta$ agonists in its effect and in one clinical trial appeared to be superior to salmeterol in some measures over 6 months [14].

\subsubsection{Nebulised drugs}

Drug delivery by MDI and DPI is preferable. However, decisions on choice of nebulised therapy will depend on local aspects such as costs, reimbursement and patient preference.

High doses of nebulised $\beta$-agonists and anticholinergics singly or in combination can be used in exacerbations of severe disease when the simplicity of administration is an advantage.

In stable disease, limited data have failed to show any significant difference in exercise performance between drugs given by nebuliser and by the spacer device.

Empirical guidance about the assessment of these agents is available [15] and focuses on objective improvements in peak expiratory flow measured daily over 2 weeks. 


\subsubsection{Clinical use of bronchodilator drugs}

See figure 1.

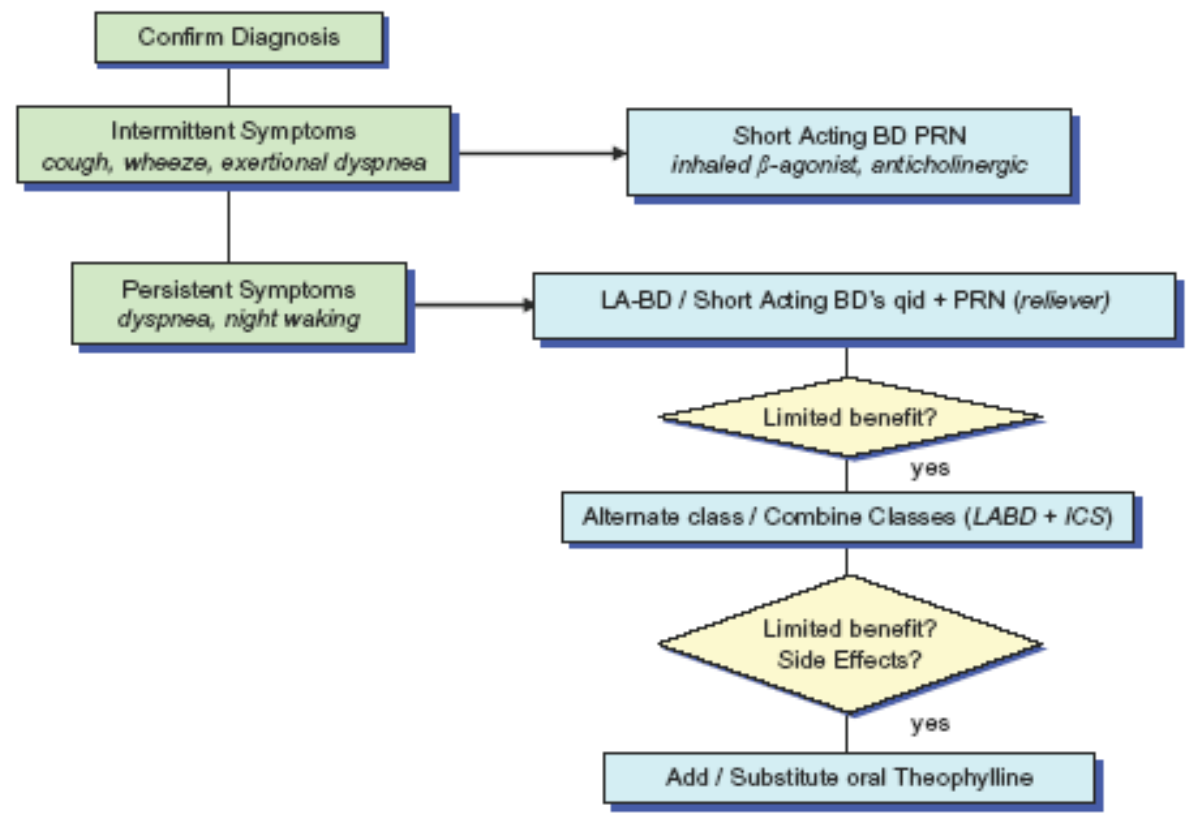

Fig. 1. - Algorithm for pharmacological treatment of chronic obstructive pulmonary disease (COPD). SABD: short-acting bronchodilator; LA-BD: long-acting bronchodilator; ICS: inhaled corticosteroid. Assess effectiveness by treatment response criteria. If forced expiratory volume $<50 \%$ predicted and exacerbations of COPD requiring a course of oral corticosteroid or antibiotic occurred at least once within the last year, consider adding regular ICS. Always ensure the patient can use an inhaled device effectively and understands its purpose. If an ICS and a long-acting ß-agonist are used, prescribe a combination inhaler.

Assessing treatment response is based on the questions in table 1.

Table 1. - Assessment of symptomatic benefit from pharmacological therapy

- Has your treatment helped you?

- Is your breathing easier in any way?

- Can you do some things now that you couldn't do before or do the same things faster?

- Do you get less breathless when you are doing the things you did before?

- Has your sleep improved?

Try to obtain a specific example of something that has changed and reassess this symptom at latter visits. Ask whether the treatment is ineffective, satisfactory, effective or very effective. 
Table 2 summarises the effects of frequently used medications in patients with COPD. The evidence level was obtained from the GOLD document [15], using the same grade of evidence. Grade A: randomised clinical trial (RCT), rich body of data; Grade B: RCT, limited body of data; Grade C: nonrandomised trials, observational studies; Grade D: panel consensus.

Table 2. - Effect of commonly used medications on important clinical outcomes

\begin{tabular}{|c|c|c|c|c|c|c|c|c|c|}
\hline Medication & FEV1 & $\begin{array}{c}\text { Lung } \\
\text { volume }\end{array}$ & Dyspnoea & HRQoL & $\mathrm{AE}$ & $\begin{array}{c}\text { Exercise } \\
\text { endurance }\end{array}$ & $\begin{array}{c}\text { Disease } \\
\text { modifier } \\
\text { by FEV1 }\end{array}$ & Mortality & $\begin{array}{l}\text { Side- } \\
\text { effects }\end{array}$ \\
\hline $\begin{array}{l}\text { Short-acting } \quad \beta- \\
\text { agonist }\end{array}$ & $\begin{array}{l}\text { Yes } \\
\text { (A) }\end{array}$ & $\begin{array}{l}\text { Yes } \\
\text { (B) }\end{array}$ & $\begin{array}{l}\text { Yes } \\
\text { (A) }\end{array}$ & NA & NA & $\begin{array}{l}\text { Yes } \\
\text { (B) }\end{array}$ & NA & NA & Some \\
\hline $\begin{array}{l}\text { Ipratropium } \\
\text { bromide }\end{array}$ & $\begin{array}{l}\text { Yes } \\
\text { (A) }\end{array}$ & $\begin{array}{l}\text { Yes } \\
\text { (B) }\end{array}$ & $\begin{array}{l}\text { Yes } \\
\text { (A) }\end{array}$ & $\begin{array}{l}\text { No } \\
\text { (B) }\end{array}$ & $\begin{array}{l}\text { Yes } \\
\text { (B) }\end{array}$ & $\begin{array}{l}\text { Yes } \\
\text { (B) }\end{array}$ & No & NA & Some \\
\hline $\begin{array}{l}\text { Long acting } \beta \text { - } \\
\text { agonists }\end{array}$ & $\begin{array}{l}\text { Yes } \\
\text { (A) }\end{array}$ & $\begin{array}{l}\text { Yes } \\
\text { (A) }\end{array}$ & $\begin{array}{l}\text { Yes } \\
\text { (A) }\end{array}$ & $\begin{array}{l}\text { Yes } \\
\text { (A) }\end{array}$ & $\begin{array}{l}\text { Yes } \\
\text { (A) }\end{array}$ & $\begin{array}{l}\text { Yes } \\
\text { (B) }\end{array}$ & No & NA & Minimal \\
\hline Tiotropium & $\begin{array}{l}\text { Yes } \\
\text { (A) }\end{array}$ & $\begin{array}{l}\text { Yes } \\
\text { (A) }\end{array}$ & $\begin{array}{l}\text { Yes } \\
\text { (A) }\end{array}$ & $\begin{array}{l}\text { Yes } \\
\text { (A) }\end{array}$ & $\begin{array}{l}\text { Yes } \\
\text { (A) }\end{array}$ & $\begin{array}{l}\text { Yes } \\
\text { (B) }\end{array}$ & NA & NA & Minimal \\
\hline $\begin{array}{l}\text { Inhaled } \\
\text { corticosteroids }\end{array}$ & $\begin{array}{l}\text { Yes } \\
\text { (A) }\end{array}$ & NA & $\begin{array}{l}\text { Yes } \\
\text { (B) }\end{array}$ & $\begin{array}{l}\text { Yes } \\
\text { (A) }\end{array}$ & $\begin{array}{l}\text { Yes } \\
\text { (A) }\end{array}$ & NA & No & NA & Some \\
\hline Theophylline & $\begin{array}{l}\text { Yes } \\
\text { (A) }\end{array}$ & $\begin{array}{l}\text { Yes } \\
\text { (B) }\end{array}$ & $\begin{array}{l}\text { Yes } \\
\text { (A) }\end{array}$ & $\begin{array}{l}\text { Yes } \\
\text { (B) }\end{array}$ & $\begin{array}{l}\mathrm{N} \\
\mathrm{A}\end{array}$ & $\begin{array}{l}\text { Yes } \\
\text { (B) }\end{array}$ & NA & NA & Important \\
\hline
\end{tabular}

FEV1: forced expiratory volume in one second; HRQoL: health-related quality of life; AE: exacerbation of COPD; NA: evidence not available. 


\subsection{4. $\quad \beta$-Agonists}

These are available in several formulations, as follows.

- Inhaled: short acting $(<6 \mathrm{~h})$ effect on lung function; long acting $(>12 \mathrm{~h})$ effect on lung function.

- Oral: there is a limited role for regular oral $\beta$-agonist treatment in COPD (see Patients: medication).

\subsubsection{Pharmacology}

These drugs increase cyclic adenosine monophosphate (AMP) within many cells and promote airway smooth muscle relaxation. Other nonbronchodilator effects have been observed but their significance is uncertain.

The time of onset evaluated by FEV1 is longer than in bronchial asthma and tends to be greater with long-acting inhaled $\beta$-agonists like salmeterol, but not formoterol [16]. It is not yet clear if the differences in onset of action (fast-onset action versus slow-onset action) have any clinical role in COPD.

The duration of action is influenced by the outcome selected. An increase in FEV1 beyond baseline is present for up to $6 \mathrm{~h}$ after albuterol/salbutemol, although a clinically significant change is unlikely beyond $4 \mathrm{~h}$ [17]. Long-acting inhaled $\beta$-agonists (salmeterol, formoterol) increase lung function for at least $12 \mathrm{~h}$ in $\operatorname{COPD}[7,18]$.

There is a relatively small and flat dose-response relationship with all $\beta$-agonists.

\subsubsection{Side-effects}

These are dose related, more frequent in oral than inhaled formulations and include the following.

- Palpitations and premature ventricular contraction, resulting from stimulation of $\beta_{1}$ receptors in the heart. There is no evidence of clinically important adverse cardiac effects even in individuals with a history of stable cardiac disease. 
- Tremor, a troublesome symptom, particularly evident after high-dose nebulisation. With the use of MDI, tremor can be reduced by the use of spacer chambers.

- Sleep disturbance appears to be worse on higher doses of inhaled long-acting drugs [8].

- Metabolic, including hypokalaemia and increased resting oxygen consumption with high dose therapy, but both show evidence of tachyphylaxis and are probably more evident in people with milder degrees of airways disease [19]. Clinically, neither presents a significant problem [20]. Likewise, transient resting hypoxaemia is a consistent but clinically unimportant finding [21].

\subsubsection{Anticholinergic drugs}

These are only available by the inhaled route, although a number of preparations are available, the commonest are:

- ipratropium

- oxitropium

- tiotropium

\subsubsection{Pharmacology}

These drugs act by blocking muscarinic receptors that are known to be functional in COPD [22].

Tiotropium remains bound to receptors for up to $36 \mathrm{~h}$, producing sustained bronchodilitation after a once-daily dose [23]. Other anticholinergics have to be given more frequently, up to four times daily, and are often used as maintenance treatment.

Onset of bronchodilation takes place within $30 \mathrm{~min}$ and there is a modest dose-response relationship as evaluated by FEV1.

\subsubsection{Side-effects}

The drugs in this class are not associated with a significant incidence of prostatism or cardiac side-effects. Nonetheless, caution is recommended in the context of prostatic symptoms or glaucoma. 
The most commonly reported adverse events are as follows.

- Dry mouth, which is most marked with tiotropium.

- Metallic taste after inhalation, which is most marked with ipratropium.

- Closed angle glaucoma, a very rare complication that has only been reported in individuals using a high dose of treatment with a nebuliser and face mask.

- Paradoxical bronchoconstriction has been reported in asthmatics but not confirmed in COPD.

\subsubsection{Methylxanthines}

These agents can only be taken by mouth and include theophylline, aminophylline and its derivatives.

\subsubsection{Pharmacology}

These drugs are nonspecific phosphodiesterase inhibitors that increase intracellular cyclic AMP within airway smooth muscle. The bronchodilator effects of these drugs are best seen at high doses where there is also a higher risk of toxicity [24]. Other actions than bronchodilatation have been proposed. How important they are clinically remains to be established.

The narrow therapeutic margin and complex pharmacokinetics make their use difficult but modern slow-release preparations have greatly improved this problem and lead to a stable plasma level throughout the day. Generally, therapeutic levels should be measured and patients should be kept on the lowest effective dose (recommended serum level $8-14 \mu \mathrm{g} \cdot \mathrm{dl}^{-1}$ ).

These drugs are commonly taken in the morning and the evening but 24-h formulations are available. The slow onset of action makes these agents suitable for maintenance but not rescue therapy. There is some evidence of a dose-response effect [25], which is limited by toxicity.

\subsubsection{2. $\quad$ Side-effects}

Major toxicity: ventricular and atrial rhythm disturbances, and convulsions. 
Significant minor toxicity: headache, nausea, vomiting, diarrhoea and heartburn.

Drug interactions: plasma levels are decreased by cigarette smoking, anticonvulsant drugs and rifampicin, and increased by respiratory acidosis, congestive cardiac failure, liver cirrhosis and other therapies such as erythromycin and ciprofloxacin.

\subsection{Glucocorticoids}

Preparations: by inhalation

- beclomethasone

- budesonide

- triamcinolone

- fluticasone

- flunisolide

Oral corticosteroids are not indicated in stable COPD due to the multiple side-effects and skeletal muscle myopathy in particular. They are also important during exacerbations.

\subsubsection{Pharmacology}

Glucocorticoids act at multiple points within the inflammatory cascade, although their effects in COPD are more modest compared with bronchial asthma. Data from large patient studies suggest that inhaled corticosteroids can produce a small increase in postbronchodilator FEV1 and a small reduction in bronchial reactivity in stable COPD [1, 26, 27].

The onset of action is slow and there are little data to support a dose-response relationship. Most studies have been performed using relatively high doses as "proof of principle" rather than to define the effective dose of treatment.

High-dose inhaled glucocorticoids can be systemically available due to absorption from the pulmonary circulation, but the effect is also less than that of oral corticosteroids (prednisolone). 


\subsubsection{Side-effects}

Oral glucocorticosteroids produce many side-effects, especially osteoporosis, peripheral myopathy and cataract. Clear evidence that these complications occur as a result of inhaled corticosteroid use in COPD is lacking.

Data on the effect of inhaled corticosteroids on bone mineral density is contradictory, with evidence of significant reductions in femoral neck mineralisation after use of triamcinolone [27] but improvements in bone density after budesonide [26].

Spontaneous skin bruising is a common finding that has been noted to occur with inhaled corticosteroids more frequently than in patients randomised to placebo medication in the one clinical trial where it has been assessed.

Topical side-effects due to pharyngeal deposition are well recognised and include oropharyngeal candiasis and hoarse voice.

\subsubsection{Clinical outcomes}

In patients with more advanced disease (usually classified as an FEV $1<50 \%$ predicted) there is evidence that the number of exacerbations per year and the rate of deterioration in health status can be reduced by inhaled corticosteroids in COPD [1].

Evidence from four large prospective 3-yr studies has shown no effect of inhaled corticosteroids on rate of change of FEV1 in any severity of COPD [1, 26-28].

\subsubsection{Clinical indication}

See figure 1.

When therapy is thought to be ineffective, a trial of withdrawing treatment is reasonable. Some patients will exacerbate when this occurs, which is a reason for re-instituting this therapy [29]. 


\subsection{Combination therapy}

Combining long-acting inhaled $\beta$-agonists and inhaled corticosteroids in one inhaler seems a convenient way of delivering treatment [30-32].

The initial trial data show a significant additional effect on pulmonary function and a reduction in symptoms in those receiving combination therapy compared with its components [32]. The largest effects in terms of exacerbations and health status are seen in patients with an FEV1 $<50 \%$ predicted, where combining treatment is clearly better than either component drug used by itself.

\subsection{Mucolytic/antioxidant therapy}

These include drugs such as:

- ambroxol

- erdosteine

- carbocysteine

- iodinated glycerol

The regular use of these drugs has been evaluated in a number of studies with little evidence of any effect on lung function.

Data from a Cochrane review of the studies supports a role for these drugs in reducing the number of exacerbations of chronic bronchitis [33].

There is better evidence that $N$-acetylcysteine, a drug with mucolytic and anti-oxidant actions, can reduce the number of exacerbations of COPD and this is currently under study in a large prospective trial [34].

\section{7. $\alpha$-Trypsin augmentation therapy}

Patients identified with $\alpha_{1}$-antitrypsin deficiency are eligible for treatment with this agent in the USA but not in Europe. 
This is presently administered by intravenous infusion of purified protein twice weekly, which can sustain circulating $\alpha_{1}$-antitrypsin to have a biological effect. It is extremely expensive and, to date, no randomised trial has shown an improvement in the decline of lung function with time with this treatment. However, the observational cohort in the US National Registry has provided data suggesting that the rate of decline of lung function is less in those patients treated with replacement therapy than would be anticipated in historical controls. A European trial has suggested that disease progression, as judged by computed tomography-measured emphysema, is slower than patients not receiving replacement therapy [35].

\subsection{Other agents}

\subsubsection{Leukotriene receptor antagonists/cromones}

There are no data to support the use of these agents in COPD.

\subsubsection{Maintenance antibiotic therapy}

Despite the attraction of reducing lower respiratory tract colonisation, there are no data to indicate that these drugs are effective in modifying symptoms, exacerbations or lung function decline.

\subsubsection{Immunoregulators}

One study has shown that an immunostimulator can reduce the severity, but not the frequency, of exacerbations in stable COPD. However, these data have not been supported by further publications [36].

\subsubsection{Vasodilators}

Many drugs, including inhaled nitric oxide and oral calcium antagonists, have been given to COPD patients to reduce pulmonary artery pressure and/or prevent progression of pulmonary hypertension. In all cases this has resulted in a deterioration of ventilation-perfusion matching and a reduction in arterial oxygen tension, which has offset any beneficial effect. 
Other side-effects, e.g. peripheral oedema with calcium antagonists, outweigh any modest advantages these drugs provide

\subsubsection{Respiratory stimulants}

Almitrine bismesylate is a specific oral peripheral chemoreceptor stimulant, which modifies ventilation-perfusion matching within the lung. Given orally it can improve oxygenation in COPD. It also induces peripheral neuropathy, which has restricted its widespread use. At present, it is not licensed for use in the USA and many European Union countries.

\subsubsection{Vaccination}

Vaccination against influenza, using an appropriate recommended vaccine, can reduce serious illness and death in COPD by $\sim 50 \%$ [37]. Vaccines containing cold or live inactivated viruses are recommended, as they are more effective in elderly patients with COPD [38].

Vaccination against pneumococcal disease reduces bacteraemia in vaccinated patients with pneumonia [39]. The vaccination is indicated for all elderly patients depending on national recommendations.

\subsubsection{Anabolic steroids}

This is addressed in Management of stable COPD: pulmonary rehabilitation. 


\subsection{References}

1. Burge PS, Calverley PM, Jones PW, Spencer S, Anderson JA, Maslen TK. Randomised, double blind, placebo controlled study of fluticasone propionate in patients with moderate to severe chronic obstructive pulmonary disease: the ISOLDE trial. BMJ 2000; 320: 1297-1303.

2. Hay JG, Stone P, Carter J, et al. Bronchodilator reversibility, exercise performance and breathlessness in stable chronic obstructive pulmonary disease. Eur Respir J 1992; 5: 659-664.

3. Rennard SI, Anderson W, ZuWallack R, et al. Use of a long-acting inhaled $\beta_{2}$-adrenergic agonist, salmeterol xinafoate, in patients with chronic obstructive pulmonary disease. Am $J$ Respir Crit Care Med 2001; 163: 1087-1092.

4. O’Donnell DE, Lam M, Webb KA. Spirometric correlates of improvement in exercise performance after anticholinergic therapy in chronic obstructive pulmonary disease. Am $J$ Respir Crit Care Med 1999; 160: 542-549.

5. Belman MJ, Botnick WC, Shin JW. Inhaled bronchodilators reduce dynamic hyperinflation during exercise in patients with chronic obstructive pulmonary disease. Am J Respir Crit Care Med 1996; 153: 967-975.

6. Mahler DA, Donohue JF, Barbee RA, et al. Efficacy of salmeterol xinafoate in the treatment of COPD. Chest 1999; 115: 957-965.

7. Dahl R, Greefhorst LA, Nowak D, et al. Inhaled formoterol dry powder versus ipratropium bromide in chronic obstructive pulmonary disease. Am J Respir Crit Care Med 2001; 164: $778-784$.

8. Jones PW, Bosh TK. Quality of life changes in COPD patients treated with salmeterol. Am J Respir Crit Care Med 1997; 155: 1283-1289.

9. Gross N, Tashkin D, Miller R, et al. Inhalation by nebulization of albuterol-ipatropium combination (Dey combination) is superior to either agent alone in the treatment of chronic obstructive pulmonary disease. Respiration 1998; 65: 354-362.

10. Van Noord JA, de Munck DR, Bantje TA, Hop WC, Akveld ML, Bommer AM. Longterm treatment of chronic obstructive pulmonary disease with salmeterol and the additive effect of ipratropium. Eur Respir J 2000; 15: 878-885.

11. Zuwallack RL, Mahler DA, Reilly D, et al. Salmeterol plus theophylline combination therapy in the treatment of COPD. Chest 2001; 119: 1661-1670. 
12. Casaburi R, Mahler DA, Jones PW, et al. A long-term evaluation of once-daily inhaled tiotropium in chronic obstructive pulmonary disease. Eur Respir J 2002; 19: 217-224.

13. Vincken W, van Noord JA, Greefhorst AP, et al. on behalf of the Dutch/Belgian Tiotrpium Study Group. Improved health outcomes in patients with COPD during 1-year treatment with tiotropium. Eur Respir J 2002; 19: 209-216.

14. Donohue JF, Van Noord JA, Bateman ED, et al. A 6-month, placebo-controlled study comparing lung function and health status changes in COPD patients treated with tiotropium or salmeterol. Chest 2002; 122: 47-55.

15. O’Driscoll BR, Pearson MG, Muers MF. Nebulizers in severe stable chronic obstructive pulmonary disease. Eur Respir Rev 2001; 10: 516-522.

16. Celik G, Kayacan O, Beder S, Durmaz G. Formoterol and salmeterol in partially reversible chronic obstructive pulmonary disease: A crossover, placebo-controlled comparison of onset and duration of action. Respiration 1999; 66: 434-439.

17. Combivent trialists. In chronic obstructive pulmonary disease, a combination of ipratropium and albuterol is more effective than either agent alone. An 85-day multicenter trial. COMBIVENT Inhalation Aerosol Study Group. Chest 1994; 105: 1411-1419.

18. Ulrik CS. Efficacy of inhaled salmeterol in the management of smokers with chronic obstructive pulmonary disease: a single centre randomised, double blind, placebo controlled, crossover study. Thorax 1995; 50: 750-754.

19. Amoroso P, Wilson SR, Moxham J, Ponte J. Acute effects of inhaled salbutamol on the metabolic rate of normal subjects. Thorax 1993; 48: 882-885.

20. Wilson SR, Amoroso P, Moxham J, Ponte J. Modification of the thermogenic effect of acutely inhaled salbutamol by chronic inhalation in normal subjects. Thorax 1993; 48: 886889.

21. Khoukaz G, Gross NJ. Effects of salmeterol on arterial blood gases in patients with stable chronic obstructive pulmonary disease. Comparison with albuterol and ipratropium. Am J Respir Crit Care Med 1999; 160: 1028-1030.

22. On LS, Boonyongsunchai P, Webb S, Davies L, Calverley PMA, Costello RW. Function of pulmonary neuronal M2 muscarinic receptors in stable chronic obstructive pulmonary disease. Am J Respir Crit Care Med 2001; 163: 1320-1325.

23. Barnes PJ. The pharmacological properties of tiotropium. Chest 2000; 117: 63S-66S. 
24. McKay SE, Howie CA, Thomson AH, Whiting B, Addis GJ. Value of theophylline treatment in patients handicapped by chronic obstructive lung disease. Thorax 1993; 48: 227232.

25. Chrystyn H, Mulley BA, Peake MD. Dose response relation to oral theophylline in severe chronic obstructive airways disease. BMJ 1988; 297: 1506-1510.

26. Pauwels RA, Lofdahl C-G, Laitinen LA, et al. Long-term treatment with inhaled budesonide in persons with mild chronic obstructive pulmonary disease who continue smoking. New Engl J Med 1999; 340: 1948-1953.

27. The Lung Health Study Research Group. Effect of inhaled triamcinolone on the decline in pulmonary function in chronic obstructive pulmonary disease. New Engl J Med 2000; 343: 1902-1909.

28. Vestbo J, Sorensen T, Lange P, Brix A, TorreP, Viskum K. Long-term effect of inhaled budesonide in mild and moderate chronic obstructive pulmonary disease: A randomised controlled trial. Lancet 1999; 353: 1819-1823.

29. Jarad NA, Wedzicha JA, Burge PS, Calverley PMA. An observational study of inhaled corticosteroid withdrawal in stable chronic obstructive pulmonary disease. Respir Med 1999; 93: $161-168$.

30. Calverley PM, Boonsawat W, Cseke Z, et al. Maintenance therapy with budesonide and formoterol in chronic obstructive pulmonary disease. Eur Respir J 2003; 22: 912-919.

31. Szafranski W, Cukier A, Ramirez A, et al. Efficacy and safety of budesonide/formoterol in the management of COPD. Eur Respir J 2003; 21: 74-81.

32. Calverley P, Pauwels R, Vestbo J, et al. Combined salmeterol and fluticasone in the treatment of chronic obstructive pulmonalry disease: a randomised controlled trial. Lancet 2003; 361: 449-456.

33. Poole PJ, Black PN. Mucolytic agents for chronic bronchitis or chronic obstructive pulmonary disease. Cochrane Database Syst Rev 2000; 2: CD001287.

34. Poole P, Black P. Oral mucolytic drugs for exacerbations of chronic obstructive pulmonary disease: systematic review. BMJ 2001; 322: 1271.

35. Dirksen A, Dijkman JH, Madsen F, et al. A randomized clinical trial of $\alpha(1)$-antitrypsin augmentation therapy. Am J Respir Crit Care Med 1999. 160:1468-1472. 
36. Collet JP, Shapiro P, Ernst P, Renzi T, Ducruet T, Robinson A. Effects of an immunostimulating agent on acute exacerbations and hospitalizations in patients with chronic obstructive pulmonary disease. The PARI-IS Study Steering Committee and Research Group. Prevention of Acute Respiratory Infection by an Immunostimulant. Am J Respir Crit Care Med 1997; 156: 1719-1724.

37. Nichol KL, Baken L, Nelson A. Relation between influenza vaccination and outpatient visits, hospitalization, and mortality in elderly persons with chronic lung disease. Ann Intern Med 1999; 130: 397-403.

38. Nichol KL, Mendelman PM, Mallon KP, et al. Effectiveness of live, attenuated intranasal influenza virus vaccine in healthy, working adults: a randomized controlled trial JAMA 1999; 282: $137-144$.

39. Nichol KL, Baken L, Wuorenma J, Nelson A. The health and economic benefits associated with pneumococcal vaccinations of elderly persons with chronic lung disease. Arch Int Med 1999; 159: 2437-2447. 


\section{Management of stable COPD: long-term oxygen $\mathbf{R x}$}

\subsection{Key points}

- Long-term oxygen therapy (LTOT) improves survival, exercise, sleep and cognitive performance.

- Reversal of hypoxaemia supersedes concerns about carbon dioxide $\left(\mathrm{CO}_{2}\right)$ retention.

- Arterial blood gas (ABG) is the preferred measure and includes acid-base information; arterial oxygen saturation as measured by pulse oximetry $\left(S_{\mathrm{p}, \mathrm{O}_{2}}\right)$ is adequate for trending.

- Oxygen sources include gas, liquid and concentrator.

- Oxygen delivery methods include nasal continuous flow, pulse demand, reservoir cannulas and transtracheal catheter.

- Physiological indications for oxygen include an arterial oxygen tension $\left(\mathrm{Pa}, \mathrm{O}_{2}\right)<7.3$ $\mathrm{kPa}(55 \mathrm{mmHg})$. The therapeutic goal is to maintain $\mathrm{Sp}_{\mathrm{p}} \mathrm{O}_{2}>90 \%$ during rest, sleep and exertion.

- Active patients require portable oxygen.

- If oxygen was prescribed during an exacerbation, recheck ABGs in 30-90 days.

- Withdrawal of oxygen because of improved $\mathrm{Pa}, \mathrm{O}_{2}$ in patients with a documented need for oxygen may be detrimental.

- Patient education improves compliance.

\subsection{Rationale}

LTOT reverses hypoxaemia and prevents hypoxia, and has been shown to improve life expectancy in patients with chronic lung disease.

A British Medical Research Council (MRC) study compared hypoxaemic patients receiving oxygen for $15 \mathrm{~h}^{-\mathrm{day}^{-1}}$, including the hours of sleep, with patients receiving no oxygen. This trial demonstrated that oxygen was associated with a significant reduction in mortality [1]. The Nocturnal Oxygen Therapy Trial (NOTT), comparing continuous oxygen therapy (average 19 
$\mathrm{h} \cdot \mathrm{day}^{-1}$ ) with therapy for $12 \mathrm{~h} \cdot \mathrm{day}^{-1}$, including the hours of sleep, demonstrated a further reduction in mortality using continuous oxygen [2].

The mechanism for improved survival has yet to be completely delineated, but pulmonary haemodynamics appear to play a role [3-7]. Oxygen therapy has been accompanied by a modest yearly decline in pulmonary artery pressure [3]. Pulmonary vascular resistance may be decreased in acute response to oxygen if the patient is nonoedematous, but not in patients with oedema [6].

Continuous oxygen therapy reverses secondary polycythemia, improves cardiac function during rest and exercise $[8,9]$, reduces the oxygen cost of ventilation, and improves exercise tolerance [10-12] and quality of life [13]. Hypoxemic patients $\left(\mathrm{Pa}, \mathrm{O}_{2}<50 \mathrm{mmHg}\right)$ may experience neuropsychiatric deficits in abstract thinking, motor skills and perceptual motor abilities [14-16].

\subsubsection{Oxygen therapy during sleep}

Many patients on chronic oxygen spend $>30 \%$ of the night with an $\mathrm{Sp}, \mathrm{O}_{2}<90 \%$ while breathing oxygen at the daytime flow rate $[17,18]$. If the patient does not have sleep-disordered breathing due to other causes, the administration of oxygen at a flow rate higher than the daytime setting will usually correct nocturnal hypoxaemia.

There is evidence that patients who desaturate only during sleep benefit from nocturnal supplemental oxygen [18]. Increased mortality among patients with nocturnal desaturation and daytime $P \mathrm{a}, \mathrm{O}_{2} \geq 8 \mathrm{kPa}(60 \mathrm{mmHg})$ has been demonstrated in retrospective studies [19]. However, well-controlled studies have not shown that use of nocturnal supplemental oxygen alters mortality or clinical course in patients who experience hypoxaemia only during sleep, other than slightly lowering pulmonary artery pressure [20].

\subsubsection{Oxygen therapy during exercise}

Oxygen therapy during exercise decreases dyspnoea and improves exercise tolerance at submaximal workloads [21]. Supplemental oxygen may increase exercise endurance and 
decrease dyspnoea via a reduction in minute ventilation, dynamic hyperinflation and improved breathing patterns $[12,22]$.

COPD patients are encouraged to remain active. Many patients with COPD who are hypoxaemic at rest are more hypoxaemic during exertion, while others develop hypoxaemia only during exertion. LTOT is prescribed commonly for both groups, even though studies designed to determine the long-term benefit of oxygen solely for exercise have yet to be conducted.

There is no standardised method for determining exercise oxygen settings. Oxygen settings should be determined while the patient is doing a typical level of exertion, usually walking in a hallway, using the prescribed delivery device (nasal cannula or oxygen conserving device). The goal is to maintain the $\mathrm{Sp}, \mathrm{O}_{2}>90 \%$ when the patient is exercising at a submaximal level equal to or slightly greater than usual exertion in their daily activities.

\subsection{Measuring oxygenation}

Ways of measuring oxygenation include $\mathrm{ABG}$, noninvasive $\mathrm{Sp}, \mathrm{O}_{2}$ and transcutaneous $P \mathrm{a}, \mathrm{O}_{2}$.

\subsubsection{Arterial blood gases}

Gas exchange and acid base status are measured via $\mathrm{ABG}$. ABG is recommended for initiation of oxygen therapy as well as to determine arterial carbon dioxide tension $\left(\mathrm{Pa}, \mathrm{CO}_{2}\right)$ and acidbase status. ABG may also be used initially to confirm the accuracy of pulse oximetry. Measured at the beginning and end of an exercise session, ABG will provide confirmatory data on oxygenation as well as $\mathrm{Pa}, \mathrm{CO}_{2}$ and acid base status.

The methodology for arterial sampling is standardised and safe, and complications are uncommon and relatively minor. Sources of error in ABG measurements include improper sample site (vein rather than artery), inadequate blood handling techniques, high white blood cell count (decreases the $\mathrm{Pa}, \mathrm{O}_{2}$ ) and poor instrument calibration. The arterial blood gas analyser

measures $\mathrm{Pa}, \mathrm{O}_{2}, P \mathrm{a}, \mathrm{CO}_{2}$ and $\mathrm{pH}$. Bicarbonate and arterial oxygen saturation $\left(\mathrm{Sa}, \mathrm{O}_{2}\right)$ are 
calculated using algorithms. $\mathrm{Sa}, \mathrm{O}_{2}$ can also be measured directly, via a co-oximeter, which also measures carboxyhaemoglobin.

\subsubsection{Noninvasive pulse oximetry}

$\mathrm{Sp}_{\mathrm{p}} \mathrm{O}_{2}$ is measured by comparing the transmission of two wavelengths of light through the finger, earlobe or other dermal locations. It compares oxygenated blood (red band) with unoxygenated blood (infrared band), and computes the saturation [23]. Pulse oximetry generally correlates well with arterial co-oximetry, with a 1-2\% error.

High levels of methaemoglobin, carboxyhaemoglobin, bilirubin, dark skin pigment, inadequate tissue perfusion and movement artefact create inaccuracies [24].

Newer pulse oximeters are less sensitive to movement artifact. In general, pulse oximetry $S \mathrm{p}, \mathrm{O}_{2}$ is a good method for following trends in oxygen saturation and can be used for titrating the oxygen flow setting in stable patients with good circulation.

\subsubsection{Transcutaneous arterial oxygen tension}

Transcutaneous $\mathrm{Pa}, \mathrm{O}_{2}$ measures the local oxygen level directly on the dermal surface. It allows continuous assessment and, in contrast to oximetry, can measure hyperoxia. It requires a heated electrode to promote local tissue perfusion, which may cause burns and heat blisters. Transcutaneous $\mathrm{Pa}, \mathrm{O}_{2}$ is inaccurate in adults and therefore not recommended.

\subsection{Hazards of oxygen}

Oxygen therapy may be associated with such adverse effects as absorptive atelectasis and reduction of hypoxic vasoconstriction that might extend ventilation/perfusion $\left(V^{\prime} / Q^{\prime}\right)$ mismatch. In general, oxygen therapy is safe and effective. The net effect of oxygen therapy is to reverse hypoxaemia and the benefits far outweigh any risks [25]. Hazards the clinician must recognise include oxygen toxicity, $\mathrm{CO}_{2}$ retention and physical hazards during the storage and handling of oxygen. 


\subsubsection{Oxygen toxicity}

Patients exposed to inspiratory oxygen fraction $\left(F \mathrm{I}, \mathrm{O}_{2}\right)>50 \%$ may experience oxygen toxicity, particularly if the exposure is prolonged. Oxygen toxicity is related to free radicals. The major end product of normal oxygen metabolism is water. Some oxygen molecules, however, are converted into highly reactive species called radicals, which include superoxide anions, perhydroxy radicals and hydroxyl radicals, and are toxic to alveolar and tracheobronchial cells.

Pathophysiological changes include decreased lung compliance, reduced inspiratory airflow, decreased diffusing capacity and small airway dysfunction. While these changes are well recognised in the acute care setting of mechanically ventilated patients receiving $\mathrm{FI}_{\mathrm{I}} \mathrm{O}_{2}>50 \%$, little is known about the long-term effect of low flow (24-28\%) oxygen. It is widely accepted that the increased survival and quality-of-life benefits of long-term oxygen therapy outweigh the possible risks.

\subsubsection{Carbon dioxide retention}

There has been an overemphasis that administration of oxygen may lead to respiratory drive depression, hypercapnia with resulting respiratory acidosis [26-29]. This has caused some clinicians to be overly timid about prescribing oxygen. Oxygen-induced hypercapnia does rarely occur, but it is even rarer that this leads to respiratory acidosis.

The mechanism is that alveolar hypoxia leads to pulmonary artery vasoconstriction, which causes increased blood perfusion to under-ventilated alveoli [27, 28]. As better-ventilated lung units receive less perfusion, the $V^{\prime} / Q^{\prime}$ mismatch becomes greater. In most cases, titrating oxygen flow so as to maintain $\mathrm{Pa}, \mathrm{O}_{2}$ at $8-8.6 \mathrm{kPa}(60-65 \mathrm{mmHg})$ can minimise the likelihood of hypercapnia and respiratory acidosis. When hypercapnia is present, initial oxygen delivery settings should be titrated using serial ABG assessments rather than relying solely on oximetry.

$\mathrm{CO}_{2}$ retention is tolerable for patients with an intact renal system, since they are capable of reabsorbing enough bicarbonate and maintain acid-base balance. The ability of patients to tolerate $\mathrm{CO}_{2}$ retention (permissive hypercapnia) is thought to be an adaptive mechanism that lessens the work of breathing. Accordingly, there is a significant population of COPD patients 
who are chronic $\mathrm{CO}_{2}$ retainers while maintaining their $\mathrm{pH}$ in a normal range. In all cases, correction of hypoxaemia takes precedence over concerns about $\mathrm{CO}_{2}$ retention.

\subsubsection{Physical hazards}

The major physical hazards of oxygen therapy are fires or explosions. Most fires are caused by patients lighting cigarettes as oxygen is flowing into their noses [30]. While the cannula is constructed of fire-retardant plastic, both the cannula and the patient's nose will burn in the presence of a flame and oxygen in high concentrations. Patients, family and other care-givers must be warned not to smoke near oxygen. In general, major accidents associated with oxygen therapy are rare and can be avoided by good patient and family training along with common sense.

\subsubsection{Gas Oxygen}

Compressed gas oxygen containers should not be stored near water heaters, furnaces or other sources of heat or flame. A compressed oxygen cylinder can be accidentally knocked over, causing explosive disconnection of the regulator and rendering the cylinder a dangerous missile.

\subsubsection{2. $\quad$ Liquid Oxygen}

Serious freeze burns can occur if the patient does not take proper precautions while transfilling liquid oxygen.

\subsection{Oxygen sources and delivery devices}

\subsubsection{Oxygen sources}

Oxygen comes packaged in three types of systems: compressed gas, liquid and oxygen concentrators. The trade-offs include size and weight of the device, storage capacity, cost and transfillability. The features of the systems are compared in table 1. Both liquid and compressed gas systems are becoming smaller and lighter. 
Table 1. - Gas, liquid and concentrator oxygen systems

\begin{tabular}{llll}
\hline Features & Concentrator & Compressed gas & Liquid \\
\hline Availability & Common & Common & Limited \\
Reliability & Good with regular service & Good but gauges may & Generally good; connector \\
& & become inaccurate & may freeze \\
Cost & Low but cost of electricity born by patient & Moderate & High \\
Power:wall current & Required & Not required & Not required \\
Transfilling & Only on special units that allow transfilling & Limited & Excellent \\
Ambulatory use & Good with transfill systems to gas+ OCD & Good with OCD & Good alone and with OCD \\
Stationary weight & 35-50 lb & H cylinder 200 lb & Reservoir 120 lb \\
Use time at $2 \mathrm{~L} \cdot \mathrm{min}^{-1}$ & Continuous & 2.5 days & 8.9 days, special system $>30 d$ \\
Portable weight & Portable units are not presently available & E cylinder 22 lb + cart & $6 \mathrm{lb}$ with no OCD \\
Use time at $2 \mathrm{~L} \cdot \mathrm{min}^{-1}$ & Unlimited & $5 \mathrm{~h}$ & $4 \mathrm{~h}$ \\
Portable with $\mathrm{OCD}$ & See gas transfill portable with OCD & M6 cylinder $4.5 \mathrm{lb}$ & $3.4 \mathrm{lb}$ with OCD \\
Use time at $2 \mathrm{~L} \cdot \mathrm{min}^{-1}$ & See gas transfill portable with OCD & $12 \mathrm{~h}$ & $10 \mathrm{~h}$
\end{tabular}

Conserver: oxygen conserving device (OCD). ${ }^{\#}$ : there is now a choice in oxygen delivery devices and systems that combine the benefits of conserving devices either gas or liquid systems. For example, the smallest liquid system weighs only $3.4 \mathrm{lb}$ and provides $10 \mathrm{~h}$ of oxygen. The smallest gas system weighs $4.5 \mathrm{lb}$, refills from an oxygen concentrator and provides $12 \mathrm{~h}$ of oxygen. Availability of these systems varies by locality.

\subsubsection{Transfilling}

Liquid has been the standard transfill system. Now, portable compressed gas oxygen cylinders can be safely transfilled from a uniquely constructed oxygen concentrator. An additional advantage of these systems is that home oxygen deliveries are no longer required.

\subsubsection{Oxygen Delivery Devices}

\subsubsection{Continuous flow dual-prong nasal cannula}

The continuous flow dual-prong nasal cannula is the standard means of oxygen delivery for the stable hypoxaemic patient. It is simple, reliable and generally well tolerated [31-34].

The nasal cannula delivers a low flow of pure oxygen entrained in a much larger volume of atmospheric air (20.9\% oxygen). Each litre per minute of oxygen flow adds about 3-4\% to the $F \mathrm{I}, \mathrm{O}_{2}$. A rough approximation is that $1 \mathrm{~L} \cdot \mathrm{min}^{-1}$ increases the $F \mathrm{I}, \mathrm{O}_{2}$ to $24 \%, 2 \mathrm{~L} \cdot \mathrm{min}^{-1}$ to $28 \%$, 
and $3 \mathrm{~L} \cdot \mathrm{min}^{-1}$ to $32 \%$. However, these small increases are usually sufficient to increase the arterial oxygen content to acceptable clinical levels.

The actual $F \mathrm{I}, \mathrm{O}_{2}$ for any particular patient is variable, depending on the anatomy and patency of the nares and moment-to-moment variation in respiratory rate and pattern, as well as the underlying pathophysiological process. The $F \mathrm{I}_{,} \mathrm{O}_{2}$ is inversely related to the inspiratory rate, i.e. a more rapid inspiratory rate dilutes the oxygen flowing into the nares with more room air, thereby reducing the $\mathrm{F}, \mathrm{O}_{2}$.

\section{Mouth breathing}

Some studies indicate that mouth breathing impairs oxygen delivery, while others show no such reduction $[31,32]$. Most mouth breathers have some nasal airflow as well. Since only a small nasal inspiratory flow is necessary, and some oxygen is stored in the nasal and sinus passages, nasal oxygen delivery is still beneficial to these patients.

\subsubsection{Oxygen-conserving devices}

Oxygen-conserving devices function by targeting oxygen delivery to early inhalation. These devices were developed in an effort to improve the portability of oxygen therapy by reducing the litre flow and thereby enabling patients to use a smaller and lighter ambulatory system, or a standard system for longer time periods [33]. Other advantages include a reduction of overall costs of LTOT and the ability to treat refractory hypoxaemia more effectively. There are three distinct devices: reservoir cannulae, demand pulsing oxygen delivery devices and transtracheal oxygen. Their characteristics are summarised in table 2. 
Table 2. - Comparison of oxygen-conserving devices

\begin{tabular}{llll}
\hline Conserving device & Reservoir cannula & Demand pulse delivery & Transtracheal catheter \\
\hline Conserving method & Store during exhalation & Early inspiration delivery & Store: end-exhale; UAW Vd \\
Efficiency gain (savings) & $2: 1-4: 1$ & $2: 1-7: 1$ & $2: 1-3: 1$ \\
Reliability & Good & Mechanically complex & Mucus plug possible \\
Comfort & Adequate-good & Adequate-good & Good \\
Cosmetics & Obtrusive & Adequate & Best \\
Cost & Low & Higher & Higher \\
Unique advantages & Inexpensive & Most efficient & Cosmetics \\
& Easy initiation & Alarms programmable & No nasal/ear irritation \\
& Reliable & & Good compliance \\
& Effective with exercise & & Reduce minute ventilation \\
Disadvantages & Bulky on face & Mechanically complex & Special care + training required \\
& & Failure is possible & Surgical complications
\end{tabular}

UAW: upper airway; Vd: dead space

\section{Oxygen-conserving devices overall}

The goal of prescribing oxygen-conserving devices is to improve portability, mobility and comfort and enable patients to be more active. They lessen the cost of home oxygen therapy by reducing number of home deliveries. This is in spite of the fact that oxygen-conserving systems are initially more expensive. As they are more efficient they are a prescribing option that can meet the needs of patients who require higher flow settings.

\section{Humidification}

There is no evidence that humidification is necessary when oxygen is given by nasal cannula at flows $<5 \mathrm{~L} \cdot \mathrm{min}^{-1}$, as evidenced by subjective complaints or severity of symptoms [35]. There are no differences in subjective complaints or in severity of symptoms over time. These findings are explained by the low water vapour output of bubble humidifiers and small contribution of oxygen flow to the patient's inspired minute ventilation, since most of the patient's tidal volume consists of atmospheric gas. Moreover, oxygen flowing through the bubble humidifier is at room temperature; when it is raised to body temperature, the relative humidity falls. 
This finding does not apply to patients receiving oxygen by tracheostomy or transtracheal oxygen (TTO), in whom the catheter has bypassed the upper airway. For these patients, humidification of inspired gas is essential even at low flow rates $\left(1 \mathrm{~L} \cdot \mathrm{min}^{-1}\right)$. TTO patients, who are at high risk for mucus ball formation, including those with high oxygen flows $>5$ $\mathrm{L} \cdot \mathrm{min}^{-1}$, may produce large amounts of mucus, or have a weak cough. These patients might benefit from heated and humidified oxygen.

Reservoir cannulas actually return some of the patient's humidification at the temperature of exhaled gases. Hence, the patient receives his own humidification at higher than room temperature.

\section{Reservoir cannulas}

Reservoir cannulas operate by storing oxygen in a small chamber during exhalation for subsequent delivery during early phase inhalation. They are cycled by the patient's nasal inspiratory and expiratory pressures. They are available in two configurations: Oxymizer and Pendant $[34,36]$. The delivery efficacies of the two are roughly equivalent.

Compared with continuous flow oxygen, reservoir cannulas are two to four times as efficacious. They reduce oxygen usage by lowering the oxygen flow setting to $25-50 \%$ of that required for continuous flow oxygen to achieve equivalent $\mathrm{Sa}_{\mathrm{a}} \mathrm{O}_{2}$. They are also indicated for patients with high flow oxygen needs.

\section{Demand pulsing oxygen delivery devices}

Demand pulsing oxygen delivery devices deliver a small bolus of oxygen at the onset of inhalation [37]. Connected between the nasal cannula and the pressurised oxygen source, they sense the start of inhalation through the nasal cannula, whereupon they immediately enable a short pulse of oxygen to flow to the patient. Because oxygen delivered at the beginning of inhalation reaches the ventilated alveoli, small oxygen pulses are very effective in oxygenating the patient. 
These devices vary in their design features, including delivery strategy, missing breath alarms and battery life. Pulse demand devices have also been combined with a transtracheal oxygen catheter, which further improves the delivery efficacy of transtracheal oxygen delivery [38]. The overall delivery efficacy of this combination is about equivalent to the most efficacious pulsed demand nasal delivery.

There have been recent concerns that pulsing devices may not maintain $\mathrm{Sa}, \mathrm{O}_{2}$ during exercise. Some newer pulsing devices have been specifically designed to maintain $\mathrm{Sa}_{2} \mathrm{O}_{2}$ during exertion [39].

\section{Transtracheal oxygen}

TTO is delivered directly by the insertion of a catheter percutaneously between the second and third tracheal rings [40]. Conservation occurs because the anatomic reservoir is increased to include the airways above the catheter insertion site. TTO can reduce the flow rate of oxygen by $\sim 50 \%$ at rest and $30 \%$ during exercise compared with nasal cannula delivery [41].

\section{Unique considerations}

Although TTO is considered in the category of oxygen conserving devices, it is considerably different from the approaches discussed earlier. TTO reduces inspired minute ventilation [42], which may lessen the work of breathing, conserve energy expenditure while lessening dyspnoea. High flow via a transtracheal catheter reduces total dead space volumes in an amount proportional to the increase in flow rate. The pleural pressure-time index and tensiontime index for the diaphragm decreases, which may account for the decrease in dyspnoea and increase in exercise tolerance seen in these patients.

\section{Transtracheal team}

TTO requires a trained team of clinicians to evaluate, educate and monitor patients [43]. The ideal candidate for TTO has a strong desire to remain active, is willing to follow the care protocol, is not experiencing frequent exacerbations, has a care-giver who is willing to assist with problem solving and details of care, and lives within $2 \mathrm{~h}$ of the institution or has 
equivalent follow-up in the home community [44]. TTO is of particular benefit to patients who are unwilling to accept the visible nasal cannula and thereby reject oxygen therapy.

\section{Contraindications}

Relative contraindications include high-dose steroids (e.g. prednisone $>30 \mathrm{mg} \cdot \mathrm{day}^{-1}$ ) and conditions that predispose to delayed healing, e.g. diabetes mellitus, connective tissue disease or severe obesity. Absolute contraindications include subglottic stenosis or vocal cord paralysis, herniation of the pleura into the insertion site, severe coagulopathy, uncompensated respiratory acidosis and inability to practice self-care.

\section{Complications}

Complications of TTO are infrequent but can be serious. They include catheter displacement, bacterial cellulitis, subcutaneous emphysema, haemoptysis, severed catheter and mucus balls. Mucus balls can develop on the catheter due to the drying effect of the oxygen, increased sputum production and poor adherence to cleaning schedules; they may cause coughing, catheter blockage and tracheal obstruction, with serious consequences. Daily cleaning prevents mucus ball formation in most patients.

\subsection{Home oxygen therapy}

\subsubsection{Appropriate candidates for long-term oxygen therapy}

Patients whose disease is stable on a full medical regimen, with $\mathrm{Pa}_{\mathrm{a}} \mathrm{O}_{2}<7.3 \mathrm{kPa}(55 \mathrm{mmHg})$ (corresponding to an $\mathrm{Sa}_{2} \mathrm{O}_{2}<88 \%$ ), should receive LTOT.

A patient whose $\mathrm{Pa}, \mathrm{O}_{2}$ is $7.3-7.8 \mathrm{kPa}(55-59 \mathrm{mmHg})\left(\mathrm{Sa}_{\mathrm{a}} \mathrm{O}_{2} 89 \%\right)$ and who exhibits signs of tissue hypoxia, such as pulmonary hypertension, cor pulmonale, erythrocytosis, oedema from right heart failure or impaired mental status, should also receive LTOT.

Desaturation only during exercise or sleep suggests consideration of oxygen therapy specifically under those conditions. 
These guidelines are generally accepted and have been adopted by various healthcare systems as reimbursement criteria. Some gray areas remain, such as patients with adequate $P \mathrm{a}, \mathrm{O}_{2}$ who have severe dyspnoea relieved by low-flow oxygen or patients who are limited in their exertional capacity but improve their exercise performance with supplemental oxygen.

These LTOT indications are summarised in the table 3.

Table 3. - Physiological indications for long-term oxygen therapy (LTOT)

\begin{tabular}{llll}
\hline $\mathrm{Pa}, \mathrm{O}_{2} \mathrm{mmHg}$ & $\mathrm{Sa}, \mathrm{O}_{2} \%$ & LTOT indication & Qualifying condition \\
\hline$\leq 55$ & $\leq 88$ & Absolute & None \\
$55-59$ & 89 & Relative with qualifier & "P" pulmonale, polycythemia $>55 \%$ \\
& & & History of oedema \\
$\geq 60$ & $\geq 90$ & None except with qualifier & $\begin{array}{l}\text { Exercise desaturation } \\
\end{array}$ \\
& & Sleep desaturation not corrected by CPAP \\
& & Lung disease with severe dyspnea responding to $\mathrm{O}_{2}$
\end{tabular}

$\mathrm{Pa}, \mathrm{O}_{2}$ : arterial oxygen tension; $\mathrm{Sa}, \mathrm{O}_{2}$ : arterial oxygen saturation; Right heart failure; CPAP: continuous positive airways pressure; $\mathrm{O}_{2}$ : oxygen.

\subsubsection{Optimal medical regimen}

One of the goals of any medical regimen is to optimise $V^{\prime} / Q^{\prime}$ matching as a means of correcting hypoxaemia. This is particularly important during and after an acute exacerbation.

The NOTT [2] incorporated an initial 4-week period in order to optimise medical therapy prior to initiation of oxygen therapy. During this stabilisation phase, nearly $50 \%$ of patients who initially qualified for the study according to blood gas criteria alone improved to such an extent on bronchodilators, antimicrobials and corticosteroids (when indicated) that they no longer qualified by blood gas criteria. Consequently, ensuring that the patient is receiving optimal medical management is an important component of the evaluation of need for LTOT. Particular attention should be given to the pharmacological regimen, exacerbation history and the presence of comorbidities that may exacerbate symptoms, e.g. congestive heart failure, sleep-disordered breathing. If the regimen is not optimal but the patient meets criteria, oxygen therapy should be initiated followed by an evaluation in 1-3 months to determine continued need. 
One aspect of good medical management is the oxygen therapy itself. Recent reports suggest that oxygen may have a reparative effect by reducing pulmonary artery vasoconstriction, improving $V^{\prime} / Q^{\prime}$ matching and other mechanisms [45]. Accordingly, withdrawing oxygen because of improved $\mathrm{Pa}, \mathrm{O}_{2}$ may be detrimental.

\subsubsection{Prescribing home oxygen therapy}

See figure 1 .

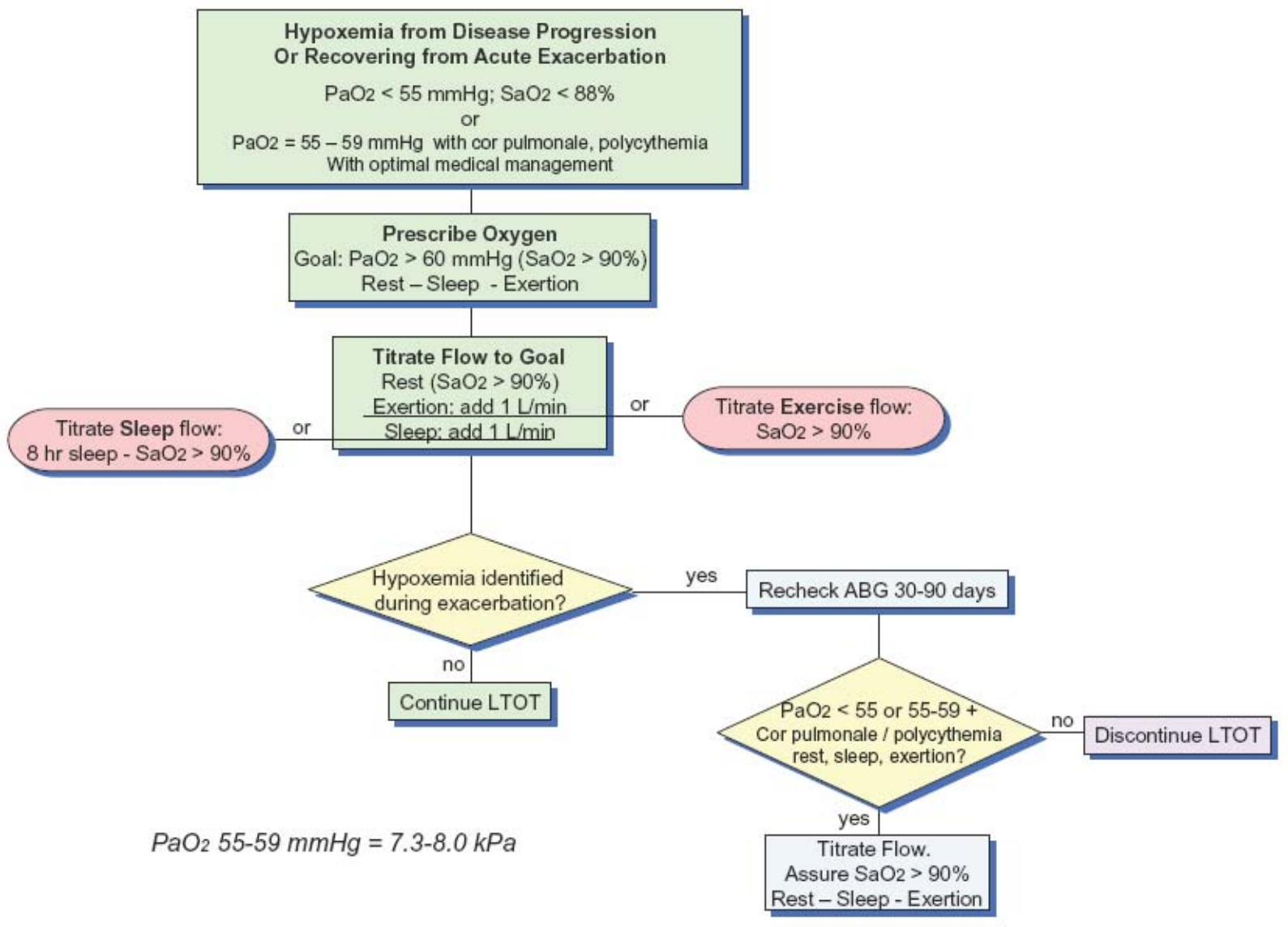

Fig. 1. - A flow chart for prescribing long-term oxygen therapy (LTOT). $\mathrm{Pa}, \mathrm{O}_{2}$ : arterial oxygen tension; $\mathrm{Sa}, \mathrm{O}_{2}$ : arterial oxygen saturation; $\mathrm{ABG}$ : arterial blood gases.

\subsubsection{Initiating long-term oxygen therapy}

When initiating LTOT it is advisable to measure an ABG after breathing room air for 30 min.

An $\mathrm{ABG}$ is also required to determine the presence of hypercapnia or respiratory acidosis. 
Pulse oximetry $\left(\mathrm{Sp}, \mathrm{O}_{2}\right)$ is not considered adequate for initiating LTOT. However, oximetry may be used to adjust oxygen flow settings over time.

\subsubsection{2. $\quad$ Administering long-term oxygen therapy}

The standard of care for administration of LTOT should be continuous administration (24 $\left.\mathrm{h} \cdot \mathrm{day}^{-1}\right)$ with ambulatory capability $[2,46]$.

Exceptions to continuous administration with ambulatory capability include patients who: 1) are incapable or unwilling to be mobile; 2) require oxygen only during sleep; 3) require oxygen only during exercise; or 4) refuse to use a portable device for ambulation.

\subsubsection{Ambulatory oxygen systems}

Ambulatory oxygen systems should weigh $<10 \mathrm{lb}$, provide oxygen at $2 \mathrm{~L} \mathrm{~h} \cdot \mathrm{min}^{-1}$ for $\geq 4-6 \mathrm{~h}$ and be packaged so that they can be carried by the patient.

\subsubsection{Stationary oxygen}

Stationary oxygen may be delivered via a concentrator, compressed gas or liquid. The choice of system will depend upon availability, cost and which portable system is suitable.

\subsubsection{Larger portable oxygen systems}

Larger portable oxygen systems, such as a steel cylinder on wheels, are suitable for patients who only occasionally go beyond the limits of the stationary delivery system (generally considered to be $50 \mathrm{ft}$ of tubing) [46]. If the patient is not mobile beyond a $150 \mathrm{~m}$ radius, an oxygen concentrator is suitable.

\subsubsection{Oxygen settings}

Oxygen settings should be adjusted for rest, exertion and sleep to meet the individual patient's needs. See figure 1. 


\section{Settings for rest, exertion and sleep}

Rest. The resting oxygen flow rate can be adjusted, while monitoring oximetry to $\mathrm{Sp}_{\mathrm{p}} \mathrm{O}_{2} \geq 90 \%$. ABG should then be used to establish initial $\mathrm{Pa}, \mathrm{O}_{2}$ with corroborating oximetry $\mathrm{Sp}, \mathrm{O}_{2}$. To insure equilibration, 20-30 min should be allowed after each change in litre flow. For a more accurate reading, the clinician should check the oximeter display for a stable signal and a pulse that is in synchrony with the patient's heart rate. Fingernail polish, if worn, may need to be removed.

Sleep. The sleep oxygen flow rate can be determined using two strategies: 1) the flow can be increased $1 \mathrm{~L} \cdot \mathrm{min}^{-1}$ above the daytime resting prescription; or 2) nocturnal polysomnography or nocturnal pulse oximetry can be performed to support a more accurate prescription. If there are signs of cor pulmonale despite adequate daytime oxygenation, the patient should be monitored during sleep to determine the best sleep oxygen setting.

Exertion. During exertion, the goal is to maintain $\mathrm{Pa}, \mathrm{O}_{2}>60 \mathrm{mmHg}(8 \mathrm{kPa})$ or $\mathrm{Sa}_{2} \mathrm{O}_{2}>90 \%$. If the patient is using an oxygen-conserving system, titration should be performed while the patient is using that system. This is particularly true during exercise conditions.

\subsubsection{Determination of continued need}

Standards for continuing oxygen therapy differ depending on whether it is prescribed for the first time during an acute exacerbation or at a time when the patient is relatively stable and receiving optimal therapy [45].

\section{Identification during exacerbation}

Some patients with COPD become hypoxaemic during an exacerbation.

Approximately 25-65\% of these patients will subsequently heal to the point of not requiring oxygen. When they are clinically stable, this subpopulation should be retested in 30-90 days. If the patient does not meet blood gas criteria at that time, oxygen therapy can be discontinued. 


\section{Identification when clinically stable}

The majority of patients, who are clinically stable when LTOT is initially prescribed will continue to meet prescribing criteria for LTOT. Some patients, however, experience an improvement in $\mathrm{Pa}, \mathrm{O}_{2}$ over time to the point of not meeting the criteria for LTOT. This can occur in stable patients receiving optimal therapy, who have been on oxygen for months or years [45].

When oxygen is withdrawn from these patients, their $P a, \mathrm{O}_{2}$ begins to decline [45]. The conclusion is that oxygen is reparative (including reversal of hypoxic pulmonary vasoconstriction) and, therefore, should not be discontinued.

Once the need for LTOT has been established in a stable patient on optimal therapy, LTOT is considered to be a lifetime commitment [45].

\section{Physiological indication for long-term oxygen therapy}

The physician prescribes oxygen based on physiological findings and clinical judgment. However, LTOT may not be reimbursed unless the patient meets specific physiological criteria. These criteria tend to be similar in most countries. It is therefore essential for the physician to provide appropriate documentation that oxygen is medically necessary and meets the prescribing criteria. The documentation requirements vary widely over the different countries.

\subsubsection{Patient education and compliance}

Patient education and monitoring of compliance are essential to assure the success of LTOT. Many patients harbour fears regarding the therapy. Some patients associate a need for LTOT with profound deterioration rather than prolongation of life and enhancement of quality of life. Some may experience anger or denial and therefore avoid using LTOT. Some patients may avoid using oxygen in public, because they fear reaction of others. Some may regard oxygen as an addictive substance and may therefore avoid its use as much as possible. These and other concerns need to be explored and discussed with the patient and family to provide appropriate rationale and reassurance of the benefits of LTOT (see Patient section). 


\subsection{References}

1. Report of the Medical Research Council Working Party. Long-term domiciliary oxygen therapy in chronic hypoxic cor pulmonale complicating chronic bronchitis and emphysema. Lancet 1981; 1: 681-685.

2. Nocturnal Oxygen Therapy Trial Group. Continuous or nocturnal oxygen therapy in hypoxemic chronic obstructive lung disease. Ann Intern Med 1980; 93: 391-398.

3. Weitzenblum E, Sautegeau A, Ehrhart M, Mammosser M, Pelletier A. Long-term oxygen therapy can reverse the progression of pulmonary hypertension in patients with chronic obstructive pulmonary disease. Am Rev Respir Dis 1985; 131: 493-498.

4. Oswald-Mammosser M, Weitzenblum E, Quoix E, et al. Prognostic factors in COPD patients receiving long-term oxygen therapy: importance of pulmonary artery pressure. Chest 1995; 107: 1193-1198.

5. Zielinski J, Tobiasz M, Hawrylkiewicz I, Sliwinksi P, Palasiewicz G. Effects of long-term oxygen therapy on pulmonary hemodynamics in COPD patients: a 6-year prospective study. Chest 1998; 113: 65-70.

6. MacNee W, Wathen CG, Flenley DC, Muir AD. The effects of controlled oxygen therapy on ventricular function in patients with stable and decompensated cor pulmonale. Am Rev Respir Dis 1988; 137: 1289-1295.

7. Timms RM, Khaja FU, Williams GW. Hemodynamic response to oxygen therapy in chronic obstructive pulmonary disease. Ann Inter Med 1985; 102: 29-36.

8. Balter MS, Daniak N, Chapman KR, Sorba SA, Rebuck AS. Erythropoietin response to acute hypoxemia in patients with chronic pulmonary disease. Chest 1992; 102: 482-485.

9. Zielinski J. Effects of long-term oxygen therapy in patients with chronic obstructive pulmonary disease. Curr Opin Pulm Med 1999; 5: 81-87.

10. Mannix ET, Manfredi F, Palange P, Dowdeswell IRG, Farber MO. Oxygen may lower the $\mathrm{O}_{2}$ cost of breathing in chronic obstructive lung disease. Chest 1992; 101: 910-915.

11. Dean NC, Brown JK, Himelman RB, et al. Oxygen may improve dyspnea and endurance in patients with chronic obstructive pulmonary disease and only mild hypoxemia. Am Rev Respir Dis 1992; 146: 941-945. 
12. Somfay A, Porszasz J, Lee SM, Casaburi R. Dose-response effect of oxygen on hypertension and exercise endurance in nonhypoxaemic COPD patients. Eur Respir J 2001; 18: 77-84.

13. Eaton T, Garrett JE, Young P, et al. Ambulatory oxygen improves quality of life of COPD patients: a randomised controlled study. Eur Respir J 2002; 20: 306-312.

14. Krop HD, Block AJ, Cohen E. Neuropsychologic effects of continuous oxygen therapy in chronic obstructive pulmonary disease. Chest 1973; 64: 317-322.

15. Heaton RK, Grant I, McSweeny AJ, Adams KM, Petty TL. Psychologic effects of continuous and nocturnal oxygen therapy in hypoxemic chronic obstructive pulmonary disease. Arch Intern Med 1983; 143: 1941-1947.

16. Grant I, Heaton RK. Neuropsychiatric abnomalities in advanced COPD. In: Petty TL, ed. Chronic Obstructive Pulmonary Disease. New York, Marcel Dekker, 1985; pp. 355-373.

17. Plywaczewski R, Sliwinski P, Nowinski A, Kaminksi D, Zielinski J. Incidence of nocturnal desaturation while breathing oxygen in COPD patients undergoing long-term oxygen therapy. Chest 2000; 117: 679-683.

18. Fletcher EC, Luckett RA, Goodnight-White S, Miller CC, Qian W, Costarangos-Galarza C. A double-blind trial of nocturnal supplemental oxygen for sleep desaturation in patients with chronic obstructive pulmonary disease and a daytime $\mathrm{Pa}, \mathrm{O}_{2}$ above $60 \mathrm{~mm} \mathrm{Hg}$. Am Rev Respir Dis 1992; 145: 1070-1076.

19. Kimura H, Suda A, Sakuma T, Tatsumi K, Kawakami Y, Kuriyama T. Nocturnal oxyhemoglobin desaturation and prognosis in chronic obstructive pulmonary disease and late sequelae of pulmonary tuberculosis. Intern Med 1998; 37: 354-359.

20. Chaouat A, Weitzenblum E, Kessler R, et al. A randomized trial of nocturnal oxygen therapy in chronic obstructive pulmonary disease patients. Eur Respir J 1999; 14: 997-999.

21. Liker ES, Karnick A, Lerner L. Portable oxygen in chronic obstructive lung disease with hypoxemia and cor pulmonale. Chest 1975; 68: 236.

22. Rooyackers JM, Dekhuijzen PN, Van Herwaarden CL, Folgering HT. Training with supplemental oxygen in patients with COPD and hypoxaemia at peak exercise. Eur Respir $J$ 1997; 10: 1278-1284. 
23. Carter R. Oxygen and acid-base status: measurement, interpretation, and rationale for oxygen therapy. Chapter 5. In: Tiep BL, ed. Portable Oxygen Therapy: Including Oxygen Conserving Methodology. Mt. Kisco, NY, Futura Publishing Co, 1991; pp. 136-138.

24. Webb RK, Ralston C, Runciman WB. Potential errors in pulse oximetry. Part II: Effects of changes in saturation and signal quality. Anesthesia 1991; 46: 207-212.

25. Petty TL, Stanford RE, Neff TA. Continuous oxygen therapy in chronic airway obstruction: observations on possible oxygen toxicity and survival. Ann Intern Med 1971; 75: 361-367.

26. Dunn WF, Nelson SB, Hubmayrm RD. Oxygen-induced hypercarbia in obstructive pulmonary disease. Am Rev Respir Dis 1991; 144: 526-530.

27. Aubier M, Murciano D, Milie-Emili M, et al. Effects of the administration of oxygen therapy on ventilation and blood gases in patients with chronic obstructive pulmonary disease during acute respiratory failure. Am Rev Respir Dis 1980; 122: 747-754.

28. Aubier M, Murciano D, Fournier M, et al. Central respiratory drive in acute respiratory failure of patients with chronic obstructive pulmonary disease. Am Rev Respir Dis 1980; 122: 191-199.

29. Sassoon CS, Hassell KT, Mahutte CK. Hyperoxic-induced hypercapnia in stable chronic obstructive pulmonary disease. Am Rev Respir Dis 1987; 135: 907-911.

30. West GA, Primeau P. Nonmedical hazards of long-term oxygen therapy. Respir Care 1983; 28: 906-912.

31. Kory RC, Bergmann JC, Sweet RD, et al. Comparative evaluation of oxygen therapy techniques. JAMA 1962; 179: 123-128.

32. Gibson RL, Comer PB, Beckman RW, et al. Actual tracheal oxygen concentration with commonly used therapy. Anesthesiology 1976; 44: 71-73.

33. Hoffman LA. Novel strategies for delivering oxygen: reservoir cannula, demand flow, and transtracheal oxygen administration. Respir Care 1994; 39: 363-376.

34. Soffer M, Tashkin DP, Shapiro BJ, Littner M, Harvey E, Farr S. Conservation of oxygen supply using a reservoir nasal cannula in hypoxemic patients at rest and during exercise. Chest 1985; 89: 806-810.

35. Campbell EJ, Baker D, Crites-Silver P. Subjective effects of humidification of oxygen for delivery by nasal cannula. Chest 1988; 93: 289-293. 
36. Carter R, Williams JS, Berry J, Peavler M, Griner D, Tiep B. Evaluation of the pendant oxygen-conserving nasal cannula during exercise. Chest 1986; 89: 806-810.

37. Tiep BL, Christopher KL, Spofford BT, Goodman J, Worley PD, Macey SL. Pulsed nasal and transtracheal oxygen delivery. Chest 1990; 97: 364-368.

38. Yaeger ES, Goodman S, Hoddes E, Christopher KL. Oxygen therapy using pulse and continuous flow with a transtracheal catheter and a nasal cannula. Chest 1994; 106: 854-860.

39. Tiep BL, Barnett J, Schiffman G, Sanchez O, Carter R. Maintaining oxygenation via demand oxygen delivery during rest and exercise. Respir Care 2002; 47: 887-892.

40. Heimlich HJ, Carr GC. The Micro-Trach: a seven-year experience with transtracheal oxygen therapy. Chest 1989; 95: 1008-1012.

41. Hoffman LA, Johnson JT, Wesmiller SW, et al. Transtracheal delivery of oxygen: efficacy and safety for long-term continuous therapy. Ann Otolol Rhinol Laryngol 1991; 100: 108-115. 42 Benditt J, Pollock M, Roa J, Celli B. Transtracheal delivery of gas decreases the oxygen cost of breathing. Am Rev Respir Dis 147; 1993: 1207-1210.

43. Christopher KL, Spofford BT, Petrun MD, McCarty DC, Goodman JR, Petty TL. A program for transtracheal oxygen delivery: assessment of safety and efficacy. Ann Intern Med 1987; 107: 802-808.

44. Kampelmacher MJ, Deenstra M, van Kesteren RG, Melissant CF, Douze JMC, Lammers JWJ. Transtracheal oxygen therapy: an effective and safe alternative to nasal oxygen administration. Eur Respir J 1997; 10: 828-833.

45. O'Donohue WJ. Effect of arterial oxygen therapy on increasing arterial oxygen tension in hypoxemia patients with stable chronic obstructive pulmonary disease while breathing ambient air. Chest 1991; 100: 968-972.

46. Petty TL, Casaburi R. Recommendations of the Fifth Oxygen Consensus Conference. Writing and organizing committees. Respir Care 2000; 45: 957-961. 


\section{Management of stable COPD: pulmonary rehabilitation 9.1. Key points}

- Pulmonary rehabilitation is a multidisciplinary programme of care that is individually tailored and designed to optimise physical and social performance and autonomy.

- This therapy results in significant and clinically meaningful improvements in multiple outcome areas, including dyspnoea, exercise ability, health status and healthcare utilisation.

- Pulmonary rehabilitation should be considered for patients with chronic obstructive pulmonary disease (COPD) who have dyspnoea or other respiratory symptoms, reduced exercise tolerance, a restriction in activities because of their disease, or impaired health status.

- There are no specific pulmonary function inclusion criteria that indicate the need for pulmonary rehabilitation, since symptoms and functional limitations direct the need for pulmonary rehabilitation.

- This comprehensive intervention includes exercise training, education, psychosocial/behavioural intervention, nutritional therapy, outcome assessment and promotion of long-term adherence to the rehabilitation recommendations.

\subsection{Background}

Pulmonary rehabilitation is defined as "a multidisciplinary programme of care for patients with chronic respiratory impairment that is individually tailored and designed to optimise physical and social performance and autonomy" [1] (see ATS statement on Pulmonary rehabilitation).

Pulmonary rehabilitation results in improvements in multiple outcome areas of considerable importance to the patient, including dyspnoea, exercise ability, health status and healthcare utilisation. These positive effects occur despite the fact that it has a minimal effect on static pulmonary function measurements. This reflects the fact that much of the morbidity from COPD results from secondary conditions, which are often treatable if recognised. Examples of these treatable conditions are cardiac deconditioning, peripheral muscle dysfunction, and a reduction in total and lean body mass anxiety, and poor coping skills. Elements of 
comprehensive pulmonary rehabilitation, including promoting a healthy lifestyle, stressing adherence to therapy and encouraging physical activity, should be incorporated into the care of all patients with COPD.

\subsection{Outcomes from pulmonary rehabilitation}

Several randomised, controlled trials have documented the effectiveness of pulmonary rehabilitation in COPD. A list of these studies is given in table 1. 
Table 1. - Randomised, controlled trials of pulmonary rehabilitation

\begin{tabular}{|c|c|}
\hline First author [ref.] & sults \\
\hline OLDSTEIN [2] & $\begin{array}{l}\text { Significant treatment outcomes, including } 37.9 \mathrm{~m} \text { in } 6 \text {-min walk distance, } 4.7 \text { min increase in } \\
\text { submaximal cycle endurance time, improvements in the dyspnoea, emotion and mastery components of } \\
\text { the CRQ, and a } 2.7 \text { unit improvement in the TDI }\end{array}$ \\
\hline REARDON [3] & $\begin{array}{l}\text { There was no significant group difference in change in peak oxygen consumption } \\
\text { Rehabilitation patients had significantly lower dyspnoea measured with a visual analogue scale during } \\
\text { exercise testing and lower overall dyspnoea measured by the TDI }\end{array}$ \\
\hline RIES [4] & $\begin{array}{l}\text { Significant improvements favouring rehabilitation in maximal oxygen consumption, treadmill endurance } \\
\text { time, exertional and overall dyspnoea, and self-efficacy for walking } \\
\text { No significant difference in health status (Quality of Well-Being score), number of hospital days or } \\
\text { survival }\end{array}$ \\
\hline WIJKSTRA [5] & $\begin{array}{l}\text { Significant improvements favouring rehabilitation in work rate, peak oxygen consumption, the 6-min } \\
\text { walk distance, exertional dyspnoea and health status measured with the CRQ }\end{array}$ \\
\hline STRIJBOS [6] & $\begin{array}{l}\text { Both outpatient and home-based rehabilitation had significant improvement over control in maximal } \\
\text { cycle work rate, 4-min walk distance and exertional dyspnoea }\end{array}$ \\
\hline BENDSTRUP [7] & $\begin{array}{l}\text { Significant improvements favouring the treatment group in the 6-min walk distance, activities of daily } \\
\text { living and CRQ health status }\end{array}$ \\
\hline WEDZICHA [8] & $\begin{array}{l}\text { In patients with moderate dyspnoea, significant improvement favouring rehabilitation in the shuttle } \\
\text { walking distance and health status } \\
\text { Exercise ability and health status did not significantly change in either group with severe dyspnoea }\end{array}$ \\
\hline GRIFFITHS [9] & $\begin{array}{l}\text { Significant improvement favouring rehabilitation in the shuttle walk distance, heath status measured } \\
\text { with the CRQ, the SGRQ and the most SF- } 36 \text { questionnaire components } \\
\text { Fewer days spent in the hospital and fewer primary care home visits }\end{array}$ \\
\hline FINNERTY [10] & $\begin{array}{l}\text { Significant improvements and clinically meaningful improvement in the rehabilitation group in health } \\
\text { status using the SGRQ total score }\end{array}$ \\
\hline TROOSTERS [11] & $\begin{array}{l}\text { Significant improvements favouring rehabilitation in 6-min walk distance, maximal work rate and } \\
\text { oxygen consumption, quadriceps force, inspiratory muscle force, and CRQ-measured health status } \\
\text { Improvements in walk distance and health status exceeded the clinically-meaningful threshold values }\end{array}$ \\
\hline
\end{tabular}

CRQ : Chronic Respiratory Questionnaire; TDI : transitional dyspnoea index; SGRQ : St. George Respiratory Questionnaire.

As outlined by the Global Initiative for Obstructive Lung Disease (GOLD) recommendations [12], effective management of COPD is directed to following goals: 1) prevention of disease progression; 2) relief of symptoms; 3) improvement in exercise tolerance; 4) improvement in 
health status; 5) prevention of complications; 6) prevention of exacerbations; and 7) reduction in mortality. Pulmonary rehabilitation, as an adjunct to standard medical therapy, may result in improvement in some of these areas.

\subsubsection{Relief of symptoms}

Dyspnoea and fatigue are hallmark symptoms in most COPD patients. There is a considerable body of evidence that pulmonary rehabilitation improves exertional dyspnoea [3, 13] and dyspnoea associated with daily activities in COPD [2, 4, 6, 8-11, 14].

\subsubsection{Improvement in exercise tolerance}

Pulmonary rehabilitation improves exercise ability in COPD [4-11, 14-16]. Favourable outcomes include increases in maximal exercise tolerance, peak oxygen uptake, endurance time during submaximal testing, functional walking distance, and peripheral and respiratory muscle strength.

\subsubsection{Improvement in health status}

Pulmonary rehabilitation results in a significant improvement in disease-specific and general measures of health status $[4,6,9,14,17]$. These effects are relatively long lasting and not necessarily related to improvements in exercise ability. Multiple domains of health status usually show improvement, such as dyspnoea, fatigue, emotional function and mastery components of the Chronic Respiratory Disease Questionnaire or symptoms, activity and impact components of the St. George's Respiratory Questionnaire. Improvement in health status following rehabilitation usually exceeds the thresholds for minimum clinically important differences established for respiratory-specific health status questionnaires [18].

\subsubsection{Prevention of complications and exacerbations}

There are conflicting reports on the effect of pulmonary rehabilitation on healthcare service utilisation. A randomised, controlled trial of pulmonary rehabilitation in California failed to show a beneficial effect on hospitalisations in COPD [11]. However, a study of outpatient pulmonary rehabilitation in Wales demonstrated that the rehabilitation group had a similar frequency of hospitalisations but a smaller number of hospital days than a control group in the year following the intervention (10.4 versus 21.0 days) [10]. The reduction in hospital days for 
both respiratory illness and all causes was noted. In a subsequent cost/utility analysis, these authors demonstrated that outpatient rehabilitation produces cost-per-quality adjusted life-year ratios within bounds considered to be cost effective and resulted in financial benefits to the health service [19].

\subsubsection{Effect on mortality}

Limited data from prospective studies do not support the conclusion that pulmonary rehabilitation affects long-term survival $[8,11]$. These studies, however, are relatively small and probably were not sufficiently powered to detect this possible effect. In one clinical trial, nutritional intervention, which is commonly incorporated into a comprehensive pulmonary rehabilitation programme, was associated with improved survival rates in a single clinical trial [20].

\subsubsection{Effect on disease progression}

Pulmonary rehabilitation has no significant effects on forced expiratory volume in one second and presumably does not attenuate the decline of airflow limitation in COPD. However, using a broader concept of disease progression, which includes symptoms, exercise capacity, health status and healthcare utilisation, pulmonary rehabilitation would then be considered to have marked effectiveness.

\subsection{Principles of pulmonary rehabilitation}

Each COPD patient enrolled in a rehabilitation programme has to be considered as a unique individual, with specific physio- and psychopathological impairment caused by the underlying disease and its associated morbidity. In this approach, components of a rehabilitation programme are individualised based on a thorough assessment of the patient, not limited to lung function testing. This assessment must address distressing symptoms, functional limitation, emotional disturbance, knowledge of the disease, cognitive and psychosocial functioning, and nutritional assessment. Furthermore, this assessment must be an ongoing process during the whole rehabilitation process. 
Pulmonary rehabilitation is usually coordinated by an experienced healthcare professional, such as a registered nurse, physical therapist or respiratory therapist. Also involved is a multidisciplinary team that varies between programmes, but often includes physicians, nurses, respiratory therapists, physical therapists, occupational therapists, psychologists, dieticians and social workers.

\subsection{Selection criteria for pulmonary rehabilitation}

Pulmonary rehabilitation should be considered for patients with COPD who have dyspnoea or other respiratory symptoms, reduced exercise tolerance, a restriction in activities because of their disease, or impaired health status (see Definition, diagnosis and staging).

There are no specific pulmonary function inclusion criteria that indicate the need for pulmonary rehabilitation, since symptoms and functional limitations, not the severity of the underlying physiology, direct the need for pulmonary rehabilitation. Often, referral to pulmonary rehabilitation is delayed until patients reach a stage of advanced lung disease. While these patients still stand to derive considerable benefit from pulmonary rehabilitation [21], referral at an earlier stage would allow for earlier preventative strategies, such as smoking cessation, nutritional therapy and a greater latitude in the exercise prescription.

Current cigarette smokers are reasonable candidates for pulmonary rehabilitation and probably obtain similar benefits as nonsmokers or exsmokers. Smoking cessation intervention is an obviously important component of the pulmonary rehabilitation process for smokers.

Impediments to the pulmonary rehabilitation intervention fall into two broad categories: 1) conditions which would interfere with the patient's ability to participate in the rehabilitative process (such as disabling arthritis); and 2) conditions which might place the patient at undue risk during exercise training (such as unstable angina) (see ATS Pulmonary Rehabilitation Guidelines). 


\subsection{Components of pulmonary rehabilitation}

Comprehensive pulmonary rehabilitation generally includes exercise training, education, psychosocial and behavioural intervention, nutritional therapy and outcome assessment.

\subsubsection{Exercise training}

Exercise training is an essential component of pulmonary rehabilitation. In general, two types of exercise training can be given: endurance (or aerobic) training and strength training (see ATS Statement on Pulmonary Rehabilitation).

Endurance training involves dynamic activity of large muscles, usually performed three to four times a week for 20-30 min per session at an intensity of $\geq 50 \%$ of maximal oxygen consumption. This induces structural and physiological adaptations that provide the trained individual with improved endurance for performance of high-intensity activity.

Lower extremity training is the mainstay of endurance training, although there is scientific rationale for incorporating upper extremity training. The optimal training duration for exercise training in COPD has not been established. Most programmes include exercise sessions of $\geq 30$ min, two to five times a week, for 6-12 weeks. The effect of exercise training on exercise capacity and exertional dyspnoea in COPD is dose dependent [22]. However, many patients have difficulty sustaining prolonged high intensity (80\% of maximum power output) for prolonged periods [23]. Despite this, lower intensity exercise training is at least as good as high intensity training in improving health-related quality of life [23, 24]. Interval exercise training (repeated periods of near-maximal exercise alternating with short intervals of rest) may give similar benefits as continuous training, but has less associated dyspnoea $[25,26]$.

Strength training has proven benefits in pulmonary rehabilitation and can be considered supplemental to endurance training [27-29]. While endurance training of the peripheral muscles is of proven benefit in COPD, ventilatory muscle training is also frequently given. While this probably improves respiratory muscle strength, its effect on symptoms and functional limitation has not yet been firmly established [30]. 


\subsubsection{Education}

Education is considered an important component of comprehensive pulmonary rehabilitation and is integrated into virtually all programmes. Because of this, its effect in isolation cannot be readily determined. Among the potential benefits of education are: active participation in healthcare [31, 32], increased coping skills [33, 34], a better understanding of the physical and psychological changes of chronic illness, more skill in collaborative self-management and better adherence to the treatment plan [35]. In addition to standard didactic sessions, education may also incorporate breathing strategies, such as pursed-lip and diaphragmatic breathing, energy conservation and work simplification, and advance directives (see Ethical and palliative care issues).

\subsubsection{Psychosocial and behavioural intervention.}

Anxiety, depression and difficulties in coping with chronic disease are common in COPD patients and contribute to morbidity.

Psychosocial and behavioural intervention in pulmonary rehabilitation may include educational sessions or support groups focusing on specific problems such as stress management, or instruction in progressive muscle relaxation, stress reduction and panic control [36].

Informal discussions during rehabilitation sessions of symptoms, concerns and problems common to COPD patients may be beneficial. Participation by family members or friends in pulmonary rehabilitation support groups is encouraged. Motivation for pulmonary rehabilitation, which may be suboptimal at the onset, might improve during therapy.

Individuals with major psychiatric conditions should be referred to appropriate professionals.

\subsubsection{Nutritional therapy}

Weight loss and muscle wasting, which are present in 20-35\% of patients with stable COPD, contribute to morbidity and mortality in COPD, independent of the pulmonary physiological abnormality [20]. Nutritional intervention should be considered for these individuals, 
especially under conditions of increased exercise-related energy expenditure (see with Management of stable COPD: nutrition).

\subsection{Programme setting}

Documented clinical efficacy has been demonstrated in outpatient, inpatient and home settings for pulmonary rehabilitation. The choice of setting for pulmonary rehabilitation depends on the prerehabilitation physical, functional and psychosocial status of the patient, the availability and distance to the programme, reimbursement, and patient preference.

\subsection{Outcome assessment}

Measurement of the individual's change in performance reinforces the gains made through the efforts of the patient and staff, while evaluation of the programme through standardised outcome measures rates its overall effectiveness and serves as a tool for quality improvement.

Outcome assessment should be made in several areas, including dyspnoea, exercise ability and health status.

\subsection{Promotion of long-term adherence}

Although the short-term effects of pulmonary rehabilitation in multiple outcome areas is firmly established, its long-term effectiveness (i.e. after $\sim 2$ yrs) is disappointing. This drop-off in beneficial effect is probably multifactorial. However, two factors play a large part in this loss of effectiveness: exacerbations of COPD postrehabilitation and a gradual decrease in adherence with the postrehabilitation exercise prescription [37]. Pulmonary rehabilitation should include strategies to promote long-term adherence. 


\subsection{References}

1. Pulmonary rehabilitation: official statement of the American Thoracic Society. Am J Respir Crit Care Med 1999; 159: 1666-1682.

2. Goldstein RS, Gort EH, Stubbing D, et al. Randomised controlled trial of respiratory rehabilitation. Lancet 1994; 344: 1394-1397.

3. Reardon J, Awad E, Normandin E, Vale F, Clark B, ZuWallack RL. The effect of comprehensive outpatient pulmonary rehabilitation on dyspnea. Chest 1994; 105: 1046-1052.

4. Ries AL, Kaplan RM, Limberg TM, Prewitt LM. Effects of pulmonary rehabilitation on physiologic and psychosocial outcomes in patients with chronic obstructive pulmonary disease. Ann Intern Med 1995; 122: 823-832.

5. Wijkstra PJ, van der Mark TW, Kraan J, van Altena R, Koeter GH, Postma DS. Effects of home rehabilitation on physical performance in patients with chronic obstructive pulmonary disease (COPD). Eur Respir J 1996; 9: 104-110.

6. Strijbos JH, Postma DS, van Altena R, Gimeno F, Koeter GH. A comparison between an outpatient hospital-based pulmonary rehabilitation program and a home-care pulmonary rehabilitation program in patients with COPD. A follow-up of 18 months. Chest 1996; 109: $366-372$.

7. Bendstrup KE, Ingemann Jensen J, Holm S, Bengtsson B. Out-patient rehabilitation improves activities of daily living, quality of life and exercise tolerance in chronic obstructive pulmonary disease. Eur Respir J 1997; 10: 2801-2806.

8. Wedzicha JA, Bestall JC, Garrod R, Garnham R, Paul EA, Jones PW. Randomized controlled trial of pulmonary rehabilitation in severe chronic obstructive pulmonary disease patients, stratified with the MRC dyspnoea scale. Eur Respir J 1998; 12: 363-369.

9.Griffiths TL, Burr ML, Campbell IA, et al. Results at 1 year of outpatient multidisciplinary pulmonary rehabilitation: a randomized clinical trial. Lancet 2000; 355: 362-368.

10. Finnerty JP, Keeping I, Bullough I, Jones J. The effectiveness of outpatient pulmonary rehabilitation in chronic lung disease. A randomized controlled trial. Chest 2001; 119: 17051710.

11. Troosters T, Gosselink R, Decramer M. Short- and long-term effects of outpatient rehabilitation in patients with chronic obstructive pulmonary disease: a randomized trial. Am $J$ Med 2000; 109: 207-212. 
12. Pauwels RA, Buist AS, Calverley PM, Jenkins CR, Hurd SS. Global strategy for the diagnosis, management, and prevention of chronic obstructive pulmonary disease. NHLBI/WHO Global Initiative for Chronic Obstructive Lung Disease (GOLD) Workshop summary. Am J Respir Crit Care Med 2001; 163: 1256-1276.

13. O'Donnell DE, McGuire M, Samis L, Webb KA. The impact of exercise reconditioning on breathlessness in severe chronic airflow limitation. Am J Respir Crit Care Med 1995; 152: 2005-2013.

14. Lacasse $\mathrm{Y}$, Wong E, Guyatt GH, et al. Meta-analysis of respiratory rehabilitation in chronic obstructive pulmonary disease. Lancet 1996; 348: 1115-1119.

15. Swerts PM, Kretzers LM, Terpstra Lindeman E, Verstappen FT, Wouters EF. Exercise reconditioning in the rehabilitation of patients with chronic obstructive pulmonary disease: a short- and long-term analysis. Arch Phys Med Rehabil 1990; 71: 570-573.

16. Cambach W, Chadwick-Straver RVM, Wagenaar RC, et al. The effects of a communitybased pulmonary rehabilitation programme on exercise tolerance and quality of life: a randomized controlled trial. Eur Respir J 1997; 10: 104-113.

17. Boueri FMV, Bucher-Bartelson BL, Glenn KA, Make BJ. Quality of life measured with a generic instrument (Short Form-36) improves following pulmonary rehabilitation in patients with COPD. Chest 2001; 119: 77-84.

18. Jones PW. Interpreting thresholds for a clinically significant change in health status in asthma and COPD. Eur Respir J 2002; 19: 398-404.

19. Griffiths TL, Phillips CJ, Davies S, Burr ML, Campbell IA. Cost effectiveness of an outpatient multidisciplinary pulmonary rehabilitation programme. Thorax 2001; 56: 779-784.

20. Schols AM, Slangen J, Volovics L, Wouters EF. Weight loss is a reversible factor in the prognosis of chronic obstructive pulmonary disease. Am J Respir Crit Care Med 1998; 157: 1791-1797.

21. ZuWallack RL, Patel K, Reardon JZ, Clark BA, Normandin EA. Predictors of improvement in the 12-minute walking distance following a six-week outpatient pulmonary rehabilitation program. Chest 1991; 99: 805-808.

22. Casaburi R, Patessio A, Ioli F, Zanaboni S, Donner CF, Wasserman K. Reductions in exercise lactic acidosis and ventilation as a result of exercise training in patients with chronic obstructive lung disease. Am Rev Respir Dis 1991; 143: 9-18. 
23. Maltais $\mathrm{F}$, LeBlanc $\mathrm{P}$, Jobin $\mathrm{J}$, et al. Intensity of training and physiologic adaptation in patient with chronic obstructive pulmonary disease. Am J Respir Crit Care Med 1997; 155: $555-561$.

24. Normandin E, McCusker C, Connors ML, Vale F, Gerardi D, ZuWallack R. An evaluation of two approaches to exercise conditioning in pulmonary rehabilitation. Chest 2002; 121 : 1085-1091.

25. Coppoolse R, Schols AMWJ, Baarends EM, et al. Interval versus continuous training in patients with severe COPD: a randomized clinical trial. Eur Respir J 1999; 14: 258-263.

26. Vogiatzis I, Nanas S, Roussos C. Interval training as an alternative modality to continuous exercise in patients with COPD. Eur Respir J 2002; 20: 12-19.

27. Bernard S, Whittom F, LeBlanc $\mathrm{P}$, et al. Aerobic and strength training in patients with chronic obstructive pulmonary disease. Am J Respir Crit Care Med 1999; 159: 896-901.

28. Simpson K, Killian K, McCartney N, et al. Randomised controlled trial of weightlifting exercise in patients with chronic airflow obstruction. Thorax 1992; 47: 70-75.

29. Ortega F, Toral J, Cejudo P, et al. Comparison of the effects of strength and endurance training in patients with chronic obstructive pulmonary disease. Am J Respir Crit Care Med 2002; 166: 669-674.

30. Lotters F, van Tol B, Kwakkel G, Gosselink R. Effects of controlled inspiratory muscle training in patients with COPD: a meta-analysis. Eur Respir J 2002; 20: 570-576.

31. Ries AL, Moser KM, Bullock PJ, et al., eds. Shortness of breath: a guide to better living and breathing. St. Louis, Mosby, 1996.

32. Ries AL. Pulmonary rehabilitation. In: Tierney DF, ed. Current pulmonology. St. Louis, Mosby, 1994; pp. 441-467.

33. Gilmartin ME. Patient and family education. Clin Chest Med 1986; 7: 619-627.

34. Neish CM, Hopp JW. The role of education in pulmonary rehabilitation. J Cardiopulm Rehabil 1988; 11: 439-441.

35. Von Korff M, Gruman J, Schaefer J, Curry SJ, Wagner EH. Collaborative management of chronic illness. Ann Intern Med 1997; 127: 1097-1102.

36. Renfroe KL. Effect of progressive relaxation on dyspnea and state anxiety in patients with chronic obstructive pulmonary disease. Heart Lung 1988; 17: 408-413. 
37. Brooks D, Krip B, Mangovski-Alzamora S, Goldstein RS. The effect of postrehabilitation programmes among individuals with chronic obstructive pulmonary disease. Eur Respir $J$ 2002; 20: 20-29. 


\section{Management of stable COPD: nutrition}

\subsection{Key points}

- Weight loss as well as a depletion of fat-free mass (FFM) may be observed in stable chronic obstructive pulmonary disease (COPD) patients, irrespective of the degree of airflow limitation.

- Weight loss and being underweight is associated with an increased mortality risk.

- Weight loss and particularly muscle wasting contribute significantly to morbidity, disability and handicap in COPD patients.

- Muscle wasting may also be present in patients with a stable weight.

- Weight loss and loss of fat mass are primarily the result of a negative balance between dietary intake and energy expenditure, while muscle wasting is a consequence of an impaired balance between protein synthesis and protein breakdown.

- In advanced stages of COPD both energy balance and protein balance are disturbed. Therefore, nutritional therapy may only be effective if combined with exercise or other anabolic stimuli. Nutritional intervention per se should focus more on prevention and early treatment of weight loss to preserve energy balance

\subsection{Prevalence of nutritional abnormalities}

In clinically stable patients with moderate-to-severe COPD, depletion of FFM has been reported in $20 \%$ of COPD outpatients [1] and in 35\% of those eligible for pulmonary rehabilitation [2]. Limited data are available regarding the prevalence of nutritional depletion in mild COPD. There is no clear relationship between measures of nutritional status and airflow obstruction. Weight loss and being underweight are associated with decreased diffusing capacity and are observed more frequently in emphysematous patients than those with chronic bronchitis [1,3]. Although weight loss is generally accompanied by a significant loss in FFM, muscle wasting may occur even in weight-stable COPD patients. 


\subsection{Consequences of weight loss and muscle wasting}

Significant loss in FFM is related to impaired skeletal muscle strength and exercise capacity [4, 5]. Weight loss also affects diaphragm muscle mass and depresses diaphragm contractility [6]. The functional consequences of being underweight and particularly of FFM depletion are reflected in decreased health status $[7,8]$.

A relationship between weight loss, or being underweight, and mortality has been reported in several studies [9-12]. A recent study (including moderate-to-advanced COPD patients) suggested that muscle mass is a better predictor of survival than body weight [13].

\subsection{Pathogenesis of weight loss and muscle wasting}

Weight loss and, particularly, loss of fat mass, occurs if energy expenditure exceeds dietary intake. In contrast to an adaptive decreased energy metabolism during starvation, increased resting energy requirements have been observed in some COPD patients, linked to low-grade systemic inflammation and increased protein turnover [14-16]. Furthermore, elevated activityinduced and daily energy expenditure have been found in ambulatory COPD patients [17]. As a consequence of this elevated energy metabolism, COPD patients who suffer from weight loss, and even some whose weight is stable, may lose weight despite an apparently normal energy intake. In addition, the symptoms of the disease and an enhanced systemic inflammatory response may affect appetite and dietary intake.

Increased muscle protein breakdown is a key feature in muscle wasting. This process of cachexia can be considered the result of an interplay of systemic factors, including systemic inflammation, oxidative stress and growth factors, that may synergise with local factors leading to protein imbalance [18].

\subsection{Assessment of body composition}

Nutritional screening is recommended in the assessment of COPD. 
Simple screening can be based on measurement of body mass index (BMI) and weight change. BMI is defined as weight in $\mathrm{kg} / \mathrm{height}$ in $\mathrm{m}^{2}$.

Based on BMI, patients are divided into underweight (BMI $<21 \mathrm{~kg} \cdot \mathrm{m}^{-2}$, age $>50 \mathrm{yrs}$ ), normal weight (BMI 21-25 kg $\mathrm{m}^{-2}$ ), overweight $\left(25<\mathrm{BMI}<30 \mathrm{~kg} \cdot \mathrm{m}^{-2}\right.$ ) and obese patients (BMI $\geq 30$ $\left.\mathrm{kg} \cdot \mathrm{m}^{-2}\right)$.

Criteria to define weight loss are: weight loss $>10 \%$ in the past 6 months or $>5 \%$ in the past month.

Functional consequences of weight loss in COPD relate to a decrease in muscle mass. Muscle mass can be measured indirectly in clinically stable COPD by assessment of FFM [19], by anthropometrics, bioelectrical impedance or dual energy X-ray absorptiometry [20]. Bioelectrical impedance analysis is at present a quick, easy and reliable screening technique [21].

Indices of relative FFM as the FFMI can be used (FFM in $\mathrm{kg}^{-h e i g h t}{ }^{-2}$ ) for targeted intervention. Depletion of FFM is defined as FFMI <15 (females) 16 (males) $\mathrm{kg}^{\cdot} \cdot \mathrm{m}^{-2}$ [19].

\subsection{Indications and outcomes of nutritional interventions}

Based on the adverse effects of weight loss on exercise tolerance, health status and mortality, efforts to prevent weight loss are warranted in the routine management of patients with COPD. Nutritional intervention should be considered in case of one or more of the following conditions:

- $\mathrm{BMI}<21 \mathrm{~kg} \cdot \mathrm{m}^{-2}$

- involuntary weight loss: (>10\% during last 6 months or $>5 \%$ in the past month)

- depletion in FFM ( FFMI $<16 \mathrm{~kg} \cdot \mathrm{m}^{-2}$ males, $<15 \mathrm{~kg} \cdot \mathrm{m}^{-2}$ females)

Nutritional supplementation should initially consist of adaptations in the patients' dietary habits and should be extended to administration of energy-dense supplements in quantities well divided during the day to avoid loss of appetite, and adverse metabolic and ventilatory efforts 
resulting from a high caloric load. Liquid carbohydrate-rich supplements are more tolerated than an equicaloric fat-rich supplement [22]. The available studies on therapeutic dietary supplementation were reviewed in a meta-analysis, which concluded that the beneficial effects of nutritional therapy are limited [23] and that increasing energy intake among severe COPD patients is difficult to accomplish.

Besides noncompliance or suboptimal incorporation of nutritional supplements in daily dietary and activity pattern, nonresponse to nutritional therapy is also related to a variety of biological characteristics including systemic inflammation [24]. In advanced stages of COPD, combining nutritional support with an anabolic stimulus, such as exercise, to optimise function should be advocated $[25,26]$. In one study, weight gain under these circumstances was related to decreased mortality independently of forced expiratory volume in one second, resting arterial blood gases, smoking behaviour, age and sex [11].

In future, nutritional interventions should be extended to prevention and early treatment of weight loss in COPD patients. 


\subsection{References}

1. Engelen MPKJ, Schols AMWJ, Baken WC, Wesseling GJ, Wouters EF. Nutritional depletion in relation to respiratory and peripheral skeletal muscle function in outpatients with COPD. Eur Respir J 1994; 7: 1793-1797.

2. Schols AMWJ, Soeters PB, Dingemans AMC, Mostert R, Frantzen PJ, Wouters EF. Prevalence and characteristics of nutritional depletion in patients with stable COPD eligible for pulmonary rehabilitation. Am Rev Respir Dis 1993; 147: 1151-1156.

3. Engelen MPKJ, Schols AMWJ, Lamers R, Wouters EF. Different patterns of chronic tissue wasting among emphysema and chronic bronchitis patients. Clin Nutr 1999; 18: 275-280.

4. Baarends EM, Schols AMWJ, Mostert R, Wouters EF. Peak exercise response in relation to tissue depletion in patients with chronic obstructive pulmonary disease. Eur Respir J 1997; 10: 2807-2813.

5. Palange P, Forte S, Felli A, Galassetti P, Serra P, Carlone S. Nutritional state and exercise tolerance in patients with COPD. Chest 1995; 107: 1206-1212.

6. Thurlbeck W. Diaphragm and body weight in emphysema. Thorax 1978; 33: 483-487.

7. Shoup R, Dalsky G, Warner S, et al. Body composition and health-related quality of life in patients with obstructive airways disease. Eur Respir J 1997; 10: 1576-1580.

8. Mostert RM, Goris A, Weling-Scheepers C, Wouters EF, Schols AM. Tissue depletion and health related quality of life in patients with chronic obstructive pulmonary disease. Respir Med 2000; 94: 859-867.

9. Wilson DO, Rogers RM, Wright EC, Anthonisen NR. Body weight in chronic obstructive pulmonary disease. The National Institutes of Health Intermittent Positive-Pressure Breathing Trial. Am Rev Respir Dis 1989; 139: 1435-1438.

10. Gray Donald K, Gibbons L, Shapiro SH, Macklem PT, Martin JG. Nutritional status and mortality in chronic obstructive pulmonary disease. Am J Respir Crit Care Med 1996; 153: 961-966.

11. Schols AM, Slangen J, Volovics L, Wouters EF. Weight loss is a reversible factor in the prognosis of chronic obstructive pulmonary disease. Am J Respir Crit Care Med 1998; 157: 1791-1797.

12. Landbo C, Prescott E, Lange P, Vestbo J, Almdal TP. Prognostic value of nutritional status in chronic obstructive pulmonary disease. Am J Respir Crit Care Med 1999; 160: 1856-1861. 
13. Marquis K, Debigaré R, Lacasse $\mathrm{Y}$, et al. Midthigh muscle cross-sectional area is a better predictor of mortality than body mass index in patients with chronic obstructive pulmonary disease. Am J Respir Crit Care Med 2002; 166: 809-813.

14. Creutzberg EC, Schols AMWJ, Bothmer-Quaedvlieg FCM, Wouters EF. Prevalence of an elevated resting energy expenditure in patients with chronic obstructive pulmonary disease in relation to body composition and lung function. Eur J Clin Nutr 1998; 52: 396-401.

15. Schols AM, Buurman WA, Staal van den Brekel AJ, Dentener MA, Wouters EF. Evidence for a relation between metabolic derangements and increased levels of inflammatory mediators in a subgroup of patients with chronic obstructive pulmonary disease. Thorax 1996; 51: 819824.

16. Engelen MPKJ, Deutz NEP, Wouters EFM, Schols AMWJ. Enhanced levels of whole body protein turnover in patients with chronic obstructive pulmonary disease. Am J Respir Crit Care Med 2000; 162: 1488-1492.

17. Baarends EM, Schols AM, Pannemans DL, Westerterp KR, Wouters EF. Total free living energy expenditure in patients with severe chronic obstructive pulmonary disease. Am J Respir Crit Care Med 1997; 155: 549-554.

18. Debigaré R, Maltais F. Peripheral muscle wasting in chronic obstructive pulmonary disease. Clinical relevance and mechanisms. Am J Respir Crit Care Med 2001; 164: 17121717.

19. Schols AMWJ, Fredrix EW, Soeters PB, Westerterp KR, Wouters EFM. Resting energy expenditure in patients with chronic obstructive pulmonary disease. Am J Clin Nutr 1991; 5: 983-987.

20. Engelen MPKJ, Schols AMWJ, Heidendal GAK, Wouters EFM. Dual-energy X-ray absorptiometry in the clinical evaluation of body composition and bone mineral density in patients with chronic obstructive pulmonary disease. Am J Clin Nutr 1998; 68: 1298-1303.

21. Steiner MC, Barton RL, Singh SJ, Morgan MDL. Bedside methods versus dual energy Xray absorptiometry for body composition measurement in COPD. Eur Respir J 2002; 19: 626631.

22. Vermeeren MA, Wouters EF, Nelissen LH, van Lier A, Hofman Z, Schols AM. Acute effects of different nutritional supplements on symptoms and functional capacity in patients with chronic obstructive pulmonary disease. Am J Clin Nutr 2001; 73: 295-301. 
23. Ferreira IM, Brooks D, Lacasse Y, Goldstein RS. Nutritional support for individuals with COPD: a meta-analysis. Chest 2000; 117: 672-678.

24. Creutzberg EC, Schols AM, Weling Scheepers CA, Buurman WA, Wouters EF. Characterization of nonresponse to high caloric oral nutritional therapy in depleted patients with chronic obstructive pulmonary disease. Am J Respir Crit Care Med 2000; 161: 745-752. 25. Schols AM, Soeters PB, Mostert R, Pluymers RJ, Wouters EF. Physiologic effects of nutritional support and anabolic steroids in patients with chronic obstructive pulmonary disease. A placebo-controlled randomized trial. Am J Respir Crit Care Med 1995; 152: 12681274.

26. Creutzberg EC, Wouters EFM, Mostert R, Weling-Scheepers APM, Schols AMWJ. Efficacy of nutritional supplementation therapy in depleted patients with chronic obstructive pulmonary disease. Nutrition 2003; 19: 120-127. 


\section{Management of stable COPD: surgery in / for COPD}

\subsection{Key points}

\section{Surgery in COPD}

- Patients with a diagnosis of chronic obstructive pulmonary disease (COPD) have a 2.74.7-fold increased risk of postoperative pulmonary complications.

- COPD is not an absolute contraindication to any surgery.

- The further the procedure from the diaphragm the lower the pulmonary complication rate.

- Preoperative pulmonary function studies have a well-documented role in the evaluation of patients undergoing lung surgery.

- Smoking cessation at least 4-8 weeks preoperatively and optimisation of lung function can decrease postoperative complications.

- Early mobilisation, deep breathing, intermittent positive-pressure breathing, incentive spirometry and effective analgesia may decrease postoperative complications.

\section{Surgery for COPD}

- Bullectomy and lung volume reduction surgery may result in improved spirometry, lung volume, exercise capacity, dyspnoea, health-related quality of life and possibly survival in highly selected patients.

- Lung transplantation results in improved pulmonary function, exercise capacity, quality of life and possibly survival in highly selected patients.

\subsection{Background}

Patients with a diagnosis of COPD have a 2.7-4.7-fold increased risk of postoperative pulmonary complications $[1,2]$. Preoperatively, patients at risk for COPD should undergo screening (see Definition, diagnosis and staging). The preoperative evaluation must identify the goal of surgery and determine whether the risk/benefit ratio makes attainment of the goal worthwhile [3]. However, there are no absolute contraindications to surgery. 
The risks of surgery depend upon the indications for the surgery, the surgical procedure, the type of anaesthesia and the degree of respiratory impairment [2,3]. Patient-related risk factors are identified by history, physical examination, chest radiography, and a battery of pulmonary and cardiovascular screening tests. Careful attention to the perioperative respiratory management of patients with COPD can improve both outcomes and resource utilisation [4-6]. The healthcare provider is thus challenged to assess risk, project benefit and provide perioperative management.

\subsection{Assessment of general operative risk}

\subsubsection{Personnel involved}

In a patient with COPD, an individual with expertise in the disease should guide the perioperative management.

In patients with more severe disease, a multidisciplinary team should be involved. Optimally the team would include a pulmonologist, the patient's primary care physician, an anaesthesiologist, a respiratory therapist and a respiratory nurse specialist.

As many patients with COPD may have other illnesses, including those associated with tobacco abuse, input from cardiologists, vascular surgeons and otorhinolaryngologists is often helpful.

\subsubsection{Methodologies of assessment}

Essential components of the preoperative assessment are a careful history, physical examination and assessment of the functional capacity. Close attention should be paid to a history of smoking, dyspnoea, cough and sputum production. Functional capacity can be assessed by the ASA questionnaire [1,2] (table 1). 
Table 1. - American Society of Anesthesiology physical status scale

\begin{tabular}{ll}
\hline Class & Physical status \\
\hline I & Normal healthy $<80$ yrs \\
II & Mild systemic disease or healthy person $\geq 80$ yrs \\
III & Severe but not incapacitating systemic disease \\
IV & Incapacitating systemic disease that is a constant threat to life \\
V & Moribund patient not expected to survive 24 h despite surgery \\
E & Suffix to any class indicating emergency surgery \\
\hline
\end{tabular}

The perioperative risk of venous thromboembolism and potential prophylactic strategies should be assessed for all patients [7].

In patients with a known diagnosis of COPD, or those at increased risk for COPD, preoperative spirometry should be performed. Identification of severe airflow obstruction may be particularly important in patients who are candidates for upper abdominal or thoracic surgical procedures [8].

Analysis of arterial blood gas (ABG) composition should be available for patients with moderate-to-severe COPD. For patients who may require ventilatory assistance, knowledge of preoperative blood gases may be helpful in determining appropriate postoperative ventilator settings. Although ABG values should not be used as a sole determinant of general surgical candidacy, they may influence decision making for high-risk procedures (see Surgery for COPD).

Since patients with COPD are at increased risk of pulmonary neoplasm and other pathologies, a preoperative chest radiography, if not recently performed, is reasonable. This recommendation is in keeping with the recommendations for the general assessment of COPD. 


\subsection{Surgery in the COPD patient}

In patients with COPD and reduced airflow, complication rates vary with the region of the body upon which surgery is performed. The further the procedure from the diaphragm; the lower the risk $[1,2,9]$.

\subsubsection{Ophthalmologic procedures}

In general, these procedures carry a low mortality rate $(<1 \%)$ [10]. However, cough may be of concern to the ophthalmologist because of increased ocular pressure. Conversely, excessive suppression of cough may lead to retained secretions, atelectasis, pneumonitis and problems in gas exchange. Topical, ophthalmologic, $\beta$-blocker medications, used to reduce intraocular pressure, may precipitate bronchospasm and cardiorespiratory failure [11].

\subsubsection{Head/neck procedures}

Procedures involving the airway carry an increased risk of postoperative pneumonia [1]. Management of secretions in the patient who has undergone laryngectomy may require early postoperative humidification.

\subsubsection{Orthopaedic procedures}

Orthopedic procedures are associated with a relatively high frequency of venous thromboembolism [12]. In the patient with COPD, pulmonary embolism is associated with greater mortality [13].

\subsubsection{Lower abdominal/pelvic surgery}

In general, COPD does not increase the risk of perioperative risk with lower abdominal procedures.

\subsubsection{Upper abdominal surgery}

Patients who undergo surgery in the upper abdomen are at risk for perioperative pulmonary complications [1,9]. COPD independently increases this risk [1]. Complications are particularly liable to occur in persons with predisposing factors such as morbid obesity, cigarette smoking, heart disease and advanced age [1,3]. 
Laparoscopic procedures appear to decrease perioperative pulmonary complications [14].

\subsubsection{Cardiovascular surgery}

COPD is a common cause of perioperative pulmonary dysfunction in patients undergoing cardiac surgery [15]. Screening for COPD in this patient population is particularly important because COPD has been associated with prolonged intubation after cardiac surgery [16].

\subsubsection{Abdominal vascular surgery}

Patients who undergo elective major abdominal vascular surgery are at high risk of postoperative pulmonary complications [1]. Patients with COPD are at particularly high risk [1]. Factors associated with the need for prolonged mechanical ventilation include a history of heavy cigarette smoking, preoperative arterial hypoxaemia and major intraoperative blood loss [17].

\subsubsection{Lung surgery}

Preoperative pulmonary function studies have a well-documented role in the evaluation of patients who are to undergo lung surgery $[18,19]$.

\section{Procedure-related issues}

Thoracotomy has a reversible (several months) adverse effect on lung function [20]. Thoracoscopy is less invasive and better tolerated than open thoracotomy [21].

\section{Lung resection}

Lobectomy results in an additional $\leq 10 \%$ reduction in forced vital capacity (FVC) at 6 months after surgery [22].

Pneumonectomy usually causes a permanent reduction of about $30 \%$ in all lung function. This decrement in lung function can prove devastating to COPD patients [23]. 
In select cases, wedge resection, lobectomy or pneumonectomy may actually improve lung function if the resected areas of lung are significantly destroyed by emphysema and the nonresected areas are significantly spared from emphysema (see Lung volume reduction surgery).

\title{
Physiological evaluation
}

If the region resected has no function, then no loss other than that temporary decrement attributable to the thoracotomy should result. This approach forms the basis of the regional physiological assessment of lung function via ventilation or perfusion scintigraphy [20].

\begin{abstract}
All patients undergoing lung resection should undergo spirometry and determination of diffusing capacity of the lungs [24]. The risk of postoperative respiratory insufficiency or death is greater in patients undergoing a pneumonectomy with a preoperative forced expiratory volume in one second (FEV1) $<2 \mathrm{~L}$ or $50 \%$ of predicted, a maximal voluntary ventilation $<50 \%$ predicted or carbon monoxide diffusing capacity of the lung $<60 \%$ predicted [24].
\end{abstract}

Patients at high risk for poor outcomes due to poor underlying lung function should undergo further physiological evaluation [25]. The two general areas of evaluation are: 1) regional distribution of lung function; and 2) functional capacity of the patient. An algorithm has been proposed that incorporates these concepts (fig. 1). Although this algorithm has been prospectively validated $[23,24,26]$, several issues remain controversial. A second, simpler algorithm has also been proposed, but not validated (fig. 2). 


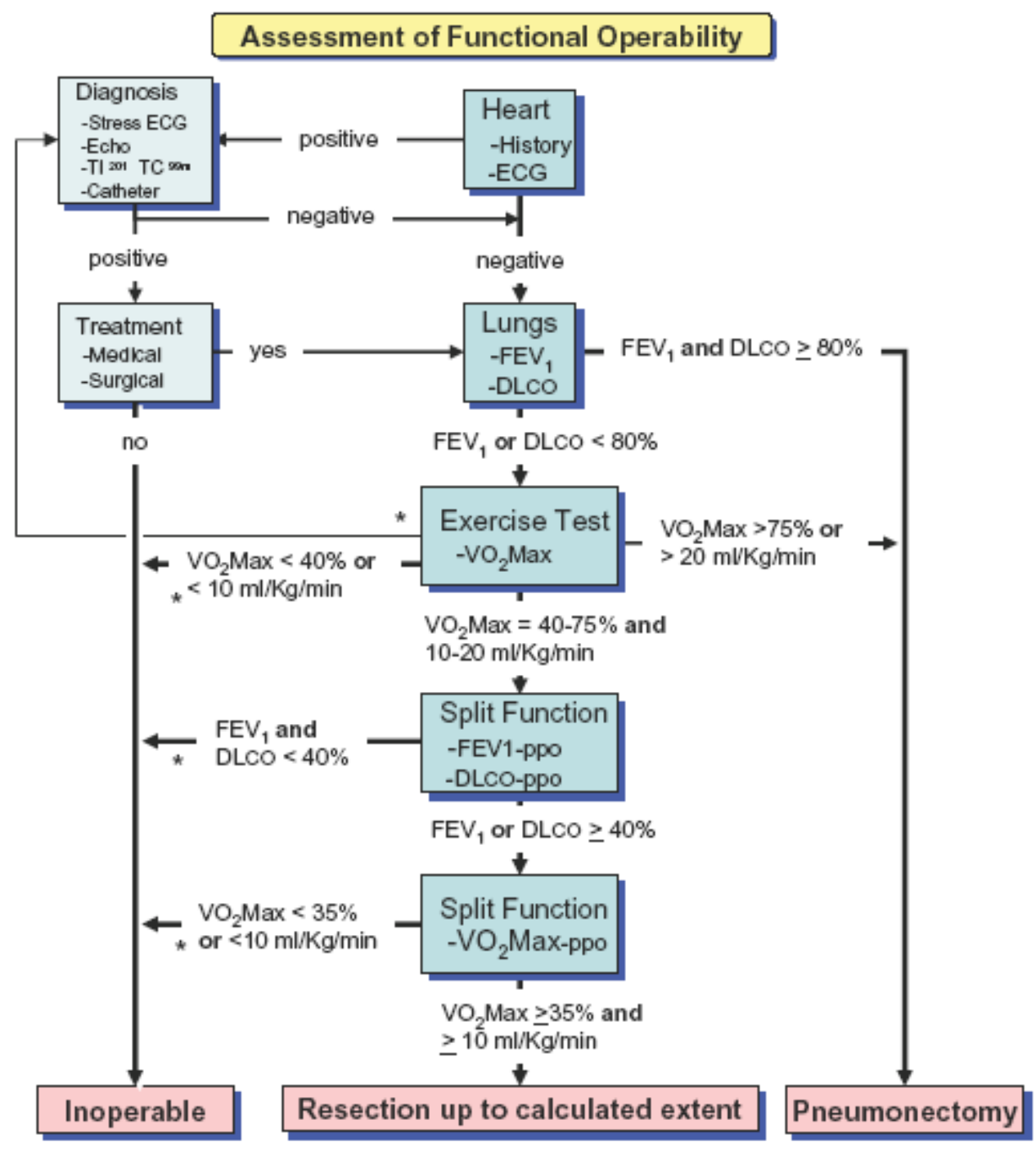

Fig. 1. - A validated algorithm for pre-operative testing for lung resection. ECG:

electrocardiogram; FEV1: forced expiratory volume in one second; DL,CO: carbon dioxide diffusing capacity of the lung; V'O2, max: maximum oxygen consumption; ppo: predicted postoperative. 


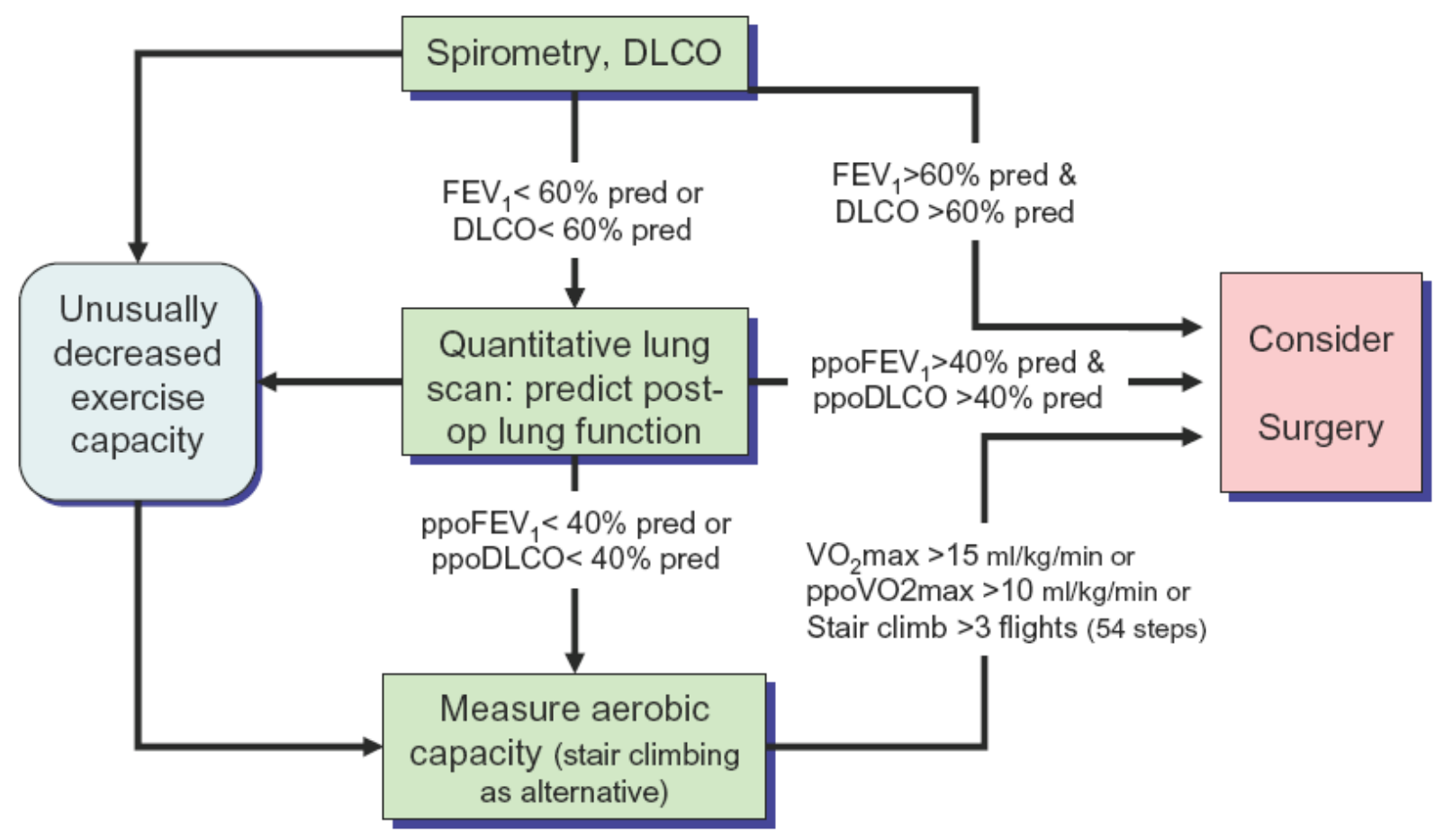

Fig. 2. - A simplified algorithm for pre-operative testing for lung resection. DL,CO: carbon dioxide diffusing capacity of the lung; FEV1: forced expiratory volume in one second; ppo: predicted postoperative; V'O2,max: maximum oxygen consumption.

Lung volume reduction surgery (LVRS) has altered the preoperative assessment for thoracic resection in some of these patients (see Lung volume reduction surgery). Patients with severe pulmonary dysfunction may undergo simultaneous resection of a pulmonary nodule and LVRS $[19,27]$. Some patients have successfully had lobectomy in the setting of severe obstructive lung disease $[28,29]$.

If the patient has cardiovascular risk factors an appropriate cardiovascular evaluation should be undertaken $[30,31]$.

\subsection{Surgery for COPD}

During the past few decades multiple surgical interventions have been suggested to improve symptoms in patients with COPD [32]. These include bullectomy, lung volume reduction surgery and lung transplantation (see Patient section). 


\subsubsection{Bullectomy}

\subsubsection{Outcomes}

Bullectomy appears to be of benefit in highly selected patients [33], resulting in short-term improvements in airflow obstruction, lung volumes, hypoxaemia and hypercapnia, exercise capacity, dyspnoea, and health-related quality of life.

Surgical mortality ranges from $0-22.5 \%$ [33].

Long-term follow-up data are more limited with $1 / 3-1 / 2$ of patients maintaining benefits for $\sim 5$ yrs [33].

\subsubsection{Patient selection}

Based on the presumption that improvement is dependent on relief of compressed normal lung, most investigators have attempted to identify optimal surgical candidates on the basis of pulmonary function and radiographic features, as enumerated in table 2 [34]. 
Table 2. - Factors associated with favourable or unfavourable outcome in classical bullectomy

\begin{tabular}{|c|c|c|}
\hline Parameter & Favourable & Unfavourable \\
\hline Clinical & $\begin{array}{l}\text { Rapid progressive dyspnoea despite maximal medical } \\
\text { therapy } \\
\text { Exsmoker }\end{array}$ & $\begin{array}{l}\text { Older age } \\
\text { Comorbid illness } \\
\text { Cardiac disease } \\
\text { Pulmonary hypertension } \\
>10 \% \text { weight loss } \\
\text { Frequent respiratory infections } \\
\text { Chronic bronchitis. }\end{array}$ \\
\hline Physiological & $\begin{array}{l}\text { Normal FVC or slightly reduced } \\
\text { FEV1 }>40 \% \text { pred } \\
\text { Little bronchoreversibility } \\
\text { High trapped lung volume } \\
\text { Normal or near normal } \mathrm{DL}, \mathrm{CO} \\
\text { Normal } \mathrm{Pa}, \mathrm{O}_{2} \text { and } \mathrm{Pa}, \mathrm{CO}_{2}\end{array}$ & $\begin{array}{l}\text { FEV } 1<35 \% \text { pred } \\
\text { Low trapped gas volume } \\
\text { Decreased } D \mathrm{~L}, \mathrm{CO}\end{array}$ \\
\hline Imaging & & \\
\hline CXR & Bulla $>1 / 3$ hemithorax & $\begin{array}{l}\text { Vanishing lung syndrome } \\
\text { Poorly defined bullae }\end{array}$ \\
\hline $\mathrm{CT}$ & $\begin{array}{l}\text { Large and localised bulla with vascular crowding and } \\
\text { normal pulmonary parenchyma around bulla }\end{array}$ & Multiple ill-defined bullae in underlying lung \\
\hline Angiography & Vascular crowding with preserved distal vascular branching & $\begin{array}{l}\text { Vague bullae; disrupted vasculature } \\
\text { elsewhere }\end{array}$ \\
\hline Isotope scan & $\begin{array}{l}\text { Well-localised matching defect with normal uptake and } \\
\text { washout for underlying lung }\end{array}$ & $\begin{array}{l}\text { Absence of target zones, poor washout in } \\
\text { remaining of lung }\end{array}$ \\
\hline
\end{tabular}

CXR: chest radiography; CT: computed tomography; FVC: forced vital capacity; FEV1: forced expiratory volume in one second;

$D \mathrm{~L}, \mathrm{CO}$ : carbon monoxide diffusing capacity of the lung; $\mathrm{Pa}, \mathrm{O}_{2}$; arterial oxygen tension; $\mathrm{Pa}, \mathrm{CO}_{2}$; arterial carbon dioxide tension.

Modified from [34]. 


\subsubsection{Lung volume reduction surgery}

\subsubsection{Outcomes}

LVRS results in short-term improvements in spirometry, lung volumes, exercise tolerance, dyspnoea and health-related quality of life, and potentially long-term improvement in survival [35].

LVRS using resection of lung tissue has significantly better results than laser treatment of the lung [36].

Bilateral LVRS shows greater improvements compared to unilateral LVRS among similar patients [37].

\subsubsection{Patient selection}

Selection criteria for LVRS remain controversial [27].

A systematic review proposed the following features, as determined by expert opinion, to be associated with better outcomes: smoking-related emphysema, heterogeneous emphysema with surgically accessible "target" areas, bilateral surgery, good general fitness/condition and thoracic hyperinflation [38]. The National Emphysema Treatment Trial (NETT) suggests that upper lobe predominance of emphysema on high resolution computed tomography of the chest and low post rehabilitation exercise capacity measured while breathing $30 \%$ inspiratory oxygen fraction on a cycle ergometry are predictive of the best chance of post-surgical improvement [35].

Table 3 enumerates potential criteria to identify patients more likely to experience benefit after LVRS. Figure 3 proposes an algorithm delineating expected improvements of bilateral LVRS compared to medical therapy based on the NETT Research Group experience [35]. Potential outcomes of such a selection algorithm are enumerated in table 4. 
Table 3. - Factors associated with favourable or unfavourable outcome in lung volume reduction surgery

\begin{tabular}{|c|c|c|}
\hline Parameter & Favourable & Unfavourable \\
\hline Clinical & $\begin{array}{l}\text { Age }<75 \text { yrs } \\
\text { Clinical picture consistent with emphysema } \\
\text { Not actively smoking }\left(>3-6 \text { months) }{ }^{\#}\right. \\
\text { Severe dyspnea despite maximal medical } \\
\text { treatment including pulmonary rehabilitation }{ }^{\#} \\
\text { Requiring }<20 \mathrm{mg} \text { prednisone } \cdot \text { day }^{-1}\end{array}$ & $\begin{array}{l}\text { Age }>75-80 \text { yrs. } \\
\text { Comorbid illness which would increase surgical mortality } \\
\text { Clinically significant coronary artery disease } \\
\text { Pulmonary hypertension (PA systolic }>45, \text { PA mean }>35 \\
\text { mmHg) } \\
\text { Severe obesity or cachexia } \\
\text { Surgical constraints } \\
\text { Previous thoracic procedure } \\
\text { Pleurodesis }{ }^{\#} \\
\text { Chest wall deformity }^{\#}\end{array}$ \\
\hline Physiological & $\begin{array}{l}\text { FEV1 after bronchodilator }<45 \% \text { pred } \\
\text { Hyperinflation } \\
\mathrm{RV}>150 \% \\
\mathrm{TLC}>100 \% \text { pred } \\
\mathrm{Pa}, \mathrm{O}_{2}>6 \mathrm{kPa}(45 \mathrm{mmHg}) \\
\mathrm{Pa}_{\mathrm{C}} \mathrm{CO}_{2}<8 \mathrm{kPa}(60 \mathrm{mmHg}) \\
\text { Postrehabilitation 6-min walk }>140 \mathrm{~m} \\
\text { Low post-rehabilitation maximal achieved } \\
\text { cycle ergometry watts }\end{array}$ & $\begin{array}{l}\text { FEV1 }<20 \% \text { pred and } D \mathrm{~L}, \mathrm{CO}<20 \% \text { pred }^{\#} \\
\text { Decreased inspiratory conductance }\end{array}$ \\
\hline Radiographical & $\begin{array}{l}\text { High-resolution computed tomography } \\
\text { confirming severe emphysema, ideally with } \\
\text { upper lobe predominance }\end{array}$ & $\begin{array}{l}\text { Homogeneous emphysema and FEV } 1<20 \% \text { pred }^{\#} \\
\text { Non-upper lobe predominant emphysema and high post- } \\
\text { rehabilitation cycle ergometry maximal achieved wattage }\end{array}$ \\
\hline
\end{tabular}

$P$ A: alveolar pressure; $\mathrm{RV}$ : residual volume; TLC: total lung capacity; $\mathrm{Pa}, \mathrm{O}_{2}$ : arterial oxygen tension; $P \mathrm{a}, \mathrm{CO}_{2}$ : arterial carbon dioxide tension; FEV1: forced expiratory volume in one second; DL,CO: carbon dioxide diffusing capacity of the lung. " : confirmed recommendations using NETT data [35, 39] or expert opinion [40]. Modified from [34]. 


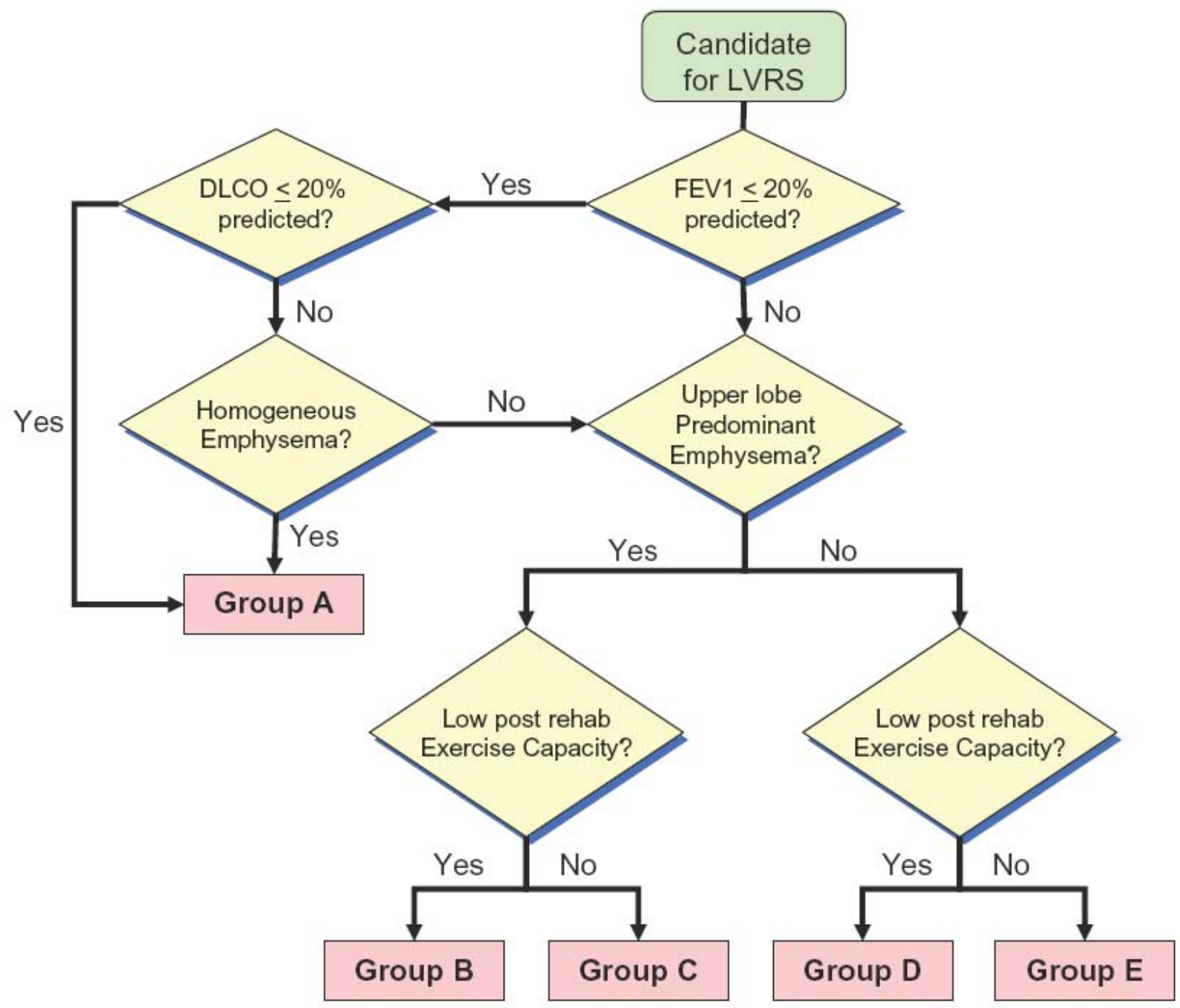

Fig. 3. - Diagnostic algorithm based on the National Emphysema Treatment Trial (NETT) [35, 39]. The groups refer to the outcomes detailed in table 4. LVRS: lung volume reduction surgery; FEV1: forced expiratory volume in one second; DL,CO: carbon dioxide diffusing capacity of the lung. 
Table 4. - Bilateral lung volume reduction surgery vs medical therapy in patients with severe emphysema

\begin{tabular}{|c|c|c|c|c|c|c|c|}
\hline \multirow[t]{3}{*}{ Patients } & \multicolumn{2}{|c|}{ 90-Day mortality } & \multirow[t]{3}{*}{ p-value } & \multicolumn{2}{|c|}{ Total mortality } & \multirow[t]{3}{*}{ Risk ratio $^{\#}$} & \multirow[t]{3}{*}{ p-value } \\
\hline & LVRS & Medical & & LVRS & Medical & & \\
\hline & & Therapy & & & Therapy & & \\
\hline Group A & $48 / 608(7.9)$ & $8 / 610(1.3)$ & $<0.001$ & $42 / 70$ & $30 / 70$ & 1.82 & 0.06 \\
\hline Group B & 4/139 (2.9) & $5 / 151(3.3)$ & 1.00 & $26 / 139$ & $51 / 151$ & 0.47 & 0.005 \\
\hline Group C & $6 / 206(2.9)$ & $2 / 213(0.9)$ & 0.17 & $34 / 206$ & $39 / 213$ & 0.98 & 0.70 \\
\hline Group D & $7 / 84(8.3)$ & $0 / 65(0)$ & 0.02 & $28 / 84$ & $26 / 65$ & 0.81 & 0.49 \\
\hline Group E & $11 / 109(10.1)$ & $1 / 111(0.9)$ & 0.003 & $27 / 109$ & $14 / 111$ & 2.06 & 0.02 \\
\hline
\end{tabular}

\begin{tabular}{|c|c|c|c|c|c|c|c|c|}
\hline \multirow[t]{3}{*}{ Patients } & \multicolumn{4}{|c|}{ Improvement in Exercise Capacity ${ }^{\mathbb{I}}$} & \multicolumn{4}{|c|}{ Improvement in Health-related Quality of Life ${ }^{+}$} \\
\hline & LVRS & Medical & Odds & p-value & LVRS & Medical & Odds & p-value \\
\hline & & Therapy & Ratio & & & therapy & Ratio & \\
\hline Group A & $4 / 58(7)$ & $1 / 48(2)$ & 3.48 & 0.37 & $6 / 58(10)$ & $0 / 48(0)$ & & 0.03 \\
\hline Group B & $25 / 84(30)$ & $0 / 92(0)$ & & $<0.001$ & $40 / 84(48)$ & $9 / 92(10)$ & 8.38 & $<0.001$ \\
\hline Group C & $17 / 115(15)$ & $4 / 138(3)$ & 5.81 & 0.001 & $47 / 115(41)$ & $15 / 138(11)$ & 5.67 & $<0.001$ \\
\hline Group D & $6 / 49(12)$ & $3 / 41(7)$ & 1.77 & 0.50 & $18 / 49(37)$ & $3 / 41(7)$ & 7.35 & 0.001 \\
\hline Group E & $2 / 65(3)$ & $2 / 59(3)$ & 0.90 & 1.00 & $10 / 65(15)$ & $7 / 59(12)$ & 1.35 & 0.61 \\
\hline
\end{tabular}

Data are presented as $\mathrm{n} / \mathrm{n}(\%)$. Groups A-E refer to the patients as defined in fig. 3. "\#: risk ratio for total mortality in surgically versus medically treated patients during a mean follow-up of 29.2 months; ${ }^{\text {Tl: }}$ increase in the maximal workload $>10 \mathrm{~W}$ from the patient's postrehabilitation baseline value ( 24 months after randomisation); ${ }^{+}$: decrease in the score on the $\mathrm{St}$ George's Respiratory Questionnaire >8 points (on a 100-point scale) from the patient's postrehabilitation baseline score (24 months after randomisation). Modified from [35].

\subsubsection{Spirometry}

The mean improvement from baseline in FEV1 ranges from 5-96\%, although 20-50\% of patients show little spirometric improvement after LVRS [27, 35].

\subsubsection{Lung volume}

Lung volume changes include a mean decrease in total lung capacity from baseline varying from $1-23 \%$ and residual volume ranging from $3-46 \%$ [27]. 


\subsubsection{Exercise tolerance}

Improved timed walk distance, ranging a mean of 7-103\% [27], and an increase in maximal work load [35], oxygen uptake and minute ventilation [27] have been reported after LVRS.

\subsubsection{Dyspnoea and health-related quality of life}

Improved dyspnoea and health-related quality of life has been reported after LVRS (table 5). 
Table 5. - Health-related quality of life and survival following bilateral lung volume reduction surgery (LVRS)

\begin{tabular}{|c|c|c|c|c|c|c|c|c|c|}
\hline $\begin{array}{ll}\text { First } & \text { author } \\
\text { [ref.] } & \end{array}$ & Operation & Subjects & $\begin{array}{l}\text { Preop. } \\
\text { rehab. }\end{array}$ & $\begin{array}{l}\text { HRQOL } \\
\text { assessment }\end{array}$ & $\begin{array}{l}\text { Duration of } \\
\text { follow-up }\end{array}$ & Evaluable & Died & Lost & Results \\
\hline \multicolumn{10}{|c|}{ Cohort studies with $\mathrm{n} \geq 50$, consecutive enrollment and full accountability of patients at follow-up } \\
\hline YUSEN [41] & Sternotomy & 200 & Yes & $\begin{array}{l}\text { Patient } \\
\text { satisfaction }\end{array}$ & 6 months & 184 & 12 & 4 & $\begin{array}{l}\text { Good-to-excellent } \\
\text { satisfaction in most } \\
\text { patients }\end{array}$ \\
\hline YUSEN [41] & Sternotomy & 193 & Yes & $\begin{array}{l}\text { Patient } \\
\text { satisfaction }\end{array}$ & $3 \mathrm{yrs}$ & $159^{\mathbb{I}}$ & 25 & 8 & $\begin{array}{l}\text { Good-to-excellent } \\
\text { satisfaction in most } \\
\text { patients }\end{array}$ \\
\hline YUSEN [41] & Sternotomy & 144 & Yes & $\begin{array}{l}\text { Patient } \\
\text { satisfaction }\end{array}$ & $5 \mathrm{yrs}$ & $82^{\S}$ & 41 & 13 & $\begin{array}{l}\text { Good-to-excellent } \\
\text { satisfaction in most } \\
\text { patients }\end{array}$ \\
\hline YUSEN [41] & Sternotomy & 119 & Yes & $\begin{array}{l}\text { MRC } \\
\text { dyspnoea scale }\end{array}$ & 6 months & 109 & 7 & 3 & Decreased dyspnoea \\
\hline YUSEN [41] & Sternotomy & 112 & Yes & $\begin{array}{l}\text { MRC } \\
\text { dyspnoea scale }\end{array}$ & $3 \mathrm{yrs}$ & 92 & 15 & 5 & Decreased dyspnoea \\
\hline YUSEN [41] & Sternotomy & 66 & Yes & $\begin{array}{l}\text { MRC } \\
\text { dyspnoea scale }\end{array}$ & $5 \mathrm{yrs}$ & $35^{\mathbb{\pi}}$ & 23 & 7 & Decreased dyspnoea \\
\hline YUSEN [41] & Sternotomy & 159 & Yes & SF-36 & 6 months & 150 & 6 & 3 & $\begin{array}{l}\text { Improved physical } \\
\text { functioning and } \\
\text { physical component } \\
\text { summary scores }\end{array}$ \\
\hline YUSEN [41] & Sternotomy & 152 & Yes & SF-36 & $3 \mathrm{yrs}$ & $122^{\mathbb{\pi}}$ & 21 & 8 & $\begin{array}{l}\text { Improved physical } \\
\text { functioning and } \\
\text { physical component } \\
\text { summary scores }\end{array}$ \\
\hline YusEn [41] & Sternotomy & 111 & Yes & SF-36 & $5 \mathrm{yrs}$ & 67 & $31^{+}$ & 7 & $\begin{array}{l}\text { Improved physical } \\
\text { functioning and } \\
\text { physical component } \\
\text { summary scores }\end{array}$ \\
\hline COOPER [42] & Sternotomy & 150 & Yes & NHP & 6 months & 108 & 7 & 35 & $\begin{array}{l}\text { Improved physical } \\
\text { mobility, energy, } \\
\text { emotional reaction } \\
\text { and sleep scale scores }\end{array}$ \\
\hline $\begin{array}{l}\text { BRENNER } \\
\text { [43] }\end{array}$ & VATS & 145 & $\begin{array}{l}\text { Not } \\
\text { require }\end{array}$ & $\begin{array}{l}\text { MRC } \\
\text { dyspnoea }\end{array}$ & 3 months & 130 & 6 & 9 & Decreased dyspnoea \\
\hline
\end{tabular}




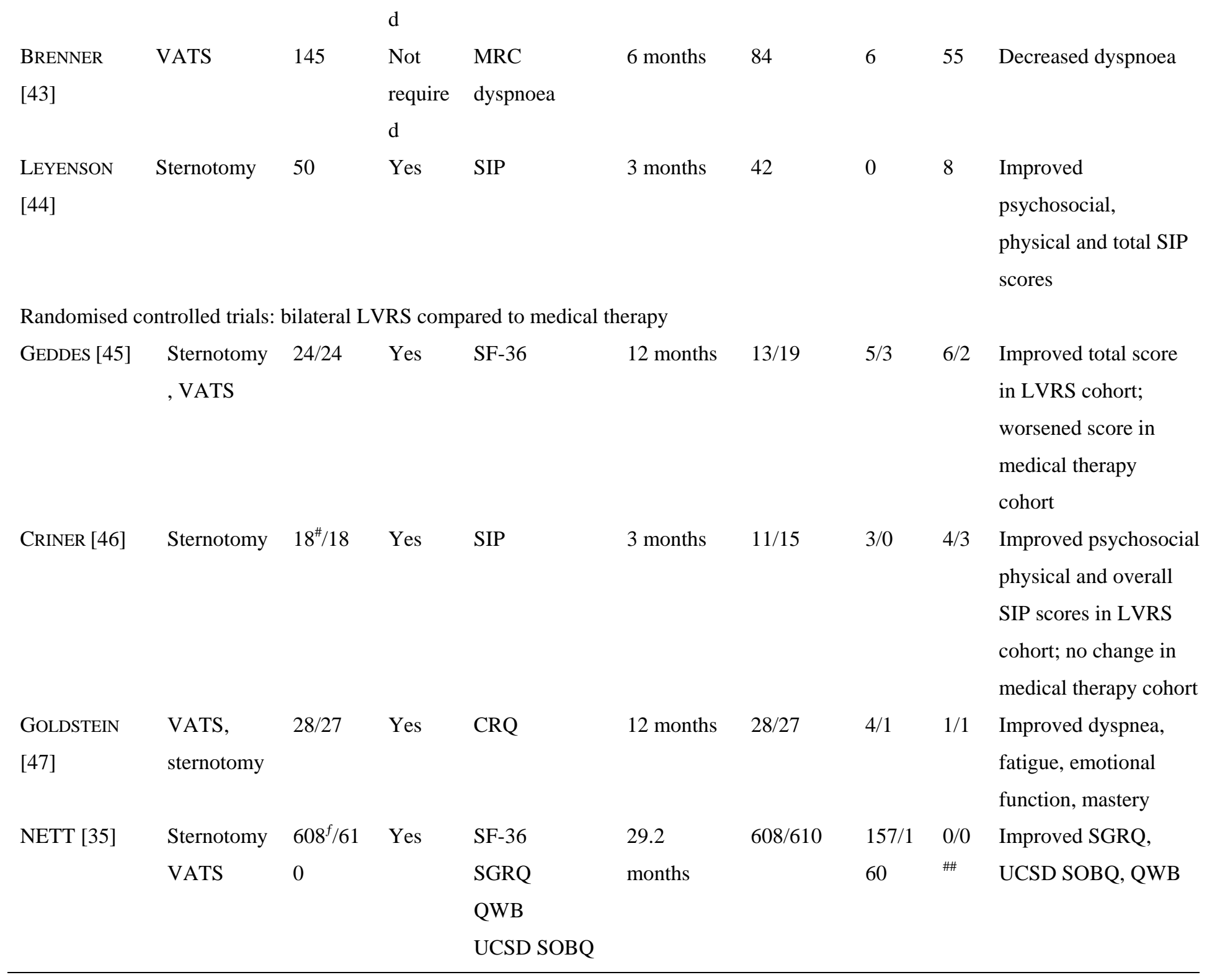

HRQOL: health-related quality of life; VATS: video-assisted thoracoscopic surgery; SF-36: medical outcomes survey shortform 36; NHP: Nottingham health profile; SIP: symptom impact profile; MRC: modified medical research council dyspnoea scale; CRQ: Chronic Respiratory Questionnaire; SGRQ: St. George's Respiratory Questionnaire; QWB: Quality of Well-Being; UCSD SOBQ: University of California, San Diego Shortness of Breath Questionnaire. \#: one of the 19 patients randomised to

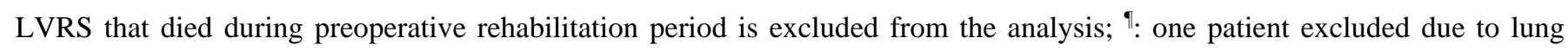
transplantation; ${ }^{+}$: eight patients excluded due to lung transplantation; ${ }^{\S}$ : six patients excluded due to lung transplantation; ${ }^{f}: 406$ median sternotomy/174 VATS, 28 patients refused LVRS; ; : patients missing data had imputed scores. Modified from [48]. 


\subsubsection{Mortality}

Mortality following LVRS varies greatly among centres. The NETT Research Group documented a 90 -day surgical mortality of $7.9 \%$ in all randomised patients, compared to $1.3 \%$ in a comparable medically treated arm [35]; much of this mortality was accounted for by highrisk patients [39] in whom the 90 -day surgical mortality was $28.6 \%$, as compared to $0 \%$ in the respective medical arm [35]. In nonhigh risk patients, the 90-day surgical mortality was 5.2\%, as compared to $1.5 \%$ in the medically treated patients [35].

In the NETT study, baseline patient characteristics were found to predict long-term mortality risks. In patients with upper lobe predominant emphysema on high-resolution computed tomography and a low postrehabilitation, maximal-achieved cycle ergometry work load, there was an improved long-term (mean follow-up 29 months) survival in patients undergoing bilateral LVRS compared to those treated with medical therapy (risk ratio 0.47, $\mathrm{p}=0.005$ ). Early higher mortality in patients treated surgically was compensated for by lower mortality risk in LVRS patients during long-term follow-up [35]. In patients with nonupper lobe predominant emphysema and a higher post-rehabilitation cycle ergometry work load, surgically treated patients experienced a higher mortality than comparable, medically treated patients (risk ratio 2.06, p=0.02) [35] (table 4). The other two sub-groups experienced no mortality difference with LVRS [35] (table 4).

\subsubsection{Long-term results}

Few studies have reported long-term results, but they suggest widely varying long-term morbidity and mortality among centres, return of spirometric function and lung volumes towards preoperative baseline and worsening dyspnoea over time [49]. There appears to be slower loss of 6-min walk distance after LVRS than of other functional measures [40]. 


\subsubsection{Lung transplantation}

Lung transplantation should be considered in selected patients with advanced COPD. COPD is the most common indication for lung transplantation (UNOS on-line data base). The choice of single lung transplantation (SLT) or bilateral lung transplantation (BLT) for COPD remains controversial [50, 51].

\subsubsection{Outcomes}

Lung transplantation results in improved pulmonary function, exercise capacity and quality of life. However, its effect on survival remains controversial.

\subsubsection{Patient selection}

In selecting candidates, several issues must be considered, including the patient's pulmonary disability, projected survival without transplantation, comorbid conditions and patient preferences. To optimise results of transplantation, the procedure must be carefully timed such that transplantation is performed when the patient is neither "too healthy" nor "too ill" [52]. Selection criteria for COPD patients are shown in tables 6 and 7 [52]. 
Table 6. - General selection guidelines for candidate selection for lung transplantation in COPD patients

\begin{tabular}{|c|c|}
\hline \multirow[t]{9}{*}{ Relative contraindications } & Age limits \\
\hline & Heart-lung transplants $\sim 55$ yrs \\
\hline & Double lung transplant $\sim 60$ yrs \\
\hline & Single lung transplant $\sim 65 \mathrm{yrs}$ \\
\hline & Symptomatic osteoporosis \\
\hline & Oral corticosteroids $>20 \mathrm{mg} \cdot \mathrm{day}^{-1}$ prednisone \\
\hline & Psychosocial problems \\
\hline & Requirement for invasive mechanical ventilation \\
\hline & Colonisation with fungi or atypical mycobacteria \\
\hline \multirow[t]{7}{*}{ Absolute contraindications } & Severe musculoskeletal disease affecting the thorax \\
\hline & Substance addiction within previous 6 months \\
\hline & Dysfunction of extrathoracic organ, particularly renal dysfunction \\
\hline & HIV infection \\
\hline & Active malignancy within 2 yrs except basal or squamous cell carcinoma of skin \\
\hline & Hepatitis B antigen positivity \\
\hline & Hepatitis $\mathrm{C}$ with biopsy-proven evidence of liver disease \\
\hline
\end{tabular}

HIV: human immunodeficiency virus.

Table 7. - Disease-specific guidelines for candidate selection for lung transplantation in COPD patients

- FEV1 $\leq 25 \%$ pred (without reversibility) and/or

- Resting, room air $\mathrm{Pa}, \mathrm{CO}_{2}>7.3 \mathrm{kPa}(55 \mathrm{mmHg})$ and/or

- Elevated $\mathrm{Pa}, \mathrm{CO}_{2}$ with progressive deterioration requiring long-term oxygen therapy

- Elevated pulmonary artery pressure with progressive deterioration.

FEV1: forced expiratory volume in one second; $\mathrm{Pa}, \mathrm{CO}_{2}$ : arterial carbon dioxide tension. Modified from [52].

\subsubsection{Pulmonary function}

Following SLT for COPD, FEV1 is expected to rise to $\sim 50 \%$ of the predicted normal value and FVC to $\sim 70 \%$ of the predicted normal value $[50,51,53]$.

Following BLT, FEV1 increases to $78-85 \%$ and FVC to $66-92 \%$ of the predicted normal values [53, 54]. 


\subsubsection{Exercise capacity}

Despite the differential improvements in spirometry, peak exercise capacity is similar between SLT and BLT [55].

\subsubsection{Quality of life}

Quality of life following lung transplantation improves dramatically, in particular for those patients who do not develop chronic rejection [56].

Only a minority of patients return to full-time work [57].

\subsubsection{Survival}

Average actuarial survival following lung transplantation for recipients with COPD is 81.7, 61.9 and $43.4 \%$ at 1,3 and 5 yrs (UNOS online data base).

Compared to patients with other cardiopulmonary diseases, patients with emphysema exhibit the best overall survival after transplantation [57-59].

Data on whether transplantation actually confers a survival advantage compared to the natural history of the disease are conflicting $[50,60,61]$.

By 5 yrs following lung transplantation, the prevalence of chronic allograft rejection (obliterative bronchiolitis), the leading cause of long-term morbidity and mortality, is as high as $50-70 \%$ among survivors [62].

\subsection{Perioperative management}

\subsubsection{Preoperative}

General factors include the following.

- Every effort should be made to aid with smoking cessation (see Management of stable COPD: smoking). Smoking cessation at least $4-8$ weeks preoperatively is optimal [6, $63]$. 
- Optimisation of lung function using inhaled bronchodilators (see Management of stable COPD: pharmacological therapy) in patients with severe COPD can decrease postoperative complications [64]. Although oral corticosteroids are not recommended for chronic disease management in the patient with COPD, those who are taking these agents chronically should be treated with systemic steroids in the perioperative period to minimise the risk of adrenal insufficiency. Although the potential for adrenal insufficiency does exist in patients taking high-dose inhaled corticosteroids, the risk appears to be low in asthmatics [65].

- Pulmonary rehabilitation should be considered in high-risk patients undergoing elective procedures. Pre- and postoperative pulmonary rehabilitation (see Management of stable COPD: pulmonary rehabilitation) have been shown to decrease postoperative pulmonary complications after abdominal surgery [66].

\subsubsection{Intraoperative}

The COPD patient may be more sensitive to the ventilatory depressant effects of the analgesic, regional and general anaesthetic agents used [67].

Volatile anesthetics, intravenous anaesthetics and neuromuscular blocking agents vary in their ability to provoke unwanted autonomic effects and alter airway reactivity [68]. The risk of pulmonary complications may be higher with the use of the long-acting neuromuscular blocker pancuronium than shorter-acting atracurium or vecuronium [69].

The role of general versus regional anaesthesia remains controversial. A meta-analysis suggested that neuroaxial blockade with epidural or spinal anaesthesia decrease postoperative mortality, deep venous thrombosis, pulmonary embolism, transfusion requirements, pneumonia and respiratory depression [70]. A subsequent randomised trial of intraoperative and postoperative epidural analgesia plus general anaesthesia for upper abdominal surgery in highrisk patients (7-8\% with severe COPD) noted only a reduction in postoperative respiratory failure (number needed to treat to prevent one episode of respiratory failure was 15) [71]. 
In COPD patients, the combination of thoracic epidural and general anesthesia may result in less shunting and better oxygenation during thoracic surgical procedures [72].

Thoracic epidural anaesthesia appears to have only limited deleterious effects on pulmonary function in patients with severe COPD [73] and has been used as the primary mode of anaesthesia for COPD patients undergoing chest wall surgery [74].

The immediate postoperative recovery period is a period of high risk because of the possibilities of respiratory muscle dysfunction, acidemia, hypoxaemia and hypoventilation. Close monitoring and, if necessary, mechanical ventilatory (see Exacerbation: assisted ventilation) support become crucial at this time [9].

\subsubsection{Postoperative}

Early mobilisation, deep breathing, intermittent positive-pressure breathing or incentive spirometry have been reported to decrease postoperative complications after upper abdominal surgery [5]. However, this remains controversial [75].

A necessary component of postoperative management is effective analgesia. Epidural administration may offer superior analgesia with less sedation by promoting patient mobility and deep breathing $[76,77]$.

Indications for postoperative mechanical ventilation are respiratory failure with retained secretions, atelectasis and pneumonia [9].

Continuation of preoperatively prescribed respiratory medications (see Management of stable COPD: pharmacological therapy) is standard therapy.

Weaning from mechanical ventilation patients with COPD who have had cardiac surgery may be prolonged [16]. The patient should be ventilated at a level that maintains arterial carbon dioxide tension at the preoperative level with a normal $\mathrm{pH}$. In the COPD patient who is difficult to extubate, gradual weaning may permit the patient's cardiovascular status to become 
sufficiently stable to tolerate assumption of the full work of breathing. In this group of patients, early consultation with an intensivist or pulmonologist may optimise weaning (see Exacerbation: assisted ventilation). 


\subsection{References}

1. Arozullah AM, Khuri SF, Henderson WG, Daley J. Development and validation of a multifactorial risk index for predicting postoperative pneumonia after major noncardiac surgery. Ann Intern Med 2001; 135: 847-857.

2. Smetana GW. Preoperative pulmonary evaluation. N Engl J Med 1999; 340: 937-944.

3. Trayner E Jr, Celli BR. Postoperative pulmonary complications. Med Clin North Am 2001; 85: 1129-1139.

4. Gracey DR, Divertie MB, Didier EP. Preoperative pulmonary preparation of patients with chronic obstructive pulmonary disease: a prospective study. Chest 1979; 76: 123-129.

5. Celli BR, Rodriguez KS, Snider GLA controlled trial of intermittent positive pressure breathing, incentive spirometry, and deep breathing exercises in preventing pulmonary complications after abdominal surgery. Am Rev Respir Dis 1984; 130: 12-15.

6. Warner MA, Offord KP, Warner ME, Lennon RL, Conover MA, Jansson-Schumacher U. Role of preoperative cessation of smoking and other factors in postoperative pulmonary complications: a blinded prospective study of coronary artery bypass patients. Mayo Clin Proc 1989; 64: 609-616.

7. Geerts WH, Heit JA, Clagett GP, et al. Prevention of venous thromboembolism. Chest 2001; 119: 132S-175S.

8. American College of Chest Physicians. Diagnosis and treatment of chronic obstructive pulmonary disease. Chest 1990; 97: 1S-33S.

9. Celli BR. Perioperative respiratory care of the patient undergoing upper abdominal surgery. Clin Chest Med 1993; 14: 253-261.

10. Gozum M, Turner B, Tipperman R. Perioperative management of the ophthalmology patient. Medical management of the surgical patient. WB Saunders Co, Philadelphia, PA, 1992.

11. Stewart WC, Garrison PM. Beta-blocker-induced complications and the patient with glaucoma. Newer treatments to help reduce systemic adverse events. Arch Intern Med 1998; 158: 221-226.

12. Collins R, Scrimgeour A, Yusuf S, Peto R. Reduction in fatal pulmonary embolism and venous thrombosis by perioperative administration of subcutaneous heparin. Overview of 
results of randomized trials in general, orthopedic, and urologic surgery. N Engl J Med 1988; 318: 1162-1173.

13. Goldhaber SZ, Visani L, De Rosa M. Acute pulmonary embolism: clinical outcomes in the International Cooperative Pulmonary Embolism Registry (ICOPER). Lancet 1999; 353: 13861389.

14. Mimica Z, Biocic M, Bacic A, et al. Laparoscopic and laparotomic cholecystectomy: a randomized trial comparing postoperative respiratory function. Respiration 2000; 67: 153-158. 15. Samuels LE, Kaufman MS, Morris RJ, Promisloff R, Brockman SK. Coronary artery bypass grafting in patients with COPD. Chest 1998; 113: 878-882.

16. Rady MY, Ryan T. Perioperative predictors of extubation failure and the effect on clinical outcome after cardiac surgery. Crit Care Med 1999; 27: 340-347.

17. Jayr C, Matthay MA, Goldstone J, Gold WM, Wiener-Kronish JP. Preoperative and intraoperative factors associated with prolonged mechanical ventilation. A study in patients following major abdominal vascular surgery. Chest 1993; 103: 1231-1236.

18. Reilly JJ Jr. Evidence-based preoperative evaluation of candidates for thoracotomy. Chest 1999; 116: 474S-476S.

19. Weisman IM. Cardiopulmonary exercise testing in the preoperative assessment for lung resection surgery. Semin Thorac Cardiovasc Surg 2001; 13: 116-125.

20. Martinez FJ, Iannettoni M, Paine III R. Medical evaluation and management of the lung cancer patient prior to surgery, radiation or chemotherapy. In: Pass H, Mitchell J, Johnson D, Turrisi A, eds. Lung cancer: principles and practice. Philadelphia, PA, Lippincott Williams \& Williams, 2000; pp. 649-681.

21. Yim AP. VATS major pulmonary resection revisited - controversies, techniques, and results. Ann Thorac Surg 2002; 74: 615-623.

22. Bolliger CT, Jordan P, Soler M, et al. Pulmonary function and exercise capacity after lung resection. Eur Respir J 1996; 9: 415-421.

23. Bolliger CT, Perruchoud AP. Functional evaluation of the lung resection candidate. Eur Respir J 1998; 11: 198-212.

24. Schuurmans MM, Diacon AH, Bolliger CT. Functional evaluation before lung resection. Clin Chest Med 2002; 23: 159-172. 
25. British Thoracic Society, Cardiothoracic Surgeons of Great Britain, Ireland Working Party. Guidelines on the selection of patients with lung cancer for surgery. Thorax 2001; 56: 89-108. 26. Brutsche MH, Spiliopoulos A, Bolliger CT, Licker M, Frey JG, Tschopp JM. Exercise capacity and extent of resection as predictors of surgical risk in lung cancer. Eur Respir J 2000; 15: 828-832.

27. Flaherty KR, Martinez FJ. Lung volume reduction surgery for emphysema. Clin Chest Med 2000; 21: 819-848.

28. Edwards JG, Duthie DJ, Waller DA. Lobar volume reduction surgery: a method of increasing the lung cancer resection rate in patients with emphysema. Thorax 2001; 56: 791795.

29. DeMeester SR, Patterson GA, Sundaresan RS, Cooper JD. Lobectomy combined with volume reduction for patients with lung cancer and advanced emphysema. $J$ Thorac Cardiovasc Surg 1998; 115: 681-688.

30. Heffernan J, Witzburg R, Smetana G. Medical Evaluation of the Patient Undergoing Surgery. Textbook of Primary Care Medicine, 3rd ed. Mosby Inc., St. Louis, MO, 2001.

31. Eagle KA, Berger PB, Calkins $\mathrm{H}$, et al. ACC/AHA guideline update for perioperative cardiovascular evaluation for noncardiac surgery - executive summary. A report of the American College of Cardiology/American Heart Association Task Force on Practice Guidelines (Committee to Update the 1996 Guidelines on Perioperative Cardiovascular Evaluation for Noncardiac Surgery). Anesth Analg 2002; 94: 1052-1064.

32. Deslauriers J. History of surgery for emphysema. Semin Thorac Cardiovasc Surg 1996; 8: $43-51$.

33. Snider GL. Reduction pneumoplasty for giant bullous emphysema. Implications for surgical treatment of nonbullous emphysema. Chest 1996; 109: 540-548.

34. Martinez FJ. Surgical therapy for chronic obstructive pulmonary disease: conventional bullectomy and lung volume reduction surgery in the absence of giant bullae. Semin Respir Crit Care Med 1999; 20: 351-364.

35. National Emphysema Treatment Trial Research Group. A randomized trial comparing lung-volume-reduction surgery with medical therapy for severe emphysema. $N$ Engl J Med 2003; 348: 2059-2073. 
36. McKenna RJ Jr, Brenner M, Gelb AF, et al. A randomized, prospective trial of stapled lung reduction versus laser bullectomy for diffuse emphysema. J Thorac Cardiovasc Surg 1996; 111: 317-321; discussion 322.

37. McKenna RJ Jr, Brenner M, Fischel RJ, Gelb AF. Should lung volume reduction for emphysema be unilateral or bilateral? J Thorac Cardiovasc Surg 1996; 112: 1331-1138; discussion 1338-1339.

38. Stirling GR, Babidge WJ, Peacock MJ, et al. Lung volume reduction surgery in emphysema: a systematic review. Ann Thorac Surg 2001; 72: 641-648.

39. National Emphysema Treatment Trial Research Group. Patients at high risk of death after lung-volume-reduction surgery. N Engl J Med 2001; 345: 1075-1083.

40. Flaherty KR, Kazerooni EA, Curtis JL, et al. Short-term and long-term outcomes after bilateral lung volume reduction surgery: prediction by quantitative CT. Chest 2001; 119: 13371346.

41. Yusen RD, Lefrak SS, Gierada DS, et al. A prospective evaluation of lung volume reduction surgery in 200 consecutive patients. Chest 2003; 123: 1026-1037.

42. Cooper JD, Patterson GA, Sundaresan RS, et al. Results of 150 consecutive bilateral lung volume reduction procedures in patients with severe emphysema. $J$ Thorac Cardiovasc Surg 1996; 112: 1319-1329; discussion 1329-1330.

43. Brenner M, McKenna RJ, Gelb AF, et al. Dyspnea response following bilateral thoracoscopic staple lung volume reduction surgery. Chest 1997; 112: 916-923.

44. Leyenson V, Furukawa S, Kuzma AM, Cordova F, Travaline J, Criner GJ. Correlation of changes in quality of life after lung volume reduction surgery with changes in lung function, exercise, and gas exchange. Chest 2000; 118: 728-735.

45. Geddes D, Davies M, Koyama $\mathrm{H}$, et al. Effect of lung-volume-reduction surgery in patients with severe emphysema. $N$ Engl J Med 2000; 343: 239-245.

46. Criner GJ, Cordova FC, Furukawa S, et al. Prospective randomized trial comparing bilateral lung volume reduction surgery to pulmonary rehabilitation in severe chronic obstructive pulmonary disease. Am J Respir Crit Care Med 1999; 160: 2018-2027.

47. Goldstein RS, Todd TR, Guyatt G, et al. Influence of lung volume reduction surgery (LVRS) on health related quality of life in patients with chronic obstructive pulmonary disease. Thorax 2003; 58: 405-410. 
48. Yusen RD, Morrow LE, Brown KL. Health-related quality of life after lung volume reduction surgery. Semin Thorac Cardiovasc Surg 2002; 14: 403-412.

49. Gelb AF, Brenner M, McKenna RJ Jr, Fischel R, Zamel N, Schein MJ. Serial lung function and elastic recoil 2 years after lung volume reduction surgery for emphysema. Chest 1998; 113: $1497-1506$.

50. Mal H, Sleiman C, Jebrak G, et al. Functional results of single-lung transplantation for chronic obstructive lung disease. Am J Respir Crit Care Med 1994; 149: 1476-1481.

51. Patterson GA, Maurer JR, Williams TJ, Cardoso PG, Scavuzzo M, Todd TR. Comparison of outcomes of double and single lung transplantation for obstructive lung disease. The Toronto Lung Transplant Group. J Thorac Cardiovasc Surg 1991; 101: 623-631; discussion $631-632$.

52. American Thoracic Society. International guidelines for the selection of lung transplant candidates. Am J Respir Crit Care Med 1998; 158: 335-339.

53. Bando K, Paradis IL, Keenan RJ, et al. Comparison of outcomes after single and bilateral lung transplantation for obstructive lung disease. J Heart Lung Transplant 1995; 14: 692-698.

54. Williams TJ, Grossman RF, Maurer JR. Long-term functional follow-up of lung transplant recipients. Clin Chest Med 1990; 11: 347-358.

55. Orens JB, Becker FS, Lynch JP 3rd, Christensen PJ, Deeb GM, Martinez FJ. Cardiopulmonary exercise testing following allogeneic lung transplantation for different underlying disease states. Chest 1995; 107: 144-149.

56. Gross CR, Savik K, Bolman RM 3rd, Hertz MI. Long-term health status and quality of life outcomes of lung transplant recipients. Chest 1995; 108: 1587-1593.

57. Hosenpud JD, Bennett LE, Keck BM, Boucek MM, Novick RJ. The Registry of the International Society for Heart and Lung Transplantation: eighteenth Official Report-2001. $J$ Heart Lung Transplant 2001; 20: 805-815.

58. De Meester J, Smits JM, Persijn GG, Haverich A. Listing for lung transplantation: life expectancy and transplant effect, stratified by type of end-stage lung disease, the Eurotransplant experience. J Heart Lung Transplant 2001; 20: 518-524.

59. De Meester J, Smits JM, Persijn GG, Haverich A. Lung transplant waiting list: differential outcome of type of end-stage lung disease, one year after registration. J Heart Lung Transplant 1999; 18: 563-571. 
60. Charman SC, Sharples LD, McNeil KD, Wallwork J. Assessment of survival benefit after lung transplantation by patient diagnosis. J Heart Lung Transplant 2002; 21: 226-232.

61. Hosenpud JD, Bennett LE, Keck BM, Edwards EB, Novick RJ. Effect of diagnosis on survival benefit of lung transplantation for end-stage lung disease. Lancet 1998; 351: 24-27.

62. Heng D, Sharples LD, McNeil K, Stewart S, Wreghitt T, Wallwork J. Bronchiolitis obliterans syndrome: incidence, natural history, prognosis, and risk factors. J Heart Lung Transplant 1998; 17: 1255-1263.

63. Nakagawa M, Tanaka H, Tsukuma H, Kishi Y. Relationship between the duration of the preoperative smoke-free period and the incidence of postoperative pulmonary complications after pulmonary surgery. Chest 2001; 120: 705-710.

64. Tarhan S, Moffitt EA, Sessler AD, Douglas WW, Taylor WF. Risk of anesthesia and surgery in patients with chronic bronchitis and chronic obstructive pulmonary disease. Surgery 1973; 74: 720-726.

65. Pien LC, Grammer LC, Patterson R. Minimal complications in a surgical population with severe asthma receiving prophylactic corticosteroids. J Allergy Clin Immunol 1988; 82: 696700.

66. Chumillas S, Ponce JL, Delgado F, Viciano V, Mateu M. Prevention of postoperative pulmonary complications through respiratory rehabilitation: a controlled clinical study. Arch Phys Med Rehabil 1998; 79: 5-9.

67. Sykes LA, Bowe EA. Cardiorespiratory effects of anesthesia. Clin Chest Med 1993; 14: 211-226.

68. Gruber EM, Tschernko EM. Anaesthesia and postoperative analgesia in older patients with chronic obstructive pulmonary disease. Special considerations. Drugs Aging 2003; 20: 347360.

69. Berg H, Roed J, Viby-Mogensen J, et al. Residual neuromuscular block is a risk factor for postoperative pulmonary complications. A prospective, randomised, and blinded study of postoperative pulmonary complications after atracurium, vecuronium and pancuronium. Acta Anaesthesiol Scand 1997; 41: 1095-1103.

70. Rodgers A, Walker N, Schug S, et al. Reduction of postoperative mortality and morbidity with epidural or spinal anaesthesia: results from overview of randomised trials. BMJ 2000; 321: 1493-1497. 
71. Rigg JRA, Jamrozik K, Myles PS, et al. Epidural anasesthesia and analgesia and outcome of major surgery: a randomised trial. Lancet 2002; 359: 1276-1282.

72. von Dossow V, Welte M, Zaune U, et al. Thoracic epidural anesthesia combined with general anesthesia: The preferred anesthetic technique for thoracic surgery. Anesth Analg 2001; 92: 848-854.

73. Gruber EM, Tschernko EM, Kritzinger M, et al. The effects of thoracic epidural analgesia with bupivicaine $0.25 \%$ on ventilatory mechanics in patients with severe chronic obstructive pulmonary disease. Anesth Analg 2001; 92: 1015-1019.

74. Groeben H, Schafer B, Pavlakovic G, Silvanus MT, Peters J. Lung function under high thoracic segmental epidural anesthesia with ropivacaine or bupivacaine in patients with severe obstructive pulmonary disease undergoing breast surgery. Anesthesiology 2002; 96: 536-541.

75. Overend TJ, Anderson CM, Lucy SD, Bhatia C, Jonsson BI, Timmermans C. The effect of incentive spirometry on postoperative pulmonary complications: a systematic review. Chest 2001; 120: 971-978.

76. Logas WG, el-Baz N, el-Ganzouri A, et al. Continuous thoracic epidural analgesia for postoperative pain relief following thoracotomy: a randomized prospective study. Anesthesiology 1987; 67: 787-791.

77. Sandler AN, Stringer D, Panos L, Badner N, et al. A randomized, double-blind comparison of lumbar epidural and intravenous fentanyl infusions for postthoracotomy pain relief. Analgesic, pharmacokinetic, and respiratory effects. Anesthesiology 1992; 77: 626-634. 


\section{Management of stable COPD: sleep}

\subsection{Key points}

- Sleep in chronic obstructive pulmonary disease (COPD) is associated with oxygen desaturation, which is predominantly due to the disease itself rather than to sleep apnoea. The desaturation during sleep may be greater than during maximum exercise.

- Sleep quality is markedly impaired in COPD, both subjectively and objectively.

- Sleep apnoea syndrome is about as prevalent in COPD as a general population of similar age but oxygen desaturation during sleep is more pronounced when the two conditions co-exist.

- Clinical assessment in all patients with COPD should include questions about sleep quality and possible co-existing sleep apnoea syndrome.

- Sleep studies are not indicated in COPD except in special circumstances, such as a clinical suspicion of sleep apnoea or complications of hypoxaemia that are not explained by the awake arterial oxygen levels.

- Management of sleep problems in COPD should particularly focus on minimising sleep disturbance by measures to limit cough and dyspnoea, and nocturnal oxygen therapy is rarely indicated for isolated nocturnal hypoxaemia.

- Hypnotics should be avoided, if possible, in patients with severe COPD.

\subsection{Background}

Sleep has effects on breathing that include changes in central respiratory control, airways resistance and muscle contractility. These do not have an adverse effect in healthy individuals but may cause problems in patients with COPD.

The sleep-related disturbances in gas exchange in COPD are a consequence of the disease itself, and are separate and distinct from sleep apnoea. Sleep-related hypoxaemia and hypercapnia in COPD are most pronounced during rapid eye movement (REM) sleep [1]. 
Oxygen desaturation in COPD is considerably greater during sleep than during maximum exercise [2], and predisposes to nocturnal cardiac dysrhythmias [3] and pulmonary hypertension [4], and possibly death during acute exacerbations [5].

\subsection{Sleep problems in COPD}

\subsubsection{Sleep quality in COPD}

Patients with COPD have a higher prevalence of insomnia, nightmares and daytime sleepiness than the general population [6], with close to $50 \%$ of patients reporting significant disturbance in sleep quality.

Polysomnographic studies show sleep fragmentation with frequent arousals and diminished slow wave and REM sleep [7].

Sleep disturbance is probably a consequence of the underlying lung disease, although adverse effects of drug therapy may also contribute.

Sleep disturbance probably contributes to the nonspecific daytime symptoms of chronic fatigue, lethargy and overall impairment in quality of life described by these patients $[7,8]$.

The potential effects of chronic sleep disturbance on pulmonary function in COPD are unknown but 1 night's sleep deprivation leads to small transient falls in forced vital capacity and forced expiratory volume in one second [9].

\subsubsection{Mechanisms of oxygen desaturation during sleep in COPD}

\subsubsection{Hypoventilation}

Sleep-related hypoventilation has been demonstrated in COPD, particularly during REM, with associated oxygen desaturation [10]. There is a close relationship between the awake arterial oxygen tension $\left(\mathrm{Pa}, \mathrm{O}_{2}\right)$ and nocturnal arterial oxygen saturation $\left(\mathrm{Sa}_{\mathrm{a}} \mathrm{O}_{2}\right)$ levels [2, 11], although hypercapnia is associated with more pronounced nocturnal oxygen desaturation than normocapnia for any given level of awake $\mathrm{Sa}_{\mathrm{a}} \mathrm{O}_{2}$ in some studies [11, 12] but not in others [2]. 
Nocturnal oxygen desaturation in COPD is probably the consequence of the combined effects of physiological hypoventilation during sleep and the fact that hypoxaemic patients show a proportionately greater fall in $\mathrm{Sa}_{\mathrm{a}} \mathrm{O}_{2}$ with hypoventilation because they are on, or close to, the steep portion of the oxyhaemoglobin dissociation curve. However, some patients with awake $\mathrm{Pa}, \mathrm{O}_{2}$ levels in the mildly hypoxaemic range can also develop clinically significant nocturnal oxygen desaturation, which may predispose to pulmonary hypertension [13].

The mechanisms of hypoventilation in sleep include a diminished responsiveness of the respiratory centre to chemical, mechanical and cortical inputs, particularly during REM sleep. Furthermore, there is a normal circadian change in airway calibre resulting in mild nocturnal bronchoconstriction.

\subsubsection{Altered ventilation/perfusion relationships}

The accessory muscle contribution to breathing is reduced in sleep, particularly during REM, which results in a decreased functional residual capacity. This contributes to worsening ventilation/perfusion relationships, which also aggravates hypoxaemia. This fall in intercostal muscle activity is particularly significant in patients who are dependent on accessory muscle activity to maintain ventilation, such as those with COPD, where lung hyperinflation reduces the efficiency of diaphragmatic contraction.

\subsubsection{Effect of oxygen desaturation during sleep on hemodynamics, morbidity, mortality}

Studies of COPD patients with nocturnal desaturation and mild daytime hypoxemia have demonstrated higher daytime pulmonary artery pressures in these patients than in a similar group of patients who did not desaturate at night [14].

REM-associated falls in $\mathrm{S}_{\mathrm{a}, \mathrm{O}_{2}}$ are associated with increases in pulmonary artery pressure during sleep that can be reversed by supplemental oxygen, although most COPD patients with sustained pulmonary hypertension are also hypoxaemic during the daytime. However, there is no convincing evidence that isolated nocturnal pulmonary hypertension in COPD is a significant independent predictor of survival. 
Patients with COPD have also been reported to have an increase in premature ventricular contractions during sleep, which decrease in frequency with supplemental oxygen [3]. Furthermore, hypoxaemia in REM sleep may have myocardial effects similar to those found during maximal exercise [15].

There is evidence that nocturnal oxygen desaturation contributes to mortality, particularly during acute exacerbations. Two studies have demonstrated a significant relationship between nocturnal desaturation and long-term survival, although the data are less clear on whether the relationship is independent of other factors such as lung function or awake blood gases [11, 16]. Furthermore, there is no clear evidence that correction of nocturnal oxygen desaturation improves survival [16]. However, there is evidence that patients with exacerbations are more likely to die at night, particularly those with hypercapnia [5].

\subsubsection{Co-existing sleep apnoea syndrome and COPD}

The prevalence of sleep apnoea in patients with COPD is about the same as a normal population of similar age [17]. However, patients with co-existing COPD and sleep apnoea typically develop more severe oxygen desaturation during sleep because such patients may be hypoxaemic at the commencement of each apnoea, whereas patients with pure sleep apnoea tend to resaturate to normal $\mathrm{Sa}_{2} \mathrm{O}_{2}$ levels in between apnoeas. Therefore, they are particularly prone to the complications of chronic hypoxaemia, such as cor pulmonale and polycythaemia.

\subsection{Assessment}

\subsubsection{Clinical evaluation of sleep abnormalities in COPD}

All patients with COPD should be questioned about symptoms of sleep disturbance and possible associated sleep apnoea syndromes, such as snoring, witnessed apnoea during sleep and excessive daytime sleepiness.

\subsubsection{Sleep studies in COPD}

Since the best predictor of nocturnal oxygen desaturation is awake arterial blood gas levels, overnight sleep studies are not indicated in COPD except in special circumstances such as a 
clinical suspicion of co-existing sleep apnoea, or the presence of complications such as polycythaemia or cor pulmonale that cannot be explained by the awake $\mathrm{Pa}, \mathrm{O}_{2}$.

\subsection{Therapy}

\subsubsection{Management of sleep-related disturbances}

Management of sleep problems in COPD should first focus on optimising the patient's overall respiratory condition. Measures to improve sleep quality should focus on minimising symptoms such as cough and dyspnoea that may disturb sleep patterns by arousal.

Nocturnal oxygen therapy is not recommended for isolated nocturnal hypoxaemia except in special circumstances, such as the presence of complications of hypoxaemia, i.e. polycythaemia or cor pulmonale that are not explained by the awake $\mathrm{Pa}, \mathrm{O}_{2}$.

A number of pharmaceutical agents have been shown to benefit nocturnal $\mathrm{Sa}_{\mathrm{a}} \mathrm{O}_{2}$, including theophylline [18] and anticholinergic agents [19, 20], and ipratropium has been shown to improve sleep quality [19].

There is no evidence to support the use of pulmonary vasodilator therapy.

\subsubsection{Pressure support for nocturnal respiratory failure in COPD}

Patients with nocturnal respiratory failure due to COPD that is not adequately corrected by oxygen and pharmacological therapy can be considered for external pressure support during sleep. Bi-level positive airway pressure is generally more effective than continuous positive airway pressure (CPAP), since the most important contributing mechanism to nocturnal hypoxaemia is hypoventilation. However, if there is co-existing COPD and sleep apnoea syndrome, CPAP may be indicated if the latter condition predominates.

\subsubsection{Hypnotics and COPD}

Hypnotics, particularly benzodiazepines, should be avoided, if possible, because of a potential deleterious effect on ventilation, although there is evidence that some hypnotics, such as 
zolpidem, can be used in less severe COPD without significant adverse effects on gas exchange [21]. 


\subsection{References}

1. Douglas NJ, Calverley PMA, Leggett RJE, Brash HM, Flenley DC, Brezinova V. Transient hypoxaemia during sleep in chronic bronchitis and emphysema. Lancet 1979; 1: 1-4.

2. Mulloy E, McNicholas WT. Ventilation and gas exchange during sleep and exercise in patients with severe COPD. Chest 1996; 109: 387-394.

3. Tirlapur VG, Mir MA. Nocturnal hypoxemia and associated electrocardiographic changes in patients with chronic obstructive airways disease. $N$ Engl J Med 1982; 306: 125-130.

4. Fletcher EC, Luckett RA, Miller T, et al. Pulmonary vascular hemodynamics in chronic lung disease patients with and without oxyhemoglobin desaturation during sleep. Chest 1989; 95: $757-766$.

5. McNicholas WT, FitzGerald MX. Nocturnal death among patients with chronic bronchitis and emphysema. BMJ 1984; 289: 878.

6. Klink M, Quan S. Prevalence of reported sleep disturbances in a general population and their relationship to obstructive airways diseases. Chest 1987; 91: 540-546.

7. Cormick W, Olson LG, Hensley MJ, Saunders NA. Nocturnal hypoxaemia and quality of sleep in patients with chronic obstructive lung disease. Thorax 1986; 41: 846-854.

8. Breslin E, Van der Schans C, Breubink S, et al. Perception of fatigue and quality of life in patients with COPD. Chest 1998; 114: 958-964.

9. Phillips B, Cooper K, Burke T. The effect of sleep loss of breathing in chronic obstructive pulmonary disease. Chest 1987; 91: 29-32.

10. Hudgel DW, Martin RJ, Capehart M, Johnson B, Hill P. Contribution of hypoventilation to sleep oxygen desaturation in chronic obstructive pulmonary disease. J Appl Physiol 1983; 55: 669-677.

11. Connaughton JJ, Caterall JR, Elton RA, Stradling JR, Douglas NJ. Do sleep studies contribute to the management of patients with severe chronic obstructive pulmonary disease? Am Rev Resp Dis 1988; 138: 341-344.

12. Bradley TD, Mateika J, Li D, Avenado M, Goldstein RS. Daytime hypercapnia in the development of nocturnal hypoxemia in COPD. Chest 1990: 97; 308-312.

13. Fletcher E, Miller J, Divine G, Fletcher J, Miller T. Nocturnal oxyhemoglobin desaturation in COPD patients with arterial oxygen tensions above $60 \mathrm{mmHg}$. Chest 1987; 92: 604-608. 
14. Levi-Valensi $\mathrm{P}$, Weitzenblum E, Rida A, et al. Sleep-related oxygen desaturation and daytime pulmonary hemodynamics in COPD patients. Eur Resp J 1992; 5: 301-307.

15. Shepard JW, Schweitzer PK, Kellar CA, Chun DS, Dolan GF. Myocardial stress. Exercise versus sleep in patients with COPD. Chest 1984; 86: 366-374.

16. Fletcher E, Donner C, Midgren B, et al. Survival in COPD patients with a daytime $\mathrm{PaO} 2$ $>60 \mathrm{mmHg}$ with and without nocturnal oxyhemoglobin desaturation. Chest 1992; 101: 649655.

17. Sanders MH, Newman AB, Haggerty CL, et al. Sleep and Sleep-disordered Breathing in Adults with Predominantly Mild Obstructive Airway Disease. Am J Respir Crit Care Med 2003 167: 7-14.

18. Mulloy E, McNicholas WT. Theophylline improves gas exchange during rest, exercise and sleep in severe chronic obstructive pulmonary disease. Am Rev Respir Dis 1993; 148: 10301036.

19. Martin RJ, Bucher BL, Smith P, et al. Effect of ipratropium bromide treatment on oxygen saturation and sleep quality in COPD. Chest 1999; 115: 1338-1345.

20. McNicholas WT, Calverley PMA, Edwards C, Lee A. Effects of anticholinergic therapy (Tiotropium) on REM-related desaturation and sleep quality in patients with COPD. Am J Respir Crit Care Med 2001; 163: Suppl, A281.

21. Steens R, Pouliot Z, Millar T, Kryger M, George C. Effects of Zolpidem and Triazolam on sleep and respiration in mild to moderate chronic obstructive pulmonary disease. Sleep 1993; 16: $318-326$. 


\section{Management of stable COPD: air travel}

\subsection{Key points}

- Commercial airliners can cruise at >12,192 m (>40,000 feet) as long as the cabin is pressurised from $1,829-2,438 \mathrm{~m}(6,000-8,000$ feet). This is equivalent to an inspired oxygen $\left(\mathrm{O}_{2}\right)$ concentration at sea level of $\sim 15 \%$.

- Patients with chronic obstructive pulmonary disease (COPD) can exhibit falls in arterial $\mathrm{O}_{2}$ tension $\left(\mathrm{Pa}, \mathrm{O}_{2}\right)$ that average $25 \mathrm{mmHg}(3.3 \mathrm{kPa})$.

- Pre-flight assessment can help determine $\mathrm{O}_{2}$ needs and the presence of comorbidities.

- $\mathrm{O}_{2}$ needs can be estimated by using the hypoxia inhalation test or through the use of regression formulae.

- Most airlines will provide supplemental $\mathrm{O}_{2}$ on request.

- There is increasing evidence that patients on long flights may be at increased risk for deep vein thrombosis.

\subsection{Background}

Commercial airliners can cruise at altitudes above 12,192 m (40,000 feet) when the cabin is pressurised from $1,829-2,438 \mathrm{~m}(6,000-8,000$ feet $)$. This is equivalent to an inspired $\mathrm{O}_{2}$ concentration at sea-level of $\sim 15 \%$ [1]. Patients with severe COPD experience falls in their $P \mathrm{a}, \mathrm{O}_{2}$ that average $25 \mathrm{mmHg}(3.3 \mathrm{kPa})$, however, these falls may exceed $30 \mathrm{mmHg}(4 \mathrm{kPa})$ at $2,438 \mathrm{~m}$ (8,000 feet) due to the exposure to hypobaric hypoxia [1]. Since sea-level $P \mathrm{a}, \mathrm{O}_{2}$ values are on the steep portion of the $\mathrm{O}_{2}$-haemoglobin dissociation curve, the corresponding fall in arterial $\mathrm{O}_{2}$ saturation $\left(\mathrm{Sa}, \mathrm{O}_{2}\right)$ may be quite severe.

The expected reduction of $\mathrm{O}_{2}$ partial pressure $\left(\mathrm{PO}_{2}\right)$ in the cabin of commercial aircraft routinely produces hypoxaemia in patients who have stable, compensated COPD at sea level [1]. During flights, patients may develop dyspnoea, wheezing, chest pain, cyanosis and right heart failure, leading to urgent requests for $\mathrm{O}_{2}$ [2]. Even light physical exertion during a flight can increase the risk of an exacerbation of symptoms [3]. Although death due to a purely 
respiratory cause rarely occurs during flight, the frequency of less-morbid events, including worsening symptoms after exiting the plane, may be underreported.

\subsection{Cabin environment}

Clinicians should consider 2,438 $\mathrm{m}$ (8,000 feet) above sea level as a realistic environment for most patients who plan to engage in commercial air travel in the USA [4]. Air travel in small aircraft with pressurised and unpressurised cabins, including commuter planes, can also result in significant hypobaric exposure. If specific information concerning cabin altitude is known in advance, it should be integrated into decision-making processes.

\subsection{Co-morbidities}

Recent literature has suggested that pulmonary embolism is a risk factor for many airline travellers. This seems to be related to the duration of flight and underlying predisposing factors [5]. Patients with COPD are presumably at an equal or higher risk than the general population. The number of passengers with COPD and air travel hypoxaemia contributing to cardiac arrest, stroke, seizure or pulmonary embolism during flight is unknown.

\subsection{Pre-flight assessment}

The pre-flight assessment should incorporate the following steps in many cases: 1) estimate the expected degree of hypoxaemia at altitude; 2) identify co-morbid disease conditions; and 3) prescribe $\mathrm{O}_{2}$ if necessary. Counselling the patient and documenting recent clinical condition and laboratory tests are also desirable elements of pre-flight patient care, particularly if the patient is travelling abroad.

At present, the two most widespread means of estimating the degree of hypoxaemia at altitude consist of the hypoxia inhalation test $[6,7]$ and the use of regression formulae [1]. The use of a sea level $\mathrm{O}_{2}$ pressure threshold of $68-72 \mathrm{mmHg}(9-9.6 \mathrm{kPa})$ as safe or unsafe will misclassify many patients and is not recommended [1]. 


\subsubsection{Hypoxia inhalation test}

The hypoxia inhalation test (HIT) provides the opportunity to assess the effects of normobaric hypoxaemia on the individual patient with COPD [6, 7]. However, symptoms and electrocardiogram (ECG) abnormalities rarely occur during a short hypoxic exposure in patients with uncomplicated COPD [8].

At sea level, the HIT should expose patients to $15.1 \% \mathrm{O}_{2}$ (simulating 2,438 $\mathrm{m}(8,000$ feet)), breathing from a reservoir through a mouthpiece with nose clips in place for 15-20 mins with a 12-lead ECG monitoring for ischemia [9]. The primary end-point for the HIT consists of sampling arterial blood in the upright position in most cases. Pulse oximetry tends to underestimate the degree of acute hypobaric hypoxia and should not be used alone to decide if significant hypoxaemia has occurred [10]. Pulse oximetry can be used to titrate $\mathrm{O}_{2}$ supplementation and avoid multiple needle sticks for blood gas testing. ECG leads should be employed in selected patients to monitor for ischemia and arrhythmias.

Candidates for the HIT may include: 1) COPD patients with co-morbid diseases that may be affected by hypoxaemia (coronary artery disease, congestive heart failure, arrhythmias and other cardiac diseases; cerebrovascular disease; anaemia; seizure disorders and other neurological diseases; and pulmonary vascular disease including pulmonary embolism); 2) COPD patients who previously manifested symptoms during air travel; 3) COPD patients recovering from acute exacerbations; 4) COPD patients known to develop hypoventilation with $\mathrm{O}_{2}$ administration; 5) COPD patients who have a regression equation prediction of altitude $\mathrm{Pa}, \mathrm{O}_{2}$ that is borderline; and 6) $\mathrm{COPD}$ patients who require additional reassurance before embarking on air travel.

\subsubsection{Regression equations}

Regression equations offer the opportunity to compare an individual to a group of patients with similar clinical characteristics who have been previously studied during exposure to hypobaric hypoxia [1]. The regression approach does not assess the individual's susceptibility to the development of symptoms or ECG changes during hypoxia. Regression equations can be used as a screening tool to identify patients with borderline $\mathrm{Pa}, \mathrm{O}_{2}$ estimates for further testing with 
the HIT. The alveolar/arterial $\mathrm{O}_{2}$ gradient $\left(P \mathrm{~A}-\mathrm{a}, \mathrm{O}_{2}\right)$ and alveolar/arterial $\mathrm{O}_{2}$ ratio generally have no advantage over regression equations. Furthermore, the alveolar/arterial gradient at sea level should not be assumed constant at altitude.

The timing of pre-flight testing should be within 2-14 days of travel if practical. A prior study that compared a HIT (17.2\% $\mathrm{O}_{2}$ at sea level) with a $1,650 \mathrm{~m}$ (5,413 feet) flight 3 weeks to 4 months later in $13 \mathrm{COPD}$ patients found considerable variability of up to $1.5 \mathrm{kPa}(11 \mathrm{mmHg})$ in $\mathrm{Pa}, \mathrm{O}_{2}$ values [6]. Assessments within $2 \mathrm{~h}$ of flight have greater accuracy but less practicality [11]. 


\subsection{Oxygen supplementation}

It is currently recommended that the $\mathrm{Pa}_{\mathrm{a}} \mathrm{O}_{2}$ during air travel should be maintained above 50 mmHg $(6.7 \mathrm{kPa})[12]$. Treatment with $2-3 \mathrm{~L}$ of $\mathrm{O}_{2}$ by nasal cannula will replace the inspired $\mathrm{O}_{2}$ partial pressure lost at 2,438 m (8,000 feet) compared to sea level [13]. For high-risk patients, the goal should be to maintain $\mathrm{PO}_{2}$ during flight at the same level at which the patient is clinically stable at sea level.

Patients will also require additional $\mathrm{O}_{2}$ supplementation if the elevation at the destination is significantly greater than at home. $\mathrm{O}_{2}$ conserving devices have been demonstrated to be effective at altitude and may be practical for long-duration flights.

An $\mathrm{O}_{2}$ prescription may be required for each segment of the travel itinerary. In a recent review, seven out of 11 US based air carriers and 18 out of 22 international carriers allowed $\mathrm{O}_{2}$ supplementation [14]. All carriers provided nasal cannulas with a wide variation in other devices, $\mathrm{O}_{2}$ flow rates and prices.

Stable COPD patients not requiring home $\mathrm{O}_{2}$ and without co-morbid diseases who have recently travelled safely by air without $\mathrm{O}_{2}$ and who are clinically stable since their previous air travel can make an informed decision to travel without $\mathrm{O}_{2}$. 


\subsection{References}

1. Dillard TA, Berg BW, Rajagopal KR, Dooley JW, Mehm WJ. Hypoxemia during air travel in patients with chronic obstructive pulmonary disease. Ann Intern Med 1989; 111: 362-367.

2. Dillard TA, Beninati WA, Berg BW. Air travel in patients with chronic obstructive pulmonary disease. Arch Intern Med 1991; 151: 1793-1795.

3. Christensen CC, Ryg M, Refvem OK, et al. Development of severe hypoxaemia in chronic obstructive pulmonary disease patients at $2438 \mathrm{~m}(8000 \mathrm{ft})$ altitude. Eur Respir J 2000; 15: 635-639.

4. Cottrell JJ. Altitude exposures during aircraft flight: flying higher. Chest 1988; 92: 81-84.

5. Lapostolle F, Surget V, Borron SW, et al. Severe pulmonary embolism associated with air travel. N Engl J Med 2001; 345: 779-783.

6. Schwartz JS, Bencowitz HZ, Moser KM. Air travel hypoxemia with chronic obstructive pulmonary disease. Ann Intern Med 1984; 100: 473-477.

7. Gong H, Tashkin DP, Lee EY, Simmons MS. Hypoxia-altitude simulation test. Am Rev Respir Dis 1984; 130: 980-986.

8. Berg BW, Dillard TA, Derderian SS, Rajagopal KR. Hemodynamic effects of altitude exposure and oxygen administration in chronic obstructive pulmonary disease. Am J Med 1993; 94: 407-412

9. Dillard TA, Moores LK, Bilello KL, et al. The preflight evaluation: a comparison of the hypoxia inhalation test with hypobaric exposure. Chest 1995; 107: 352-357.

10. Mehm WJ, Dillard TA, Berg BW, et al. Accuracy of oxyhemoglobin saturation monitors during simulated altitude exposure of men with chronic obstructive pulmonary disease. Aviat Space Environ Med 1991; 62: 418-421.

11. Naughton MT, Rochford PD, Pretto JJ, et al. Is normobaric simulation of hypobaric hypoxia accurate in chronic airflow limitation? Am J Respir Crit Care Med 1960; 152: 19561960.

12. AMA Commission on Emergency Medical Services. Medical aspects of transportation aboard commercial aircraft. JAMA 1982; 247: 1007-1011.

13. Berg BW, Dillard TA, Rajagopal KR, Mehm WJ. Oxygen supplementation during air travel in patients with chronic obstructive pulmonary disease. Chest 1992; 101: 638-641. 
14. Stoller JK, Hoisington E, Auger G. A comparative analysis of arranging in-flight oxygen aboard commercial air carriers. Chest 1999; 115: 991-995. 


\section{Exacerbation: definition, evaluation and treatment}

\subsection{Key points}

- The definition of a chronic obstructive pulmonary disease (COPD) exacerbation is an acute change in a patient's baseline dyspnoea, cough and/or sputum beyond day-to-day variability sufficient to warrant a change in therapy.

- The Operational Classification of Severity is as follows: ambulatory (Level I), requiring hospitalisation (Level II) and acute respiratory failure (Level III).

- Causes of exacerbation can be both infectious and noninfectious.

- Medical therapy includes bronchodilators, corticosteroids, antibiotics and supplemental oxygen therapy.

- Ventilatory support (see Exacerbation: assisted ventilation).

- End-of-life issues (see Ethical and palliative care issues).

\subsection{Background}

Exacerbations are a common cause of morbidity [1-3] and mortality in COPD patients [4-6] (see Epidemiology, risk factors and natural history). COPD in the USA annually accounts for 16,000,367 office visits, 500,000 hospitalisations and \$18 billion in direct healthcare costs [69]. In the EU, the annual number of consultations per 100,000 population averages 17,300 and accounts for $€ 10.3$ billion in healthcare cost. Despite aggressive medical treatment, approximately one third of patients discharged from the emergency department with acute exacerbations have recurrent symptoms within 14 days [10], and 17\% relapse and require hospitalisation [11]. Identification of patients at risk for relapse improves decisions about hospital admissions and follow-up [12-14].

Conventional end-points for efficacy of therapy (bronchodilators, corticosteroids and antibiotic treatment) in exacerbations include symptoms and bacteriological resolution at 2-4 weeks. These end-points have been used to evaluate new drugs but may lack clinical relevance. Other end-points, such as an exacerbation-free interval, resource utilisation (hospitalisation, clinic 
visits, medication use, lost work days, etc.) and improved quality of life may be more suitable end-points in this patient population [15-18].

\subsection{Definition}

An exacerbation of COPD is an event in the natural course of the disease characterised by a change in the patient's baseline dyspnoea, cough and/or sputum beyond day-to-day variability sufficient to warrant a change in management.

\subsection{Classification}

There is no agreed classification of exacerbations. The following operational classification of severity can help rank the clinical relevance of the episode and its outcome.

- Level I: treated at home.

- Level II: requires hospitalisation.

- Level III: leads to respiratory failure.

\subsubsection{Risk factors}

- Infectious process [7, 8]: viral (Rhinovirus spp., influenza); bacteria (Haemophilus influenzae, Streptococcus pneumoniae, Moraxella catarrhalis, Enterobacteriaceae spp., Pseudomonas spp.).

- Environmental conditions.

- Air pollution exposure.

- Lack of compliance with long-term oxygen therapy.

- Failure to participate in pulmonary rehabilitation.

\subsubsection{Relapse}

- Incidence 21-40 \% [11, 14, 19-21].

- Risk factors for relapses include [11-14, 19-21]: low pretreatment forced expiratory volume in one second; need to increased bronchodilator or corticosteroid use; previous exacerbations (more than three in the last $2 \mathrm{yrs}$ ); prior antibiotic treatment (mainly ampicillin); presence of comorbid conditions (congestive heart failure, coronary artery disease, chronic renal or liver failure). 


\subsection{Assessment}

Several clinical elements must be considered when evaluating patients with exacerbations. These include the severity of the underlying COPD, the presence of comorbidity and the history of previous exacerbation. The physical examination should evaluate the effect of the episode on the haemodynamic and respiratory systems. The diagnostic procedures to be performed depend on the setting of the evaluation [22, 23].

Table 1 shows the elements of the clinical evaluation and diagnostic procedures that are usually informative in patients with exacerbations according to the severity of the episode.

Table 1. - Clinical history, physical findings and diagnostic procedures

\begin{tabular}{|c|c|c|c|}
\hline & Level I & Level II & Level III \\
\hline \multicolumn{4}{|l|}{ Clinical history } \\
\hline Co-morbid conditions ${ }^{\#}$ & + & +++ & +++ \\
\hline Frequent exacerbations & + & +++ & +++ \\
\hline Severity of COPD & Mild/moderate & Moderate/severe & Severe \\
\hline \multicolumn{4}{|l|}{ Physical findings } \\
\hline Haemodynamic & Stable & Stable & Stable/unstable \\
\hline Use accessory respiratory muscles, tachypnoea & Not present & ++ & +++ \\
\hline Persistent symptoms after initial therapy & No & ++ & +++ \\
\hline \multicolumn{4}{|l|}{ Diagnostic procedures } \\
\hline Oxygen saturation & Yes & Yes & Yes \\
\hline Arterial blood gases & No & Yes & Yes \\
\hline Chest radiograph & No & Yes & Yes \\
\hline Blood tests ${ }^{\text {gl }}$ & No & Yes & Yes \\
\hline Serum drug concentrations ${ }^{+}$ & If applicable & If applicable & If applicable \\
\hline Sputum gram stain and culture & $\mathrm{No}^{\S}$ & Yes & Yes \\
\hline Electrocardiogram & No & Yes & Yes \\
\hline \multicolumn{4}{|c|}{$\begin{array}{l}\text { +: unlikely to be present; ++: likely to be present; +++: very likely to be present. }{ }^{\#}: \text { the more common comorbid } \\
\text { conditions associated with poor prognosis in exacerbations are congestive heart failure, coronary artery disease, } \\
\text { diabetes mellitus, renal and liver failure; }{ }^{\text {Tl}}: \text { blood tests include cell blood count, serum electrolytes, renal and liver } \\
\text { function; }{ }^{+} \text {: serum drug concentrations, consider if patients are using theophyllin, warfarin, carbamezepine, } \\
\text { digoxin; }{ }^{\S} \text { : consider if patient has recently been on antibiotics. }\end{array}$} \\
\hline
\end{tabular}




\subsection{Outpatient}

\subsubsection{Treatment}

The treatment of exacerbation has to be based on the clinical presentation of the patient, as shown in table 2 for Level I.

Table 2. - Level I: outpatient treatment

Patient education

- Check inhalation technique

- $\quad$ Consider use of spacer devices

Bronchodilators

- Short-acting $\beta_{2}$-agonist ${ }^{\#}$ and/or ipratropium MDI with spacer or hand-held nebuliser as needed [24-26]

- Consider adding long-acting bronchodilator if patient is not using it

Corticosteroids (the actual dose may vary)

- $\quad$ Prednisone 30-40 mg per os $q$ day for 10 days [27-29]

- Consider using an inhaled corticosteroid [30]

Antibiotics [7, 11, 18, 31-34]

- May be initiated in patients with altered sputum characteristics

- Choice should be based on local bacteria resistance patterns

- Amoxicillin/ampicillin", cephalosporins ${ }^{\text {\#\# }}$

- Doxycycline

- $\quad$ Macrolides $^{\S}[35-37]$

- If the patient has failed prior antibiotic therapy consider: Amoxicillin/clavulanate [36] Respiratory fluoroquinolones ${ }^{f}[18,38,39]$

- Cefdinir, Cefprozil, Cefuroxime

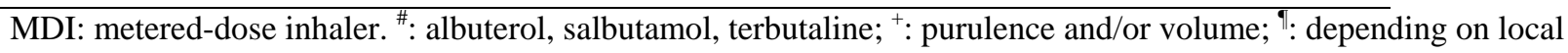
prevalence of bacterial $\beta$-lactamases; ${ }^{\S}$ : azithromycin, clarithromycin, dirithromycin. roxithromycin; ${ }^{f}$ : gatifloxacin, levofloxacin and moxifloxacin; ${ }^{\#}$ : cefpodoxime, cefprozil, cefuroxime, Cefdinir. 


\subsection{Inpatient}

\subsubsection{Hospitalisation}

Traditionally, the decision to admit derives from subjective interpretation of clinical features, such as the severity of dyspnoea, determination of respiratory failure, short-term response to emergency room therapy, degree of cor pulmonale and the presence of complicating features, such as severe bronchitis, pneumonia or other comorbid conditions.

Few clinical studies have investigated patient-specific objective clinical and laboratory features that identify patients with COPD who require hospitalisation. General consensus supports the need for hospitalisation in patients with severe acute hypoxaemia or acute hypercarbia. Less extreme arterial blood gas abnormalities, however, do not assist decision analysis. Other factors that identify "high-risk" patients include a previous emergency room visit within 7 days, the number of doses of nebulised bronchodilators, use of home oxygen, previous relapse rate, administration of aminophylline, and the use of corticosteroids and antibiotics at the time of previous emergency room discharge [10, 40-42].

\subsubsection{Indications}

Table 3 below provides reasonable guidelines for patient hospitalisation. Based on expert consensus, they consider the severity of the underlying respiratory dysfunction, progression of symptoms, response to outpatient therapy, existence of comorbid conditions, necessity of surgical interventions that may affect pulmonary function and the availability of adequate home care. 
Table 3. - Indications for hospitalisation of patients with a COPD exacerbation

- The presence of high-risk comorbid conditions, including pneumonia, cardiac arrhythmia, congestive heart failure, diabetes mellitus, renal or liver failure

- Inadequate response of symptoms to outpatient management

- Marked increase in dyspnoea

- Inability to eat or sleep due to symptoms

- Worsening hypoxaemia

- Worsening hypercapnia

- Changes in mental status

- Inability of the patient to care for her/himself (lack of home support)

- Uncertain diagnosis.

\subsubsection{Treatment}

The treatment of exacerbation has to be based on the clinical presentation of the patient, as shown in table 4 for Level II.

Table 4. - Level II: treatment for hospitalised patient

Bronchodilators

- Short acting $\beta_{2}$ agonist (Albuterol, salbutamol) and/or

- Ipratropium MDI with spacer or hand-held nebuliser as needed [24-26]

Supplemental oxygen (if saturation <90\%) (see Inpatient oxygen therapy)

Corticosteroids

- If patient tolerates, prednisone 30-40 mg per os $q$ day for 10 days [27-29]

- If patient can not tolerate oral intake, equivalent dose i.v. for up to 14 days [40, 41]

- Consider use inhaled corticosteroids by MDI or hand-held nebuliser [30]

Antibiotics (based on local bacteria resistance patterns) [7-11,18, 28-36]

- May be initiated in patients that have a change in their sputum characteristics (purulence and/or volume)

- $\quad$ Choice should be based on local bacteria resistance patterns

- Amoxicillin/clavulanate [36]

- Respiratory fluoroquinolones (gatifloxacin, levofloxacin, moxifloxacin) [18, 38, 39]

- If Pseudomonas spp. and/or other Enterobactereaces spp. are suspected, consider combination therapy

MDI: metered-dose inhaler. 


\subsubsection{Criteria for special care and/or intensive care unit admission}

\subsubsection{Indications}

The severity of respiratory dysfunction dictates the need for admission to an intensive care unit (ICU) (table 5). Depending on the resources available within an institution, admission of patients with severe exacerbations of COPD to intermediate or special respiratory care units may be appropriate if personnel, skills and equipment exist to identify and manage acute respiratory failure successfully.

Table 5. - Indications for intensive care unit or special care unit admission

- Impending or actual respiratory failure

- Presence of other end-organ dysfunction, i.e. shock, renal, liver or neurological disturbance

- Haemodynamic instability

\subsubsection{Treatment}

The treatment of exacerbation has to be based on the clinical presentation of the patient, as shown in table 6 for Level III.

Table 6. - Level III: treatment in patients requiring special or intensive care unit

Supplemental oxygen (see Exacerbation: inpatient oxygen therapy)

Ventilatory support (see Exacerbation: assisted ventilation)

Bronchodilators

- Short acting $\beta_{2}$ agonist (Albuterol, salbutamol) and ipratropium MDI with spacer, two puffs every 2-4 h [24-

26]. If the patient is on the ventilator, consider MDI administration [43, 44], Consider long-acting $\beta$ agonist

Corticosteroids

- If patient tolerates oral medications, prednisone 30-40 $\mathrm{mg}$ per os $q$ day for 10 days [27-29]

- If patient can not tolerate, give the equivalent dose i.v. for up 14 days [45, 46]

- Consider use inhaled corticosteroids by MDI or hand-held nebuliser [30]

Antibiotics (based on local bacteria resistance patterns) [7-11, 18, 28-36]

- Choice should be based on local bacteria resistance patterns

- Amoxicillin/clavulanate

- Respiratory fluoroquinolones (gatifloxacin, levofloxacin, moxifloxacin)

- If Pseudomonas spp. and or other Enterobactereaces spp. are suspected consider combination therapy [7]

MDI: metered-dose inhaler. 


\subsubsection{Ventilatory support}

Several controlled trials have evaluated the effect of noninvasive ventilation on different outcomes, including rate of intubation, length of ICU and hospital stay, and dyspnoea and mortality. Although not all showed the same results in the most important outcomes, such as mortality, there was uniform agreement that noninvasive positive-pressure ventilation was effective in reversing acute respiratory failure. The patients most likely to benefit from noninvasive ventilation are those with elevated arterial carbon dioxide, who are able to cooperate with the care givers and with no other important comorbid problems (sepsis, severe pneumonia, cardiovascular collapse, arrhythmias) (see Exacerbation: assisted ventilation). 


\subsubsection{Criteria for hospital discharge}

As a general rule, patients hospitalised for an acute exacerbation can be considered for discharge once the reasons for admission are controlled and/or reversed. Based on consensus, the guidelines described on table 7 have proven useful in practice.

Table 7. - Conditions that need to be met when considering patients for discharge

- Symptoms are returning to baseline, including eating, sleeping etc.

- Haemodynamic stability

- Oxygenation returning to baseline (see Exacerbation: inpatient oxygen therapy)

- Inhaled $\beta$-agonist therapy is required less frequently

- Patient able to resume ambulation

- Able to eat and sleep without frequent awakening by dyspnoea

- Off parenteral therapy for 12-24 h

- Patient (or home caregiver) understands correct use of medications

- Follow-up and homecare arrangements have been completed (e.g. visiting nurse, oxygen delivery, meal provisions etc.)

\subsubsection{Follow-up evaluation}

Once discharged, the patient should be followed. There are no studies that have addressed the specific schedules more likely to result in positive outcome but patients with frequent exacerbations are more likely to relapse. Likewise, patients who have developed respiratory failure requiring admission to an intensive care carry a very high mortality risk. Based on this, the guidelines in table 8 are reasonable.

Table 8. - Guidelines for the re-evaluation of patients admitted for exacerbation of COPD

- $\quad$ Patients need to be reassessed within 4 weeks

- Evaluate improvement in symptoms and physical exam

- Assess need for supplemental oxygen (see Exacerbation: inpatient oxygen therapy)

- Repeat complementary exams if previous abnormalities were present.

- Assess ability of the patient to cope with the environment

- Understand and re-adjust the treatment regimen 


\subsection{End of life}

For end-of-life issues see Ethical and palliative care issues. 


\subsection{References}

1. Peters DK, Kochanek DK, Murphy SL. Deaths: final data for 1996. Natl Vital Stat Rep 1998; 47: 1-100.

2. Higgins $\mathrm{MW}$, Thom $\mathrm{T}$. Incidence, prevalence and mortality: intra-and inter-country difference. In: Hensley MJ, Saunders NA, eds. Clinical Epidemiology of Chronic Obstructive Pulmonary Disease. New York, Marcel Dekker, 1990; pp. 23-43.

3. Mannino D, Homa DM, Akinbami LJ, Ford ES, Red SC. Chronic obstructive pulmonary disease surveillance, United States 1971-2000. MMWR 2002; 51: 1-16.

4. Connors AF Jr, Dawson NV, Tomas C, et al. Outcomes following acute exacerbation of severe chronic obstructive lung disease. The SUPPORT investigators (Study to Understand Prognoses and Preferences for Outcomes and Risks of Treatment). Am J Respir Crit Care Med 1996; 154: 959-967.

5. Seneff MG, Wagner DP, Wagner RP, et al. Hospital and 1-year survival of patients admitted to intensive care units with acute exacerbation of chronic obstructive pulmonary disease. JAMA 1995; 274: 1852-1857.

6. Fuso L, Incalzi RA, Pistrelli R, et al. Predicting mortality of patients hospitalized for acutely exacerbated chronic obstructive pulmonary disease. Am J Med 1995; 98: 272-277.

7. Adams SG, Anzueto A. Treatment of acute exacerbations of chronic bronchitis. In: Antibiotics in Respiratory Infections. A. Anzueto, ed. Seminar Respir Infect 2000; 15: 234247.

8. Fagon JY, Chastre J. Severe exacerbations of COPD patients; the role of pulmonary infections. Semin Respir Infect 1996; 11: 109-118.

9. Wedzicha JA. The heterogeneity of chronic obstructive pulmonary disease. Thorax 2000; 55: 631-632.

10. Emerman CL, Effron D, Lukens TW. Spirometric criteria for hospital admission of patients with acute exacerbations of COPD. Chest 1991; 99: 595-599.

11. Miravitlles M, Guerrero T, Mayordomo C, Sanchez-Agudo L, Nicolu J, EOLO study group. Factors associated with increased risk of exacerbation and hospital admission in a 
cohort of ambulatory COPD patients: a multiple logistics regression analysis. Respiration 2000; 67: 495-501.

12. Miravitlles M. Epidemiology of chronic obstructive pulmonary disease exacerbations. Clin Pulm Med 2002; 9: 191-197.

13. Ball P, Harris JM, Lowson D, et al. Acute infective exacerbations of chronic bronchitis. QJM 1995; 88: 61-68.

14. Adams SG, Melo J, Luther M, Anzueto A. Antibiotics are associated with lower relapse rates in outpatients with acute exacerbations of COPD. Chest 2000; 117: 1345-1352.

15. Anzueto A, Rizzo JA, Grossman RF. The infection-free interval: its use in evaluating antimicrobial treatment in acute exacerbations of chronic bronchitis. Clin Infect Dis 1999; 28: $1344-1345$.

16. Chodosh S, McCarthy J, Farkas S, et al. Randomized, double-blind study of ciprofloxacin and cefuroxime axetil for treatment of acute exacerbations of chronic bronchitis. Clin Inf Dis 1998; 27: 722-729.

17. Chodosh S, Schreurs JM, Siami G, et al. Efficacy of oral ciprofloxacin vs clarithromycin for treatment of acute exacerbations of chronic bronchitis. Clin Inf Dis 1998; 27: 730-738.

18. Wilson R, Schentag JJ, Ball P, Mandell. A comparison of gemifloxacin and clarithromycin in acute exacerbations of chronic bronchitis and long-term clinical outcomes. Clin Ther 2002; 24: 639-652.

19. Miravitles M, Murio C, Guerrero T, Gisbert R for the DAFNE Study Group. Pharmacoeconimic evaluation of acute exacerbations of chronic bronchitis and COPD. Chest 2002; 121: 1449-1455.

20. Aaron SD, Vandermheen KL, Clinch JJ, et al. Measurement of short-term changes in dyspnea and disease specific quality of life following an acute COPD exacerbation. Chest 2002; 121: 688-696.

21. Janson DI. Anxiety and depression are related to the outcome of emergency treatment in patients with obstructive pulmonary disease. Chest 2002; 122: 1633-1637.

22. Emerman CL, Cydulka RAK. Evaluation of high-yield criteria for chest radiography in acute exacerbation of chronic obstructive pulmonary disease. Ann Emerg Med 1993; 22; 680684. 
23. O'Brien C, Guest PF. Physiological and radiological characterization of patients diagnosed with chronic obstructive pulmonary disease in primary care. Thorax 2000; 55: 631-632.

24. Karpel JP, Pesin J, Greenberg D, et al. A comparison of the effects of ipratropium bromide and metaproterenol sulfate in acute exacerbation of COPD. Chest 1990; 98: 835-839.

25. Emerman CL, Cydulk RK. Effect of difficult albuterol dosing regimens in the treatment of acute exacerbation of chronic obstructive disease. Ann Emerg Med 1997; 29: 474-478.

26. Turner MO, Patel A, Ginsburg S, et al. Bronchodilator delivery in acute airflow obstruction. A meta-analysis. Arch Intern Med 1997; 157: 1736-1744.

27. Hudson LD, Monti M. Rationale and use of corticosteroids in chronic obstructive pulmonary disease. Med Clin N Am 1990; 74: 661-690.

28. Davies L. Angus RM, Calverley PM. Oral corticosteroids in patients admitted to hospital with exacerbations of chronic obstructive pulmonary disease: a prospective randomized controlled trial. Lancet 1999; 345: 456-460.

29. Thompson WH, Nielson CP, Carvalho P, et al. Controlled trial of oral prednisone in outpatients with acute COPD exacerbation. Am J Respir Crit Care Med 1996; 154: 407-412.

30. Maltais F, Ostinelli J, Bourbeau J, Tonnel A, Jacquemet N, Haddon J. Comparison of nebulized budesonide and oral prednisolone with placebo in the treatment of acute exacerbations of chronic obstructive pulmonary disease: a randomized controlled trial. Am J Respir Crit Care Med 2002; 1654: 698-703.

31. Anthonisen NR, Manfreda J, Warren CPW, et al. Antibiotic therapy in exacerbations of chronic obstructive pulmonary disease. Ann Intern Med 1987; 106: 196-204.

32. Saint SK, Bent S. Vittinghoff E, et al. Antibiotics in chronic obstructive pulmonary disease exacerbations: a meta-analysis. JAMA 1995; 273: 957-960.

33. Wilson R, Tillotson G, Ball P. Clinical studies in chronic bronchitis: a need for better definition and classification of severity. J Antimicrob Chemother 1996; 37: 205-208.

34. Nouira S, Marghli S, Belghith M, Besbes L, Elatrous S, Abroug F. Once daily oral ofloxacin in chronic obstructive pulmonary disease exacerbation requiring mechanical ventilation: a randomized placebo-controlled trial. Lancet 2001; 358: 2020-2035.

35. Swanson RN, Lainez-Ventosilla A, De Salvo MC, et al. Three-day azithromycin $500 \mathrm{mg}$ q.i.d. vs 10-day clarithromycin $500 \mathrm{mg}$ b.i.d. for acute exacerbation of chronic bronchitis in adults. Am J Respir Crit Care Med 2002; I65: A269. 
36. Anzueto A, Fisher CL, Busman T, et al. Comparison of the efficacy of extended-release clarithromycin tablets and amoxicillin/clavulanate tablets in the treatment of acute exacerbations of chronic bronchitis. Clin Ther 2001; 23: 72-86.

37. Cazzola M, Vinciguerra A, Di Perna F, et al. Comparative study of dirithromycin and azithromycin in the treatment of acute bacterial exacerbation of chronic bronchitis. $J$ Chemother 1999; 11: 119-125.

38. Gotfried MH, De Abate A, Fogarty C, et al. Comparison of 5-day, short course gatifloxacin therapy with 7-day gatifloxacin therapy and 10-day clarithromycin therapy for acute exacerbation of chronic bronchitis. Clin Ther 2001; 23: 97-107.

39. Wilson R, Kubin R, Ballin I, et al. Five day moxifloxacin therapy compared with 7 day clarithromycin therapy for the treatment of acute exacerbations of chronic bronchitis. $J$ Antimicrobial Chemother 1999; 44: 501-513.

40. Grossman R, Mukherjee J, Vaughan D, et al. The Canadian Ciprofloxacin health economic study group. A 1-year community based health economic study of ciprofloxacin $v s$ usual antibiotic treatment in acute exacerbations of chronic bronchitis. Chest 1998; 113: 131-141.

41. Kessler R, Faller M, Fourgaut G, Nennevier B, Weitsenblum E. Predictive factors of hospitalization for acute exacerbation in a series of 64 patients with chronic obstructive pulmonary disease. Am J Crit Care Med 1999; 159: 158-164.

42. Garcia-Aymerich J, Monso E, Marrales R, et al. Risk factors for a chronic obstructive pulmonary disease exacerbation. Am J Respir Crit Care Med 2001; 164: 1002-1007.

43. Dhand R, Jubran A, Tobin MJ. Bronchodilator delivery by metered-dose inhaler in ventilator-supported patients. Am J Respir Crit Care Med 1995; 151: 1827-1833.

44. Duarte AG, Dhand R, Reid R, et al. Serum albuterol levels in mechanically ventilated patients and healthy subjects after metered-dose inhaler administration. Am J Respir Crit Care Med 1996; 154: 1658-1663

45. Albert RK, Martin TR, Lewis SW. Controlled clinical trial of methylprednisolone in patients with chronic bronchitis and acute respiratory insufficiency. Ann Intern Med 1980; 92: $753-758$.

46. Niewhoehner DE, Erbland ML, Deupree RH, et al. Effect of systemic glucocorticoids on exacerbations of chronic obstructive pulmonary disease. Department of Veterans Affairs Cooperative Study Group. N Engl J Med 1999; 340; 1941-1947. 


\section{Exacerbation: inpatient oxygen therapy}

\subsection{Key points}

- The goal is to prevent tissue hypoxia by maintaining arterial oxygen saturation $\left(\mathrm{Sa}_{\mathrm{a}} \mathrm{O}_{2}\right)$ at $>90 \%$.

- Main delivery devices include nasal cannula and venturi mask.

- Alternative delivery devices include nonrebreather mask, reservoir cannula, nasal cannula or transtracheal catheter.

- Arterial blood gases should be monitored for arterial oxygen tension $\left(\mathrm{Pa}, \mathrm{O}_{2}\right)$, arterial carbon dioxide tension $\left(\mathrm{Pa}_{\mathrm{a}} \mathrm{CO}_{2}\right)$ and $\mathrm{pH}$.

- Arterial oxygen saturation as measured by pulse oximetry $\left(\mathrm{S}_{\mathrm{p}}, \mathrm{O}_{2}\right)$ should be monitored for trending and adjusting oxygen settings.

- Prevention of tissue hypoxia supercedes $\mathrm{CO}_{2}$ retention concerns.

- If $\mathrm{CO}_{2}$ retention occurs, monitor for acidemia.

- If acidemia occurs, consider mechanical ventilation.

\subsection{Goal}

The goal of inpatient oxygen therapy is to maintain $\mathrm{Pa}, \mathrm{O}_{2}>8 \mathrm{kPa}(60 \mathrm{mmHg})$ or $\mathrm{Sp}_{\mathrm{p}}, \mathrm{O}_{2}>90 \%$ in order to prevent tissue hypoxia and preserve cellular oxygenation. Because of the shape of the oxyhaemoglobin dissociation curve, increasing the $\mathrm{Pa}, \mathrm{O}_{2}$ to values much greater than $8 \mathrm{kPa}$ (60 $\mathrm{mmHg}$ ) confers little added benefit (1-2 vol \%) and may increase the risk of $\mathrm{CO}_{2}$ retention, which may lead to respiratory acidosis [1].

\subsection{Oxygen delivery methods}

The choice of delivery devices depends on the patient's oxygen requirement, efficacy of the device, reliability, ease of therapeutic application and patient acceptance. An arterial blood gas $(\mathrm{ABG})$ or oximetry is advised upon switching delivery devices. Frequent monitoring is highly advisable in the unstable patient [2-5].

The first-line options and the second-line options for oxygen delivery are presented here. 


\subsubsection{First-line options}

\subsubsection{Standard nasal cannula}

The standard nasal cannula delivers an inspiratory oxygen fraction $\left(F \mathrm{I}, \mathrm{O}_{2}\right)$ of $24-40 \%$ at supply flows ranging from $1-5 \mathrm{~L} \cdot \mathrm{min}^{-1}$. The formula is $\mathrm{FI}_{\mathrm{I}} \mathrm{O}_{2}=20 \%+(4 \times$ oxygen litre flow $)$. The $F \mathrm{I}, \mathrm{O}_{2}$ is influenced by breath rate, tidal volume and pathophysiology. The slower the inspiratory flow the higher the $F \mathrm{I}, \mathrm{O}_{2}[6]$.

\subsubsection{Venturi mask}

A Venturi mask mixes oxygen with room air, creating high-flow enriched oxygen of a settable concentration. It provides an accurate and constant $F \mathrm{I}_{1} \mathrm{O}_{2}$. Typical $F \mathrm{I}, \mathrm{O}_{2}$ delivery settings are 24, $28,31,35$ and $40 \%$ oxygen. The Venturi mask is often employed when the clinician has a concern about $\mathrm{CO}_{2}$ retention [2].

\subsubsection{Second-line options}

\subsubsection{Simple face mask}

The volume of the face mask is $100-300 \mathrm{~mL}$. It delivers an $F \mathrm{I}, \mathrm{O}_{2}$ of $40-60 \%$ at $5-10 \mathrm{~L} \cdot \mathrm{min}^{-1}$. The $F \mathrm{I}, \mathrm{O}_{2}$ is influenced by breath rate, tidal volume and pathology. The face mask is indicated in patients with nasal irritation or epistaxis. It is also useful for patients who are strictly mouth breathers. However, the face mask is obtrusive, uncomfortable and confining. It muffles communication, obstructs coughing and impedes eating [2].

\subsubsection{Nonrebreathing face mask with reservoir and one-way valve}

The nonrebreathing face mask is indicated when an $F \mathrm{I}, \mathrm{O}_{2}>40 \%$ is required. It may deliver $\mathrm{FI}, \mathrm{O}_{2}$ up to $90 \%$ at high flow settings. Oxygen flows into the reservoir at $8-10 \mathrm{~L} \cdot \mathrm{min}^{-1}$, washing the patient with a high concentration of oxygen. Its major drawback is that the mask must be tightly sealed on the face, which is uncomfortable. There is also a risk of $\mathrm{CO}_{2}$ retention [2].

\subsubsection{Reservoir cannulas}

Reservoir cannulas improve the efficiency of oxygen delivery. Hence, patients may be well oxygenated at lower flows. Litre flows of $\geq 8 \mathrm{~L} \cdot \mathrm{min}^{-1}$ have been reported to adequately oxygenate patients with a high flow requirement $[7,8]$. 


\subsubsection{High-flow transtracheal catheters}

Transtracheal catheters deliver oxygen directly into the trachea. There are wash-out and storage effects that promote gas exchange as well as providing high-flow oxygen. High-flow transtracheal catheters may reduce the work of breathing and augment $\mathrm{CO}_{2}$ removal. Patients who have been extubated may benefit from an interim of high-flow transtracheal oxygen to better ensure weaning success $[9,10]$.

\subsubsection{High-flow warmed and humidified nasal oxygen}

Nasal oxygen has been administered at lows ranging from $10-40 \mathrm{~L} \cdot \mathrm{min}^{-1}$. When this oxygen is warmed to body temperature and saturated to full humidity, it is comfortable. Early clinical and bench studies have demonstrated $\mathrm{Sa}, \mathrm{O}_{2}$ equivalent to or surpassing nonrebreathing face masks at the same supply flow setting. Definitive recommendations about high-flow nasal oxygen will await more definitive studies [11].

\subsection{Setting and adjusting oxygen flow}

See figure 1. 


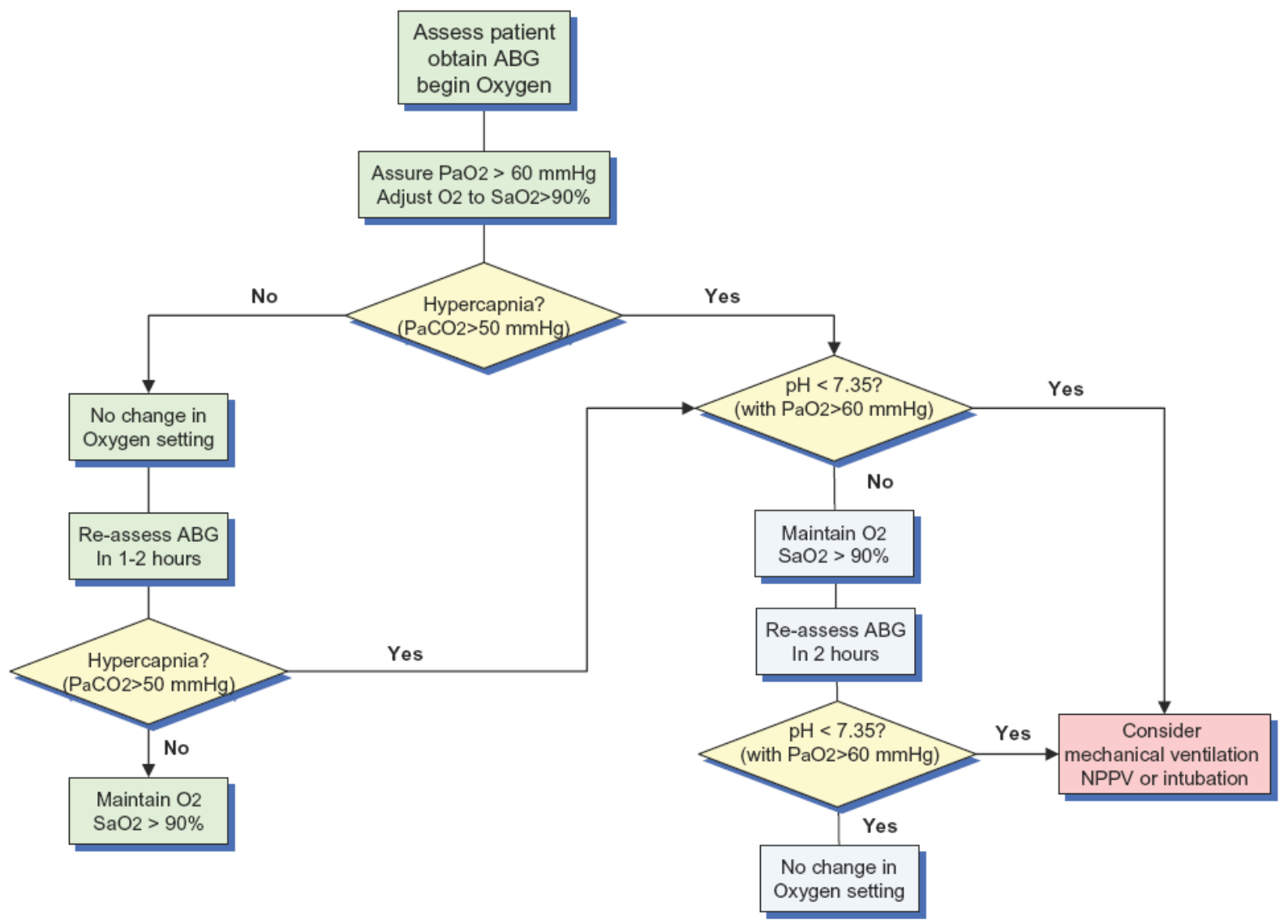

Fig. 1. - Algorithm to correct hypoxaemia in an acutely ill chronic obstructive pulmonary disease patient. ABG: arterial blood gas; $\mathrm{Pa}, \mathrm{O} 2$ : arterial oxygen tension; O2: oxygen; Sa,O2: arterial oxygen saturation; $\mathrm{Pa}, \mathrm{CO}_{2}$ : arterial carbon dioxide tension; NPPV: noninvasive positive pressure ventilation.

\subsubsection{Initial setting}

Acute increases in $F \mathrm{I}_{2} \mathrm{O}_{2}$ may cause a ventilation/perfusion mismatch and lead to hypercarbia. Hence, it is recommended that the initial flow setting be adjusted to increase the $P a, O_{2}$ to just above $8 \mathrm{kPa}(60 \mathrm{mmHg})[12,13]$.

\subsubsection{Oxygen titration}

Following the initial setting, the oxygen flow should be adjusted via ABG to bring the oxygen pressure to $>8 \mathrm{kPa}(60 \mathrm{mmHg})$ or $\mathrm{Sa}_{\mathrm{a}} \mathrm{O}_{2}>90 \%(92-96 \%)$. If $\mathrm{CO}_{2}$ retention occurs, the $\mathrm{pH}$ should be observed. If it is nonacidemic, the high $\mathrm{CO}_{2}$ should be accepted as it is chronic. If the $\mathrm{pH}$ is acidemic, a Venturi mask should be considered, to closely control the $F \mathrm{I}, \mathrm{O}_{2}$, or invasive 
or noninvasive mechanical ventilation. All other medical treatments, including bronchodilators, secretion clearance, steroids and treatment of infection, should be optimised. As the patient becomes ambulatory, pulse oximetry can be used to determine an exercise flow setting while walking in the hallway (fig. 1) [1].

\subsubsection{Hypercarbia concern}

Patients with $\mathrm{Pa}, \mathrm{CO}_{2}<6 \mathrm{kPa}(45 \mathrm{mmHg})$, receiving oxygen sufficient to raise $P \mathrm{a}, \mathrm{O}_{2}$ to $8 \mathrm{kPa}$ (60 $\mathrm{mmHg}$ ), will be unlikely to experience $\mathrm{CO}_{2}$ retention [14]. If $\mathrm{CO}_{2}$ retention does occur, it is often minor and not usually accompanied by significant acidosis. It is a reasonable goal to adjust the oxygen setting to correct the hypoxaemia to a $\mathrm{Pa}_{2} \mathrm{O}_{2}$ slightly $>8 \mathrm{kPa}(60 \mathrm{mmHg})$, allowing 20-30 min to achieve steady state. The $\mathrm{pH}$ should be monitored for changes in acidbase status. If adequate oxygenation is unachievable without progressive respiratory acidosis, then noninvasive or invasive mechanical ventilation should be considered (see Exacerbation: assisted ventilation) [15-18].

\subsubsection{Monitoring following hospital discharge}

Patients may be started on oxygen for the first time during hospitalisation for an acute exacerbation and discharged before recovery is complete. Patients with hypoxaemia at discharge may require short-term oxygen therapy as the effects of the exacerbation are clearing. After 30-90 days, oxygen may no longer be required. Thus re-evaluation of the patient's oxygen and medical status should be completed. If the patient no longer meets the prescribing criteria for long-term oxygen therapy (LTOT), oxygen should be discontinued, as there is no proven survival benefit for patients with mild hypoxaemia [19] (see Management of stable COPD: long-term oxygen therapy).

Some patients who needed oxygen prior to hospitalisation may, over time, increase their $\mathrm{Pa}, \mathrm{O}_{2}$ to the point that they no longer qualify for oxygen. This phenomenon is thought to be due to a reparative effect of LTOT. Withdrawing oxygen from these patients may negate the reparative effect and cause the patient's status to deteriorate to the point of meeting the physiological requirement for oxygen. Consequently, these patients should continue their oxygen therapy without interruption as withdrawing their oxygen might be detrimental [20, 21]. 


\subsection{References}

1. Carter R. Oxygen and acid-base status: measurement, interpretation, and rationale for oxygen therapy. Chapter 5. In: Tiep BL, ed. Portable oxygen therapy: including oxygen conserving methodology. Mt. Kisco, NY, Futura Publishing Co.; pp. 136-138.

2. Burton GG, Hodgkin JE, Ward JJ. Respiratory Care - a guide to clinical practice. $4^{\text {th }}$ ed. Philidelphia, Lippincott-Raven Pub co, 1997; pp. 381-395.

3. Kory RC, Bergmann JC, Sweet RD, et al. Comparative evaluation of oxygen therapy techniques. JAMA 1962; 179: 123-128.

4. Gibson RL, Comer PB, Beckman RW, et al. Actual tracheal oxygen concentration with commonly used therapy. Anesthesiology 1976; 44: 71-73.

5. Leigh JM. Variation in performance of oxygen therapy devices. Anaesthesia 1970; 25: 210222.

6. Tiep BL. Continuous flow oxygen therapy. In: Tiep BL, ed. Portable oxygen therapy: including oxygen conserving methodology. Mt. Kisco, NY, Futura Publishing Co.; pp. 205220.

7. Dumont CP, Tiep BL. Using a reservoir nasal cannula in acute care. Critical Care Nurse 2002; 22: 41-46.

8. Sheehan JC, O'Donohue WJ. Use of a reservoir nasal cannula in hospitalized patients with refractory hypoxemia. Chest 1996: 110.

9. Christopher K, Van Hooser DT, Jorgenson S, et al. Preliminary observations of transtracheal augmented ventilation for chronic severe respiratory distress. Respir Care 2001; 46: 15-25.

10. Schaten MA, Christopher KL, Goodman S, et al. High-flow transtracheal oxygen: a promising technique for the management of hypercarbic respiratory failure. Chest 1990; 98: $22 \mathrm{~S}$.

11. Tiep BL, Barnett M. High flow nasal versus high flow mask ox delivery: tracheal gas concentrations through a head extension airway model. Respir Care 2002; 47: A9.

12. Mithoefer JC, Keighley JF, Karetzky MS. Response of the arterial $\mathrm{PO}_{2}$ to oxygen administration in COPD: interpretation of findings in a study of 46 patients and 14 normal subjects. Ann Intern Med 1971; 74: 328-335.

13. Oxygen therapy for adults in the acute care facility - 2002 revision \& update. Respir Care 2002; 47: 717-720. 
14. Lopez-Majano V, Dutton RE. Regulation of respiratory drive during oxygen breathing in chronic obstructive lung disease. Am Rev Respir Dis 1973; 108: 232-240.

15. Dunn WF, Nelson SB, Hubmayr RD. Oxygen-induced hypercarbia in obstructive pulmonary disease. Am Rev Respir Dis 1991; 144: 526-530.

16. Aubier M, Murciano D, Milie-Emili M, et al. Effects of the administration of oxygen therapy on ventilation and blood gases in patients with chronic obstructive pulmonary disease during acute respiratory failure. Am Rev Respir Dis 1980; 122: 747-754.

17. Aubier M, Murciano D, Fournier M, et al. Central respiratory drive in acute respiratory failure of patients with chronic obstructive pulmonary disease. Am Rev Respir Dis 1980; 122: 191-199.

18. Sassoon CS, Hassell KT, Mahutte CK. Hyperoxic-induced hypercapnia in stable chronic obstructive pulmonary disease. Am Rev Respir Dis 1987; 135: 907-911.

19. Górecka D, Gorzelak K, Śliwiński P, Tobiasz M, Zieliński J. Effect of long term oxygen therapy on survival in patients with chronic obstructive pulmonary disease with moderate hypoxaemia. Thorax 1997; 52: 674-679.

20. O'Donohue WJ. Effect of arterial oxygen therapy on increasing arterial oxygen tension in hypoxemia patients with stable chronic obstructive pulmonary disease while breathing ambient air. Chest 1991; 100: 968-972.

21. Oba Y, Salzman GA, Willsie SK. Re-evaluation of continuous oxygen therapy after initial prescription in patients with chronic obstructive pulmonary disease. Respir Care 2000; 45: $401-406$. 


\section{Exacerbation: assisted ventilation}

\subsection{Key points}

- Noninvasive positive pressure ventilation (NPPV) should be offered to patients with exacerbations when, after optimal medical therapy and oxygenation, respiratory acidosis ( $\mathrm{pH}<7.36)$ and or excessive breathlessness persist. All patients considered for mechanical ventilation should have arterial blood gases measured.

- If $\mathrm{pH}<7.30$, NPPV should be delivered under controlled environments such as intermediate intensive care units (ICUs) and/or high-dependency units.

- If $\mathrm{pH}<7.25$, NPPV should be administered in the ICU and intubation should be readily available.

- The combination of some continuous positive airway pressure (CPAP) (e.g. 4-8 $\mathrm{cmH}_{2} \mathrm{O}$ ) and pressure support ventilation (PSV) (e.g. $10-15 \mathrm{cmH}_{2} \mathrm{O}$ ) provides the most effective mode of NPPV.

- Patients meeting exclusion criteria should be considered for immediate intubation and ICU admission.

- In the first hours, NPPV requires the same level of assistance as conventional mechanical ventilation.

\subsection{Background}

Mechanical ventilation, either "invasive" or "noninvasive", is not a therapy but it is a form of life support until the cause underlying the acute respiratory failure is reversed with medical therapy [1-3].

\subsection{Indications for mechanical ventilation}

The institution of mechanical ventilation should be considered when, despite "optimal" medical therapy and oxygen administration there is moderate-to-severe acidosis $(\mathrm{pH}<7.36)$ and hypercapnia (arterial carbon dioxide tension $\left(\mathrm{Pa}_{\mathrm{a}} \mathrm{CO}_{2}\right)>6-8 \mathrm{kPa}(45-60 \mathrm{mmHg})$ ) and respiratory frequency $>24$ breaths $\cdot \mathrm{min}^{-1}$. 


\subsection{Modes of mechanical ventilation}

Mechanical ventilation can be delivered as follows.

- Through an endotracheal tube bypassing the upper airway, i.e. "conventional" or "invasive" mechanical ventilation.

- Without the use of an endotracheal tube, i.e. "noninvasive" mechanical ventilation or NIMV, which can be instituted in two modes:

- Noninvasive positive pressure ventilation (NPPV) (nasal or face masks)

- $\quad$ negative pressure ventilation (NPV) (e.g. iron lung)

\subsection{Noninvasive positive pressure ventilation}

NPPV is by far the most popular mode of providing noninvasive ventilation $[3,4]$ in combination with some CPAP plus PSV $[1,5]$.

Gas exchange: arterial blood gases improve because of an increase in alveolar ventilation without significant modifications in the alveolar ventilation/perfusion mismatching and gas exchange in the lungs [6].

Pulmonary mechanics: application of CPAP during PSV provides a greater reduction of the work of breathing than either alone, because CPAP counterbalances the intrinsic positive endexpiratory pressure or positive end-expiratory pressure [7].

The pathophysiological rationale for the combined application of CPAP and PSV is illustrated figure $1[1]$. 


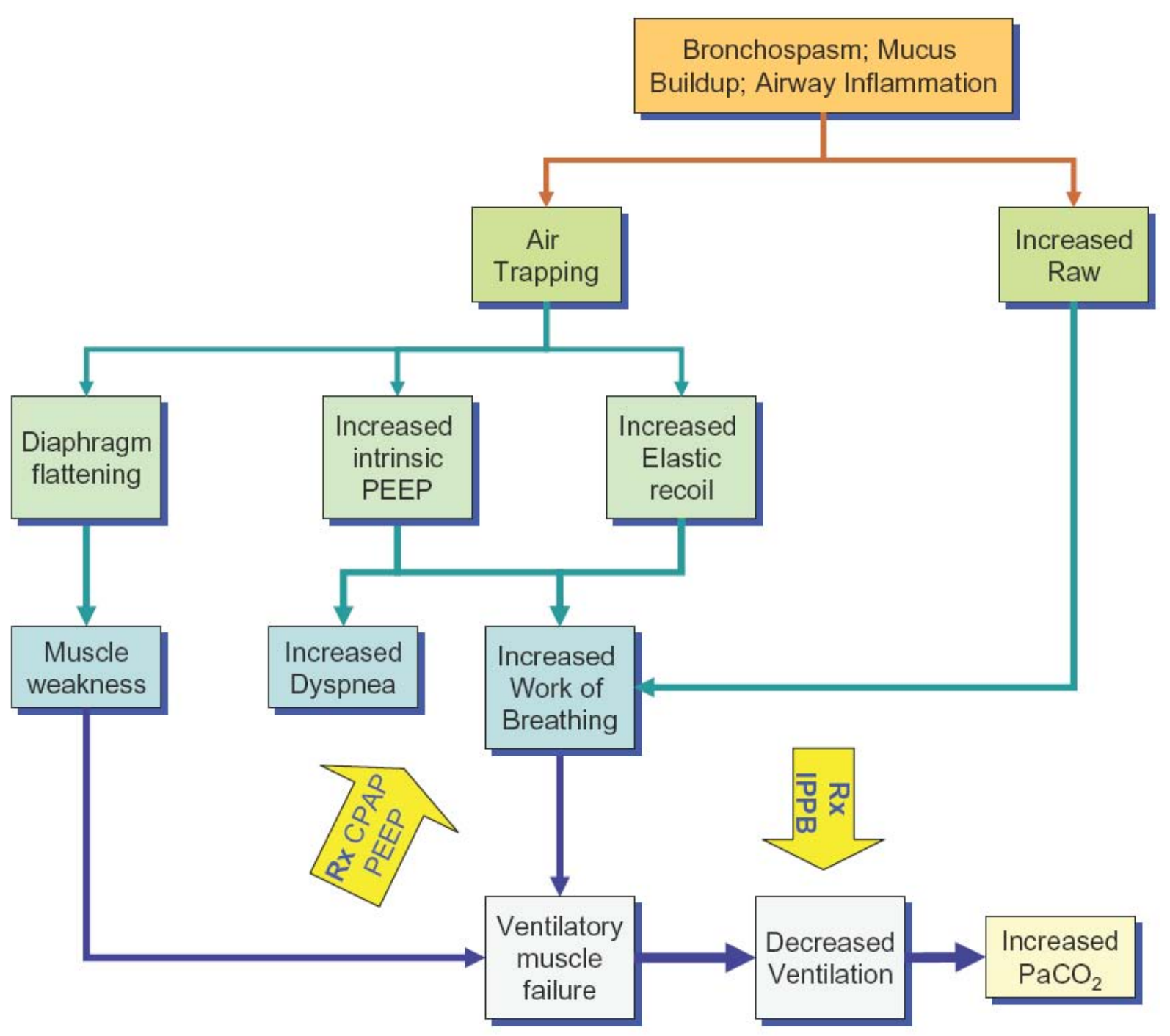

Fig. 1. - The pathophysiological rationale for the combined application of continuous positive airway pressure (CPAP) and pressure support ventilation (PSV). Raw; airway resistance; PEEP: positive end-expiratory pressure; IPPV: intermittent positive pressure ventilation; $\mathrm{Pa}, \mathrm{CO}_{2}$ : arterial carbon dioxide tension.

A few physiological [8,9] and nonrandomised clinical [10] studies suggest that NPV can also be successfully used in the management of exacerbations of chronic obstructive pulmonary disease (COPD) with respiratory failure. However, NPV cannot be recommended until prospective randomised clinical trails with document it's effectiveness and safety.

In addition to randomised clinical trials, high quality meta-analysis showed that NPPV is very effective amd safe in exacerbations of COPD [11] with respiratory acidosis [12]. 
In this section, the clinical settings, contraindications, complications and outcomes of NPPV, as well of the need for invasive ventilation and chronic "home" NPPV are discussed.

\subsubsection{Clinical settings}

NPPV can be delivered in different clinical settings.

- Medical ward [13, 14]: patients with moderate acidosis (pH 7.30-7.35) and hypercapnia (6-8 kpA $\left.\left(\mathrm{Pa}_{\mathrm{a}} \mathrm{CO}_{2} 45-60 \mathrm{mmHg}\right)\right)$.

- Intermediate- or high-dependency respiratory unit $[15,16]$ : patients who present moderate-to-severe acidosis ( $\mathrm{pH}<7.30)$; the facilities for rapid endotracheal intubation and institution of conventional mechanical ventilation should be promptly available.

- ICU [17]: patients with severe respiratory acidosis ( $\mathrm{pH}<7.25)$; in this particular setting, NPPV may be as effective as conventional mechanical ventilation to reverse acute respiratory failure due to COPD [18].

\subsubsection{Contraindications}

Contraindications for NPPV include the following:

- respiratory arrest

- cardiovascular instability (hypotension, arrhythmias, myocardial infarction)

- impaired mental status, somnolence, inability to cooperate

- copious and/or viscous secretions with high aspiration risk

- recent facial or gastro-oesophageal surgery

- craniofacial trauma and/or fixed nasopharyngeal abnormality

- burns

- extreme obesity.

\subsubsection{Complications}

Complications of NPPV include the following:

- facial skin erythema

- nasal congestion

- nasal bridge ulceration 
- sinus/ear pain

- nasal/oral dryness

- eye irritation

- gastric irritation

- aspiration pneumonia

- poor control of secretions.

\subsubsection{Outcomes}

NPPV can be considered successful when:

- arterial blood gases and $\mathrm{pH}$ improve

- dyspnoea is relieved

- the acute episode resolves without the need of endotracheal intubation

- mechanical ventilation can be discontinued

- the patient is discharged from the hospital.

One-year mortality was reported to be lower in patients receiving NPPV for exacerbations of COPD, compared to both optimal medical therapy alone [19] and conventional mechanical ventilation [18].

Factors associated with success of NPPV include:

- younger age

- ability to cooperate

- lower acuity of illness

- experienced team of caregivers

- availability of resources (monitoring).

NPPV fails when the patient either needs intubation or dies because intubation is not performed (i.e. for ethical reasons (e.g. patient's consent, oldest age, terminal condition) or because it is not available). 


\subsection{Invasive ventilation}

Intubation should be considered in patients with the following.

- NPPV failure: worsening of arterial blood gases and or $\mathrm{pH}$ in $1-2 \mathrm{~h}$; lack of improvement in arterial blood gases and or $\mathrm{pH}$ after $4 \mathrm{~h}$.

- Severe acidosis $(\mathrm{pH}<7.25)$ and hypercapnia $\left(P \mathrm{a}, \mathrm{CO}_{2}>8 \mathrm{kPa}(60 \mathrm{mmHg})\right)$.

- Life-threatening hypoxaemia (arterial oxygen tension/inspiratory oxygen fraction <26.6 $\mathrm{kPa}(200 \mathrm{mmHg}))$.

- Tachypnoea $>35$ breaths $\cdot \mathrm{min}^{-1}$.

- Other complications: metabolic abnormalities, sepsis, pneumonia, pulmonary embolism, barotrauma, massive pleural effusion [17].

NPPV should be considered as the first-line intervention, in addition to optimal mechanical therapy, for the management of patients with respiratory failure due to exacerbation of COPD [4]. In the first few hours NPPV requires the same level of assistance as conventional mechanical ventilation [20].

A recent study has clearly stated that NPPV is highly cost effective [21]. In patients who need intubation, NPPV can be considered as a potential successful strategy for weaning [22]. It can also be considered in patients with previous persistent weaning failure [23].

Figure 2 illustrates a possible "flow-chart" for the use of NPPV in exacerbation of COPD complicated by acute respiratory failure. 


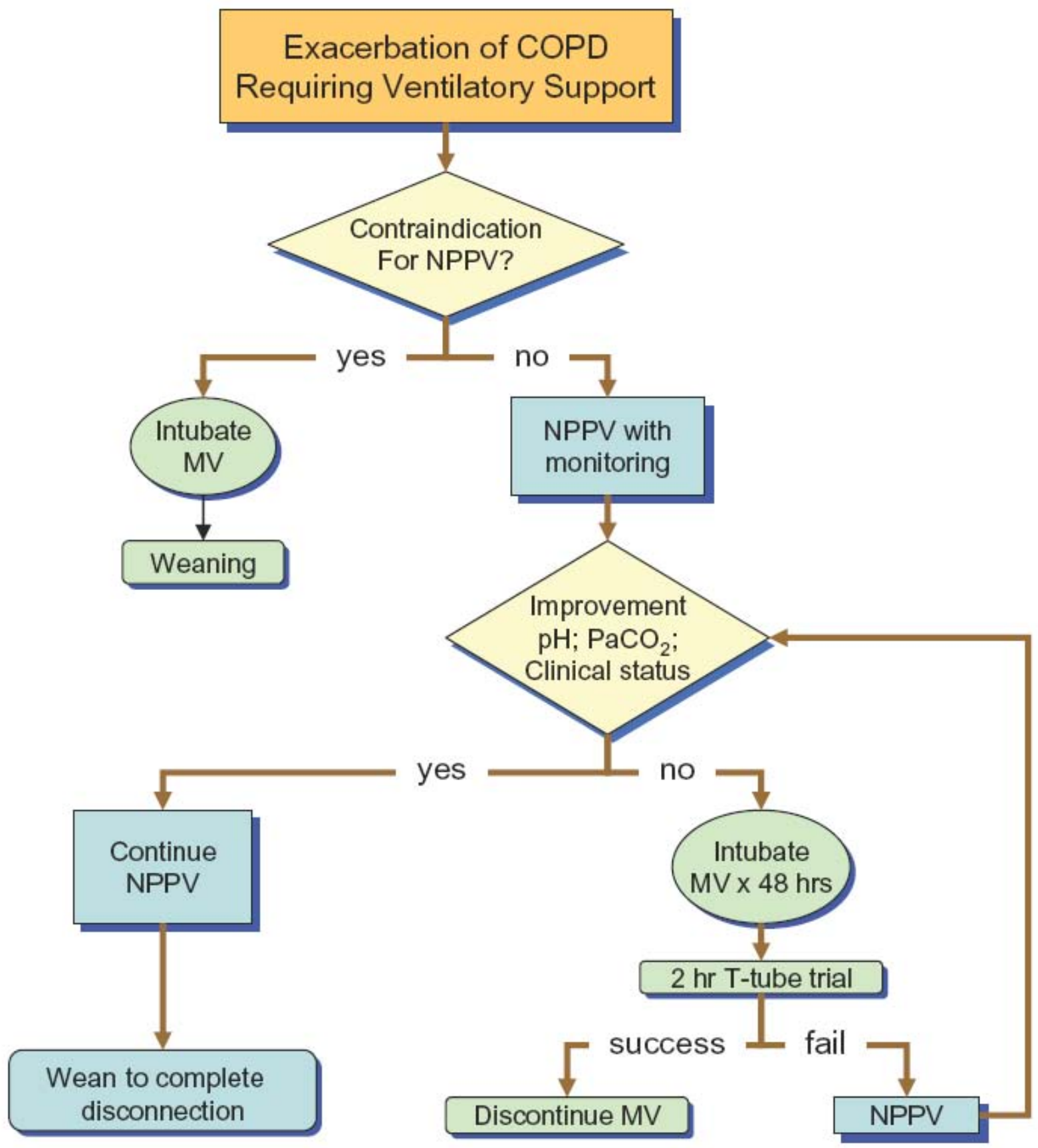

Fig. 2. - Flow-chart for the use of noninvasive positive pressure ventilation (NPPV) during exacerbation of chronic obstructive pulmonary disease (COPD) complicated by acute respiratory failure. MV: mechanical ventilation; $\mathrm{Pa}, \mathrm{CO}_{2}$ : arterial carbon dioxide tension. 


\subsection{Chronic "home" NPPV}

This is still a matter of controversy and no definitive conclusion can be presented [24, 25]. Chronic NPPV should not be systematically prescribed in COPD patients with chronic ventilatory failure, although it could produce some benefits in selected patients whose characteristics are not yet clearly defined [26]. Some patients with end-stage COPD undergo tracheostomy and become chronically ventilator-dependent patients [27]. 


\subsection{References}

1. International Consensus Conferences in Intensive Care Medicine: noninvasive positive pressure ventilation in acute respiratory failure. Am J Respir Crit Care Med 2001; 163: 283291.

2. BTS Guideline. Non invasive ventilation in acute respiratory failure. British Thoracic Society Standards of Care Committee. Thorax 2002; 57: 192-211.

3. Mehta S, Hill NS. Non invasive ventilation. State of the Art. Am J Respir Crit Care Med 2001; 163: 540-577.

4. Lightowler JV, Wedzicha JA, Elliot M, Ram SF. Non invasive positive pressure ventilation to treat respiratory failure resulting from exacerbations of chronic obstructive pulmonary disease: chocrane systematic review and meta-analysis. BMJ 2003; 326: 185-189.

5. Rossi A, Appendini L, Roca J. Physiological aspects of noninvasive positive pressure ventilation. Eur Respir Mon 2001; 16: 1-10.

6. Diaz O, Iglesia R, Ferrer M, et al. Effects of non invasive ventilation on pulmonary gas exchange and hemodynamics duricng acute hypercapnic exacerbations of chronic obstructive pulmonary disease. Am J Respir Crit Care Med 1997; 156: 1840-1845.

7. Appendini L, Patessio A, Zanaboni S, Carone N, GuKow B, Donner CF, Rossi A. Physiologic effects of positive end expiratory pressure and mask pressure support during exacerbation of chronic obstructive pulmonary disease. Am J Respir Crit Care Med 1994; 149: 1069-1076.

8. Gorini M, Corrado A, Villella G, Ginanni R, Augustynen A, Tozzi D. Physiologic effects of negative pressure ventilation in acute exacerbation of chronic obstructive chronic disease. Am $J$ Respir Crit Care Med 2001; 163: 1614-1618.

9. Gorini M, Villella G, Ginanni R, Augustynen A, Tozzi D, Corrado A. Effect of assist negative pressure ventilation by microprocessor based iron lung on breathing effort Thorax 2002; 57: 258-262.

10. Corrado A, Confalonieri M, Marchese S, Mollica C, et al. Iron lung vs mask ventilation in the treatment of acute on chronic respiratory failure in COPD patients Chest 2002; 121: 188195.

11. Peter JV, Moran JL, Philips-Hughes J, Warn D. Noninvasive ventilation in acute respiratory failure. A meta-analysis update. Crit Care Med 2002; 30: 555-562. 
12. Keenan S, Sinuff T, Cook DJ, Hill NS. Which patients with acute exacerbation of chronic obstructive pulmonary disease benefit from noninvasive positive-pressure ventilation? Ann Intern Med 2003; 138: 861-870.

13. Bott J, Carroll MP, Conway JH, et al. Randomised controlled trial of nasal ventilation in acute ventilatory failure due to chronic obstructive airways disease. Lancet 1993; 341: 15551557.

14. Plant PK, Owen JL, Elliott MW, Early use of non-invasive ventilation for acute axacerbations of chronic obstructive pulmonary disease on general respiratory wards: a multicentre randomised controlled trial. Lancet 2000; 355; 1931-1935.

15. Kramer N, Meyer TJ, Meharg J, Cece RD, Hill NS. Randomized, preospective trial of non invasive positive pressure ventilation in acute respiratory failure. Am J Respir Crit Care Med 1995; 151: 1799-1806.

16. Celikel T, Sungur M, Ceyhan B, Karakurt S. Comparison of noninvasive positive pressure ventilation with standard medical therapy in hypercapnic acute respiratory failure. Chest 1998; 114: $1636-1642$.

17. Brochard L, Mancebo J, Wysocki M, et al. Non invasive ventilation for acute exacerbations of chronic obstructive pulmonary disease. N Eng J Med 1995; 333: 817-822.

18. Conti G, Antonelli M, Navalesi P, et al. Noninvaisve vs conventional mechanical ventilation in patients with chronic obstructive pulmonary disease after failure of medical treatment in the ward: a randomized trial. Intensive Care Med 2002; 28: 1701-1707.

19. Plant PK, Owen JL, Elliott MW. Non-invasive ventilation in acute exacerbations of chronic obstructive pulmonary disease: long term survival and predictors of in-hospital outcome. Thorax 2001; 56: 708-712.

20. Nava S, Evangelisti I, Rampulla C, Compagnoni ML, Fracchia C, Rubini F. Human and financial costs of non invasive mechanical ventilation in patients affected by COPD and acute respiratory failure. Chest 1997; 111: 1631-1638.

21. Plant PK, Owen L, Parrott S, Elliott MW. Cost effectiveness of ward based non-invasive ventilation for acute exacerbations of chronic obstructive pulmonary disease: economic analysis of randomised controlled trial. BMJ 2003; 326: 956-960. 
22. Nava S, Ambrosino N, Clini E, et al. Non invasive mechanical ventilation in the weaning of patients with respiratory failure due to chronic obstructive pulmonary disease: a randomized study. Ann Intern Med 1998; 128: 721-728.

23. Ferrer M, Esquinas A, Arancibia F, et al. Noninvasive ventilation during persitent weaning failure. Am J Respir Crit Care Med 2003; 168: 70-76.

24. Clinical indications for non invasive positive pressure ventilation in chronic respiratory failure due to restrictive lung disease, COPD, and nocturnal hypoventilation - a consensus conference report. Chest 1999; 116: 521-534.

25. Casanova C, Celli BR, Tosta L, et al. Long-term controlled trial of nocturnal nasal positive pressure ventilation in patients with severe COPD. Chest 2000; 118: 1582-1590.

26. Clini E, Sturani C, Biaggi S, et al. The Italian multicenter study of non invasive nocturnal pressure support ventilation (NPSV) in COPD patients. Eur Respir J 2002; 20: 529-538.

27. Purro A, Appendini L, De Gaetano A, Gudjonsditter M, Donner CF, Rossi A. Physiologic determinants of ventilator dependence in long-term mechanically ventilated patients. Am $J$ Respir Crit Care Med 2000; 161: 1115-1123. 


\section{Ethical and palliative care issues}

\subsection{Key points}

- Patients with chronic obstructive pulmonary disease (COPD) experience acute exacerbations of their disease, which may produce respiratory failure and a possible need for either ventilatory support or accepting death.

- No clinical features can identify patients with respiratory failure who will experience more burden than benefit from life supportive care.

- Healthcare providers should assist patients during stable periods of health to think about their advance care planning by initiating discussions about end-of-life care.

- $\quad$ These discussions should prepare patients with advanced COPD for a life-threatening exacerbation of their chronic disease while assisting them to go on living and enjoying life.

- End-of-life discussions and advance care planning assist decisions regarding lifesupportive care at the end of life by providing information on probable outcomes and the existence of palliative interventions, such as dyspnoea management and terminal sedation.

- $\quad$ Patients who choose to refuse life supportive care or have it withdrawn require expert delivery of palliative care.

- Physicians and healthcare systems face challenges to ensure that their patients' end-oflife wishes and advance care plans made in one clinical setting will be known and honoured during subsequent care, whether at home, in a hospital or in a nursing facility.

\subsection{Background}

Patients with COPD benefit from advance care planning because they experience acute exacerbations of their disease, which present risks of prolonged mechanical ventilation and death, and require stand-by decisions as to how to proceed. Advanced care planning derives from the principle of patient autonomy, wherein patients shape their healthcare decisions to match their values and preferences. In addition, advance care planning allows care providers to substitute better plans for those that would automatically happen in the absence of clear 
directions. Patients with COPD desire assistance with advance care planning, which is a responsibility of their caregivers.

Unfortunately, most patients with advanced COPD have not discussed their end-of-life wishes with their physicians or other caregivers. Only $19 \%$ of patients with advanced lung disease enrolled in pulmonary rehabilitation programmes have discussed, with their physicians, the appropriateness of life supportive care relative to their lung condition. In addition, only $15 \%$ of patients have discussed, with their physicians, the nature of intubation and mechanical ventilation and $<15 \%$ of patients with advanced lung disease have confidence that their physicians understand their end-of-life wishes [1].

Formal, written documents, such as living wills and durable powers of healthcare, have not fulfilled their goals to improve end-of-life care, in part because they are too general and often too legalistic. Comprehensive advance care planning depends on a holistic approach to patient care tailored to individual needs. Patients need education on the nature of and likely outcome from life supportive interventions and the availability of palliative care to make valid end-oflife decisions.

Patients with advanced COPD suffering from disabling symptoms benefit from integrating palliative care into routine care, especially to relieve dyspnoea and to address emotional and spiritual issues. Patients dying from conditions other than COPD (such as lung cancer) also benefit from palliative services directed towards the relief of respiratory symptoms originating from coexisting COPD.

\subsection{Ethical dilemmas related to COPD}

Patients with moderate-to-severe airflow obstruction experience frequent acute exacerbations, each of which can cause respiratory failure and a possible need for ventilatory support [2].

Hospitalisation for acute respiratory failure identifies a subgroup of COPD patients with a guarded long-term prognosis. Among such patients, 89\% survive to hospital discharge [3]. However, survival to discharge decreases to $76 \%$ if intubation with mechanical ventilation is 
required [4]. Only 59\% of such patients are still alive $1 \mathrm{yr}$ after hospital discharge and the quality of life after discharge is frequently poor because of unremitting respiratory symptoms [5].

This guarded prognosis presents ethical dilemmas, because the patients may not benefit from intubation and mechanical ventilation if they have far-advanced disease, and they may have a poor baseline quality of life and a low possibility of being weaned from ventilatory support. Thus, withdrawal of life supportive care may be considered for ventilator-dependent patients who have failed to improve despite aggressive respiratory care.

Unfortunately, no clinical factors at the time of hospital admission accurately identify patients who will fail to benefit from life supportive care [2]. In the absence of accurate predictors of clinical outcome, caregivers must recognise and address the ethical dilemmas that arise in caring for patients with advanced COPD. In the end, patients and caregivers need to consider the likely benefit and burden in deciding to initiate life supportive care.

\subsection{Factors that guide end-of-life planning}

If the patient has, or can have, clear preferences about treatment, respect for the patient requires that care providers give effect to the patient's views. Autonomy of the patient is the predominant ethical principle that drives end-of-life decision-making in many societies. Most patients with advanced COPD want to make their own decisions regarding life supportive care [1]. Many, but not all, patients wish to retain control of these decisions, if they lose decisionmaking capacity, through their surrogate decision-makers or through their written advance directives [6].

To make informed decisions, patients need knowledge of the nature of alternative therapeutic decisions and their probable outcomes. Patients with severe lung disease often alter their willingness to accept life supportive care when informed of a low likelihood of survival or the likelihood that recovery will entail an unacceptable functional status. Discussions with their physicians and other healthcare providers about possible future advanced life supportive care 
interventions are needed during stable periods of health, before these interventions have taken place. Decisions about life-supportive care are aided by explaining time-limited trials of treatment, which allow medical treatments for a predetermined time, after which they can be withdrawn if the potential benefits do not occur.

Patients with COPD should be asked what they understand about how the disease will affect them over time and whether they wish to discuss their advance care planning. Most patients with advanced lung disease desire advance care planning discussions with their physicians, while a small minority $(<5 \%)$ do not [1]. Most patients with chronic health conditions believe these discussions will decrease their anxiety and depression $[1,6,7]$. Patients who initially refuse these discussions may become more receptive to talking about advance care planning after they receive general information regarding the nature of their disease [8].

All caregivers should assess patients' needs for advance care planning. The caregiver most closely involved with the patient's care should initiate advance care planning discussions, which has been termed "captaincy" [9]. Caregivers should become informed about end-of-life planning and palliative care. Patients accept nonphysician rehabilitation caregivers as acceptable sources of information on advance care planning [1].

Pulmonary rehabilitation provides an important opportunity to assist advance care planning for patients with moderate-to-severe COPD. Educational programmes on advance care planning within pulmonary rehabilitation increase the adoption rate for instruments of advance care planning and patient-physician discussion about end-of-life care [10]. Most pulmonary rehabilitation programme directors $(70 \%)$ consider end-of-life education as an appropriate component of their curriculum [11].

To date, most interventions to encourage caregivers to initiate end-of-life planning discussions with their patients, such as hospital policies, case manager facilitators, computer prompts to electronic medical records or physician education, have had only marginal benefit [12-23]. Greater research is needed to understand the barriers that limit the occurrence of these 
discussions betweens patients and their physicians and other caregivers. Recent reports propose strategies for improving implementation of advance care planning in hospital settings [24]. These strategies include defining, as sentinel events and medical errors, the absence of advance care plans or the miscommunication of patients' advance care decisions, structuring healthcare system reimbursement for hospitalisation to reward advance care planning and system-wide performance improvement efforts.

\subsection{Modern paradigm of advance care planning}

Advance care planning has historically focused on the completion of formal written instruments, such as living wills and durable powers of attorney for healthcare, which focus on the acceptability of various life-supportive interventions. Written directives, however, face major barriers in implementation and have not achieved their goals of promoting patient autonomy.

The utility of advance directives may be improved if they are tailored to a specific patient's underlying condition and clinical events that they will most likely experience [25, 26]. Caregivers should recognise that most patients want their physicians and surrogates to overrule their written advance directives if unique clinical circumstances occur [27]. Written advance directives should be considered general statements regarding treatment preferences rather than specific and unalterable instructions. Of course, in some jurisdictions, some decisions should be given clearly because they will be implemented in almost all circumstances. Practitioners will need to know their local laws on consent and substitute decision-making.

Physicians often consider advance directives as operational tools to determine which lifesustaining interventions should be applied in various clinical circumstances, whereas patients focus on preparing for death, achieving a sense of control over their lives, and fortifying personal relationships with friends and families. Patient goals, therefore, are less operational and more oriented toward their psychological, emotiona1 and spiritual needs.

Limitations of written advance directives prompt medical professionals to adopt a broader approach to advance care planning that incorporates the patient's perspective [28]. The 
emphasis of discussions on end-of-life care may shift from patient-physician discussions on the use of life-supportive interventions to patient-family-friend communication. This communication has the purpose of strengthening relationships and sharing decisions regarding life supportive care through mutual support.

Physicians, with their patient's permission, can promote a dialogue for advance care planning by involving families and encouraging discussions within families regarding the end-of-life decisions that patients may eventually face [29]. Caregivers can enrich these discussions by providing educational materials and resources for the patient that enhance informed decisions. Emphasis shifts from the completion of written advance directives towards an ongoing dialogue between patients, caregivers and their families. The topics to discuss should include the prognosis of the condition, likely outcomes of various treatment interventions, the values and goals that patients would wish to have fulfilled, likely outcomes of life-supportive care, and palliative care resources that can prevent pain and suffering at the end of life [28]. Layoriented guides that provide pragmatic tips for advance care planning prepare patients for these discussions [30, 31].

Goals of advance care planning focus on assisting patients to recognise the possibility that a life-threatening exacerbation may occur suddenly, but also helping them to go on living and continue enjoying life. Patients with severe disease gain solace in learning about palliative interventions, such as terminal sedation, which will protect them from experiencing discomfort at the end of life. Patients also require reassurance that their methods of documenting their wishes will allow their decisions to be known during a later hospitalisation. Resources exist to assist clinicians in advance care planning discussions with their patients and improving their processes of end-of-life care [32, 33].

\subsection{Palliative care at the end of life}

Patients with chronically progressive COPD who reach the terminal stage of their disease frequently develop disabling symptoms of cough, dyspnoea, anxiety and depression [34]. Such patients require clinicians with expertise in palliative care [35] and interventions that relieve intractable symptoms at the end of life [36]. 
Effective palliative care focuses on the patient's defined goals of care, amelioration of patient and family distress, and assistance with the family's bereavement after the patient's death.

Patient-centered palliative care requires a careful assessment of the individual patient's unique needs as a "whole" person. Perceptions of suffering are highly individual and experienced in widely varied ways [37]. This comprehensive assessment evaluates the patient's "whole pain," which spans the physical, emotional, independence and autonomy, communication, economic and spiritual domains [38, 39].

The physical domain represents a major source of suffering for patients with terminal lung disease. Common difficulties relate to dyspnoea, cough and retained airway secretions. Patients also need assessment for pain, loss of appetite, incontinence, risk for decubitus ulcers, and nausea or other gastrointestinal problems, such as constipation. Extreme fatigue and weakness accompany worsening dyspnoea.

The emotional domain of symptoms includes sadness and grief experienced by patients who progress with worsening dyspnoea and increasing dependency on family or other caregivers. Depression and delirium often combined with generalised anxiety commonly occur at the terminal stages of COPD.

The domains of independence and autonomy relate to the patient's need, at the end of life, to retain a sense of control over one's life and disease. Patients voice a desire to be heard as a person and to participate in decisions about medical care, activities of daily living and family events. Patients hope to retain their sense of dignity and personhood.

The domain of communication reflects patients' needs to communicate with friends and family, to create a sense of closure to life affairs. Patients may wish to speak to someone who has been distant for years to resolve old conflicts or re-establish past friendships. Patients also reflect on how they would wish to be remembered. Having friends and family near to listen becomes important to patients who wish to have someone listen to their hopes, fears, plans and 
goodbyes.

The economic domain identifies lingering concerns patients retain about financial burdens that might be left to their family. Patients, as a part of life closure and the need to contribute to their love ones, wish to complete their financial affairs and care for those left behind.

The spiritual domain transcends a patient's physical suffering and relates to fulfilment of spiritual needs and hopes for the future. Many patients wish to talk about the past burdens and blessings of their life and to tap the meaning they attach to their lives, accomplishments and suffering.

At the end of life, patients need reassurance that their caregivers will stay involved and will not abandon them [40]. Patients with COPD who die in the intensive care unit (ICU) during an acute hospitalisation have special needs [41]. Patient surrogates and family members of patients dying in the ICU rank pain control, availability of family at the bedside and efforts to address breathlessness as the most important factors that promote a peaceful and satisfying death experience [42].

\subsection{Hospice service}

Patients with COPD sometimes qualify for formal hospice services, especially when they are having repeated exacerbations and very poor measures on tests of pulmonary function. Nevertheless, many patients will have a fatal exacerbation within a short time of having fairly good function, so one cannot wait to consider using hospice until death is nearly certain. Opportunities for hospice care are frequently neglected for patients coming to the end of life with COPD [43, 44]. Hospice usually provides around-the-clock coverage, medications, counselling, support to patient and family at home, and excellent symptom control (including sedation at the end of life). These services should be made available to patients who could derive great benefit from them. Neglect in offering patients and their families appropriate resources for supportive end-of-life care results in unnecessary admissions to acute care hospitals for worsening respiratory symptoms. 
Many episodes of worsening breathlessness in patients coming to the end of life can be avoided in a reliable care system with effective treatment (with assurance of terminal sedation if warranted) and with comprehensive advance care planning. Many patients with terminal COPD choose not to use ventilator support, or to use it only for a time-limited span, if they can be sure of competent relief of terrifying breathlessness [33]. 


\subsection{References}

1. Heffner JE, Fahy B, Hilling L, Barbieri C. Attitudes regarding advance directives among patients in pulmonary rehabilitation. Am J Respir Crit Care Med 1996; 154: 1735-1740.

2. Heffner JE. Chronic obstructive pulmonary disease - ethical considerations of care. Clin Pulm Med 1996; 3: 1-8.

3. Connors AF, Dawson NV, Thomas C, et al. Outcomes following acute exacerbations of severe chronic obstructive lung disease. The SUPPORT investigators. Am J Respir Crit Care Med 1996; 154: 959-967.

4. Claessens MT, Lynn J, Zhong Z, et al. Dying with lung cancer or chronic obstructive pulmonary disease: insights from SUPPORT. Study to Understand Prognoses and Preferences for Outcomes and Risks of Treatments. J Am Geriatr Soc 2000; 48: Suppl., S146-S153.

5. Lynn J, Ely EW, Zhong Z, et al. Living and dying with chronic obstructive pulmonary disease. J Am Geriatr Soc 2000; 48: Suppl., S91-S100.

6. Reilly BM, Magnussen CR, Ross J, Ash J, Papa L, Wagner M. Can we talk? Inpatient discussions about advance directives in a community hospital. Arch Intern Med 1994; 154: 2299-2308.

7. Kellogg FR, Crain M, Corwin J, Brickner PW. Life-sustaining interventions in frail elderly persons. Talking about choices. Arch Intern Med 1992; 152: 2317-2320.

8. Steinbrook R, Lo B, Moulton J, Saika G, Hollander H, Volberding PA. Preferences of homosexual men with AIDS for life-sustaining treatment. $N$ Engl J Med 1986; 314: 457-460.

9. Pellegrino ED. Emerging ethical issues in palliative care. JAMA 1988; 279: 1521-1522.

10. Heffner JE, Fahy B, Hilling L, Barbieri C. Outcomes of advance directive education of pulmonary rehabilitation patients. Am J Respir Crit Care Med 1997; 155: 1055-1059.

11. Heffner JE, Fahy B, Barbieri C. Advance directive education during pulmonary rehabilitation. Chest 1996; 109: 373-379.

12. Hanson LC, Tulsky JA, Danis M. Can clinical interventions change care at the end of life? Ann Intern Med 1997; 126: 381-388.

13. Holley JL, Nespor S, Rault R. The effects of providing chronic hemodialysis patients written material on advance directives. Am J Kidney Dis 1993; 22: 413-418.

14. Markson LJ, Fanale J, Steel K, Kern D, Annas G. Implementing advance directives in the primary care setting. Arch Intern Med 1994; 154: 2321-2327. 
15. Cuglian AM, Miller T, Sobal J. Factors promoting completion of advance directives in the hospital. Arch Intern Med 1995; 155: 1893-1898.

16. Meier DE, Fuss BR, O'Rourke D, Baskin SA, Lewis M, Morrison RS. Marked improvement in recognition and completion of health care proxies - a randomized controlled trial of counseling by hospital patient representatives. Arch Intern Med 1996; 156: 1227-1232. 17. Meier DE, Gold G, Mertz K, et al. Enhancement of proxy appointment for older persons: physician counseling in the ambulatory setting. J Am Geriatr Soc 1996; 44: 37-43.

18. Sulmasy DP, Song KY, Marx ES, Mitchell JM. Strategies to promote the use of advance directives in a residency outpatient practice. J Gen Intern Med 1996; 11: 657-663.

19. Landry FJ, Kroenke K, Lucas C, Reeder J. Increasing the use of advance directives in medical outpatients. J Gen Intern Med 1997; 12: 412-415.

20. Rubin SM, Strull WM, Fialkow MF, Weiss SJ, Lo B. Increasing the completion of the durable power of attorney for health care. A randomized, controlled trial. J Am Med Assoc 1994; 271: 209-212.

21. Richter KP, Langel S, Fawcett SB, et al. Promoting the use of advance directives: an empirical study. Arch Fam Med 1995; 64: 609-615.

22. Connors AF Jr, Dawson NV, Desbiens NA, et al. A controlled trial to improve care for seriously ill hospitalized patients. The study to understand prognoses and preferences for outcomes and risks of treatments (SUPPORT). JAMA 1995; 274: 1591-1598.

23. Reilly BM, Wagner M, Magnussen R, Ross J, Papa L, Ash J. Promoting inpatient directives about life-sustaining treatments in a community hospital. Results of a 3-year timeseries intervention trial. Arch Intern Med 1995; 155: 2317-2323.

24. Lynn J, Goldstein NE. Advance care planning for fatal chronic illness: avoiding commonplace errors and unwarranted suffering. Ann Intern Med 2003; 138: 812-818.

25. Lanken PN, Ahlheit BD, Crawford S, et al. Withholding and withdrawing life-sustaining therapy. Am Rev Respir Dis 1991; 144: 726-731.

26. Heffner JE. End-of-life ethical decisions. Semin Respir Crit Care Med 1998; 19: 271-282.

27. Mazur DJ, Hickman DH. Patients' preferences for risk disclosure and role in decision making for invasive medical procedures. J Gen Intern Med 1997; 12: 114-117.

28. Martin DK, Thiel EC, Singer PA. A new model of advance care planning. Arch Intern Med 1999; 159: 86-92. 
29. Jennings B, Callahan D, Caplan AL. Ethical challenges of chronic illness. Hastings Cent Report 1988; 18: Suppl., 1-16.

30. Lynn J. Handbook for Mortals. Guidance for People Facing Serious Illness. Oxford, Oxford University Press, 1999.

31. Lynn J. Handbook for Mortals. Guidance for People Facing Serious Illness. http://www.medicaring.org/educate/navigate/handbook.html. Accessed: June 21, 2003.

32. Lynn J. Improving Care at the End of Life. Oxford, Oxford University Press, 2000.

33. Lynn J, Schuster JL, Kabcenell A. Offering end-of-life services to patients with advanced heart or lung failure. Improving care for the end of life: a sourcebook for health care managers and clinicians. Oxford University Press, New York, 2000.

34. Lynn J, Teno JM, Phillips RS, et al. Perceptions by family members of the dying experience of older and seriously ill patients. SUPPORT Investigators. Study to Understand Prognoses and Preferences for Outcomes and Risks of Treatments. Ann Intern Med 1997; 126: $97-106$.

35. Hansen-Flaschen JH. Palliative home care for advanced lung disease. Respir Care 2000; 45: 1478-1486; discussion 1486-1489.

36. Sulmasy DP, Pellegrino ED. The rule of double effect. Clearing up the double talk. Arch Intern Med 1999; 159: 545-550.

37. Steinhauser KE, Clipp EC, Tulsky JA. Evolution in measuring the quality of dying. $J$ Palliat Med 2002; 5: 407-414.

38. Emanuel LL, Alpert HR, Emanuel EE. Concise screening questions for clinical assessments of terminal care: the needs near the end-of-life care screening tool. $J$ Palliat Med 2001; 4: 465-474.

39. Steinhauser KE, Bosworth HB, Clipp EC, et al. Initial assessment of a new instrument to measure quality of life at the end of life. J Palliat Med 2002; 5: 829-841

40. Youngner SJ, Lewandowsky W, McClish DK, Juknialis MA, Coulton C, Bartlett ET. "Do not resuscitate" orders: incidence and implications in a medical intensive care unit. $J$ Am Med Assoc 1985; 253: 54-57.

41. Papa-Kanaan JM, Sicilian L. Ethical issues in the chronically critically ill patient. Clin Chest Med 2001; 22: 209-217. 
42. Loss CR, Ely EW, Bowman C, et al. Quality of death in the ICU: comparing the perceptions of family with multiple professional care providers. Am J Respir Crit Care Med 2001; 163: A896.

43. Emanuel EJ, Fairclough DL, Slutsman J, Alpert H, Baldwin D, Emanuel LL. Assistance from family members, friends, paid care givers, and volunteers in the care of terminally ill patients. N Engl J Med 1999; 341: 956-963.

44. Christakis NA, Escarce JJ. Survival of Medicare patients after enrollment in hospice programs. N Engl J Med 1996; 335: 172-178. 


\section{Integrated disease management for primary care.}

\subsection{Key points}

- Integrated care for chronic obstructive pulmonary disease (COPD) involves the patient and a team of clinical professionals cooperating with secondary care and rehabilitation services.

- Optimal disease management involves redesigning standard medical care to integrate rehabilitative elements into a system of patient self-management and regular exercise.

- Case finding is a simple and effective means of enhancing the diagnosis of COPD in primary care. Use of spirometry by primary care providers is recommended to detect airways obstruction and facilitate smoking cessation.

- A diagnosis of COPD is confirmed by spirometry, which can be performed in a primary care setting if personnel are specifically trained and quality assurance is maintained.

- COPD is often accompanied by deconditioning, comorbid illnesses and symptoms of depression. Even in patients with mild disease, health status can be substantially compromised.

- The majority of COPD exacerbations are managed at home by the patient or the primary care team. Approximately $50 \%$ of exacerbations are not reported to clinicians.

- Patients with COPD should be made more aware of the symptoms of an exacerbation and be encouraged to report these early to clinicians. Conversely, physicians should make use of the experience of the individual patient and ask for early signs of an exacerbation.

- In most cases, short courses of oral corticosteroids should be initiated at first signs of an exacerbation.

- Most of the professional care provided to patients reaching end of life is given by primary care teams.

- A disease management flow diagram for integrated care of COPD is introduced. 


\subsection{Background}

Disease management can be regarded as an integrated and systematic approach in which healthcare providers work together in a coordinated and cooperative manner to produce an optimal outcome for a particular patient with COPD throughout the entire continuum of care [1].

COPD is a progressive chronic disease with an increasing prevalence [2] (see Definition, diagnosis and staging). In recent years, the most substantial increase in prevalence has been in females, who now surpass the number of males dying of the disease in the USA [3] (see Epidemiology, risk factors and natural history).

Integrated care for COPD involves the patient and a team of clinical professionals working in primary care, cooperating with secondary and rehabilitation services.

In this section an integrated care flow diagram for the disease management of COPD will be introduced (fig. 1). 

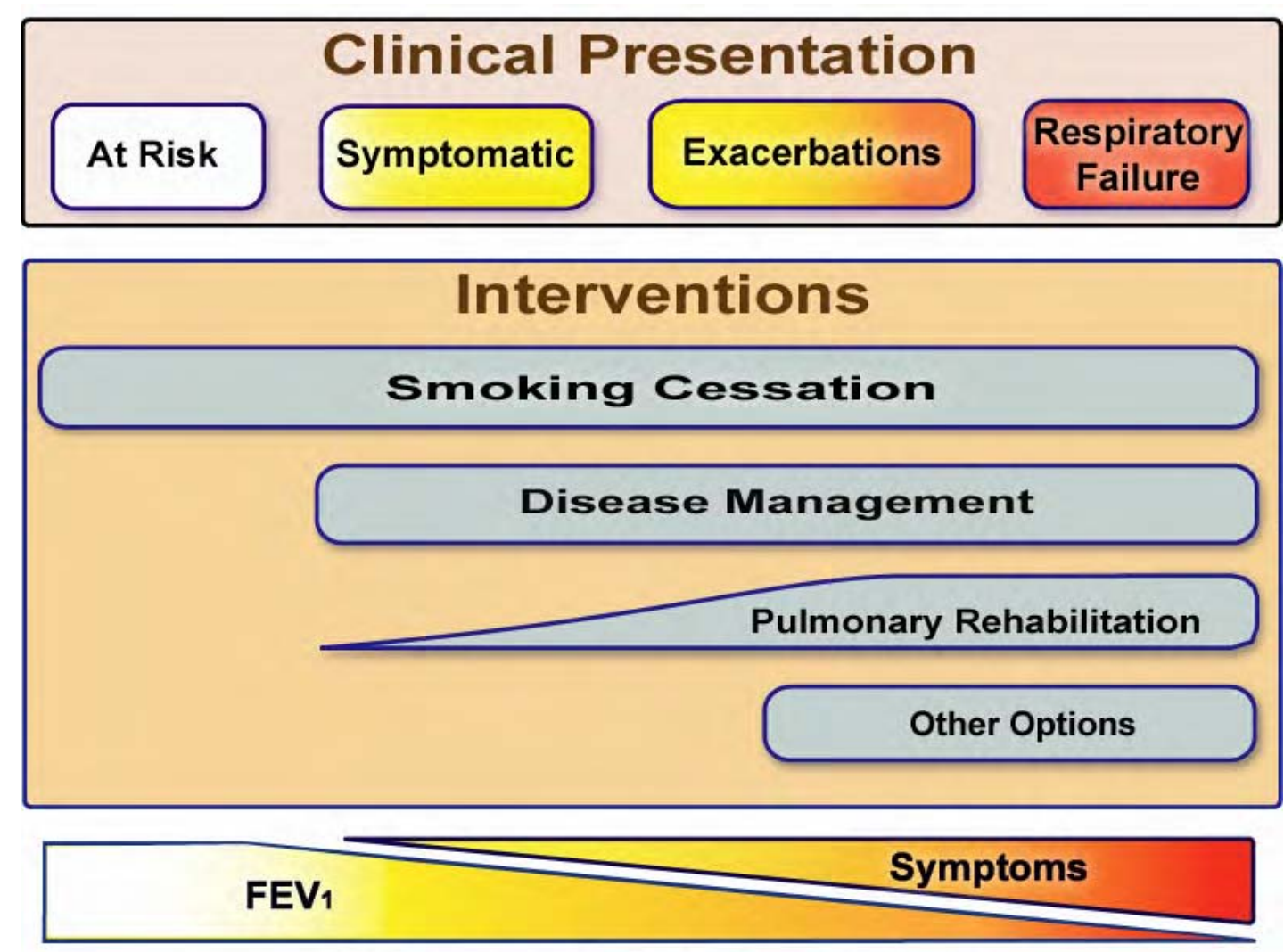

Disease Progression

Fig. 1 Optimal disease management entails redesigning standard medical care to integrate rehabilitative elements into a system of patient self-management and regular exercise 17]. 


\subsection{Prevention}

Cigarette smoking is by far the most important risk factor for COPD in the Western world (see Management of stable COPD: smoking).

Patients with COPD need to be vaccinated against influenza annually. Pneumoccocal vaccination is recommended according to national guidelines (see Management of stable COPD: pharmacological therapy).

Use of office spirometry by primary care providers is recommended to detect airways obstruction and facilitate smoking cessation [4].

\subsection{Diagnosis}

A diagnosis of COPD is confirmed by spirometry, which can be performed in a primary care setting if personnel are specifically trained and quality assurance is maintained $[5,6]$.

Case-finding is a simple and effective means of enhancing the diagnosis of COPD in primary care. Preselecting smoking patients on the basis of chronic cough and age $>60$ years increases the chance of finding airways obstruction from 18 to $48 \%$ [7].

In primary care there is a need to consider a diagnosis of COPD in smokers currently diagnosed and treated as having respiratory tract infections or asthma.

When diagnostic problems arise, or the quality of measurements cannot be assured, patients should be referred to specialised diagnostic centres in hospitals or clinics (see Clinical assessment, testing and differential diagnosis).

\subsection{Management of stable disease}

Every patient should have access to a smoking cessation programme. Cessation of smoking is the only proven way to slow the decline in lung function [8]. COPD patients who receive 
repeated counselling and spirometry stop smoking more easily than smoking controls without COPD (40 versus 22\%) after 3 yrs follow-up [9] (see Management of stable COPD: smoking).

Bronchodilators provide symptom relief and, combined with inhaled corticosteroids, may reduce the frequency and severity of exacerbations in severe COPD. Neither bronchodilators, nor inhaled corticosteroids have any effect on lung function decline [10] (see Management of stable COPD: pharmacological therapy). The inhalation technique should be regularly checked since many patients need feedback on how to use devices effectively. Especially in patients with severe COPD, the use of spacer devices should be reinforced (see Patients: medication).

It is important to recognise that even in patients with mild disease, health status can be substantially compromised [11]. There is evidence that directing patients to engage in relatively simple programmes of physical activity can improve exercise tolerance in mild-tomoderate COPD [12].

Comorbidity is a frequent problem in COPD. Other illnesses, such as bronchiectasis, lung cancer, heart failure, osteoporosis and malnutrition are frequent in patients with COPD. Depressive symptoms are also common, especially in patients with severe disease, who are at a 2.5-times greater risk [13]. It is important to search for symptoms of depression and treat appropriately.

COPD is often accompanied by deconditioning and a low level of social activity. Pulmonary rehabilitation improves exercise capacity, relieves dyspnoea and fatigue, reduces length of stay in hospital, and enhances patients' sense of control over their condition [14-16] (see Management of stable COPD: pulmonary rehabilitation). Currently, rehabilitation is available to a small percentage of those who could benefit. Optimal disease management entails redesigning standard medical care to integrate rehabilitative elements into a system of patient self-management and regular exercise [17] (fig. 1).

Long-term oxygen therapy (>15 h.day ${ }^{-1}$ ) for patients with chronic hypoxaemia has been shown to prolong life [18] (see Management of stable COPD: long-term oxygen therapy). 


\subsection{Management of exacerbations}

The majority of exacerbations are handled at home by the patient or the primary care team, with $\sim 50 \%$ of exacerbations unreported to clinicians [19]. Moderate-to-severe COPD patients with frequent exacerbations have a faster decline in lung function and are more often admitted to hospital with longer lengths of stay [20].

Symptoms and not lung function worsen significantly before an exacerbation, with dyspnoea or colds characterising the more severe (see Exacerbation: definition evaluation and treatment). Therefore, patients with COPD should be made more aware of the symptoms of an exacerbation and encouraged to report these early to clinicians [21]. Conversely, physicians should make use of the experience of the individual patient and ask for early signs of an exacerbation and initiate a plan of care.

Since oral steroids seem especially useful for the first $72 \mathrm{~h}$ [22], these should be initiated at first signs of an exacerbation. If corticosteroids are initiated, short courses [23] are recommended (fig. 1). Antibiotics may be initiated in patients with altered sputum characteristics, but level I patients with increased quantities of nonpurulent sputum improve without antibiotic therapy [24] (see Exacerbation sections).

Programmes that include social and medical support for early planned discharge may reduce hospital stay and do not result in an increased readmission rate [25-27]. Patients are more likely to prefer domiciliary care over inpatient care [28], leading to greater patient satisfaction [29].

Planned monitoring of the patient after discharge is an integral component to the rehabilitation approach and promotes the ability of the patient and family to move toward self-management [30].

It is important that long-term care for chronic relapsing diseases be delivered by a team of professionals with the "expert patient" at the centre; such an approach is likely to maintain the patient's quality of life [31]. 


\subsection{Referral indications}

Referral to specialist care generally has the purpose to confirm diagnosis, perform additional investigations, optimise and initiate treatment, or exclude other illnesses. This is indicated for COPD patients with:

- disease onset at age $<40 \mathrm{yrs}$

- frequent exacerbations (two or more per year) despite adequate treatment

- rapidly progressive course of disease (decline in forced expiratory volume in one second (FEV1), progressive dyspnoea, decreased exercise tolerance, unintentional weight loss)

- severe COPD (FEV1 <50\% predicted) despite optimal treatment

- need for oxygen therapy (see Management of stable COPD: long-term oxygen therapy)

- onset of comorbid illness (osteoporosis, heart failure, bronchiectasis, lung cancer)

- possible indication for surgery (see Management of stable COPD: surgery in and for COPD).

\subsection{Follow-up/monitoring}

Patients with COPD need to be followed and actively managed. The frequency and intensity of follow-up depend on the individual patient's disease status and course, as well as the local healthcare system. Tasks of all professionals caring for COPD patients should be clear [32] in order to reach local agreement on the organisation of:

- symptoms registration, signs of comorbidity, health status, exercise tolerance, nutritional condition and lung function data

- a call/recall system that generates appointments for education, inhalation technique check, vaccinations

- regular multidisciplinary meetings of healthcare professionals aimed at difficult cases. 


\subsection{End-stage disease management}

Patients with end-stage COPD have physical and psychosocial needs at least as severe as lung cancer patients [33]. But their significantly impaired quality of life and emotional well-being may not be met as well as those of patients with lung cancer [34].

Patients with severe COPD are often disabled longer by their disease than those with lung cancer, yet COPD patients have a mortality rate comparable to that of many cancers [35].

In practice, it seems difficult to recognise when chronic care becomes palliative care [36]. Uncertainty among primary care physicians as to how patients view the discussion of prognosis and inadequate preparation may pose potential barriers [37].

Most of the professional care received by people reaching the end of life is provided by primary care teams. Further training to incorporate the principles of palliative care explicitly into the planning and provision of care is essential [38].

Discussions about the end of life should take place when the patient is stable. Enquires should be made about their preference for end-of-life support, including ventilatory support (see Ethical and palliative care issues).

The task is complex, requiring long-term surveillance of patients who are likely to become housebound. Respiratory nurse specialists can play an important role in coordinating care of COPD at the end of life [39]. 


\subsection{References}

1. Epstein RS, Sherwood LM. From outcomes research to disease management: a guide for the perplexed. Ann Intern Med 1996; 124: 832-837.

2. Murray CJL, Lopez AD. Mortality by cause for eight regions of the world: global burden of disease study. Lancet 1997; 349: 1269-1276.

3. Mannino DM, Homa DM, Akinbami LJ, Ford ES, Redd SC. Chronic obstructive Pulmonary disease surveillance - United States, 1971-2000. Centers for Disease Control and Prevention, Surveillance Summaries. Morb Mortal Wkly Rep 2002; 51: 1-16.

4. Ferguson GT, Enright PL, Buist AS, Higgins MW. Office spirometry for lung health assessment in adults. A consensus statement from the National Lung Health Education Program. Chest 2000; 117: 1146-1161.

5. Schermer TRJ, Folgering HTM, Bottema BJAM, Jacobs JE, Schayck CP van, Weel C van. The value of spirometry for primary care: asthma and COPD. Prim Care Resp J 2000; 9: 5155.

6. Chavannes NH, Schermer TRJ, Akkermans RP, et al. Interpretation of spirometry in general practice: pattern recognition and decision-making. Eur Resp J 2002; 20: Suppl 38, 414s.

7. Schayck CP van, Loozen JMC, Wagena E, Akkermans RP, Wesseling GJ. Detecting patients at a high risk of developing chronic obstructive pulmonary disease in general practice: cross sectional case finding study. BMJ 2002; 324: 1370.

8. Anthonisen NR, Connett JE, Kiley JP, et al. Effects of smoking intervention and the use of an inhaled anticholinergic bronchodilator on the rate of decline of FEV1. The Lung Health Study. JAMA 1994; 272: 1497-1505.

9. Czajkowska-Malinowska M, Gorecka D, Zelinski J. Effects of repeated spirometries and antismoking counselling on smoking cessation rate. Eur Resp J 2002; 20: Suppl 38, 134s. 10. Calverley PMA. Modern treatment of chronic obstructive pulmonary disease. Eur Resp $J$ 2001; 18: Suppl. 34, 60s-66s.

11. Ferrer M, Alonso J, Morera J, et al. Chronic obstructive Pulmonary disease stage and health-related quality of life. Ann Intern Med 1997; 127: 1072-1079.

12. Chavannes NH, Vollenberg JJH, Schayck CP van, Wouters EFM. Effects of physical activity in mild to moderate COPD: a systematic review. Br J Gen Prac 2002; 52: 574-578. 
13. Maanen JG van, Bindels PJE, Dekker FW, IJzermans CJ, Zee JS van der, Schade E. Risk of depression in patients with chronic obstructive pulmonary disease and its determinants. Thorax 2002; 57: 412-416.

14. Lareau SC, Zuwallack R, Carlin B, et al. Pulmonary rehabilitation. Official Statement of the American Thoracic Society. AJRCCM 1999; 159: 1666-1682.

15. Lacasse Y, Brosseau L, Milne S, et al. Pulmonary rehabilitation for chronic obstructive pulmonary disease (Cochrane Review). In: The Cochrane Library, Issue 3. Oxford, Update Software, 2002.

16. Griffiths TL, Burr ML, Campbell IA, et al. Results at 1 year of outpatient multidisciplinary pulmonary rehabilitation: a randomised controlled trial. Lancet 2000; 355: 362-368.

17. Tiep BL. Disease management of COPD with pulmonary rehabilitation. Chest 1997; 112: $1630-1656$.

18. Nocturnal Oxygen Therapy Trial Group. Continuous or nocturnal oxygen therapy in hypoxemic chronic obstructive lung disease: a clinical trial. Ann Intern Med 1980; 93: 391398.

19. Seemungal TAR, Donaldson GC, Paul EA, Bestall JC, Jeffries DJ, Wedzicha JA. Effect of exacerbation on quality of life in patients with chronic obstructive pulmonary disease. Am J Respir Crit Care Med 1998; 157: 1418-1422.

20. Donaldson GC, Seemungal TA, Bhowmik A, Wedzicha JA. Relationship between exacerbation frequency and lung function decline in chronic obstructive pulmonary disease. Thorax 2002; 57: 847-852.

21. Seemungal TA, Donaldson GC, Bhowmik A, Jeffries DJ, Wedzicha JA. Time course and recovery of exacerbations in patients with chronic obstructive pulmonary disease. Am J Respir Crit Care Med 2000; 161: 1608-1613.

22. Wood-Baker R, Walters EH, Gibson P. Oral corticosteroids for acute exacerbations of chronic obstructive pulmonary disease (Cochrane Review). In: The Cochrane Library, Issue 4. Oxford, Update Software, 2002.

23. Snow V, Lascher S, Mottur-Pilson C. The evidence base for management of acute exacerbations of COPD: clinical practice guideline, part 1. Chest 2001; 119: 1185-1189.

24. Stockley RA, O'Brien C, Pye A, Hill SL. Relationship of sputum color to nature and outpatient management of acute exacerbations of COPD. Chest 2000; 117: 1638-1645. 
25. Skwarska E, Cohen G, Skwarski KM, et al. Randomized controlled trial of supported discharge in patients with exacerbations of chronic obstructive pulmonary disease. Thorax 2000; 55: 907-912.

26. Cotton MM, Bucknall CE, Dagg KD, et al. Early discharge for patients with exacerbations of chronic obstructive pulmonary disease: a randomized controlled trial. Thorax 2000; 55: 902-906.

27. Sala E, Alegre L, Carrera M, et al. Supported discharge shortens hospital stay in patients hospitalized because of an exacerbation of COPD. Eur Respir J 2001; 17: 1138-1142.

28. Ojoo JC, Moon T, McGlone S, et al. Patients' and carers' preferences in two models of care for acute exacerbations of COPD: results of a randomised controlled trial. Thorax 2002; 57: $167-169$.

29. Wilson A, Wynn A, Parker H. Patient and carer satisfaction with "hospital at home": quantitative and qualitative results from a randomised controlled trial. Br J Gen Pract 2002; 52: 9-13.

30. Bernier MJ, Leonard B. Pulmonary rehabilitation after acute COPD exacerbation. Crit Care Nurs Clin North Am 2001; 13: 375-387.

31. Rafferty S, Elborn JS. Do nurses do it better? (editorial) Thorax 2002; 57: 659-660.

32. Vrijhoef HJM, Bergh JHAM van den, Spreeuwenberg C, Diederiks JPM. The nurse specialist as central care-provider to patients with stable COPD: a justified alternative for usual outpatient care by the pulmonologist. Eur Respir J 2001; 18: Suppl 33, $206 \mathrm{~s}$.

33. Edmonds P, Karlsen S, Khan S, Addington-Hall J. A comparison of the palliative care needs of patients dying from chronic respiratory diseases and lung cancer. Palliat Med 2001; 15: 287-295.

34. Gore JM, Brophy CJ, Greenstone MA. How well do we care for patients with end stage chronic obstructive pulmonary disease (COPD)? A comparison of palliative care and quality of life in COPD and lung cancer. Thorax 2000; 55: 1000-1006.

35. Shee C. Palliation in chronic respiratory disease. Palliat Med 1995; 9: 3-12.

36. Hill KM, Muers MF. Palliative care for patients with non-malignant end stage respiratory disease. Thorax 2000; 55: 979-981.

37. Elkington H, White P, Higgs R, Pettinari CJ. GPs views of discussions of prognosis in severe COPD. Fam Pract 2001; 18: 440-444. 
38. Chavannes NH. A palliative approach for COPD and heart failure? Eur J Pall Care 2001; 8: 225-227.

39. Elkington $\mathrm{H}$, White P. Chronic obstructive pulmonary disease and primary care. Br J Gen Prac 2002; 52: 532-534. 